\title{
Moccasin Confluence: Occupation and Settlement in the Lower Fredericksburg Basin of the Edwards Plateau
}

Joel Gunn

Center for Archaeological Research

Anne C. Kerr

Center for Archaeological Research

Follow this and additional works at: https://scholarworks.sfasu.edu/ita

Part of the American Material Culture Commons, Archaeological Anthropology Commons, Environmental Studies Commons, Other American Studies Commons, Other Arts and Humanities Commons, Other History of Art, Architecture, and Archaeology Commons, and the United States History Commons

Tell us how this article helped you.

This Article is brought to you for free and open access by the Center for Regional Heritage Research at SFA ScholarWorks. It has been accepted for inclusion in Index of Texas Archaeology: Open Access Gray Literature from the Lone Star State by an authorized editor of SFA ScholarWorks. For more information, please contact cdsscholarworks@sfasu.edu. 
Moccasin Confluence: Occupation and Settlement in the Lower Fredericksburg Basin of the Edwards Plateau

\section{Creative Commons License}

(c) (1) (8)

This work is licensed under a Creative Commons Attribution-NonCommercial 4.0 International License 


\section{Moccasin Confluence: Occupation and Settlement in the Lower Fredericksburg Basin of the Edwards Plateau}

\section{by Joel Gunn and Anne C. Kerr}

Center for Archaeological Research The University of Texas at San Antonio Special Report, No.14 1986, 1996, 2000

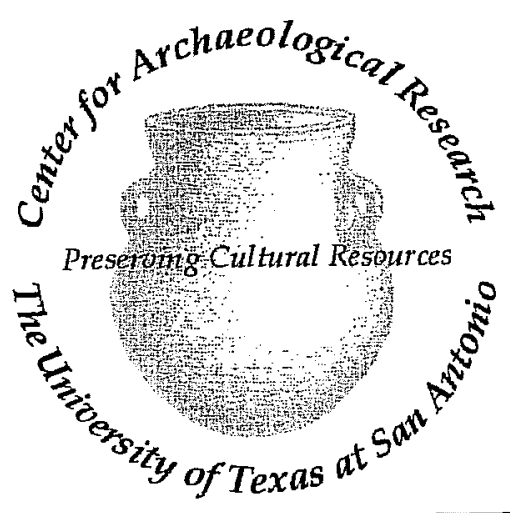




\title{
MOCCASIN CONFLUENCE: \\ OCCUPATION AND SETTLEMENT IN THE \\ LOWER FREDERICKSBURG BASIN OF THE \\ EDWARDS PLATEAU
}

\author{
by \\ Joel Gunn and Anne C. Kerr
}

With contributions by

Eric C. Gibson, David O. Brown, Anne C. Kerr, Jewel Price, Shirley Mock, Joseph H. Labadie, Frances Meskill, Darrell Sims, Elizabeth Craig, John Probst, Marlene Syverson, Frank La Rocca, David Hafernik, and Joseph Nash

Center for Archaeological Research

The University of Texas at San Antonio

Special Report, No. 14

1986

Revised and Updated

1996 


\title{
MOCCASIN CONFLUENCE: \\ OCCUPATION AND SETTLEMENT IN THE \\ LOWER FREDERICKSBURG BASIN OF THE \\ EDWARDS PLATEAU
}

\author{
by \\ Joel Gunn and Anne C. Kerr
}

With contributions by

Eric C. Gibson, David O. Brown, Anne C. Kerr, Jewel Price, Shirley Mock, Joseph H. Labadie, Frances Meskill, Darrell Sims, Elizabeth Craig, John Probst, Marlene Syverson, Frank La Rocca, David Hafernik, and Joseph Nash

Center for Archaeological Research

The University of Texas at San Antonio

Special Report, No. 14

1986

Revised and Updated

1996 
The following information is provided in accordance with the General Rules of Practice and Procedure, Chapter 41.11 (Investigative Reports), Texas Antiquities Committee:

1. Type of investigation: archaeological investigation of Hop Hill site (41 GL 21);

2. Project name: LBJ Project;

3. County: Gillespie County, Texas;

4. Principal Investigator: Joel Gunn;

5. Name and location of sponsoring agency: Texas Parks and Wildlife Department;

6. Texas Antiquities Committee Permit Nos. 175, 310, and 418;

7. Published by the Center for Archaeological Research, The University of Texas at San Antonio, San Antonio, Texas 78285, 1986. 


\section{ABSTRACT AND MANAGEMENT SUMMARY}

During the summer of 1982 the eastern half of Lyndon B. Johnson State Historical Park was surveyed and sites tested. The work was sponsored by the Texas Parks and Wildlife Department and performed by Center for Archaeological Research and the Division of Behavioral and Cultural Sciences, The University of Texas at San Antonio. The Principal Investigator was Joel D. Gunn. The field work was conducted by the field course in archaeology from the University of Texas at San Antonio. Members (listed in the Acknowledgments section) of the Anthropology Laboratory class assisted the Principal Investigator with laboratory analysis.

Most of the sites were shallow or deflated and of limited information value except for their location in the overall settlement pattern. Excavation of 41 GL 21, Hop Hill (Gunn and Mahula 1977a), was completed. An old stream channel was found in the bedrock under the site. It was filled with occupation debris from the Late Archaic. The site may have been used as an overlook to an adjacent ford in the Pedernales River.

At the confluence of the Pedernales River and Williams Creek (Moccasin Confluence) at the east end of the park a very important site was found. Moccasin Confluence consists of two segments divided by Williams Creek. The west segment (41 BC 71) is a deeply stratified alluvial site with a Holocene sequence. Whether the sequence is continuous through the Holocene remains to be determined. The levels are extremely thick in the Middle and Early Holocene. The location, at three sources of varying sediments, indicates that the site could be a very sensitive geological barometer of Holocene climate, a hypothesis that seems to have merit based on analysis of sediment grain size composition and IPF analysis of sediment chemistry. The site is very rich in chronological diagnostics and is of great potential for studying environmental and cultural process in the Edwards Plateau region. Analysis of artifact wear patterns, points, flake size and frequencies, and mollusks indicates the site was inhabited over long periods of time, sometimes with a fair amount of intensity. Nomads apparently visited the site at the beginning of each cultural period and eventually settled there until their culture was disrupted. The site is recommended for nomination to the National Register of Historic Places.

The site (41 BC 63) on the east bank of Williams Creek outside the park, considered to be the eastern segment of Moccasin Confluence, was tested enough to show that it has a dense burned rock midden. It is assumed to represent a shift of occupation locus to the east side of the creek during the Middle Archaic.

Management Summary

The following management recommendations are supported by the investigations reported in chapter 2. Recommendations for National Register of Historic Places 
(NRHP) and State Archaeological Landmark (SAL) status are tabulated for ready reference in Table 0.01. If stock tanks are constructed which impact the subsurface close to any of the known archeological sites or in the vicinity of any of the main drainages, testing may be warranted.

TABLE 0.01. RECOMMENDATION SUMMARY

\begin{tabular}{lll}
\hline Site & SAL Designation & NRHP Eligibility \\
41 GL 21 & Eligible & Eligible \\
41 GL 22a & Not Eligible & Not Eligible \\
41 GL 22b & Not Eligible & Not Eligible \\
41 GL 22C & Not Eligible & Not Eligible \\
41 GL 22d & Eligible & Eligible \\
41 GL 47 & Not Eligible & Not Eligible \\
41 GL 48 & Not Eligible & Not Eligible \\
41 BC 63 & Further Testing & Further Testing \\
41 BC 71 & Eligible & Eligible \\
\hline
\end{tabular}

Sites $41 \mathrm{BC} 71$ and $41 \mathrm{BC} 63$ appear to be complementary aspects of the same site. The occupation periods appear to provide different emphases and both are therefore required to construct a complete prehistory of the park. They should be designated as State Archaeological Landmarks and are recommended eligible for the National Register of Historical Places. 


\section{TABLE OF CONTENTS}

ABSTRACT AND MANAGEMENT SUMMARY

iii

LIST OF FIGURES

viii

LIST OF TABLES

$\mathbf{X}$

ACKNOWLEDGMENTS xii

CHAPTER 1-INTRODUCTION (Gunn)

CHAPTER 2-SURVEY OF THE EASTERN HALF OF LBJ STATE HISTORICAL PARK, JUNE 1982

Introduction

The Conceptual Perspective Made Explicit

Research Objectives and Methods

Reconnaissance Methods

Artifact Terminology

Site Descriptions

41 GL 21 (Hop Hill)

41 GL 22 (Dead Goat Draw)

$41 \mathrm{GL} 22 \mathrm{a}$

$41 \mathrm{GL} 22 \mathrm{~b}$

$41 \mathrm{GL} 22 \mathrm{c}$

$41 \mathrm{GL} 22 \mathrm{~d}$

41 GL 47 (Rabbit Run Site)

41 GL 48 (Dead Cow Hill)

41 BC 63 (Hye Site)

41 BC 71 (Moccasin Confluence)

Summary of Reconnaissance and Subsurface Testing Data

Conclusions, Observations, and Propositions

Management Summary

CHAPTER 3-MOCCASIN CONFLUENCE OVERVIEW-A LATE QUATERNARY SITE IN THE LOWER FREDERICKSBURG BASIN OF THE EDWARDS PLATEAU (Gunn)

CHAPTER 4-HOP HILL OVERVIEW-A LATE ARCHAIC OCCUPATION (Gunn)

CHAPTER 5-PHYSICAL AND LATE QUATERNARY ENVIRONMENT OF LBJ PARK (Brown, Gunn, LaRocca, Sims) 
Geology (Brown)

Geomorphology and Pedology

Soil Profile of Test Pits 1, 2, \& 3

Test Pit 4 Profile

Discussion

Analysis of Test Pit 2 Sediments (Gunn, Sims, La Rocca)

Geomorphic Process

Climatic Processes

Sediments, Gastropods, and Environment (Nash, Gunn)

59

Analysis of Snails and Sediments (Gunn)

Holocene Climate and Culture Change

Conclusions

CHAPTER 6-CHRONOLOGICAL DEMOGRAPHY

Vertical Concentrations of Lithic Debris from Moccasin Confluence (Kerr)

Method

Data

Indications and Discussion

CHAPTER 7-POINT CHRONOLOGY AND SYSTEMATICS (Gunn, Craig)

Introduction

Methodology

Analysis

Morphological Subsystems $\quad 82$

Point Transition Matrix Analysis $\quad 86$

Conclusions

CHAPTER 8-TOOL MORPHOLOGY AND FUNCTION (Mock, Price, and Gunn)

Introduction (Gunn)
Background and Hypothesis (Mock and Price)
Uniface Descriptions
Moccasin Confluence
Biface Descriptions
Moccasin Confluence
Biface Descriptions
Hop Hill
Morphological Interpretation (Mock)
Conclusions
Use-Wear Analysis of Bifaces and Unifaces (Price)
The Sample
Wear
Weight
Thickness
Edge Angle


Conclusions (Price, Gunn)

CHAPTER 9-FLAKE MORPHOLOGY AND CULTURE CHANGE (Gunn, Probst, Syverson)

114

Observations and Methodology

114

Analysis

120

Test Pit 6 Summary

125

Test Pits 2 and 4 Summary

126

Lower Levels

128

Conclusions

CHAPTER 10-FUNCTIONAL STUDIES OF FLAKES AT MOCCASIN CONFLUENCE AND HOP HILL (Labadie, Craig, Gunn)

Introduction (Gunn)

Lithic Use At Moccasin Confluence As A Function of Biological

Variation in the Environment (Labadie)

Use-Wear Analysis of Flakes At Moccasin Confluence (Labadie)

134

Methodology

Results

135

138

Test Pit 6

138

Discussion

138

Test Pit 2

140

Discussion

140

Summary

146

Use Wear Analysis At Hop Hill, 41 GL 21 (Gunn, Craig) 146

Conclusions

149

CHAPTER 11-OCCUPATION FLOORS AND FIRE AREAS AT MOCCASIN CONFLUENCE (Meskill, Gunn)

Introduction

A Method For Hearth Definition

150

Method For Interpretation of Occupation Floors

152

Rock Size Through Time

Occupation Floor Interpretations

Occupation Floor 8

Occupation Floor 10

Occupation Floor 11

Occupation Floor 12

Occupation Floor 15

Occupation Floor 25

Occupation Floor 27

Occupation Floor 29

Occupation Floor 31

Occupation Floor 33

Occupation Floor 36 
CONCLUSIONS

CHAPTER 12-SETTLEMENT PATTERNS IN THE LOWER FREDERICKSBURG BASIN (Gunn)

173

Introduction

173

Physiography of the Park Environ

173

Geomorphic Observations

176

Hydrologic Observations

176

Vegetation

178

Wildlife

178

Survey Methodology

179

Present Day Settlement Pattern

Collectors in the Study Area

179

Collectors and Prehistoric Occupation Density

Prehistoric and Modern Occupation Density

Settlement Pattern and Site Function in the Park and Its Environs

REFERENCES CITED

APPENDIX A-ANALYSIS OF FAUNAL MATERIAL (Hafernik, Gunn, Kerr) 192

Observations

Conclusions

200

References Cited

APPENDIX B-HOP HILL HUMAN SKELETAL REMAINS (Hafernik)

APPENDIX C-MEASUREMENTS OF POINTS 


\section{LIST OF FIGURES}

Figure Caption

1.01. Project Area Location.

1.02. Point Chronology (Prewitt 1981).

1.03. Global Temperature Chronology.

2.01. Eastern Half of LBJ State Historical 3ark with Sites and Tests Marked.

2.02. Site 41GL 22 with Subsites, Shovel Tests, and Test Pits.

3.01. Shovel Tests and Test Pits at Moccasin Confluence.

3.02. Diagnostic Sequence in Test Pit 6

3.03. Diagnostic Sequence in Test Pit 4

3.04. Dear-Bison Bone Ratios in the Mill Creek Culture of Iowa.

4.01. Diagnostic Sequence at Hop Hill.

5.01. Soil Profile for Test Pits 1, 2, and 3 a8 Moccasin Confluence.

5.02. Locations of Sediment Samples Relative to Excavation Levels.

5.03. Sediments, Processes, and Climate for Humidity/ Sedimentary Process II.

5.04. Sediments, Processes, and Implied Climate for Aridity SED III.

5.05. Climate-Cultural Chronology for Central Texas and Moccasin Confluence.

6.01. Moccasin Confluence Vertical Frequency Indices of Lithic Debris.

7.01. Approaches Taken to Measurement of Point

7.02. Methods of Measuring Three Types of Points with the Polar Fan

7.03. Single Dimension Component Score Plots for MSS I-IV (A-D).

7.04. Three Tends in Point Morphology.

7.05. Blade-Stem (PC III, Horizontal) and Barb-Stem (PC IV, Vertical).

8.01. FN 645 Paleoindian Uniface from 41 BC 71 Test Pit 2, Level 38.

8.02. Unifaces.

8.03. Bilaterally Trimmed Unifaces (Type 4.3).

8.04. Bifaces.

8.05. Edge Wear and Other Attributes

9.01. Flake Terminology.

9.02. Flake Technology/Morphology Form.

9.03. Platform Shapes.

9.04. Flake Terminations.

9.05. Mean Flake Width Range of Variation in Test Pit 6.

9.06. Flake Width Mean Departure F-Values.

9.07. Percentage of Fine Grained Material from All Levels.

10.01. Edge-wear Scar Patterns and Organic Residue

10.02. Edgewear Scar Patterns.

10.03. Total Lithics by Level, PER X = period Mean Frequency Per Level. $\quad 144$

10.04. Intensity of Occupation, Percent of Lithics Used as Tools.

11.01. Occupation Floor 8, View East. 154

11.02. Occupation Floor 8. 157

11.03. Occupation Floor $10 . \quad 158$

11.04. Occupation Floor 11. 160

11.05. Occupation Floor 11, View West. 161

11.06. Occupation Floor 12. 
11.07. Occupation Floor 15.

11.08. Occupation Floor 27.

11.09. Occupation Floor 27, View East. 167

11.10. Occupation Floor 31.

12.01. Pedernales River Valley.

12.02. Transect of the Study Area, Hop Hill to Hill 1831.

12.03. Study Area Soil Associations.

12.04. Properties on which Landowners were Contacted.

A-1. Vertical Bone Weight Distributions.

A-2. Bone Weights in Test Pit 6.

B-1. Human Bone from Hop Hill. 
Table Caption

\section{LIST OF TABLES}

0.01. Recommendation Summary iv

2.01. Components of Binford's Forager Mode For Hunter-Gatherers. 10

2.02. Components of Binford's Collector Mode For Hunter-Gatherers. 10

2.03. Reconnaissance/Testing Procedures For 1982 Field Season 12

2.04. Shovel Testing in the Schuman Field 15

2.05. Surface Collected Artifacts from 41 GL 22 Subsites and Locality. 18

2.06. Shovel Tests With Artifacts At 41 GL 22 and 41 GL 47

2.07. Site 41 GL 22, $1 \times 1$ Meter Test Pits 24

2.08. Site 41 GL $47,1 \times 1$ Meter Test Pits

2.09. Shovel Test At $41 \mathrm{BC} 63 \quad 28$

2.10. Shovel Tests At Moccasin Confluence (41 BC 71) 30

5.01. Sieve Sizes Used in the Moccasin Confluence Analysis 54

5.02. Particle Size Settling Times 55

5.03. Unrotated Principal Components Loadings For Particle Size Analysis 55

5.04. Gastropod Original Data 60

5.05. Average Snail Size Per Excavation Level 62

5.06. Sediments, Snails, and Lithic Debris. 63

6.01. Vertical Concentrations of Lithic Debris in Test Pit 6

6.02. Vertical Concentrations of Lithic Debris in Test Pit 4

6.03. Vertical Concentrations of Lithic Debris in Test Pit 2

7.01. Points Recovered in Place from LBJ State Historical Park 81

7.02. Morphological Subsystems (Mss) 82

7.03. Regression of Mss Component Scores Against Cultural Periods 83

7.04. Transition Matrix For Point Types Found in Place Yields 21\% 88

7.05. Reordered Transition Matrix 89

8.01. Tool Category, Fn, and Provenience List of Unifacial Tools 94

8.02. Tool Category, Fn, and Provenience List of Bifacial Tools 99

8.03. Frequencies of Unifaces and Bifaces At Moccasin Confluence 105

8.05. Percentage of Wear by Period 108

8.04. Totals by Level of Unifaces and Bifaces 109

9.01. Unrotated Principal Components Analysis of Test Pit 6 Flake Morphology 122

9.02. Column Percentages and Contingency Table Analysis of Technology 123

9.03. Column Percentages and Contingency Table Analysis of Grain by Level 124

9.04. Percentage of Bifacing Flakes and Fine-Grained Flakes Test Pits 2, 4, and 6127

10.01 Late and Middle Archaic Use-Wear Observations in Test Pit $6 \quad 138$

10.02. Percentage of Utilization by Level For Test Pit $6 \quad 139$

10.03. Percentage of Flakes and Chips Utilized by Level in Test Pit 6

10.04. Test Pit 2 Platformed Flake Utilization Frequencies 142

10.05. Test Pit 2 Chip Utilization Frequencies 143

10.06. Paleoindian to Late Archaic Use-Wear Observations in Test Pit 2

10.07. Hop Hill Utilized Flake \& Chip Frequency and Percentage 148

11.01. Moccasin Confluence Fire-Related Materials from Occupation Floors 152

11.02. Occupation Floor Average Circumference of Rocks 155

12.01. Sites Reported by Informants in the Park Area 181 


\section{ACKNOWLEDGMENTS}

The successful outcome of a project of the scale and interdisciplinary nature of the LBJ Park Project owes much to numerous people who graciously gave of their time, energy, and expertise. We wish to thank these individuals for their contributions to this undertaking.

Harold Woods of the Parks Department was very gracious in making park facilities, such as the swimming pool, available to the survey team. Henry and Anne Fox of San Antonio made the accommodations of the Fox Ranch available to the crew.

The project was greatly facilitated through the efforts of employees of The University of Texas at San Antonio administration and the Center for Archaeological Research, notably, Mary Lou Ellis. Anne Kerr and Ann Young typed the manuscript, and Sharon Quirk was the editor. Several persons, including Eileen Johnson, and Vance Holliday read and commented on the manuscript. Thomas $R$. Hester, Elton Prewitt, and Thomas C. Kelly identified the points.

The project staff, especially Eric C. Gibson, David O. Brown, and Anne C. Kerr made major contributions to the research design, as their contributions bear evidence, and to the final form of the report.

Finally, there is special recognition and appreciation due to the members of the field school and laboratory analysis class for the devotion and enthusiasm which they showed through long hours of work. Their unceasing interest in archaeological research was inspiring.

Field School Participants
Anne C. Kerr
Joseph H. Labadie
Christina Rosas
Frances Meskill
Darrell Sims
Frank La Rocca
John Probst
Marlene Syverson
David Hafernik
John Charles

Laboratory Class Participants

Anne C. Kerr

Joseph H. Labadie

Jewell Price

Frances Meskill

Darrell Sims

Frank La Rocca

John Probst

Marlene Syverson

David Hafernik

Elizabeth Craig

Shirley Mock

Joseph Nash

And still is. Joel Gunn, 1921 Billabong Lane, Chapel Hill NC 27516 jdgunn@unc.edu 30 November 1996 


\section{CHAPTER 1-INTRODUCTION (Gunn)}

During the summers of 1976, 1978, and 1982, survey, testing, and excavation were performed in and around Lyndon B. Johnson (LBJ) State Historical Park. The park is located on the south bank of the Pedernales River, a tributary of the Colorado River, on the border between Gillespie and Blanco Counties (Figure 1.01). Additional map details are in Chapter 12. The activities were conducted under the sponsorship of Texas Parks and Wildlife Department and The University of Texas at San Antonio. The principal investigator was Joel D. Gunn, and the projects were administered by the Center for Archaeological Research, The University of Texas at San Antonio (CAR-UTSA, Dr. Thomas R. Hester, Director). The work was executed under the terms of Texas Antiquities Permits, Numbers 175, 310, and 418.

Previous work in the park area had focused on Hop Hill (41 GL 21), a prehistoric quarry, workshop, and habitation site located on a bluff above the Pedernales River and facing across a natural ford of the river from the Lyndon $B$. Johnson ranch house. Investigation into the Hop Hill locality and its environs were reported by Gunn and Mahula (1977a). The 1978 season included an archaeological survey of an 134- $\mathrm{km}^{2}$ along the south side of the river surrounding the park, definition of strata in the vicinity of the primary midden at Hop Hill, excavation of a few occupation levels under those reported in the 1977 publication, and of primary interest, the excavation of a test pit into a buried gully head under the occupation floors that produced a human mastoid process. The objectives of the 1982 season were to determine the nature of the deposits under the midden at Hop Hill and explore the park east of Hop Hill by survey and testing to determine the nature of the archaeological remains in that area.

The chapters of this report are arranged, first, to overview the progress and results of the survey and testing, and then to give detailed reports that support the conclusions presented in the overview. Chapter 2 discusses the 1982 survey in the park. Testing operations are reported in a general manner in Chapters 3 and 4. Chapters 5, and the following chapters, research the details of the test and excavation results, and Chapter 12 develops a settlement pattern model for the subregion.

The general problem orientation of the research is set in the context of a broad research program that involves the issue of culture change in southcentral United States. The general outlines of a model for culture and climate change were first reported by Gunn (1977a), and have since been elaborated upon in Gunn (1979a, 1979b, 1991, 1992, 1996), Gunn and Adams (1981), Gunn and Brown (1982), and Gunn and Kerr (1984). In essence, the model suggests that the extreme climatic instability of central Texas (for documentation see Gunn 1982a, 1982b, 1989) creates a zone of climate/culture dependency between the woodlands of the Southeast and the Basin and Range province of the Southwest. Within this zone there should be an usual abundance of data for archaeologists to define the timing and causal character of climate and culture change. 


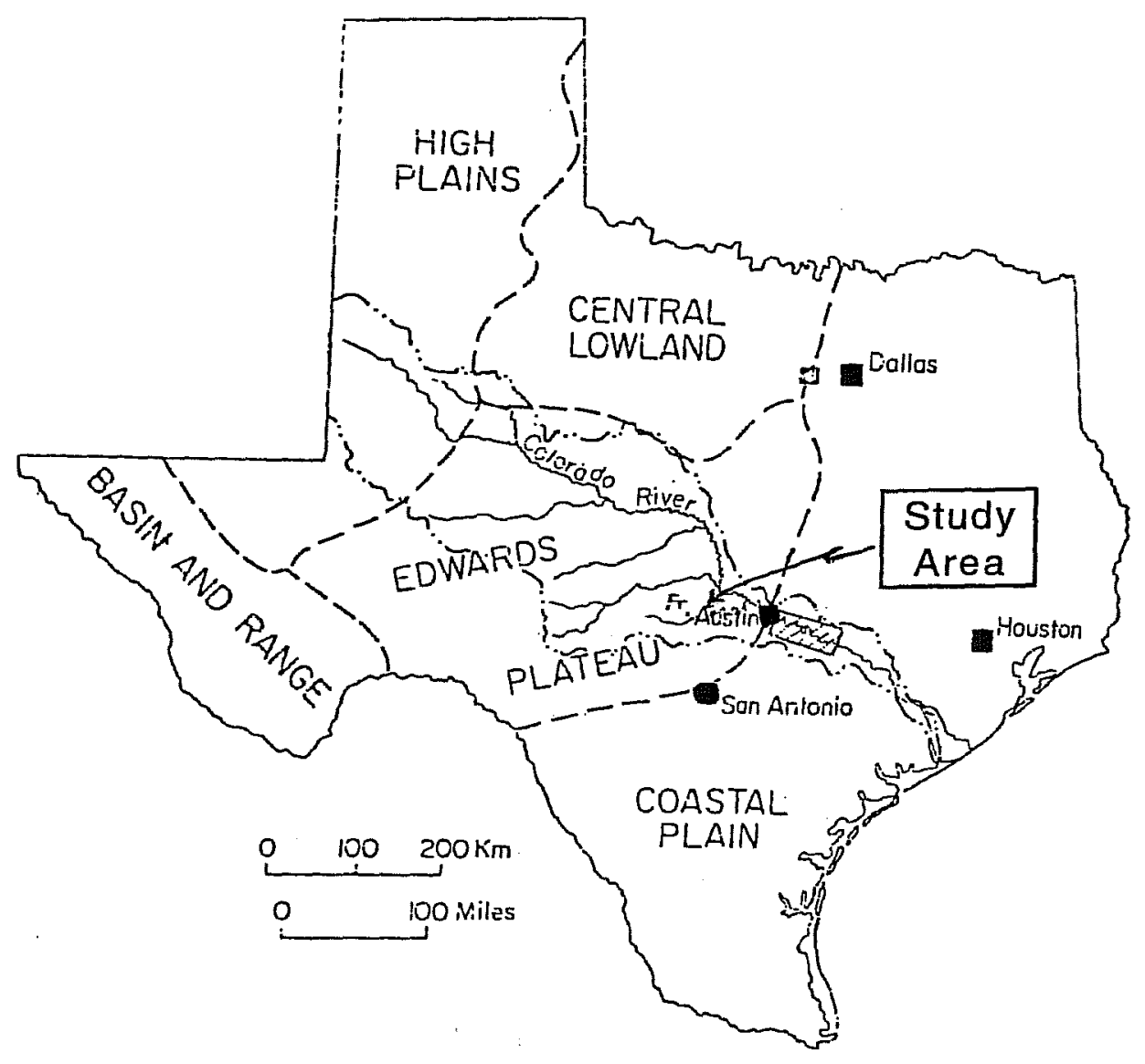

Figure 1.01. Project Area Location. 
Evidence suggests that prehistoric culture in central Texas never became more complex than possibly semisedentary collectors and hunters (Weir 1976). Presumably regions to the east and west that gave rise to more complex cultures did so because of a relatively dependable environment, whether it be woodland or desert. Cultures in the dependency zone varied substantially with climate. It is further suggested, based on Weir's (1976) analysis of the character of cultures at various times in central Texas, that culture in central Texas may be influenced from the east or west depending on prevailing climate. The issue of prehistoric climatic stability or instability is and perhaps always will be a matter of controversy. However, those who support Holocene climate stability for central Texas do so on the basis of pollen analyses (Bryant 1977). It is becoming increasingly clear that pollen analysis, unless conducted under extremely well-controlled, ideal conditions, does not yield a high resolution vegetational chronology necessary to infer climatic changes within the Holocene. The degree of control necessary is illustrated in Bernabo (1981), in which periods of hundreds of years or less were pinpointed as to their relative temperatures. Related chronologies such as the rock fall chronology at Arenosa Rock Shelter in west Texas (Patton and Dibble 1982), the Colorado River alluvial chronology in central Texas (Baker and Penteado-Orellana 1977), and the Pomme de Terre River in Missouri (Brackenridge 1980) clearly show that the ecotonal region between the eastern woodlands and the desert west was not climatically stable during the late Quaternary. The evidence for these and many other studies is reviewed in Gunn (1982a).

Another issue of even greater concern is the co-evolutionary character of biota, including pollen bearing species, and human organization. There is ample evidence that humans have interacted with the vegetation for tens of thousands if not millions of years (see Balée 1989, 1993, see Gunn 1994 for documentation). Balée, in particular provides illuminating examples of so-called anthropogenic forests. Texas grasslands could just as well be anthropogenic. Thus, pollen analysis, especially since it convey a subregional rather than local signal, is registering human and plant interaction as much as plant and climate interaction. Though themselves not free of human influence, physical phenomena such as rock fall are in greater part indicators of climate, or the climate can be registered as a function of astronomical and geophysical conditions as is done in this study (see chapter 3 ).

The specific problem orientation of the 1982 field season in LBJ State Historic Park was to test two ideas that are relevant to the problem of culture and climate change. The first is a high resolution chronology for prehistoric central Texas published by Prewitt (1981). Prewitt's chronology (Figure 1.02) is based on cultural subsistence traits and diagnostics; time periods range from 150-1500 years long with a mean of 639 years for 13 periods. Since climatic episodes appear to range in hundreds of years (high resolution) rather than thousands of years (low resolution, see low resolution chronology in the side box in this paragraph), which is characteristic of previously published chronologies, the Prewitt chronology poses an interesting opportunity to investigate the relationships between proposed cultural and climatic chronologies. 


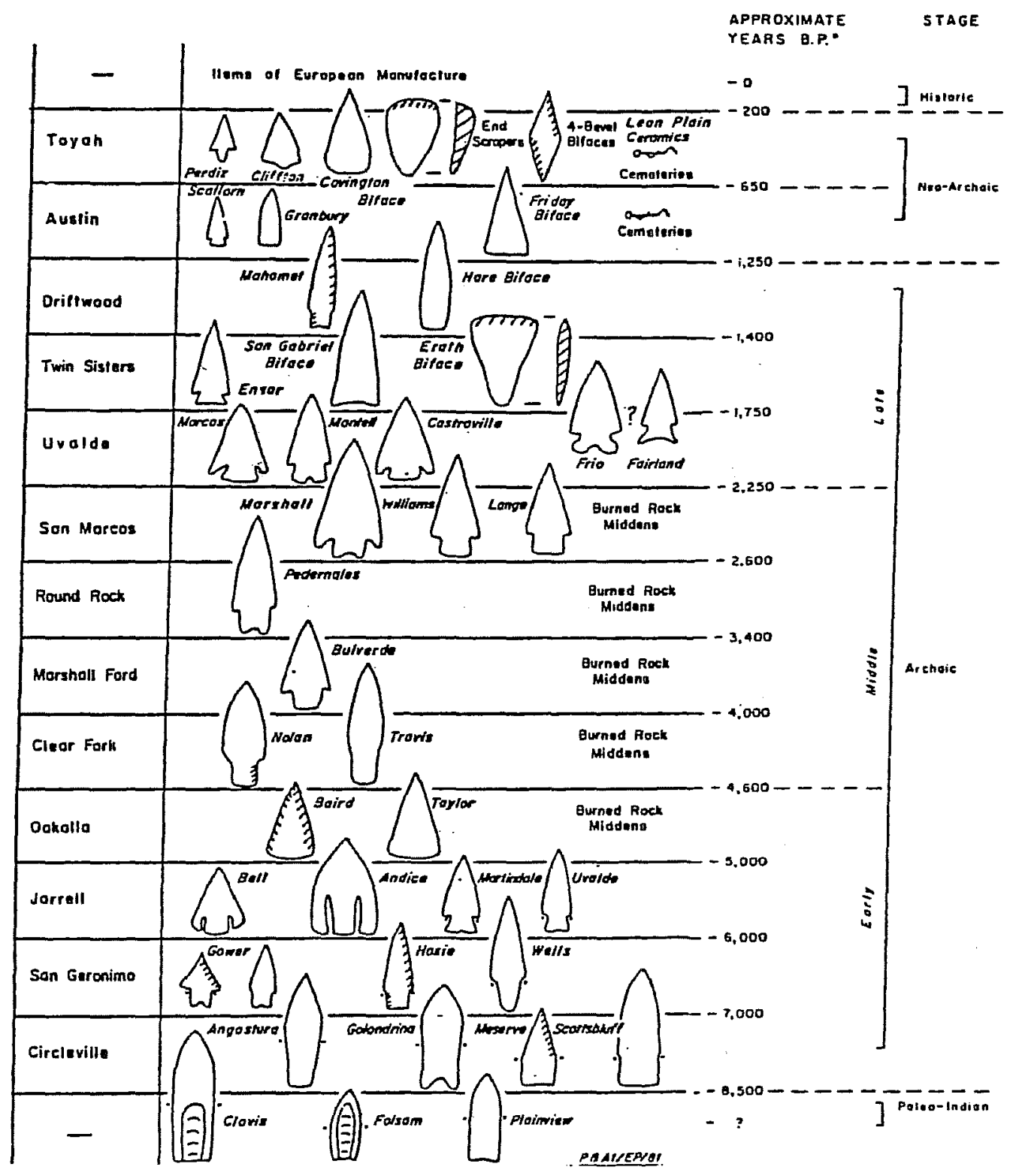

Figure 1.02. Point Chronology (calibrated dates, Prewitt 1981). 
The second development that contributes to the model for testing in this project is the publication of a substantial amount of information on Holocene and Late Pleistocene global volcanic activity. Bryson and Goodman (1980) and Simkin et. al. (1981) have published on global volcanics. Analysis of 20th century weather data by Gunn (1981) shows that Gulf Coastal Plain climate is highly susceptible to the affects of volcanic dust (aerosols) in the upper atmosphere. The data on global volcanism, then, can be converted into a 100-year resolution climatic chronology for central Texas by means of a global-to-local transformation function.

Figure 1.03 is an estimated global average temperature curve for the last 8,000 years of the Holocene. Since annual temperatures in Texas are directly correlated with global temperatures, a function can be devised to convert global average temperature into Texas temperature on an approximately decade to century scale (Gunn 1979b). Moisture appears to be inversely correlated to temperature. These functions can be used to generate a climatic chronology for the middle and late Holocene of central Texas. The curve is generated by a two-influence model (Gunn et al. 1995). Its overarching character is controlled by a calculation of the October precession of the Earth's rotation and orbit. Kukla (1975) first suggested that the October precession is an important component of global climatic change. The model was first developed for Central Texas (Gunn 1979b) and the Gulf Coastal Plain (Gunn 1981), and later elaborated to other Texas subregions (Gunn 1988, 1989, 1992). The oscillations imposed on the overarching curve are generated from global volcano frequencies (Bryson and Goodman 1980). Though work remains to be done on solar emissions variations, they are also an important component of global average temperatures (Gunn 1991, 1996), and as modeled by Landscheidt (1987) probably are reflected to some degree in the volcanic chronology. When combined, the curves give an estimate of the combined effects of tilt of the earth's rotation and the reflective properties of the atmosphere as controlled by volcanoes. This curve and its more complex subsequent developments have been used successfully to estimate moisture in the Yucatan Peninsula (Gunn et al. 1995) of Mexico and Burgundy, France (Gunn and Crumley 1991).

The issue of interpretation of this model into a climatic chronology is discussed in detail in Gunn (1983a), but for now can be viewed as a relatively simple process of assigning moist intervals to periods of high volcanic activity and dry periods to times of low volcanic activity. The overall input from the sun as modulated by this process must also be accounted for. For a discussion of combined solar and volcanic effects on climate see Schneider and Mass (1975) and Gunn (1991).

In regional perspective, the LBJ project is central to a set of problems that encompass west Texas, northeastern Mexico, central Texas, east Texas, and western Louisiana. In the United States, the ecotonal area encompassed by this space can best be characterized as the Southcentral area, as opposed to the Southwest and the Southeast. It is an area with various regional problems that is generally characterized by the ecological disposition of instability. 


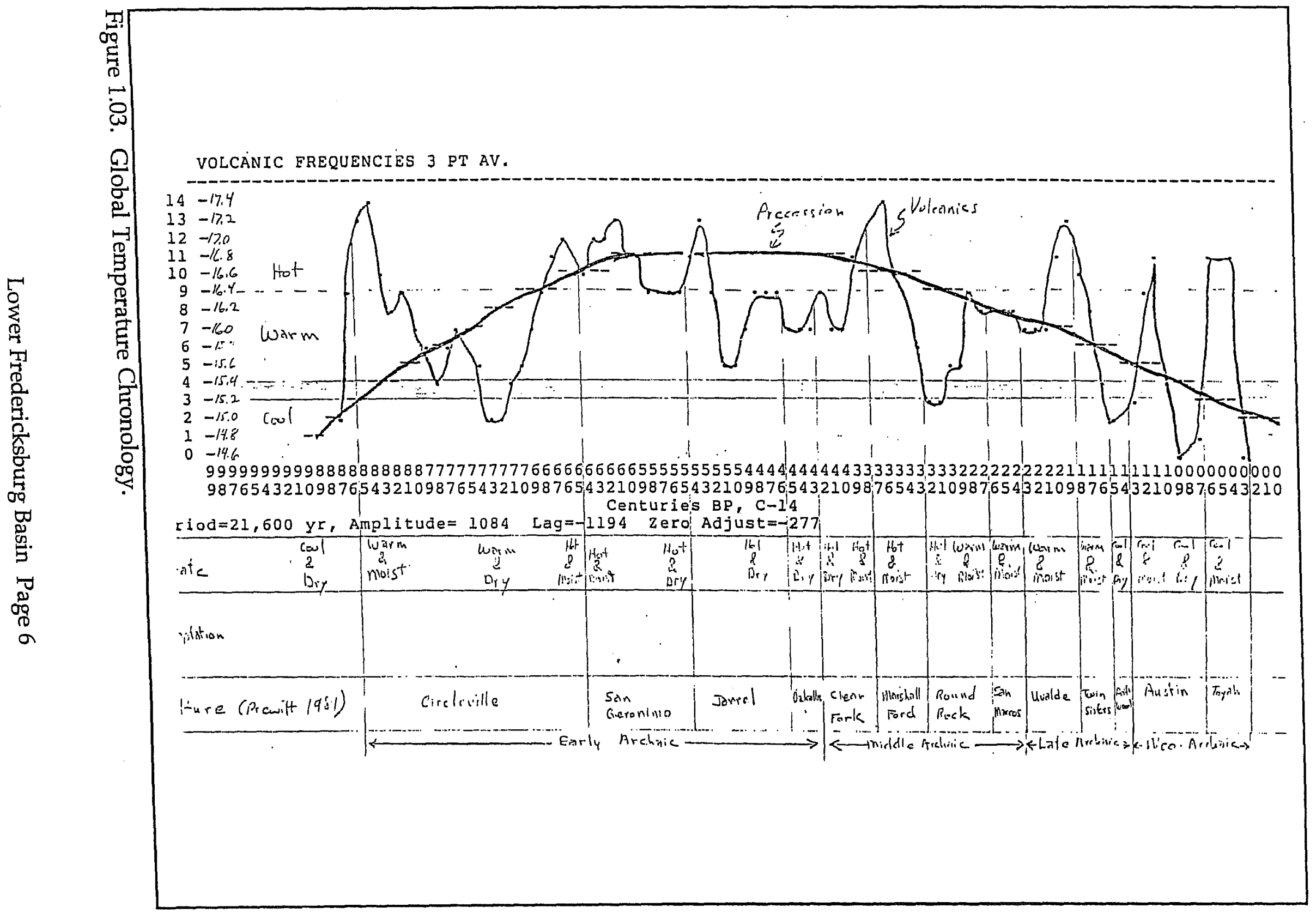




\section{CHAPTER 2-SURVEY OF THE EASTERN HALF OF LBJ STATE HISTORICAL PARK, JUNE 1982 (Gibson, Gunn)}

\section{INTRODUCTION}

The reconnaissance and testing investigations conducted in the LBJ State Historical Park during 1982 are presented in five sections. First and second, the field research methods and research orientations are described. Third, artifact categories and terms are defined (derived from Crabtree 1972; Gunn and Mahula 1977a, Gibson 1981:18-19). Fourth, the sites and their associated artifacts are described. Fifth, the conclusions based on these findings are presented as a proposed settlement pattern.

Archaeological sites can be considered as the location of one or more prehistoric activity areas. Activity areas are spatially restricted zones within which a specific task or tasks were performed (hunting, camping, cooking, tool manufacturing and/or replacement, hide-working, etc.). Sites and their associated activity areas are generally characterized by waste products, a scatter of tools, and/or raw materials (Flannery 1976:34). If activity areas are separated into spatially discrete clusters, but the clusters are related by technological remains, temporal diagnostics and the like, then the site is referred to as a locality; i.e., it contains subsites.

As discussed in Gunn and Mahula (1977a), existing within the park are many different kinds of potential sites. They are defined by different conditions of soil formation, sediment deposition, depth, and protection from erosion. The first group of sites are those with significant sediment deposition at the time, or since the occupation of the site, whether deposition is ongoing or has ceased. The second group of sites are those with no significant deposition during or since the time of human habitation, or where the sediments have eroded away (Pettigrew 1979).

The first of these two basic site types has vertical structure; vertical differences between artifacts or features at the same horizontal location which have temporal significance. At such sites the vertical structure, as well as the horizontal structure, below the surface can only be studied by standard excavation methods. The second of the two site types (those with no deposition) has no true vertical structure even though some cultural debris may be buried. At such a site vertical displacement of specimens is not caused by soil deposition but by soil disturbance processes. Burrowing rodents and tree roots are likely examples (Pettigrew 1979). When artifacts are recovered at these sites by excavation, only horizontal patterning is discovered, since there is no vertical structure (Gibson 1981). A more efficient method of investigation for such sites is mapping surface distributions and numerical analysis of the resulting data (Gunn and White 1977; Gunn 1982c).

Field research methods for the LBJ project were selected according to the conditions found at each site as classified above. The primary objective was to obtain as much 
data on vertical and horizontal site structure as possible in order to evaluate archaeological potential. Also, it was deemed important to obtain as large a sample of diagnostic artifacts as possible to evaluate the relationship between Prewitt's (1981) high resolution chronology for central Texas, and the sites of the LBJ State Historical Park which must be taken, for now, to represent the archaeological sequence of the Fredericksburg Basin. Plans were, of course, constrained by the amount of money and time available to the project.

\section{THE CONCEPTUAL PERSPECTIVE MADE EXPLICIT}

The study of archaeological sites addresses the material remains of a cultural system. When analyzing and interpreting such archaeological data, implicit assumptions should be made explicit. These explicit assumptions that follow are an extension of those offered by Fitzhugh (1972), Gunn and Mahula (1977a), and Gibson (1981).

1. In broadest perspective, humans are part of an ecosystem. They are limited in part by the environment and their ability to alter that environment to supply their needs (Fitzhugh 1972). Thus, human culture can be analyzed as a subsystem of the ecosystem which is the chief means of survival for humans (Gibson 1981) and is in part determined by the environment. As such, the study of culture is part of the larger perspective of ecological studies. In this context, cultural events and processes can be independently verified by examination of contemporary conditions in the ecosystem.

2. The authors of this chapter consider culture to be an adaptive system which articulates with the environment through a complex set of patterned relationships. These relationships are presumed to be reflected in a settlement pattern and are therefore detectable by survey, provided enough information is collected on each site to define the nature of its function relative to the overall pattern. This articulation is manifested in two contexts--social and physiographic (Fitzhugh 1972:7). Archaeologists would like to define patterns in both aspects of the system. However, the bulk of the preserved evidence is of a physiographic nature (Fitzhugh 1972).

3. As do many archaeologists, we assume that the most accessible and vivid relationship between a culture and its environment is expressed in its economic and technological adaptations which are partially preserved in material cultural remains. We further assume that ecological behavior is goal directed (e.g., focused on economic exploitation) and is a major part of a society's adaptation. In this sense, we are in accord with what Harris (1979) defines as the techno-environmental adaptation of a society. Yet, as must always be emphasized, particularly in archaeology, that technology is only part of the whole cultural system (Fitzhugh 1972). 
4. Another important archaeological assumption is that technological and economic behavior, observed ethnographically and experimentally, and the material remains produced by this behavior in similar environmental milieus, may represent similar prehistoric behavior as evidenced in the archaeological record. As is implied in assumption 3, an assemblage of artifacts indicates various activities that have occurred at a particular place at a particular time (Fitzhugh 1972). However, these activities are only partially preserved and as Gunn and Mahula (1977a:6) have observed in an analogy between archaeological sites and information systems channels; "Whatever information is encoded and survives the channel of time, is destroyed in an instant by archaeological excavation. The resolution of the archaeologists' techniques has been and still probably does consist of inadequate mechanisms to decode the delicate pulses--taps of an ancient persons's hand."

Many of the above assumptions have been expressed in a detailed model for hunter-gatherer cultural systems (Binford 1980). This study of central Texas prehistoric hunter-gatherer settlement uses Binford's model as a descriptive and analytical framework. A brief review of the characteristics of Binfords' model provides a departure point for presenting the results of the 1982 reconnaissance.

Binford (1980:10) defined hunter-gatherer subsistence and settlement into two basic types, "foragers" and "collectors," and expressed these types in terms of a model. The following discussion addressed the problem of which type best characterizes the prehistoric residents in the general park area at various times.

In discussing foragers, Binford (1980:5) writes, "One distinctive characteristic of a foraging strategy is that the foragers typically do not store foods, but gather food daily. They range out of camp gathering food on an 'encounter' basis and return to their residential bases each afternoon or evening." By contrast, "collectors" are hunters who supply themselves with specific resources through specially organized task groups (Binford 1980:10). Binford's alternative hypotheses are presented in Tables 1 and 2, in terms of their respective components. If the technoenvironmental adaptation was of the forager mode, the two types of sites, residential base and location (Table 1), would be expected in the study area (Binford 1980:9; Gibson 1981:29).

The forager mode is similar to the "Restricted Wandering Community Model" developed by Beardsley et al. (1956). In addition to the two types of sites described above, if the hunter-gatherer groups were of the "collector" mode, one would expect the three types of sites, field camp, station, and cache (Table 2) with their associated criteria for identification (Binford 1980:10- 12). 


\title{
TABLE 2.01. COMPONENTS OF BINFORD'S FORAGER MODE FOR HUNTER- GATHERERS
}

\author{
Site Types Definition Archaeological I.D. Criteria
}

\begin{tabular}{|c|c|c|}
\hline $\begin{array}{c}\text { Residential } \\
\text { Base }\end{array}$ & $\begin{array}{l}\text { Center of subsistence } \\
\text { activities where most } \\
\text { processing, manufactur- } \\
\text { ing, and maintenance } \\
\text { activities take place. } \\
\text { short term in forager } \\
\text { mode. Longer term in } \\
\text { collector mode. }\end{array}$ & $\begin{array}{l}\text { Features, consisting of hearths, } \\
\text { lithic workshops, ground stone } \\
\text { tools for plant processing, } \\
\text { mixture of diverse floral and } \\
\text { faunal remains. Depth of } \\
\text { deposit would be minimal due } \\
\text { to brief occupation. }\end{array}$ \\
\hline Location & $\begin{array}{l}\text { Where extractive ac- } \\
\text { tivities are exclu- } \\
\text { sively conducted, low- } \\
\text { bulk procurement. } \\
\text { very brief usage. }\end{array}$ & $\begin{array}{l}\text { Difficult to identify due to } \\
\text { brief occupation and low bulk } \\
\text { extraction, possibly some modi- } \\
\text { fied floral materials and remains } \\
\text { (Binford } 1980: 9 \text { ). No hearths or } \\
\text { evidence of long term occupation } \\
\text { would be present. }\end{array}$ \\
\hline
\end{tabular}

TABLE 2.02. COMPONENTS OF BINFORD'S COLLECTOR MODE-FOR HUNTERGATHERER:

\begin{tabular}{|c|c|c|}
\hline Site $T$ & Definition & eological I.D. Criteria \\
\hline $\begin{array}{r}\text { Field } \\
\text { Camp }\end{array}$ & $\begin{array}{l}\text { Temporary occupational center } \\
\text { for a task group which maintains } \\
\text { itself while away from the resi- } \\
\text { dential base. Field camps may } \\
\text { be expected to be further differ- } \\
\text { entiated by specialized toals and } \\
\text { the nature of the target resources } \\
\text { thus cartbou hunting camps, fishin } \\
\text { camps, etc. }\end{array}$ & $\begin{array}{l}\text { Small discrete scatter of } \\
\text { cuitural debris, fire-cracked } \\
\text { rock from hearth, flakes from } \\
\text { tool maintenance, and abundance } \\
\text { of one kind of fauna. Lost or } \\
\text { discarded specialized tools. } \\
\text { s, } \\
\text { ng }\end{array}$ \\
\hline Station & $\begin{array}{l}\text { Where special-purpose task groups } \\
\text { are localized in information } \\
\text { gathering, i.e. game movement } \\
\text { may be ambush iocations or } \\
\text { hunting stands }\end{array}$ & $\begin{array}{l}\text { Minimal to low cultural debris } \\
\text { and faunal remains, etc., if } \\
\text { associated nearby with a field } \\
\text { camplio. of station may be } \\
\text { facilitated. }\end{array}$ \\
\hline ache & $\begin{array}{l}\text { Comman components of a lagistical } \\
\text { strategy, i.e. successful pro- } \\
\text { curement of resources by relative } \\
\text { ly large groups generally means } \\
\text { large bulk. This bulk must be } \\
\text { transported ta consumers, tempor- } \\
\text { ary storage is required. Such } \\
\text { field storage facilities may be } \\
\text { constructed to deal specifically } \\
\text { with the bulk obtained. }\end{array}$ & $\begin{array}{l}\text { Evidence of large bu } 7 k \text { process- } \\
\text { ing large amounts of split } \\
\text { bone, discarded tools, butcher- } \\
\text { ing marks on the bones, storage } \\
\text { features, pits, racks, plat- } \\
\text { forms, etc., (evidence of } \\
\text { postholes). }\end{array}$ \\
\hline
\end{tabular}


The collector mode is similar to the "Central Based Wandering Community Model" (Beardsley et al. 1956). Within each site category, one can expect further variability that may relate to the seasonal availability and character of the resources being exploited by logistically organized task groups. Another source of intrasite variability is that all of the functions may not necessarily be independently located. As Binford (1980:12) points out, "In some situations one might be able to use the field camp as an observation point, in others, it may equally serve as a hunting stand. Many other combinations can be imagined. The point is simple: the greater the number of possible combinations, the greater the range of intersite variability we may expect." This is an important point for consideration; evidence of contemporaneous, extensive, intersite variability indicates the collector cultural system.

The applicability of Binford's model has been tested in south Texas (Gibson 1981), and it was found to be useful, particularly as a site classification and explanatory model for settlement patterns. Because of its usefulness in that specific test case, and because of the lack of settlement pattern models for central Texas (see Skinner 1981 for an exception), Binford's model is employed as the primary analytical and descriptive perspective for the 1982 investigations. The overreaching conceptual framework described in this section provides the basis for the interpretations present in the following section.

\section{RESEARCH OBJECTIVES AND METHODS}

Previous archaeological work in LBJ State Historical Park focused on Hop Hill (41 GL 21) which was excavated during the 1976 and 1978 field seasons. All that was known of the other sites in the park area was the information recorded by Texas Parks and Wildlife Department archaeologist, D. J. Ing in his site forms (on file at Texas Archeological Research Laboratory [TARL]). Thus, of concern in 1982 was to recover more data regarding the nature of the surface and subsurface components at the following sites: 41 GL 22, 41 GL 47, 41 GL 48, 41 BC 63, and 41 BC 71 (see Figure 2.01). For each of these sites a more refined understanding of the following criteria was sought: (1) site size; (2) vertical displacement; (3) intensity of occupation; (4) physiographic setting; (5) site-specific ecology; and (6) chronological placement. These criteria were sought through the procedural and sampling designs summarized in Table 2.03 . 
TABLE 2.03. RECONNAISSANCE/TESTING PROCEDURES FOR 1982 FIELD SEASON

\begin{tabular}{cccc}
\hline $\begin{array}{c}\text { Areal Coverage in } \\
\text { Site Number }\end{array}$ & Reconnaissance & Shovel Tests & 1-m2 Units \\
41 GL 21 & $100 \%$ & no & 6 \\
41 GL 22 & $100 \%$ & yes & 3 \\
41 GL 47 & $100 \%$ & yes & 2 \\
41 GL 48 & $100 \%$ & no & 0 \\
41 BC 63 & $100 \%$ & yes & 0 \\
41 GL 47 & $100 \%$ & yes & 6 \\
\hline
\end{tabular}


Figure 2.,01 removed 
Sites that appeared to bear information relevant to any of the above criteria were to be evaluated relative to prospective park development plans. These included a grazing lease for the eastern fields of the park, and possible plowing relative to grazing. Concerning Hop Hill (41 GL 21), the impact of a camping area was to be assessed and mitigated. A recommendation relative to these matters appears at the end of each site description and in the abstract and management summary at the beginning of the report.

\section{RECONNAISSANCE METHODS}

A systematic archaeological reconnaissance was conducted at all of the known park sites. At sites 41 GL 22 and 41 GL 47 a ten person field team conducted the survey by using the skirmish-line transect technique. At sites $41 \mathrm{GL} 48$ and $41 \mathrm{BC} 71$ a four-person team was used, and at site $41 \mathrm{BC} 63$ a two-person team completed the reconnaissance. At all of the sites, each person walked north to south transects, spaced at $10 \mathrm{~m}$ intervals. As the team slowly walked over an area, a color-coded flagging system (pin flags) was used to mark the locations of cultural debris and arbitrary shovel tests. A red flag denoted a diagnostic artifact, and a yellow flag was placed wherever lithic debitage, burned rocks, or other cultural remains were located. A blue flag marked the location of shovel tests to be excavated upon completion of the transects. At site 41 GL 22, shovel tests were arbitrarily located every $30 \mathrm{~m}$ along the uneroded terrace parallel to the draw. Additional locations for shovel tests at 41 GL 22 were selected based upon intensity of surface materials and likelihood of undisturbed buried deposits. The latter selection procedure was used for shovel testing at sites $41 \mathrm{GL} 47,41 \mathrm{BC} 63$, and $41 \mathrm{BC} 71$. No shovel testing was conducted at 41 GL 48 because the entire site was deflated and eroded down to bedrock.

The shovel tests had an average depth of $80 \mathrm{~cm}$ (although some were as shallow as $60 \mathrm{~cm}$ and as deep as $1.3 \mathrm{~m}$ ). The tests range from $35-40 \mathrm{~cm}$ in diameter, and were circular in shape. All of the excavated soil was sifted through 1/4-inch mesh screen.

All of the sites were documented on standard site survey formats and shovel test forms (see Appendix D). Photographs were also taken at each site. All diagnostic artifacts were collected. In this study, diagnostic artifacts were considered to be man-made objects that are evidence of specific aboriginal functions or activities (such as a scraper or mano), and often indicate chronological or cultural-historical affinities (such as points or pottery fragments).

The concluding reconnaissance activities focused on the open fields between sites 41 GL 22 and 41 BC 71, referred to here as the Schuman Field. The fields were tested by a dozen randomly located shovel tests. The azimuth and distance to each test was drawn from a table of random numbers. The locations are shown in Figure 2.01. As Table 2.04 shows, with the exception of Shovel Test FN 951, no sites were located in the field. FN 951 is near the Schuman house and is considered part of $41 \mathrm{BC} 71$. 


\begin{tabular}{|c|c|c|c|c|}
\hline \multicolumn{2}{|c|}{ Shove1 } & \multicolumn{3}{|l|}{ Depth } \\
\hline Test & FN & $(\mathrm{cm})$ & \multirow{2}{*}{$\begin{array}{l}\text { Artifacts Recovered } \\
70 \text { nothing }\end{array}$} & \multirow{2}{*}{$\begin{array}{l}\text { Recommendations } \\
\text { no excavation }\end{array}$} \\
\hline & 950 & & & \\
\hline & 951 & & 475 flakes, 6 chips, & 1 point $1 \times 1 \mathrm{~m}$ unit, near house \\
\hline & 952 & & 5 nothing & no excavation \\
\hline & 953 & & 601 tabular chert & fragment, $1 \times 1 \mathrm{~m}$ unit \\
\hline & 954 & & 30 nothing & no excavation \\
\hline & 955 & & 30 nothing & no excavation \\
\hline & 956 & & 43 nothing & no excavation \\
\hline & 957 & & 171 chip & no excavation \\
\hline & 958 & & 3 nothing & no excavation \\
\hline & 959 & & 80 nothing & no excavation \\
\hline & 960 & & 50 nothing & no excavation \\
\hline & 961 & & 56 nothing & no excavation \\
\hline
\end{tabular}

\section{ARTIFACT TERMINOLOGY}

The following terminology was used in describing artifacts found during the survey and testing.

Bifaces: Bifaces are tools that have had flake removals from both surfaces and also along at least one edge of the implement. In this chapter, bifaces are separated into thin and thick categories. A more detailed analysis is reported in chapter 8 . In some cases, thin bifaces were probably used as cutting tools or knives, and thick bifaces may have had other uses (such as chopping or cutting). Some bifaces may have also been "preforms," which are bifaces that were intended for further modification into knives or projectile points.

Cores: Cores are pieces of siliceous stone or other raw materials that have at least one surface from which flakes have been removed.

Cortex: A stone's weathered and/or carbonaceous surface.

Flake: A piece of stone that has been removed from a core by the application of force against the core's platform. In this report, flakes are considered only to be the result of human flint knapping activities. Diagnostic attributes of a flake are: a striking platform, ripples, fissures, and a bulb of percussion (see chapter 9).

Primary Cortex Flake: A flake characterized by a cortex outer surface.

Secondary Cortex Flake: A flake characterized by some portion of cortex remaining on the outer surface. 
Interior Flake: A flake lacking cortex, usually the most common flake form found at a site. Interior flakes are flint knapping debitage produced from a core, another flake, or a tool that has had all cortex detached by previous flake removals.

Mano: a mano is usually a small (hand-sized), rounded nodule of stone exhibiting evidence of use as a grinding stone (smoothing, polish, striations) on one or more flattened surfaces.

Hammerstones: Hammerstones are usually round or rounded nodules of stone that show evidence of battering (small craters, abrasions, etc.) on one or more ends.

Points: Usually points are thin bifaces that may have been use on the end of a projectile such as an arrow, atlatl dart, or spear. Some of these specimens may also have functioned as knives or cutting tools.

Scrapers: Formal tools that show either unifacial or bifacial modification. They usually have steep edge angles. Wear patterns often appear along edges in the form of damage and/or polish.

Unifaces: Unifaces are tools that have been modified on only one surface and one edge. Edge modification resulted from intentional retouch and/or use. The uniface category applies to any non-formal unifacially worked tool.

\section{SITE DESCRIPTIONS}

In this section, the sites studied during the course of the 1982 field season are described. Each site is introduced by a summary of data gathered by D. J. Ing in 1974 and R. Ralph in 1977. Ing and Ralph conducted evaluations for the Texas Parks and Wildlife Department (notes on file at TARL). The new information provided by our 1982 investigations presents an interesting case study in how surface visibility and subsurface testing can influence perceptions of a site to a significant degree.

\section{GL 21 (Hop Hill)}

Previous Research: The Hop Hill site was originally excavated in 1976 and reported by Gunn and Mahula (1977a). During that excavation a large area of the surface midden was examined and extensive surface collections were made. In 1978 the midden was further investigated and a draw discovered with $2 \mathrm{~m}$ of deposits in it. In 1982 the buried draw, probably a relic spring was excavated. Six square meters were excavated to the bottom of the draw. The results of the later two visits are reported in Chapters 4, 8, 10 of this work. The contents of the draw were dominated by Castroville and Ensor points suggesting the draw was used as a discard area during the Twin Sisters and Uvalde phases. The sediments were dark and included ash. The draw is presumed to have been a trash discard area. 
Recommendation: Part of the utilization plan for LBJ State Historical Park is use of the area of the Hop Hill site as a camping area. Given that the midden has been extensively sampled both by surface collection and excavation, and that the draw has been excavated and sampled, it seems likely that the cumulative excavations at the site have adequately characterized the horizontal and vertical contents of the site. The only remaining deposits in the site that might be given attention are those of the draw. Since they have been vertically sampled, they are adequately treated given the apparent trash accumulation character of the deposits. Horizontal patterning of artifacts is unlikely since the narrow draw could not have been used as a living surface. It might possess some value in terms of preservation for future research when additional research questions for the park area have been devised. Given the protected context of the deposits in the ravine, they will be preserved by the normal grassing of camping areas characteristic of the park. It is therefore recommended that the camping facility be allowed to proceed. As a site with intact deposits, 41 GL 21 should retain its National Register of Historic Places status and it warrants SAL listing.

\section{GL 22 (Dead Goat Draw)}

Previous Research: Ing described this site as a lithic quarry located along the sides of the draw in Figure 2.01. He noted that the western margins had been badly disturbed by plowing, and that the eastern side was fairly intact but eroded.

Comments: The 1982 investigations, which consisted of intensive reconnaissance and extensive subsurface testing, demonstrated that 41 GL 22, instead of being one large site was, in fact, four small sites, or a site locality (designated here as 41 GL 22a, 41 GL 22b, 41 GL 22c, 41 GL 22d). Frequencies of artifacts collected from the surface are shown in Table 2.05. Shovel tests are plotted in Figure 2.02. Table 2.06 shows the frequencies of artifacts found in shovel tests. 
TABLE 2.05. SURFACE COLLECTED ARTIFACTS FROM 41 GL 22 SUBSITES AND LOCALITY

$$
\begin{array}{cll}
\text { Platformed } & \text { Large Uni- } & \text { Hamer Burnt Biface Core } \\
\text { Flakes Chips Bifaces faces Cores stones Rock Chopper Tool Mano }
\end{array}
$$

\begin{tabular}{lllllllllll}
\hline 41 GL 22a & 0 & 0 & 2 & 0 & 0 & 0 & 0 & 0 & 0 & 0 \\
41 GL 22b & 1 & 0 & 0 & 0 & 3 & 0 & 0 & 0 & 0 & 0 \\
41 GL 22C & 1 & 0 & 1 & 0 & 0 & 0 & 0 & 0 & 1 & 0 \\
41 GL 22d* & 0 & 0 & 8 & 1 & 3 & 2 & 7 & 2 & 1 & 0 \\
Locality & 6 & 0 & 6 & 0 & 6 & 0 & 1 & 2 & 0 & 0 \\
41 GL 47 & 1 & 0 & 1 & 0 & 2 & 1 & 0 & 0 & 0 & 1
\end{tabular}

Additional Surface Scatters:

FN $10050 \mathrm{~m} \mathrm{NE}$ of $41 \mathrm{GL} 22 \mathrm{~b}$, tested cobbles, flakes, core frag.

FN 10250 SE of 41 In roadbed.

FN $128100 \mathrm{~m} \mathrm{~N}$ of $41 \mathrm{GL} 22 \mathrm{~b}$, by road, chunks, core fragments, flakes.

*Field Selected Items 
Figure 2.02 removed 
TABLE 2.06. SHOVEL TESTS WITH ARTIFACTS AT 41 GL 22 AND 41 GL 47

EN Totals Rlatform-Chips other

41 GL 22

\begin{tabular}{|c|c|c|c|}
\hline \multicolumn{4}{|l|}{ 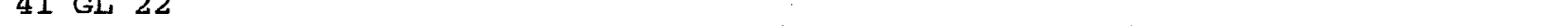 } \\
\hline $\begin{array}{l}11 \\
14\end{array}$ & 3 & 0 & 01 side scraper, 1 altered flake, 1 bone \\
\hline $\begin{array}{l}14 \\
16\end{array}$ & 1 & 0 & 1 \\
\hline $\begin{array}{l}16 \\
21\end{array}$ & 1 & 1 & 0 \\
\hline $\begin{array}{l}21 \\
24\end{array}$ & 1 & 0 & 0 modified cobble \\
\hline $\begin{array}{l}24 \\
25\end{array}$ & 1 & 0 & 1 \\
\hline $\begin{array}{l}25 \\
28\end{array}$ & 2 & 0 & 0 cobbles \\
\hline $\begin{array}{l}28 \\
34\end{array}$ & 2 & 0 & 0 small cobbles \\
\hline 34 & 1 & 0 & 0 notched stone \\
\hline 38 & 1 & $\begin{array}{l}0 \\
0\end{array}$ & $\frac{1}{1}$ \\
\hline 41 & 4 & 1 & $\begin{array}{l}1 \\
02 \text { trimmed cobbles, } 1 \text { large cobble }\end{array}$ \\
\hline 44 & 1 & 0 & $\begin{array}{l}02 \text { trimmed cobbles, } 1 \text { large cobble } \\
1\end{array}$ \\
\hline 56 & 5 & 5 & $\begin{array}{l}1 \\
0\end{array}$ \\
\hline $\begin{array}{l}57 \\
58\end{array}$ & 1 & 0 & 1 \\
\hline $\begin{array}{l}58 \\
59\end{array}$ & 1 & 0 & 1 \\
\hline $\begin{array}{l}59 \\
63\end{array}$ & 5 & 5 & 0 \\
\hline $\begin{array}{r}63 \\
131\end{array}$ & 1 & 0 & 1 \\
\hline $\begin{array}{l}131 \\
132 \\
\end{array}$ & 1 & 1 & 0 \\
\hline$\frac{132}{\text { Total }}$ & 4 & 0 & $\underline{4}$ \\
\hline Total & 37 & 13 & $\overline{12}$ \\
\hline 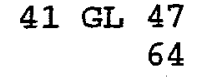 & & & \\
\hline $\begin{array}{l}64 \\
67\end{array}$ & 1 & 0 & 1 \\
\hline $\begin{array}{l}67 \\
69\end{array}$ & 17 & 15 & 01 burned rock, 1 mussel shell \\
\hline $\begin{array}{r}69 \\
133\end{array}$ & 1 & 0 & 1 \\
\hline $\begin{array}{l}133 \\
134\end{array}$ & 1 & 0 & 1 \\
\hline $\begin{array}{l}134 \\
135\end{array}$ & 3 & 3 & 0 mingd with Tost pit 136 Tete $166-1$ \\
\hline 170 & & & combined with Test Pit 136, Level 166-1 \\
\hline Total & 23 & $\frac{8}{26}$ & $\frac{0}{3}$ \\
\hline
\end{tabular}


Map Name: 7.5 USGS "Hye Texas"

Map Coordinates: Zone 14 Easting 538780; Northing 3345310.

Environmental Location: The site is on an upland floodplain of a dry creek channel (Figure 2.02). Vegetation on the site consists of an open grassy field with clumps of live oak and cedar intermixed. Other plants observed in the site area include prickly pear, yucca, and sotol. Perhaps the nearest source of water at the time of occupation was the creek bed which is less than $100 \mathrm{~m}$ to the west. Chert nodules are eroding from the slope. The soil in the site area is predominantly reddish and clayey with some depth, underlain by chert gravels.

Dimensions: Site $41 \mathrm{GL} 22 \mathrm{a}$ is about $90 \mathrm{~m}$ north-south and $120 \mathrm{~m}$ east-west along an unimproved road. The boundaries were defined by positive shovel tests and surface collection.

Description: The artifact assemblage consists of two large bifaces that may have been preforms. No burned rock was present.

Interpretation of the Site Type: This site may have been used as a quarry and initial flint knapping location where naturally occurring chert nodules were extracted and primary modification performed. The low bulk of materials suggests the site was occupied briefly. No hearths or evidence of long-term occupation is present.

Activities of Fieldworkers: Site was surveyed and mapped. Eleven shovel tests were excavated. Four proved positive (FNs 21, 24, 25, 28, see Table 2.06). The site boundaries were defined by surface collection. A test pit (FN 48, Table 2.07) also provided artifacts.

Probable Cultural Association: Unknown; no diagnostic artifacts were recovered.

Condition: Heavily eroded.

Recommendations: No further work is necessary.

\section{GL 22b}

Map Name: 7.5 USGS "Hye Texas"

Map Coordinates: Zone 14 Easting 538880; Northing 3345030.

Environmental Location: Site 41 GL $22 \mathrm{~b}$ is also located on the upland floodplain of a dry creek channel (the same channel as 41 GL 22a). Vegetation in the site area consists of open grassy fields, interspersed with clumps of live oak, cedar, hackberry, 
elm, and huisache. Ground cover is primarily bear grass and grama with scattered prickly pear and yucca plants. Lithic outcrops of river cobbles are present in the adjacent creek bed (see Figure 2.02). The soils exposed in the creek bed and shovel tests are blackish clayey loam for a depth of nearly one meter below surface underlain by reddish clay.

Dimensions: The site extends approximately $100 \mathrm{~m}$ (north to south) and is $70 \mathrm{~m}$ (east to west) as determined by positive shovel tests and surface collection.

Description: A small thin scatter of artifacts was observed on the site surface consisting of one exhausted core, two core fragments, and one large macro flake. One long flake and a few chips were found in the shovel tests. No fire-burned rock was seen in the site vicinity. Some artifacts were also found along the nearby unimproved road (FNs 100, 102, and 128).

Interpretation of the Site Type: Like $41 \mathrm{GL} 22 \mathrm{a}$, this site was used as a flint knapping location. The few flakes suggest this was a location where only a few cobbles were tested. The low frequency of artifacts indicates that this site was only occupied briefly, probably even less than 41 GL 22a.

Activities of Fieldworkers: The site was surveyed and mapped. Ten shovel tests were excavated. Shovel tests 44,63, 131, and 132 were positive (see Table 2.06); only flakes were recovered. The site boundaries were defined by the positive shovel tests and surface collection.

Probable Cultural Association: Unknown, no diagnostic artifacts were recovered.

Condition: Heavily eroded and deflated.

Recommendations: No further work is necessary.

\section{GL 22c}

Map Name: 7.5' USGS "Hye Texas"

Map Coordinates: Zone 14 Easting 538780; Northing 3345210.

Environmental Location: Site 41 GL $22 \mathrm{c}$ is located on what appears to be an erosion resistant landform (see Figure 2.02). It is at this point that the creek bed starts to migrate to the east. The site is located immediately adjacent to the creek bed. The surface vegetation is comprised of open grassy fields with clumps of live oak and cedar. Ground cover consists primarily of bear grass and grama. Lithic sources are primarily rounded river cobbles present in the dry creek channel. Soil is entirely a blackish (7.5 YR 3/2) clayey loam as far down as our subsurface test penetrated (ca. $1 \mathrm{~m}$ below surface). 
Dimensions: The site is approximately $70 \mathrm{~m}$ north south by $30 \mathrm{~m}$ east-west based on positive shovel tests (FNs 34, 36, 38; see Table 2.06).

Description: In the creek channel adjacent to the site, one large biface, one secondary cortex flake, and one edge altered core were found. In a test pit (1-x 1-m, FN 51) six interior flakes and two cores were recovered. No fire- burned rocks were recovered.

Interpretation of the Site Type: As in the cases of 41 GL 22a and 41 GL 22b, 41 GL 22c appears to be a flint knapping location. Additionally, as in the cases of the previous two sites, 41 GL 22c seems to have been occupied very briefly.

Activities of Fieldworkers: The site was surveyed and mapped. Two shovel tests and a 1- x 1-m test unit were excavated to a depth of $82 \mathrm{~cm}$.

Probable Cultural Association: Unknown; no diagnostic artifacts were recovered.

Condition: Slightly eroded.

Recommendations: No further work necessary.

41 GL 22d

Map Name: 7.5' USGS "Hye Texas"

Map Coordinates: Zone 14 Easting 538670; Northing 3345520.

Environmental Location: Site 41 GL 22d is situated on the third terrace above the floodplain of the Pedernales River. The surface vegetation is an open, grassy field composed primarily of beargrass and grama. At an adjacent picnic area (which probably is constructed over a portion of $41 \mathrm{GL} 22 \mathrm{~d}$ ), are clumps of live oak. The nearest lithic sources are rounded river cobbles eroding from the slope above the creek bed. Soils are variable--in the center of the site human occupation has resulted in the accumulation of a midden 30 to $40 \mathrm{~cm}$ thick. However, the overall underlying soil matrix consists primarily of brownish (7.5YR 3/2) clay loam.

Dimensions: The site area extends at least $70 \mathrm{~m}$ north to south and approximately $80 \mathrm{~m}$ wide east to west based on positive shovel tests (FNs 11, 14, 16, 58, see Figure 2.02) and test pits.

Description: A large number of artifacts of all types were scattered on the surface (see Table 2.05). Shovel testing and the excavation of two 1-x 1-m unit showed that the site has $40 \mathrm{~cm}$ of depth (Table 2.07). A high amount of fire- burned and cracked rock was seen on the surface and also in the 1- $x 1-\mathrm{m}$ test pits. 
TABLE 2.07. SITE $41 \mathrm{GL} 22 \mathrm{c}$ and $d, 1 \times 1$ METER TEST PITS

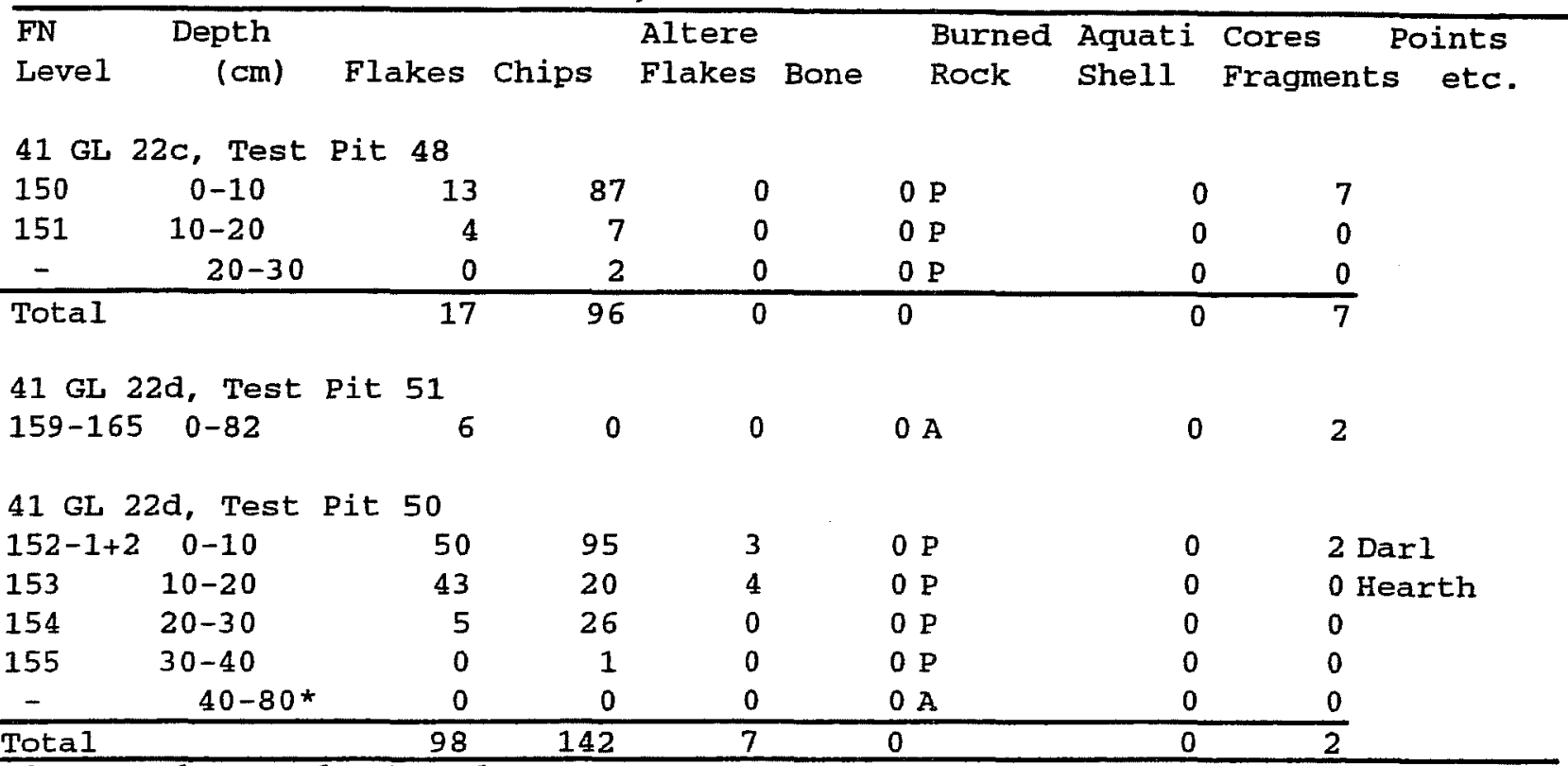

*One quadrant only; $\mathrm{A}=$ absent, $\mathrm{P}=$ present

Interpretation of the Site Type: Site $41 \mathrm{GL} 22 \mathrm{~d}$ was a residential base camp either of long-term occupation and/or of repeated usage. The quantity of cultural materials observed and collected substantiates this interpretation.

Activities of Fieldworkers: The site was surveyed and mapped. Nine shovel tests, four of which were positive (FNs 11,14, 16, 58, see Figure 2.02) and two 1- $x 1-\mathrm{m}$ units (FNs 50 and 51, see Table 2.07) were excavated. Two-hundred fifty-seven artifacts were recovered.

Probable Cultural Association: A Darl projectile point from the upper 10-cm level of Test Pit 50 date the site to the Late Archaic.

Condition: On the margins of the slope, a great deal of slope wash erosion has occurred. This process, combined with plowing of the field in the recent past, has scattered artifacts over $200 \mathrm{~m}$ to the south of the site and approximately $100 \mathrm{~m}$ to the east.

Recommendations: Should the site area be planned for development the test should be expanded to determine if there is any horizontal integrity to the subsurface levels. A 4- x 4-m excavation on top of the rise would likely be sufficient.

\section{GL 47 (Rabbit Run Site)}

Map Name: 7.5' USGS "Hye Texas"

Map Coordinates: Zone 14 Easting 538800; Northing 3345640. 
Previous Research: In his 1975 site survey, Ing described 41 GL 47 as a buried midden that was under a red clay plow zone. He observed that the midden deposit consisted of a dark gray sandy matrix, that possibly had been burned (notes on file at TARL).

Comments: The 1982 field research consisted of intensive reconnaissance and subsurface testing at this site. The results of our investigations demonstrated the following: (1) the site was much smaller than previously thought (see below); (2) the midden was deflated, plowed, and intermixed with the underlying red clay; and (3) a large amount of cultural debris was eroding from the western side of the site.

Environmental Location: Like $41 \mathrm{GL} 22 \mathrm{~d}$, site $41 \mathrm{GL} 47$ is situated on the third terrace above the floodplain of the Pedernales River. The surface is vegetated in open, grassy fields with clumps of interspersed oak and cedar. The nearest lithic sources are in tabular slabs from the eroded western slope of the site and are also abundant in the dry creek channel. Soils along the slope are thin, red clays. The slope is predominantly limestone bedrock. Near the site summit, along the terrace, soils are humic, brownish loamy clay mixed with the red clays, probably as a result of intensive plowing in the recent past.

Dimensions: The site approximately $120 \mathrm{~m}$ long (east to west) and $50 \mathrm{~m}$ wide (north to south).

TABLE 2.08. SITE 41 GL $47,1 \times 1$ METER TEST PITS

\begin{tabular}{|c|c|c|c|c|c|c|c|}
\hline $\begin{array}{l}\text { FN Depth } \\
\text { Leve1 (cm) } \\
\text { Test Pit } 136\end{array}$ & Elakes & Chips & $\begin{array}{l}\text { Altere } \\
\text { Flakes Bone }\end{array}$ & $\begin{array}{l}\text { Burned } \\
\text { Rock }\end{array}$ & $\begin{array}{l}\text { Aquati } \\
\text { Shel1 }\end{array}$ & $\begin{array}{l}\text { Core } \\
\text { Eragments }\end{array}$ & $\begin{array}{l}\text { Points } \\
\text { Ec Tools }\end{array}$ \\
\hline $166-1$ & 41 & 83 & 1 & $0 \mathrm{P}$ & 0 & 11 & 0 \\
\hline $167-2$ & 19 & 24 & 0 & $0 \mathrm{P}$ & 0 & 0 & 0 \\
\hline Total & 60 & 107 & 1 & 0 & 0 & 11 & 0 \\
\hline Test Pit 54 & & & & & & & \\
\hline $168-1$ & 101 & 138 & 4 & $0 \mathrm{P}$ & 0 & 1 & 0 \\
\hline $169-2 \quad 8-15$ & 14 & 12 & 0 & $0 \mathrm{P}$ & 0 & 1 & 1 \\
\hline Total & 115 & 150 & 4 & 0 & 0 & 2 & 1 \\
\hline
\end{tabular}

Test Pit 137

\begin{tabular}{llrrrrrrr}
$137-1$ & $0-6$ & 45 & 64 & 0 & $0 \mathrm{P}$ & 0 & 0 & 2 \\
$137-2$ & $6-12$ & 4 & 9 & 0 & $0 \mathrm{P}$ & 0 & 0 & 0 \\
\hline Total & & 49 & 73 & 0 & 0 & 0 & 0 & 2 \\
\hline
\end{tabular}

$\overline{\mathrm{P}}=$ present

Description: As mentioned above, a large amount of cultural debris (primarily debitage, cores, and broken tools) is eroding from the site surface (particularly along the western margins of the site). One mano was collected from the surface, and several hundred lithic artifacts came from the shovel tests and the three one by one 
meter units. All of our data indicate that the most intensive usage of the site was located along the west half.

Interpretation of the Site Type: Like 41 GL $22 \mathrm{~d}$, site 41 GL 47 was a residential base camp where a variety of activities occurred. This site, too, may have witnessed long-term occupations and/or may have been reoccupied numerous times.

Activities of Fieldworkers: The site was surveyed intensively, mapped, and tested. Ten shovel tests to ca. $45 \mathrm{~cm}$ below the surface were excavated seven of which proved positive (FNs 64, 67, 69, 70, 133, 134, 135, see Figure 2.02), and three 1x1 meter test pits (FNs 54, 136, 137) were completed to an average depth of $15 \mathrm{~cm}$ below surface (Table 2.08, see Figure 2.02). Site boundaries are based on positive shovel tests.

Probable Cultural Association: Not known; no diagnostic artifacts were found.

Condition: Except for occasional flakes, the material from the site is in a thin sandy surface sediment about $8 \mathrm{~cm}$ thick. The loose surface level seems to be deflated and probably suffered plow displacement in recent times. As such, the artifacts should be considered a surface collection.

Recommendations: No further work is recommended.

\section{GL 48 (Dead Cow Hill)}

Map Name: 7.5' USGS "Hye Texas"

Map Coordinates: Zone 14 Easting 539060; Northing 3345100.

Previous Research: In 1975, Ing described this site as a small quarry, located on a rocky chert and limestone outcrop. This landform is, in fact, a limestone ridge.

Environmental Location: The vegetation consists primarily of dense cedar, thorny brush, and mesquite. The nearest lithic sources are on the site surface and are abundant in nodular form. Soils are a red, gravelly clay and are very thin and weathered.

Dimensions: Site $41 \mathrm{GL} 48$ is approximately $200 \mathrm{~m}$ long (east to west) and $100 \mathrm{~m}$ wide (north to south). It was probably wider prior to the construction of U.S. Highway 290, which removed an unknown portion of its southern extent.

Description: Ing's description of $41 \mathrm{GL} 48$ as a quarry site is correct. It probably served as a prolific source of chert raw material through all of the cultural historical periods. However, there is no evidence of any long-term occupation at the site (burned rock or middens). Most of the nodules seen on the surface had been tested. 
Interpretation of the Site Type: Site 41 GL 48 is a flint knapping location of repeated, but brief, usage.

Activities of Fieldworkers: The site was intensively surveyed and mapped.

Probable Cultural Association: Unknown; no diagnostic artifacts were found.

Condition: Site 41 GL 58 has been deflated to bedrock by extensive sheetwash erosion.

Recommendations: No further work is necessary.

\section{BC 63 (Hye Site)}

Map Name: 7.5' USGS "Hye Texas"

Map Coordinates: Zone 14 Easting 540360; Northing 3345850.

Previous Research: In 1977, Ralph described this site as a midden located along the eastern first terrace of Williams Creek at its confluence with the Pedernales River.

Comments: A burned rock midden was confirmed at $41 \mathrm{BC} 63$ during the course of our 1982 field investigations.

Environmental Location: Site $41 \mathrm{BC} 63$ is located on the uppermost eastern terrace of Williams Creek near its confluence with the Pedernales River. The surface is heavily vegetated in tall beargrass and bermuda grass. Several very large oaks are located in the site vicinity. Soil is a dark blackish loam with unknown, but considerable, depth (in excess of $45 \mathrm{~cm}$ ).

Dimensions: The site size could not be determined because of heavy ground cover. In 1977, Ralph estimated the north-south extent to be $140 \mathrm{~m}$ but was unsure of the east-west extent (notes on file at TARL). Only a small portion of the presumed east-west extent of the site is on park property.

Description: The shovel test excavated in the burned rock midden produced approximately 73 lithic pieces of all types and a very dense concentration of burned rocks (Table 2.09).

Interpretation of the Site Type: These 1982 data, combined with Ralph's 1977 information, suggest that this site functioned as a residential base camp. Evidence suggests it may have had fairly long-term occupation (burned rock midden accumulation).

Activities of Fieldworkers: The site was surveyed, mapped, and one shovel test was excavated. 
TABLE 2.09. SHOVEL TEST AT 41 BC 63

Shovel Test FN 900

Depth: $45 \mathrm{~cm}$

30 platformed flakes

53 chips

quartz bearing calcareous sandstone

one possible point tip fragment, crazed

one altered flake, large

one lateral fragment, biface

one burned pecan shell fragment

Probable Cultural Association: The distinctive burned rock midden indicates a Middle Archaic association.

Condition: The burned rock midden is probably the only portion of the site that has not been plowed; undisturbed components could exist below the plow zone.

Recommendations: In the event the site is developed the test area should be expanded to determine if there is any horizontal integrity to the subsurface levels. It should be nominated for the National Register of Historic Places as a part of the $41 \mathrm{BC}$ 63-71 complex of sites. As will be shown in later sections, activity during the Middle Archaic at $41 \mathrm{BC} 71$ is marked by an unexpected reduction. It seems likely that this reduction of activity at $41 \mathrm{BC} 71$ was a product of shift of emphasis to $41 \mathrm{BC} 63$.

\section{BC 71 (Moccasin Confluence)}

Map Name: $7.5^{\prime}$ USGS "Hye Texas"

Map Coordinates: Zone 14; Geographic Center = Easting 540130; Northing 3345820; SW = Easting 540170, Northing 3345900; NW = Easting 540030, Northing 3345860; NE $=$ Easting 540170, Northing 3345900; SE = Easting 540270, Northing 3345520.

Previous Research: Ralph, in 1977, named 41 BC 71 "Schuman House Site," however, it was renamed during the course of our 1982 field work. Also, Ralph described the site as a prehistoric midden, quarry, and chipping station.

Comments: Our research showed $41 \mathrm{BC} 71$ to be a multicomponent, residential base camp that was occupied from Paleoindian times to the Late Prehistoric period. Site 41 BC 71 received a great deal of our energy and effort in 1982 and is described in detail in chapter 3 and various technical chapters. Only the salient characteristics of the site are summarized here. Without question, $41 \mathrm{BC} 71$ is one of the most important sites yet tested in central Texas. 
Environmental Location: Site $41 \mathrm{BC} 71$ is located where the floodplains of Williams Creek and the Pedernales River meet. Thus, it is situated on a wide, nearly level, terrace. Site vegetation consists primarily of grama, beargrass, and assorted weeds. Along the left bank of Williams Creek is a grove of some very large oaks, elms, hackberry, and pecans. Also, large oaks grow on the northern margins of the site near the Pedernales River. Soils consist of a deep sandy clay loam that extends to a depth in excess of two meters. The nearest source of lithic raw material occurs as stream and river cobbles on the lower banks of Williams Creek and the Pedernales River. There is an outcrop of limestone in the orchard to the southeast of the Schuman house that appears to have been a lithic resource. Also, upland lithic resources described above were probably utilized as well.

Dimensions: Site $41 \mathrm{BC} 71$ covers over four square hectares, extends approximately $400 \mathrm{~m}$ (north to south), and is approximately $150 \mathrm{~m}$ wide (east to west).

Description: The site has many components. The best represented periods are Late Paleoindian, Early, Middle and Late Archaic. Shovel tests (Table 2.10) in the eastern area of the site obtained hundreds of chert flakes and tools, as well as five points (Bell, Marcos, Nolan, Castroville, and an unknown type). A sizable midden with burned rock is located in the north central area of the site and seems to date to Middle and Late Archaic times. Subsurface testing revealed extensive occupation floors (chapter 11), and associated faunal materials, aquatic shells, and burned rock. The only evidence for the Late Prehistoric occupation was from a possible Scallorn stem recovered from a shovel test. No further Late Prehistoric evidence was uncovered in the extensive testing of the site. Therefore, Late Prehistoric occupation is considered ephemeral for the time being, and is not discussed in the subsequent technical chapters.

Interpretation of the Site Type: From the Early Archaic until at least the early Late Archaic, site 41 BC 71 functioned as a large scale, long-term residential base camp.

Activities of Fieldworkers: The site was intensively surveyed, mapped, and tested. Thirty-four deep shovel tests and six 1- $x$ 1-m test units were excavated (see subsequent chapters of this report).

Probable Cultural Association: All periods from Plainview-Angostura (Late Paleoindian) through Ensor (Late Archaic) are positively identified at $41 \mathrm{BC} 71$. Others are suggested. Local informants report that Lyndon Johnson's grandfather use the location to coral cattle before driving them to the Kansas railheads.

Condition: A local informant told us that this site, north of Ranch Road 1 has never been plowed. Thus, $41 \mathrm{BC} 71$ could be considered a pristine prehistoric site. 
TABLE 2.10. SHOVEL TESTS AT MOCCASIN CONFLUENCE (41 BC 71)

\begin{tabular}{|c|c|c|c|c|c|c|c|c|}
\hline $\begin{array}{l}\text { Shovel } \\
\text { Test FN }\end{array}$ & Depth & $\begin{array}{l}\text { Platforned } \\
\text { Flakes }\end{array}$ & Chips & $\begin{array}{l}\text { Altered } \\
\text { Flakes }\end{array}$ & Bone* & $\begin{array}{l}\text { Burnt } \\
\text { Rock* }\end{array}$ & $\begin{array}{l}\text { Core } \\
\text { Frags. }\end{array}$ & Additional Comments* \\
\hline $\begin{array}{l}200 \\
201\end{array}$ & $\begin{array}{r}124 \\
34\end{array}$ & $\begin{array}{r}69 \\
4\end{array}$ & $\begin{array}{r}87 \\
4\end{array}$ & $\begin{array}{l}0 \\
0\end{array}$ & $\mathbf{P}$ & $P$ & 0 & possible Scallorn stem \\
\hline \multirow[t]{2}{*}{202} & 37 & 48 & 73 & 2 & $P$ & $P$ & 0 & $\begin{array}{l}\text { point base, Dare, Lange, } \\
\text { Bulverde? }\end{array}$ \\
\hline & & & & 0 & A & A & 0 & \\
\hline 203 & 32 & 11 & 14 & 1 & A & $P$ & 0 & \\
\hline 204 & 28 & 5 & 6 & 0 & A & $\mathrm{P}$ & 0 & \\
\hline 205 & 70 & 27 & 46 & 0 & A & $\mathrm{P}$ & 0 & $\begin{array}{l}\text { ironware sherds, glass } \\
\text { sherd, cut square nail/ } \\
\text { late } 1900 \text { 's }\end{array}$ \\
\hline 206 & 30 & 14 & 21 & 0 & A & $P$ & 1 & $\begin{array}{l}\text { sma If piece mussel } \\
\text { shell }\end{array}$ \\
\hline 207 & 100 & 108 & 249 & 0 & $P$ & $\mathbf{P}$ & 0 & $\begin{array}{l}\text { FN235 beveled knife/ } \\
\text { FN243 EP, mussel shel1, } \\
\text { smal1 point frag. } \\
\text { Poss. Bulverde frág. } \\
\text { (crazed) }\end{array}$ \\
\hline 208 & 75 & 131 & 202 & 3 & $P$ & $P$ & 2 & $\begin{array}{l}\text { gouge (unifacial, one } \\
\text { side nibbled), Bf. point } \\
\text { tip, Bf. knife }\end{array}$ \\
\hline $\begin{array}{l}209 \\
210\end{array}$ & $\begin{array}{l}75 \\
68\end{array}$ & $\begin{array}{l}0 \\
7\end{array}$ & 2 & & A & P & 0 & \\
\hline $\begin{array}{l}210 . \\
211\end{array}$ & $\begin{array}{l}68 \\
75\end{array}$ & $\begin{array}{r}7 \\
23\end{array}$ & $\begin{array}{r}6 \\
56\end{array}$ & & & $\begin{array}{l}\mathrm{P} \\
\mathrm{A}\end{array}$ & $\begin{array}{l}0 \\
0\end{array}$ & $\begin{array}{l}\text { poss. mano frag. } \\
1 \text { frag. glass }\end{array}$ \\
\hline 212 & 75 & 2 & 2 & & A & A. & 0 & 2 glass bits \\
\hline 213 & 80 & 74 & 141 & 3 & A & $\mathrm{P}$ & 3 & $\begin{array}{l}1 \text { crazed point tip, } \\
\text { FN232 Marshale (Peder- } \\
\text { nales?) shell bits, } \\
\text { point tip (burned) }\end{array}$ \\
\hline 214 & 90 & 29 & 63 & 4 & A & $P$ & 0 & $\begin{array}{l}\text { FN231 basai point frag., } \\
\text { FN233 Bell, charcoal }\end{array}$ \\
\hline $\begin{array}{l}215 \\
216\end{array}$ & $\begin{array}{l}80 \\
87\end{array}$ & $\begin{array}{l}37 \\
43\end{array}$ & 80 & $\begin{array}{l}2 \\
4\end{array}$ & $\begin{array}{l}p \\
p\end{array}$ & $\begin{array}{l}P \\
p\end{array}$ & 2 & mussel sheil, 2 tip frag. \\
\hline $\begin{array}{l}216 \\
217\end{array}$ & $\begin{array}{l}87 \\
78\end{array}$ & $\begin{array}{l}43 \\
63\end{array}$ & $\begin{array}{l}201 \\
125\end{array}$ & $\begin{array}{l}4 \\
0\end{array}$ & A & P & 0 & Bf. latera 1 frag., \\
\hline 218 & 73 & 1 & 1 & 0 & A & $p$ & 0 & basal frag. B \\
\hline 219 & 80 & 0 & 0 & 0 & A & A & 0 & \\
\hline 220 & 85 & 0 & 0 & 0 & A & A & 0 & \\
\hline 221. & 70 & 0 & 0 & 0 & A & A & 0 & charcoal \\
\hline 222 & 100 & 0 & 0 & 0 & $A$ & $\begin{array}{l}A \\
0\end{array}$ & 0 & \\
\hline 223 & 70 & 11 & 10 & 0 & & $P$ & 1 & $\begin{array}{l}\text { charcoal, worm cast?, } \\
\text { FN238 Bf. basal frag. }\end{array}$ \\
\hline $\begin{array}{l}224 \\
225\end{array}$ & $\begin{array}{l}80 \\
73\end{array}$ & $\begin{array}{l}0 \\
37\end{array}$ & $\begin{array}{l}0 \\
46\end{array}$ & $\begin{array}{l}0 \\
0\end{array}$ & $\begin{array}{l}A \\
A\end{array}$ & $\begin{array}{l}A \\
A\end{array}$ & 0 & 1 small scraper \\
\hline 226 & 80 & 0 & 0 & 0 & A & $\begin{array}{l}A \\
A\end{array}$ & 1 & I sma if seraper \\
\hline 227 & 80 & 26 & 56 & 0 & $A$ & $\mathrm{p}$ & 0 & $\begin{array}{l}\text { FN242 oval Bf. (preform?! } \\
\text { tip gone, glass bit }\end{array}$ \\
\hline 228 & 85 & $\begin{array}{l}0 \\
20\end{array}$ & $\begin{array}{l}0 \\
28\end{array}$ & $\begin{array}{l}0 \\
0\end{array}$ & $A$ & $\mathrm{P}$ & 0 & \\
\hline $\begin{array}{l}229 \\
230\end{array}$ & $\begin{array}{r}89 \\
100\end{array}$ & $\begin{array}{l}20 \\
69\end{array}$ & $\begin{array}{l}28 \\
60\end{array}$ & 1 & $\hat{A}$ & $p$ & 1 & FN1337 Castroville or \\
\hline & & & & & & & & $\begin{array}{l}\text { Marshall, FN239 large } \\
\text { teardrop Bf. }\end{array}$ \\
\hline 626 & 123 & 43 & 54 & 0 & A & $P$ & 2 & $\begin{array}{l}\text { Bf, side scraper, barbed } \\
\text { wire, poss. barb from a } \\
\text { Bell point }\end{array}$ \\
\hline 962 & 106 & 38 & 81 & 0 & A & $P$ & 0 & $\begin{array}{l}\text { red reflector frag., } \\
\text { burnt quartz-bearing } \\
\text { sandstone. }\end{array}$ \\
\hline 963 & 57 & 0 & 0 & 0 & $P$ & A & 0 & \\
\hline
\end{tabular}

* $P=$ present; $A=a b s e n t$

** Bf. =biface 
Recommendations: The site contains deeply stratified, intact deposits with great variety and numbers of artifacts. The artifacts date from Paleoindian to modern times. The site is endangered by development upstream that will increase flooding in the Pedernales River, already a problem since the 1950s. We recommend large-scale block excavations be conducted at this site in anticipation of its eventual destruction. The site should be nominated to the National Register of Historic Places and warrants designation as a SAL.

\section{SUMMARY OF RECONNAISSANCE AND SUBSURFACE TESTING DATA}

The major interpretations obtained from the reconnaissance and testing operations of the 1982 field season are presented below. Principal activities performed at the site and primary function of sites are emphasized.

Sites 41 GL 22a, 41 GL 22b, and 41 GL 22c, with low amounts of occupational debris, were used briefly by people of unknown cultural- historical association. All of these sites functioned as briefly occupied, flint knapping locations.

The evidence from 41 GL 48 suggests it was repeatedly used as a flint resource location. Unfortunately, diagnostic artifacts were not found, and therefore the cultural-historical associations of the site is unknown.

Five residential base camps were found. Most significant of these is $41 \mathrm{BC} 71$, a multicomponent, stratified site, dating from the Paleoindian to Late Archaic period, and possibly even Late Prehistoric. Hop Hill (41 GL 21) was shown to be an intensively inhabited (semipermanent?) base camp dating to the Late Archaic Uvalde and Twin Sisters phases. Site 41 GL 22d was shown to be a less intensively occupied site dating probably to the Late Archaic as well. However, one Darl point does not necessarily mean this was the only time it was occupied. The other two residential base camps, $41 \mathrm{GL} 47$ and $41 \mathrm{BC} 63$, could not be firmly dated to a specific period, since no diagnostic artifacts were recovered. Site 41 GL 47 shows no evidence of intensive use comparable to 41 GL 21 or 41 BC 63-71. Site 41 BC 63 appears from one shovel test to be a very deep and dense burned rock midden in the classic sense. It can be assumed to date to the Middle Archaic since such middens are normally taken to be diagnostic of that period (Weir 1976; Prewitt 1981).

Further mention should be made of isolated artifacts recorded during the reconnaissance. Some artifacts (usually nondiagnostic unifaces and bifaces) were frequently found singly, mostly in the uplands, without any other associated cultural debris, and often several hundred meters from the nearest archaeological site. These artifacts may be indicators of specific prehistoric activities or, what Binford (1980:9) calls a "location," more commonly called an isolated find. Perhaps some plant extractive and associated expeditious tool making and discarding activities occurred prehistorically where these artifacts were found. 
Furthermore, we should add a cautionary note in our assessment of the prehistoric settlement patterns represented in the study area. There is a high potential that certain site functions could be "masked" to the archaeologist's observations, particularly at the large residential base camps. As stated earlier in this section, in some situations sites may serve different functions or combinations of functions. Within a seasonal exploitation cycle, a site that was a fishing camp in the summer could be a residential base camp in the autumn. If these different seasonal functions did occur prehistorically in the site area (and in all likelihood they did), they would be difficult to distinguish, owing to their sequential deposition. Thus, the only methods whereby such distinctions can be discerned at residential base camps like Hop Hill and Moccasin Confluence is through microstratigraphic excavation techniques (see chapter 3 of this report). However, owing to the enormous size of Moccasin Confluence (over four hectares), and the limited preliminary test excavation we completed, most of the differential, discrete, seasonal site functions are still unknown. These phenomena await future meticulous microstratigraphic excavations.

\section{CONCLUSIONS, OBSERVATIONS, AND PROPOSITIONS}

The size of the site samples obtained from the reconnaissance and testing procedures is small, but certain observations $(\mathrm{O})$ and testable propositions $(\mathrm{P})$ can be made concerning the prehistoric settlement patterns. These are presented as follows:

O1 In terms of site proximity, sites 41 GL 21, 41 GL 22a, 41 GL 22b, 41 GL 22c, 41 GL 22d, 41 GL 47 , and 41 GL 48 form one cluster. Sites 41 BC 63 and 41 BC 71 form another cluster.

O2 The Gillespie County sites, based on the evidence from Hop Hill, date primarily to the Late Archaic period with a trace of a Middle Archaic occupation at 41 GL 21.

P1 We propose that this site complex represents a nearly semisedentary settlement system functional during the Castroville-Ensor occupations of the Late Archaic period. Possibly this proposition can be tested in the following manner:

1. An examination of lithic raw material frequencies at the Gillespie County sites could or could not show similar outcrop utilization.

2. A study of the lithic technology represented at the Gillespie County sites should ascertain whether an integrated information system was shared by the prehistoric occupants of these sites in terms of lithic manufacturing behavior (see Weir 1976).

3. Paleoclimatological data and paleoenvironmental reconstructions could possibly shed light on why, judging by relative artifact deviation, this settlement 
system was narrow-ranging and nearly semisedentary. Narrow range implies a rich environment that supports a population locally. The Middle and Late Archaic artifact frequencies, therefore, imply a rich environment. The shift of emphasis to Hop Hill in the Late Archaic suggests a shift in resource base. Its elevated location near the locally well-known Johnson Ranch ford of the Pedernales River probably implies large, migratory game. Castroville points are frequently associated with bison (Dillehay 1974:183). Weir (1976) thinks the Middle Archaic was deer-acorn oriented. The nature of concordant climatic shifts will be discussed in chapter 5 .

O3 Site $41 \mathrm{BC} 71$ shows evidence of repeated and intensive occupations during the Early Archaic (Bulverde, Bell, etc.).

O4 Site $41 \mathrm{BC} 71$ is located at the confluence of the Pedernales River and a major tributary.

O5 Site $41 \mathrm{BC} 63$ has a location similar to $41 \mathrm{BC} 71$.

P2 The Blanco County Early Archaic Components at 41 BC 71 (and possibly at $41 \mathrm{BC} 63$, though this is problematic at present) show evidence of a riverine adaptive focus that may be the result of the Altithermal that occurred at this time (Middle Holocene).

P3 The Middle Archaic occupations at 41 BC 71 should show as a result of faunal-floral analysis an adaptive shift (still riverine, but more terrestrially oriented) and are probably part of the same narrow-ranging settlement pattern described above.

P4 Again paleoclimatological data may provide independent verification of the above propositions.

O6 Given that Hop Hill and the Moccasin Confluence are large, long-term residential base camps, the respective locations need to be analyzed to determine the faunal-floral and lithic resources that attracted differential occupation. This could be a complex problem because it would involve not only reconstructing the prehistoric environment as it differs from the present-day conditions, but also reconstructing the two environments under two different prehistoric conditions.

O7 Flotation analysis should also be designed to provide seasonality of occupation at $41 \mathrm{BC} 71$ and Hop Hill.

\section{MANAGEMENT SUMMARY}

A management summary for LBJ State Historic Park archaeological sites developed from the above reported investigations appears in the Abstract and Management Summary section at the beginning of this report. 


\section{CHAPTER 3-MOCCASIN CONFLUENCE OVERVIEW-A LATE QUATERNARY SITE IN THE LOWER FREDERICKSBURG BASIN OF THE EDWARDS PLATEAU (Gunn)}

Moccasin Confluence was tested during the 1982 season under the terms of Texas Antiquities Permit Number 310. The site was found to contain, as far as can be determined to date, a continuous sequence of sedimentary and cultural deposits from the latter part of the Pleistocene and through the Holocene virtually to the present. Concentrated residential occupation occurred during the Early and Late Archaic. Historically, it is also very interesting. It is located at the confluence of the Pedernales River and Williams Creek. According to a local informant the area was used by President Johnson's grandfather to pen cattle before driving them to Kansas to be sold at the railheads.

Geomorphologically the site is constituted of a slack water deposit at the mouth of Williams Creek and a nearby sandy knoll (Figure 3.01) across Ranch Road 1. Slack water deposits are formed when, during a flood, tributary water looses its rate of water flow as it enters the floodplain at its mouth. As the stream enters the floodplain the flatter terrain slows the rate of flow and heavier sediments settle. This accounts for the relatively high topography at the mouth of Williams Creek relative to the Pedernales floodplain, and for the preservation of the archaeological remains. Camps used by prehistoric peoples were frequently covered over by the predominantly silt-sized sediments before harm could come to them. Silt-sized particles of sediment settle out of water in about 15 seconds which gives a perspective on the relatively greater speed of the water in the uplands above the confluence.

The sandy knoll south of Ranch Road 1 is composed of coarser sediments. It appears to be an erosional remnant of an older sand body. The sand may be from an underlying, resistant sandstone, or it may have been brought in by the Pedernales River and blown out of the river bed during dry, windy seasons. Resolution of the problem of both the knoll and the confluence awaits further sediment analysis and geomorphological testing at depth.

Surface indications of the presence of a site in the confluence consisted of an area of unusually verdant grass near Test Pit 4 and a few burned rocks on the surface. A systematic program of deep shovel testing (Figure 3.01) revealed an abundance of lithic and burned rock materials within a meter of the surface. Two of the shovel tests, 213 and 214, provided five diagnostic points. Furthermore, field analysis of the points showed that the shovel tests up stream along Williams Creek contained, on the average, older points such as Bell. The tests closer to the Pedernales River usually produced younger points, generally of the Late Archaic. A shallow depression across the confluence north of Test Pit 4 suggested an old channel of the 
river passed nearby. The midden associated with Test Pit 4 may have been on the bank of the river.

Since the confluence may have been migrating northward, Test Pits 1 and 4 were placed to test the possibility that habitation migrated with the confluence. Detailed analysis of the lithics in the two test pits showed such a trend (see chapter 6). Test Pit 2, which was also located near two highly productive shovel tests, was occupied during the Paleoindian period and was accorded a relatively constant amount of occupation activity through the Holocene. Test Pit 4 analysis, on the other hand, showed a continuous increase in camp interest that peaked precipitously in the Late Archaic.

Test Pit 6 was located on the sandy knoll, in the front yard of the Schuman House. Diagnostics were limited to the Middle and Late Archaic. Occupation was most intense during the Middle Archaic. A rather interesting idea suggests itself: if the Middle Archaic was in part moist, as is suggested by the climatic chronology (see Figures 1.03 and 5.06), the elevated and well-drained knoll may have been a much favored place to camp with respect to the lower ground next to the stream. When corrected for sedimentation rates (see chapter 6) both test pits on the confluence show a drop in occupation activity during the Middle Archaic.

The Middle Archaic in central Texas is generally characterized by intensive occupation. Site 41 BC 63 across Williams Creek to the east was shovel tested. The test revealed a dense and thick burned rock midden typical of the Middle Archaic. While the locus of occupation may have been migrating to the knoll, it also seems likely that interest shifted across the creek, apparently for other reason judging by apparent site function, e.g., a burned rock midden. This may be because the east side of the creek was more proximate to raw materials, especially limestone outcrops. Any future research should investigate this prospect.

Diagnostics suggest that the break between Middle and Late Archaic in Test Pit 6 was between levels 9 and 10 (Figure 3.02). However, a detailed analysis of flake morphology showed a distinct break in flake width between levels 8 and 9 (see chapter 9). There is reason to think that the flake morphology indicator is as good a marker of the change between the two periods as diagnostics since there are so few points and many flakes. With regard to function, a change from narrow to wide flakes is also suggestive. Several indications were found that the Middle Archaic was a biface-oriented technology while the Late Archaic was a core flake oriented technology. The distinctive narrowing of flakes from Middle to Late Archaic reasonably indicates a change from broad bifacing flakes to narrow core flakes or perhaps even resharpening flakes. Weir (1976:116) notes that the Rondroele Phase and bifacing by implication, has an east Texas origin. There is also some sentiment that core flaking is Plains related. Gunn (1982d) suggests that the root of the preferences lies in a perspective on the applications of the two technologies. Bifacing lends itself to the manufacture of large, sturdy stone tools. These large, sturdy tools are amenable to both sedentary life and woodland technology. Nomads 
Figure 3.01 removed 


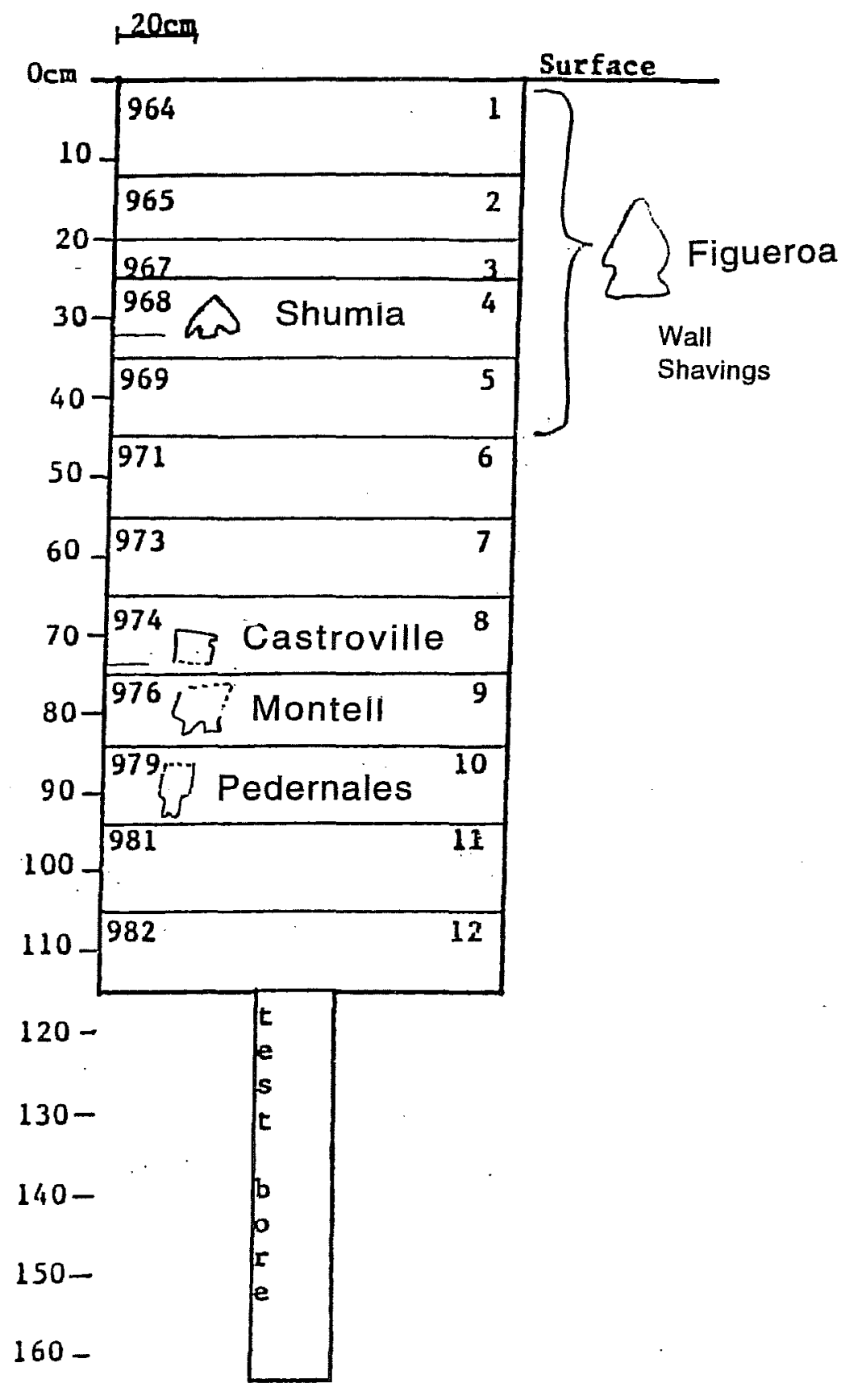

Figure 3.02. Diagnostic Sequence in Test Pit 6: Dates are BP-C14, identifications by E. Prewitt. 


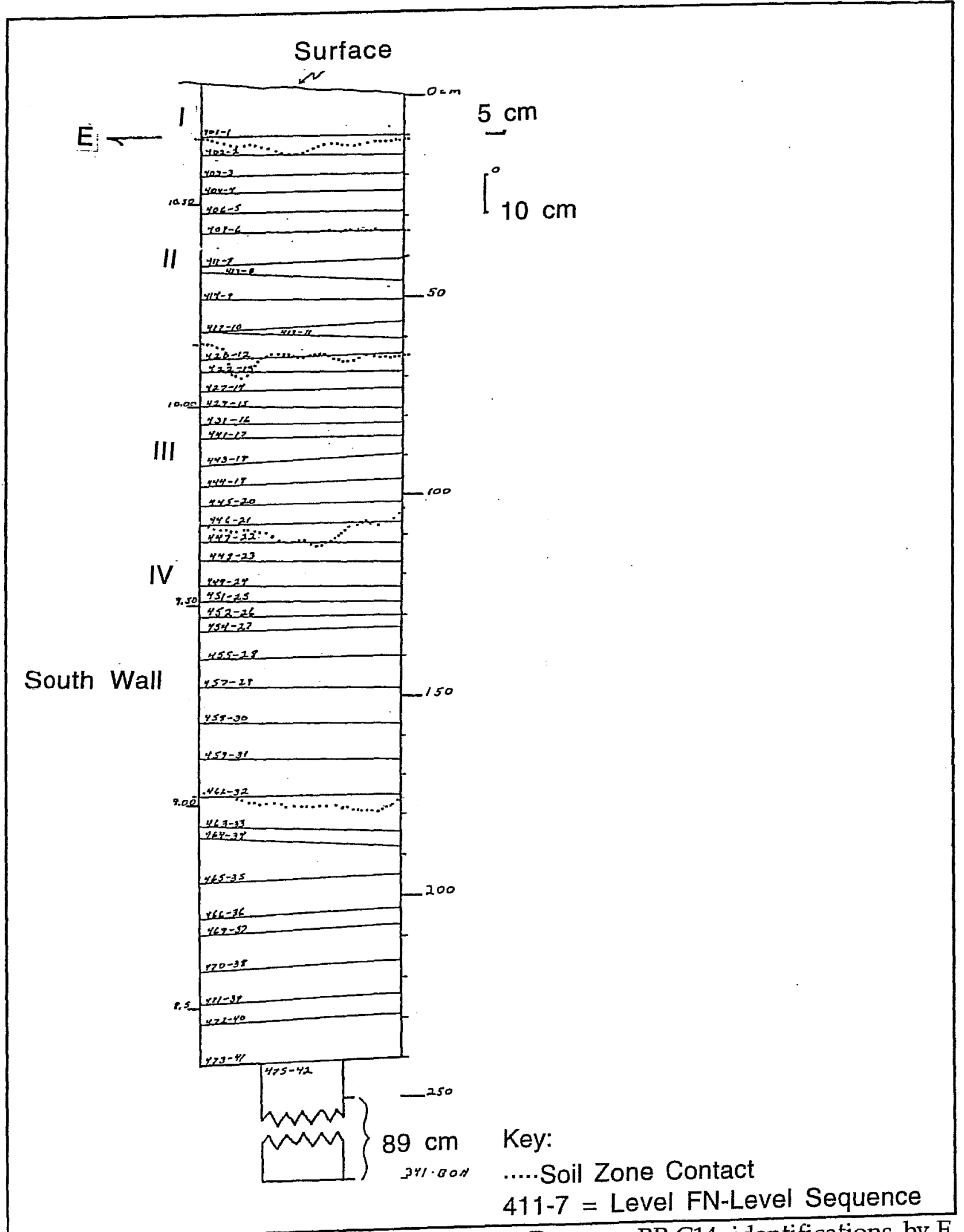

Figure 3.03. Diagnostic Sequence in Test Pit 4: Dates are BP-C14, identifications by E. Prewitt. 
do not carry large tools about with them, while sedentary dwellers can keep them around the hut. Woodland tool kits are used on tough, woody plant species to convert them into usable products such as house frames, canoes, etc.

By contrast, core technology and the similar but more refined blade technology is amenable to nomadic lifeways. Small tools that represent efficient use of material and effective dispatch of tasks are handily made by core/blade technology. Nomads, who are forced, at least in part, to carry their lithic raw material with them, would prefer an efficient technology with respect to the core bulk-to-edge ratio produced. Sheets and Muto (1972) have demonstrated the relative efficiency of core and blade technology. Binford (1978) and Goodyear (1979) have outlined the complexities of nomadic logistics that require efficient use of materials.

The alternation between core and biface technology demonstrated at Moccasin Confluence can be taken to mean that alternating Plains and Woodland influences held sway at the site. Coordination of the climatic chronology and the proposed sources of these technologies is suggestive. Final resolution of the problem will come with future work on the environment at the site. Such efforts should bring additional support to both the climatic and climate/culture hypotheses by confirming the presence of Plains-like and Woodland-like climates during the postulated technological intervals.

Test Pit 4 is located on the highest point in the confluence proper. Deposition seems to stop in the Late Archaic. This suggests that the river and the creek were no longer flooding to a level capable of continuing deposition. Note for contrast that deposition continued at the lower Test Pits 1-3. This probably suggests a lowering of the Pedernales River floodplain during the later part of the Holocene and more rainfall distributed more evenly over the year. Such a rainfall pattern would result in more vegetation, less sediment yield, and less overbank flooding.

The rock midden is clearly most concentrated in the Test Pit 4 area. It was apparently near the Pedernales River channel, a popular place to camp during the Late Archaic in particular. The deposits are quite thick during the Early Archaic and the Paleoindian periods (see chapter 4 ). This indicates relatively sparse vegetation in the uplands and high sediment yields (Schumm 1965). Model Holocene climatic change for the coastal plain (Gunn 1981) indicates that the hot and dry climate of the Middle Holocene would have been accompanied by torrential summer rainfall produced as a by-product of tropical storms. Such summer floods would very likely account for the thickness of the Early Archaic deposits. Such deposits are characteristic of south-central and southeastern rivers during the Middle Holocene (see Gunn 1982a for sources).

Test Pit 2 was the most intensively analyzed unit of the test excavations. Flake morphology was studied for all levels in the same fashion as Test Pit 6. Flake use-wear, mollusks, sediments, etc., were also studied intensively. Test Pit 2 was selected for close study because it appears to have the longest chronology of any test pit (see chapter 4). Deposition continues after the Late Archaic because of its low 
elevation. Also, a Paleoindian biface fragment was found far under the Plainview/Angostura horizon. It may well be Clovis related since the fragment is clearly not Folsom.

Much of the flake morphology and use-wear analysis suggests a situation opposite of that at Test Pit 6. Bifacing and core flake relationships are in many cases inverted. Also, the frequencies of use-wear types are often inconsistent. Two hypotheses are suggested as explanations for the inversions. First, the inversions may represent differing functions within the same societies. Manufacturing was more frequent by the creek and use more frequent on the knoll. Perhaps some thought should be given to division of labor. A second prospect is that the differences were generated by alternating visits from eastward or westward based groups. On first examination this may seem like a Deus Ex Machina approach to explaining the assemblage. However, there is plenty of evidence, both prehistoric (Dillehay 1974) and historic (Gunn and Frkuska 1982) to show that the comings and goings of bison to the southern plains were intermittent, and probably controlled by the annual average winter temperatures and length of growing season. Various historical sources show that Coastal Plains bands hunted in the Edwards Plateau in fall and winter (Campbell 1975). If so, annual fluctuations in winters alone could serve as an adequate explanation for the introduction of Plains elements into the assemblage. As will become quite clear in the Hop Hill discussion, bison hunters played a role in the deposition of Moccasin Confluence, and bison bone fragments were found in the Test Pit 1-3 sequence. Likewise, white-tailed deer bone is present in the deposits and could be an indicator of more easterly oriented hunters, since deer are browsers and, unlike bison, are able to survive in woodland environments. A distinctive shift in deer-bison ratios was found by Bryson and Baerreis (1968:291; Figure 3.04) on the prairie forest ecotone further north.

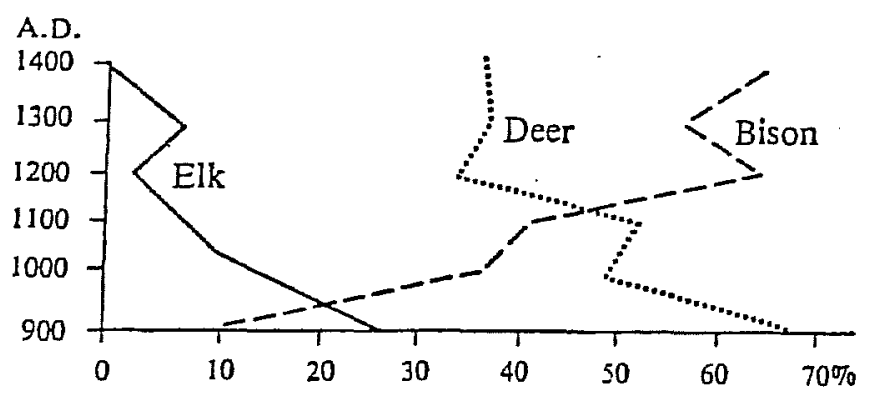

Figure 3.04. Dear-Bison Bone Ratios in the Mill Creek Culture of Iowa.

Moccasin Confluence is without a doubt one of the best sites in the Southcentral area for the study of long-term culture change. It is a large site and deserves a substantial excavation effort to determine both horizontal and vertical changes through time. It should be nominated to the National Register of Historic Places 
and preserved as a vital element in the history and future of central Texas and warrants designation as a SAL. 


\section{CHAPTER 4-HOP HILL OVERVIEW-A LATE ARCHAIC OCCUPATION (Gunn)}

The Hop Hill locality (Gunn and Mahula 1977a) was surveyed and excavated during the 1976, 1978, and 1982 seasons. The last two seasons were sanctioned by Texas Antiquities Permit Number 175. Diagnostics (Figure 4.01) from the surface indicate that it was visited from Early Archaic to Neo-Archaic times (Kelly 1977). Its primary interest to prehistoric populations seems to have been the flint nodules that outcrop below the site on slopes facing the Pedernales River. Some occupation floors were defined in a small midden explored during the 1976 and 1978 field seasons. However, no reasonable definition of the time and consequence of the occupations was possible until the 1982 excavations. The direction the 1982 excavations took was keyed by the discovery in 1978 of an area not underlain by caliche as was the rest of the occupation area. A small test on the last day of the 1978 excavation produced a mastoid process of human skull and a meter of deposits descending into the bedrock under the site. In 1982 a 6-m2 area was opened down into the deposits (see chapters 8 and 10 for analysis of lithics). A full two meters of deposits were found in what appears to have been an old ravine, perhaps the head of an extinct spring. The upper two horizons are clearly marked by Ensor and Castroville point types of the Twin Sisters and Uvalde phases of the Late Archaic (Prewitt 1981). The zone below the Uvalde phase is judged to be San Marcos, the last phase of the Middle Archaic, by stratigraphic position; no diagnostics were present.

The accumulation of debris in the ravine and the use-wear patterns on flakes suggest the following scenario. During the San Marcos phase, Hop Hill was used as a lithic procurement area as it had been for millennia. The edge damage patterns found on the lithics in the suggested San Marcos phase shows that the flakes were not used for tools and supports an inference of lithic manufacturing at the site (see chapter 10). More human bones associated with the mastoid process were fragmentary and may be the remains of a bundle burial interred during the San Marcos phase or shortly thereafter. The burial was shallow, being primarily covered with a flat stone (Appendix B). In the Late Archaic, deposition increases substantially in the ravine as does the frequency of lithic debris. Along with the increase in overall lithic debris is a modest amount of detectable use of flakes as tools.

The deposition rate and the frequency of flakes used as tools peak in the Twin Sisters phase. Most of the debris show signs of burning. The percentage of flakes used as tools was slightly higher. After the Late Archaic the ravine was filled. There is no reason, however, to suspect from the surface deposits that occupation continued with the former intensity. The relative thinness of the surface deposits suggest that the ravine was used as a natural trash pit or a gratis cooking pit. 


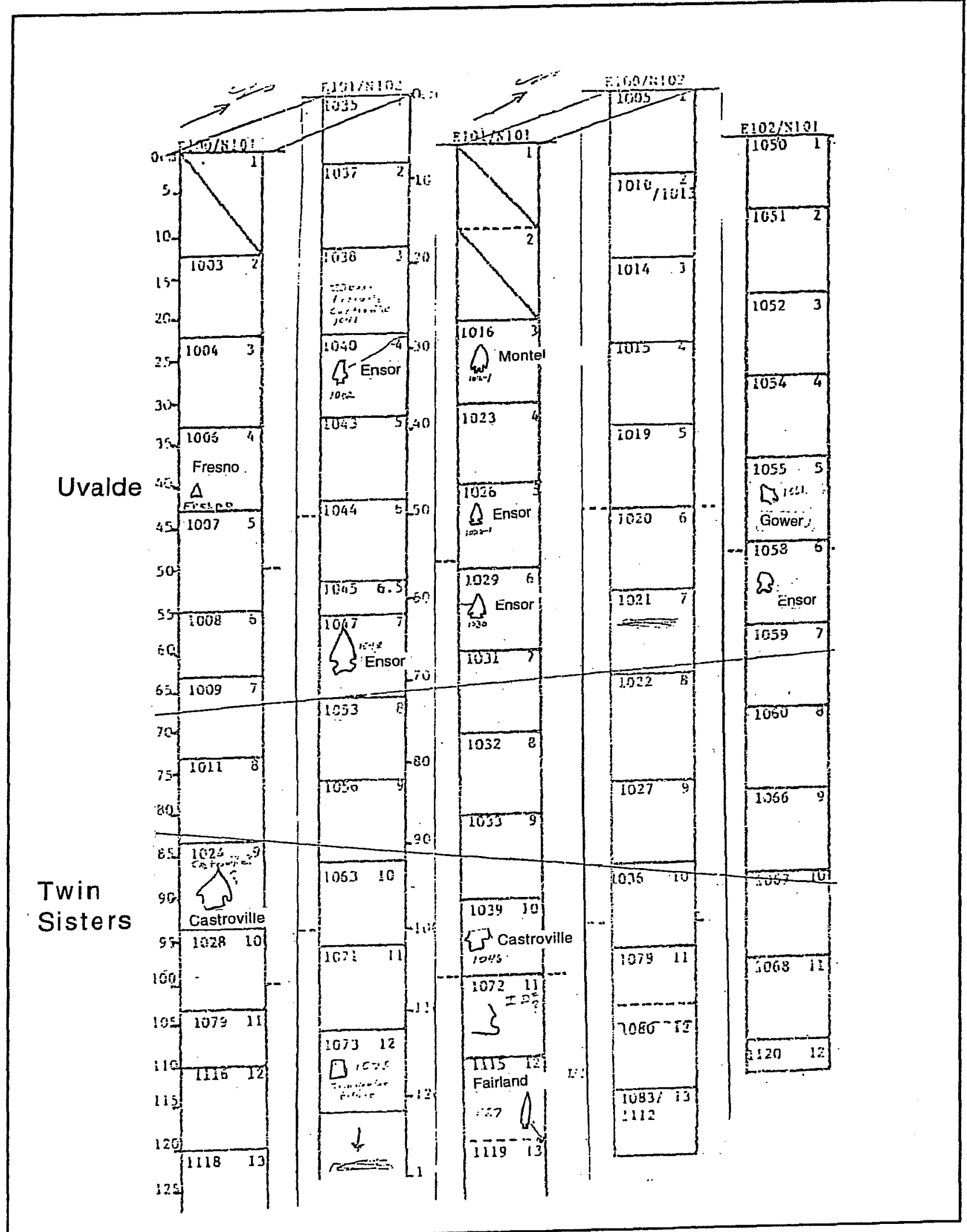

Figure 4.01. Diagnostic Sequence at Hop Hill. 
Two insights into the Hop Hill occupation are worthy of special note. First, the peak of occupation occurred at the same time, both at Hop Hill and at Test Pit 4 in Moccasin Confluence. Both are associated with modest middens of burned rock, and not classic burned rock middens of the Middle Archaic. Whatever the Late Archaic inhabitants were doing could have been done equally well in either microhabitat. Castroville points have been associated at several locations with bison procurement (Dillehay 1974). A logical explanation for the activity at Hop Hill is that the inhabitants were watching for bison crossing the ford of the Pedernales River below the location of the present day Johnson Ranch house. It is likely that the middens with rock represent subsidiary activities performed while watching for bison, or perhaps the cooking of bison meat. The lower occupation midden at Hop Hill contained flat rocks too large to be appropriate for boiling stones (Gunn and Mahula, 1977a). They could, however, have been used to heat an oven-like affair such as was used by the western Indians to prepare roots and steam meat.

The concept of the vectored seasonal round, i.e., that a seasonal round would be engineered to pass as many resources simultaneously as possible, suggests the vast utility of Hop Hill to the bison hunters, but not to nonherd oriented cultures. The site has a lithic resource area, an overlook, and a natural cooking convenience. Thus the two meters of debris as opposed to the few centimeters left by previous visitors.

Given that the midden and the trash pit have been sampled at Hop Hill, it seems unlikely that any further excavation at Hop Hill is necessary given the research goals of this project. The ravine can be traced down the hill toward the Pedernales River by a line of trees. It undoubtedly contains more trash in the same vertical sequence as excavated during the 1982 season. Further excavation would only duplicate information already obtained. For future potential the ravine should be preserved, capped or grassed. The rest of the site has no remaining archaeological value. A resume of the Hop Hill findings and recommendations appear in Chapter 2. 


\section{CHAPTER 5-PHYSICAL AND LATE QUATERNARY ENVIRONMENT OF LBJ PARK (Brown, Gunn, LaRocca, Sims)}

\section{INTRODUCTION}

The sections of this chapter survey the geology, geomorphology, soils, sediment column, and molluscan sequence in the eastern half of the Lyndon B. Johnson State Historical Park. Special techniques are used to analyze the sediments and snail sequence in an effort to infer climate at the site over its history.

\section{GEOLOGY (Brown)}

A hundred million years ago the LBJ State Historical Park area lay buried in mud, part of a shallow sea that extended northward as far as Colorado. As the waters receded, the mud, heavily laden with microscopic shelled creatures, hardened into rock, and the rock was uplifted above sea level. Almost from the moment of its emergence from the waters of the last great Cretaceous sea, erosion began to shape the landforms we see today in the LBJ State Historical Park.

Since it is far from the main twisted and shattered central core of the Balcones Fault Zone, the bedrock geology of the park presents a relatively simple picture. At the base of the Cretaceous marine deposits are the ancient rocks of the Llano Uplift.. These uplifted, faulted, and metamorphosed sedimentary and igneous rocks from the Precambrian and Paleozoic eras crop out across a broad area of central Texas to the north of the park, an area often termed the Central Mineral Region. Parts of this ancient uplifted area stood as islands above the sea at times during the Cretaceous.

Within the park area, however, these strata exert little influence on the actual geology other than serving as a platform for later deposition. They are exposed primarily. where erosion has cut deeply through the Cretaceous sediments. The most easily observed exposure is along the channel of the Pedernales River where the river flows through both coarse and fine grained dolomite. This rocky channel is mapped as the San Saba member of the Wilberns Formation (Barnes 1964, 1965) and includes small areas of calcite and limestone as well as dolomite. Most of this is non-fossiliferous and generally noncherty.

Aside from small areas of the San Saba exposed along subsidiary drainages and a few areas of other Wilberns Formation limestones (Morgan Creek member and Point Peak member, Barnes 1964, 1965) mapped near the upstream end of the park, only one other Llano uplift formation is exposed in the vicinity of the park. This is the lower Ordovician (and thus slightly more recent than the Late Cambrian Wilberns) 
Threadgill member of the Tanyard Formation which directly overlies the San Saba mentioned above. Two small outcrops occur south of Highway 290 along Williams Creek. One, bisected directly by the creek, may be of some prehistoric significance because it is noted as slightly cherty (Barnes 1964).

As the earliest Cretaceous sea rolled inland it left thick coarse-grained shoreline deposits, later buried in mud by the advancing waters. These deposits, which vary in texture from boulders to clay, are generally sorted and slightly indurated sand overlying a more strongly cemented basal conglomerate.

Designated the Hensell Member of the Travis Peak Formation, this sediment underlies a large portion of the park. It is of considerable historic economic importance as it is more readily cultivable than the surrounding limestone soils (Barnes 1964; Campbell 1962) and made the middle reaches of the Pedernales River more attractive to early settlers than the other deeply incised limestone valleys and narrow alluvium along other hill country streams. A reported dense growth of broadleaf oak that was not cultivated (Cuyler 1931) suggests that this sandy strip may have had considerable significance to the aboriginal inhabitants of the area as well.

Overlying the Hensell sand at the southern margins of the park is the Glen Rose limestone formation. It is the marine equivalent of the Hensell sand and essentially a contemporaneous deposition. This thick deposit of limestone (including beds of dolomite, clay, and silt) extends half a dozen miles south of the river where its characteristic stair step topography and shallow soils support only sparse vegetation.

South of the Glen Rose Formation, capping the low hills that form the divide between the Pedernales and Blanco Rivers is a Cretaceous formation of considerable aboriginal significance, the Edwards Limestone (Barnes 1981). The formation, represented by the Fort Terret Member, contains large quantities of high quality chert and was heavily utilized by prehistoric peoples wherever it outcropped.

\section{GEOMORPHOLOGY AND PEDOLOGY}

Despite the age of most of the deposits in the river valley, their modern configuration is due primarily to more recent geomorphic events. Erosion has stripped the ancient sediments again and again, and alluvial deposition has filled the center of the valleys. Although the modern alluvial deposits along the Pedernales River are relatively narrow, there are indications that ancient alluvial deposits were once more extensive. Patches of high terrace gravels are mapped well above the modern alluvial terraces of the river (Barnes 1964). In the Pedernales River, Concho River, and other upper Colorado River Valleys, Blum and colleagues (Blum and Velastro 1989; Blum et al. 1994) have examined and dated alluvial sediment sequences. The have found the landscape evolution on the Edwards Plateau of the Late Pleistocene and Holocene to be one of gradual degradation and removal of once thick uplands soils. High effective moisture in the Pleistocene 
gave way to Holocene cyclical droughts. The droughts reduced the vegetation and once thick soils were reduced to bedrock.

The most extensive remaining alluvial deposits in the park area are along the banks of Williams Creek at the eastern edge of the park. It is the combination of these alluvial deposits from Williams Creek with those of the Pedernales River that have shaped the depositional history at Moccasin Confluence. One of the keys to the understanding of this depositional history is the soils observable at the site.

An examination of the soils at Moccasin Confluence shows them to be clearly alluvial (Figure 5.01). The Soil Conservation Service (Dittemore and Allison 1979) has mapped the soil in this area as Oakalla silty clay loam, a deep, well drained soil formed in alluvium along major creeks. In fact, their typical profile description of the :Oakalla series soil is apparently taken from the alluvial terrace immediately across the creek from Moccasin Confluence, and agrees closely with the field description given below. The field soil profile description of the soils in the main excavation units at $41 \mathrm{BC} 71$ is given below. All colors given were recorded on dry soil.

\section{SOIL PROFILE OF TEST PITS 1, 2, \& 3: (Map see Figure 3.01)}

Soil Horizon A1, 0-18 cm. Very dark grayish brown (10YR 3.5/2) silty (clay?) loam; very strong coarse subangular blocky structure; very compact, friable, sticky when moist; many medium and fine roots, very few land snails, very few small limestone fragments $(1-3 \mathrm{~cm})$; some worm casts; insect burrows are fairly common; lower boundary smooth, abrupt.

This horizon thickens noticeably toward the creek, exhibiting a less pronounced creekward slope on its upper surface than that shown by the soil horizon below. The abrupt nature of the break between this zone and the one below may indicate a depositional break, perhaps a relatively recent one. It is possible that this horizon represents a single catastrophic flooding event.

Soil Horizon Ab2, 18-41 cm. Very dark grayish brown (10YR 3/2) silty clay loam; moderate to strong fine granular with weak to moderate coarse subangular blocky structure; very compact, friable; moderate amount of small roots; some land snails; few, very small $(<4 \mathrm{~cm})$ chert stream gravels; few tiny limestone fragments; abundant worm casts; lower boundary smooth, gradual.

Whatever the depositional origin of the horizon above, this zone is apparently an older A horizon that has been buried beneath it. A number of vertical cracks extend downward from the upper horizon through this zone. The lower boundary of this horizon is marked by a very clear cultural zone that extends downward into the next soil horizon. The thickness of this horizon is variable, almost pinching out near the creek. 


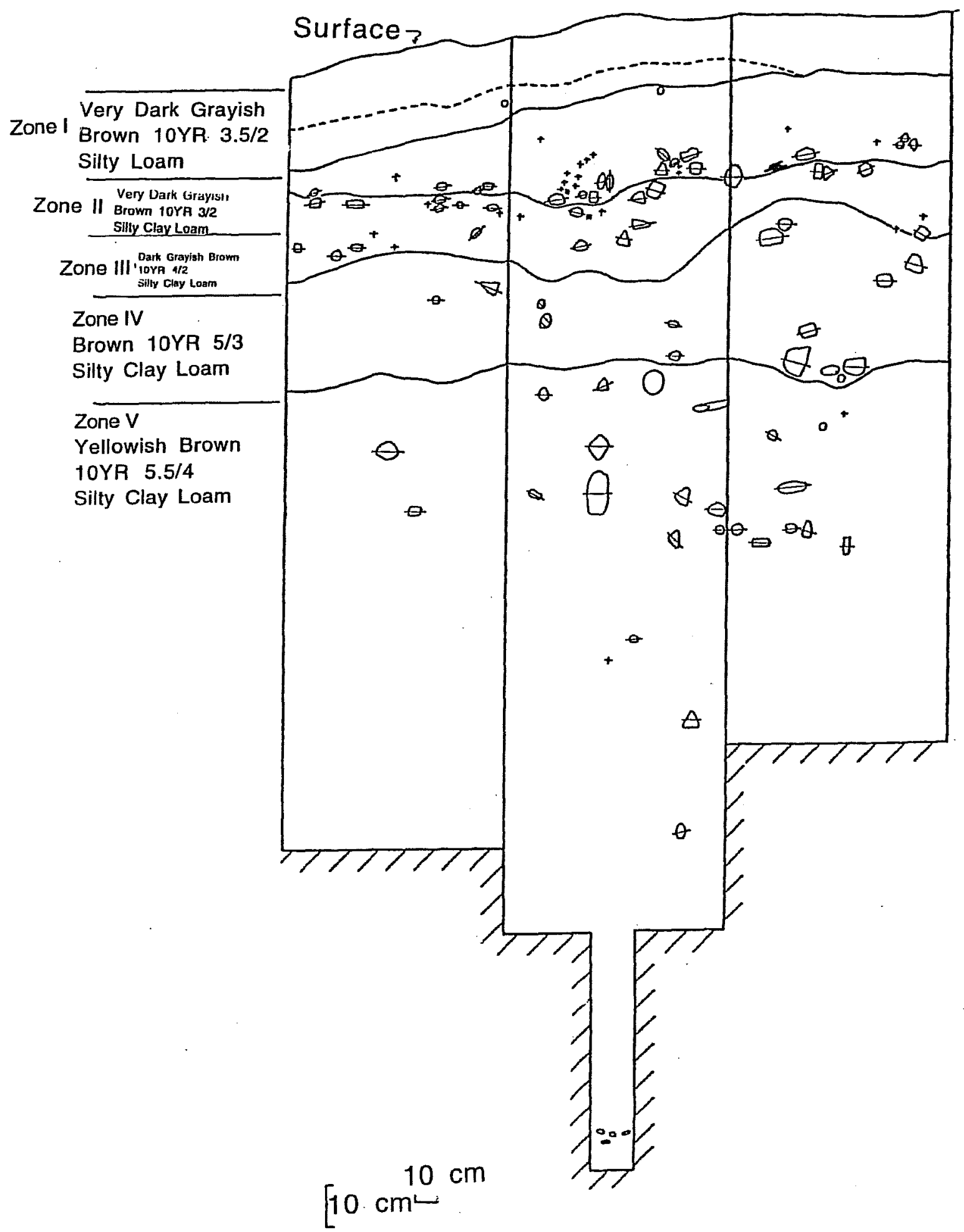

Figure 5.01. Soil Profile for Test Pits 1, 2, and 3 at Moccasin Confluence. 
Soil Horizon A3, 41-52 cm. Dark grayish brown (10YR 4/2) silty clay loam; strong fine granular with moderate to strong medium subangular blocky structure; moderate number of fine roots; moderate amount of land snails; abundant worm casts; some small alluvial pebbles; some vertical cracks extending downward from the horizon above; some carbonate accumulation on the ped faces and in cracks; lower boundary smooth, gradual.

This zone underlies the most visible cultural horizon in the profile.

Soil Horizon B, $52-80 \mathrm{~cm}$. Brown (10YR 5/3) silty clay loam; strong fine granular structure; moderate number of fine roots; moderate amount of land snails; some worm casts; few limestone pebbles; many carbonate threads on ped faces; few vertical cracks continue downward through this horizon from above; lower boundary smooth, gradual to diffuse.

This horizon generally parallels the one above, thickening slightly creekward. This horizon is clearly part of the same solum as the two lowest A horizons above (Ab2 and A3). There are no apparent depositional discontinuities in the soil profile below these horizons, suggesting a relatively stable depositional environment during this time (i.e., no major cycles of truncation and redeposition).

Soil Horizon C, 80-135 cm. Yellowish brown (10YR 5.5/4) silty clay loam (with high silt/low sand at the top of the zone and increasing sand toward the bottom); weak medium to coarse subangular blocky structure; only slightly compact; slightly friable; few roots, land snails, limestone pebbles, worm casts; marked decrease in carbonates; vertical cracks observed above do not continue downward into this level.

\section{TEST PIT 4 PROFILE (Map see Figure 3.01)}

Soil Horizon A1, 0-15 cm. Dark grayish brown (10YR 3.5/2) silty loam; strong medium to coarse subangular blocky structure; many medium and fine roots; some worm casts; some large limestone cobbles and some very small $(1-10 \mathrm{~mm})$ limestone pebbles; a few small alluvial chert gravels $(1-10 \mathrm{~mm})$; lower boundary smooth, clear.

Although some cultural material is found in this horizon (which may actually be an Ap horizon), the bottom of this horizon marks the beginning of the actual midden zone.

Soil Horizon A2, 15-35 cm. Dark gray (10YR 4/1.5) silty clay loam; strong fine granular with moderate to strong coarse subangular blocky structure; many fine roots; some worm casts; lower portion of horizon marked by zone of increased carbonates; lower boundary wavy, gradual.

The upper portion of this zone (above the carbonates) is marked by a layer of culturally derived burned limestone rocks, apparently part of a burned rock midden. 
Soil Horizon C1,35-63 cm. Light yellowish brown (10YR 5.5/4) silty clay loam; moderate coarse subangular blocky structure; moderate amount of fine roots; some land snails and worm casts; small limestone fragments; some carbonates through upper half of zone; some vertical cracking; numerous rodent disturbances marked by darker soil from above; lower boundary smooth, gradual.

This horizon appears to have a greater clay content than that of the horizon above which probably has just barely enough to classify as clay loam; it is not clear whether this increased clay is the result of argillic translocation or differences in depositional energy.

Soil Horizon C2,85-110 cm. Reddish yellow (10YR 6/6) silty clay loam; moderate coarse subangular blocky structure; some land snail fragments; very few carbonates; some rodent disturbances.

This horizon has more silt and perhaps less clay than the zone above, and, except for color, strongly resembles the $\mathrm{C}$ horizon of Test Pits 1,2, and 3.

\section{DISCUSSION}

The history of alluvial deposition at Moccasin Confluence is a complex one, primarily because of the interaction between the two drainages at the confluence. The classic alluvial terrace depositional sequence of coarse basal sediments grading upward through finer sediments is upset here by the differing characteristics of the two drainage systems. Although Williams Creek does flow for a short distance through the Hensell sand, it is likely that the major contributor of sand to the terrace is the Pedernales River itself. It flows through nothing but sand, sandstone, and very hard limestone for a number of miles above the site. The modern alluvial deposits near the banks of the river are almost pure sand.

Conversely, while the Pedernales River has quite enough energy during floods to transport silts and finer particles the requisite distance, it is likely that Williams Creek, and the fine-grained sediments that make up the majority of its drainage basin, contribute the smaller sized sand particles to the terrace. The deposition of fine sediments from Williams Creek is exaggerated by the effect of the stronger flow of the Pedernales River acting to back up the flow of the creek, increasing deposition.

In addition to the simple changes in patterns of deposition through time, it is likely that the river itself was closer to the site at times in the past. This is supported by the presence of a shallow linear depression just north of the site. This depression, which runs approximately parallel to the modern course of the Pedernales River, may be an old, filled-in channel of the river. If this is so, the original inhabitants of the area would have been at the immediate confluence rather than $100 \mathrm{~m}$ up from it as is the case today. 
A related and quite interesting feature of the depositional history of the confluence site is the apparent presence of two terraces, or a single terrace and modern floodplain sequence. The higher and older terrace, which contains the site, lies 5-7 $m$ above the elevation of the modern river and is separated from the lower terrace by a low, gradual (but nonetheless distinct) scarp running parallel to the modern course of the river. The lower terrace, at $3-5 \mathrm{~m}$ above the river, is apparently matched by another at the same elevation across the river to the north.

The old channel of the river is located on the upper terrace some $50 \mathrm{~m}$ south of the scarp. There are observable changes in the density of cultural material within and north of the depression. This suggests that the site was occupied primarily when the old channel was active, at least as an oxbow lake or seasonally wet slough. The relatively shallow depression on the top of the Archaic midden in the northern portion of the site also suggests that an active terrace formation related to this old channel ceased no later than the end of the main midden occupation there.

If it is assumed that the final upper terrace deposits are coterminous with the latest dated occupation at the site, terrace formation may have ceased at some time during the Uvalde phase of the central Texas Archaic period dated to between 2250 and 1750 B.P. (Prewitt 1981). Assuming some consistencies in deposition within the Colorado River basin, the termination of terrace formation here would correlate well with that of the third terrace level (previously termed the Riverview, or Fish Hatchery terrace) identified by Baker and Penteado-Orellana (1977) on the Colorado River near Austin. The final channel phase associated with this terrace (phase 4) is suggested to have ended around 2000 B.P. (Baker and Penteado-Orellana 1977:412). The height of this Pedernales terrace at $5-7 \mathrm{~m}$ above the river also agrees reasonably well with the height of $6-10 \mathrm{~m}$ given for the Fish Hatchery terrace by Baker and Penteado-Orellana.

Further attempts at correlation between these rather widely separated depositional units formed perhaps under quite different depositional environments would be premature. On the other hand, a carefully designed geomorphic and sedimentological study could provide useful comparative data not only for the immediate site area but for the region as a whole. Any further work at the site should consider the inclusion of such a study.

\section{ANALYSIS OF TEST PIT 2 SEDIMENTS (Gunn, Sims, La Rocca)}

A numerical analysis was undertaken of the particle size distributions at Moccasin Confluence. Samples were taken from the soil zones described above. It was expected that both regional and site specific environments would be reflected in the character of the depositional sequence.

As discussed above, Test Pits 1,2, and 3 revealed five distinct soil zones. At the close of the field season eight sediment samples were collected by horizon, from the south 
wall of the excavation unit (see Figure 5.02). At least one sample was taken per zone, with several being removed from the thickest strata. This is very broad sampling compared to the depth of the site. It was intended to characterize the sediments in a general fashion. The results must, therefore, be taken as tentative and very general. The results suggest that a restudy at higher resolution would be very helpful in describing the Holocene environment of the study area.

Six-hundred gram samples were removed from each collection bag. Each sample was then placed in water for approximately 30 minutes, in order to disaggregate the sediments. Disaggregation was encouraged by frequent stirring, and then organic material was skimmed off with a $1 / 16$-inch screen.

Separation of the sediments into grain sizes was accomplished through the use of standard geologic sieves sizes in Table 5.01. This table illustrates the three grain sizes and the type of sediment for each sieve size. The No. 12 sieve catches the very coarse sand grains and material larger than $1.7 \mathrm{~mm}$ in diameter; the No. 35 sieve separates the coarse sand, and the No. 100 sieve retains the medium and larger fine sands, i.e., particles greater than $0.15 \mathrm{~mm}$ in diameter. The remaining sediments, those not caught in the sieving process, were stirred vigorously and allowed to settle for 16 minutes. After the water was siphoned off, the particles in suspension were very fine silts and clays, while the settled material consisted of larger silt particles (Table 5.02).

All samples were dried completely in an oven set at $225^{\circ} \mathrm{F}$. Each of the samples was then weighed to $0.01 \mathrm{~g}$. To determine the weight of the very fine silts and clays the weights of the heavier fractions were summed, and the remainder was taken to be the silt and/or clay weight, plus any error in the procedure.

The data collected were the weights of each fraction for each sample. The fractions were: Very Coarse Sand, Coarse Sand, Fine Sand, Silt, Clays and Fine Silts, and Flotation Material. In the analysis to follow, a Time element was estimated by coding the excavation level number most representative of each sample.

A principal components analysis (Nie et al. 1975:479) was used to expose the sedimentary processes active at the site (Table 5.03). Three components had eigenvalues greater than 1.0, and accounted for $85 \%$ of the variance in the samples. Communality, with one exception, ranged above $86 \%$. The one exception was the flotation material with only $42 \%$ of the variance accounted for. The lack of data for the flotation variable in the Zone $\mathrm{V}$ sample may be the reason for this anomalous result.

A preliminary examination of the components suggests that they can be assigned to essentially geomorphic and climatic causes. Sedimentary Process I pertains to the elevation of the sediments. Sedimentary Processes II and III seem to relate to climate and vegetation. 


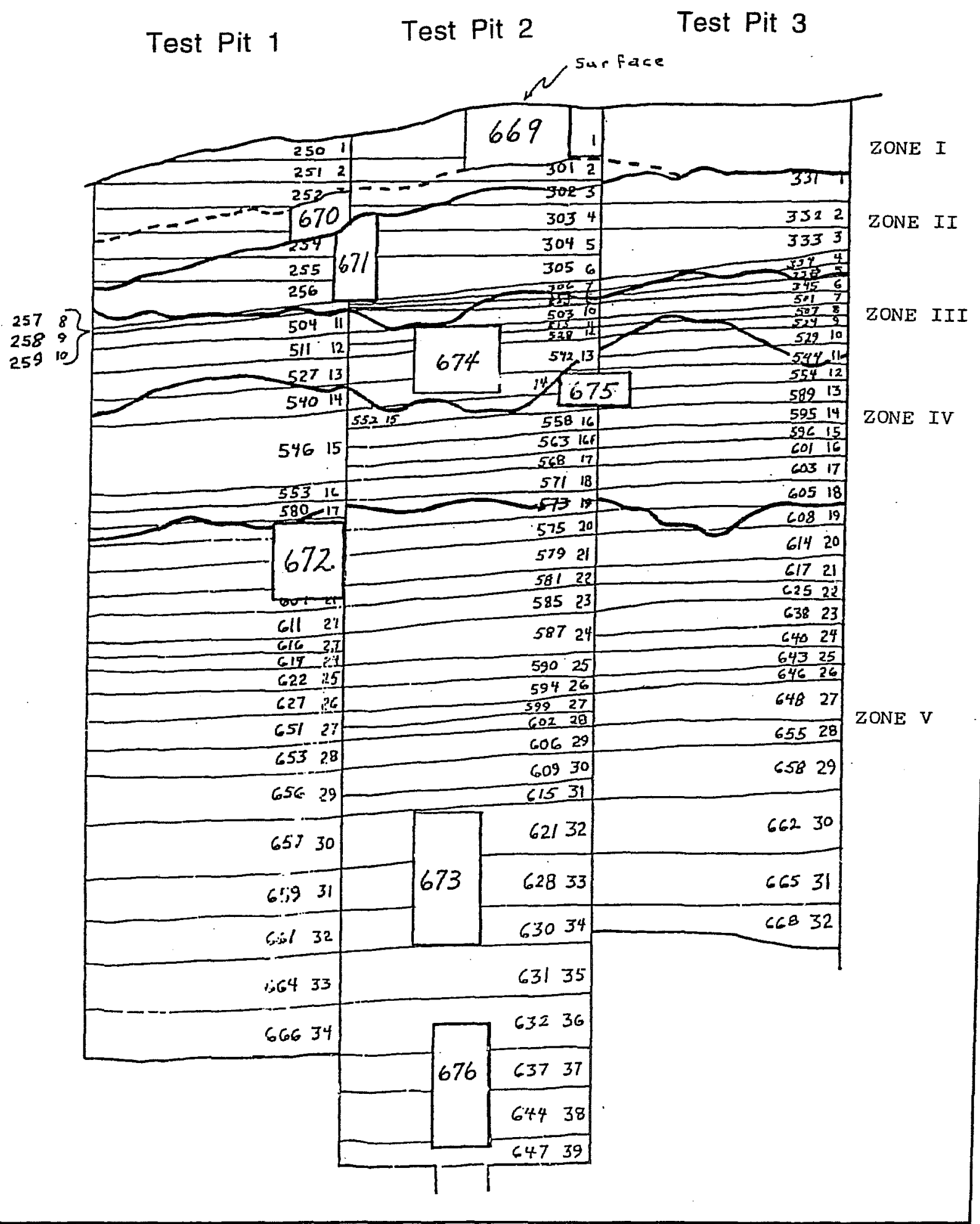

Figure 5.02. Locations of Sediment Samples (FNs in Boxes) Relative to Excavation Levels (Level FNs and Sequence Numbers). 


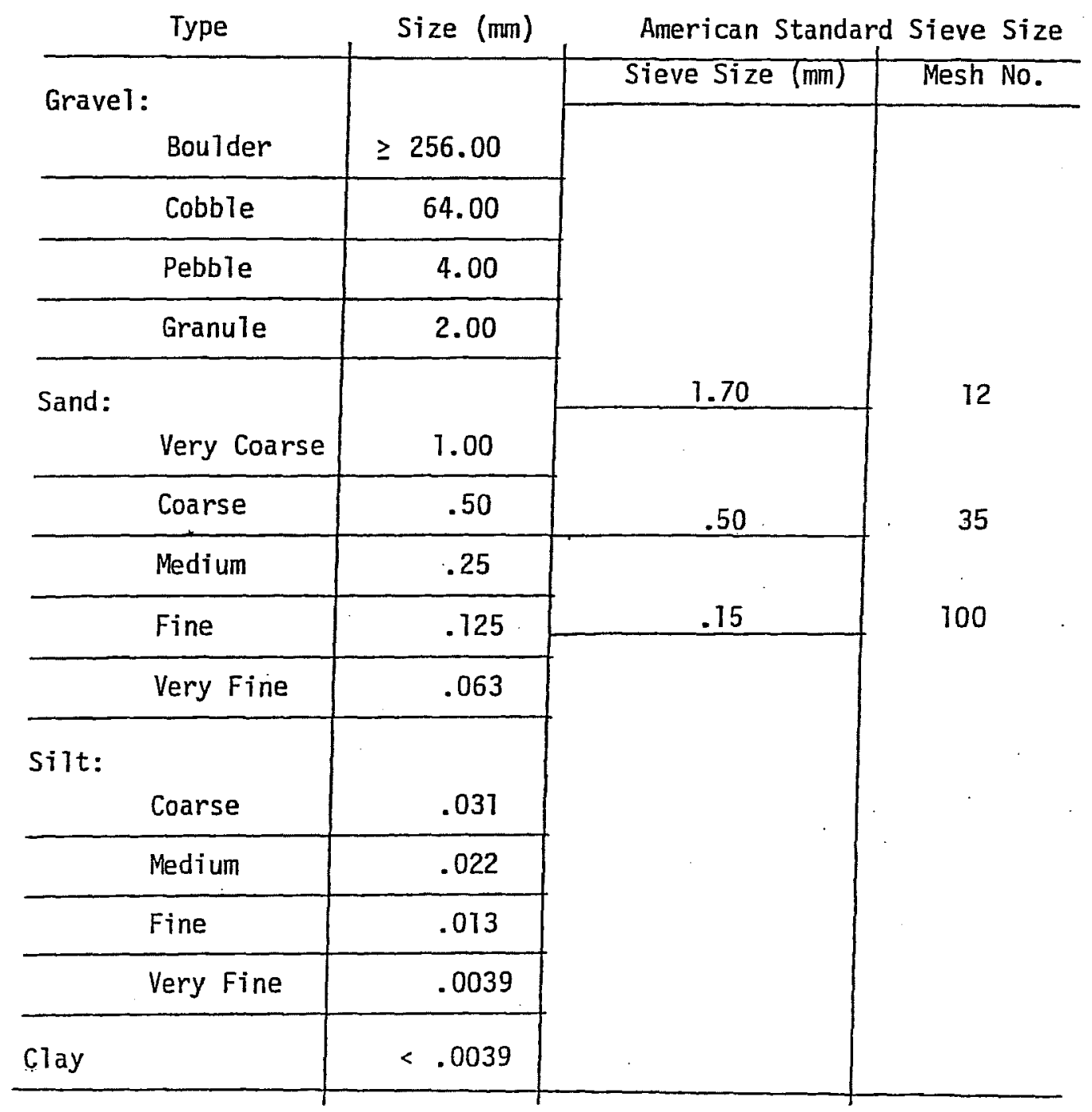

Source: Ticke11 1965 
TABLE 5.02. PARTICLE SIZE SETTLING TIMES

\begin{tabular}{|c|c|c|c|c|c|}
\hline $\begin{array}{l}\text { Particle } \\
\frac{\text { Size (mm) }}{0.062}\end{array}$ & $\begin{array}{l}\text { Withdrawal } \\
\frac{\text { Depth }(\mathrm{cm})}{20}\end{array}$ & $\begin{array}{l}\text { Time } \\
\text { Hours }\end{array}$ & Minutes & $\frac{\text { Seconds }}{58}$ & $\begin{array}{l}\text { Grain Type } \\
\text { Very Fine Sand }\end{array}$ \\
\hline 0.044 & 20 & & 1 & 56 & \\
\hline 0.031 & 10 & & 1 & 56 & Coarse Silt \\
\hline 0.022 & 10 & & 3 & 52 & Medium Silt \\
\hline 0.015 & 10 & & 7 & 42 & \\
\hline 0.011 & 10 & & 15 & 0 & Fine Silt \\
\hline 0.008 & 10 & & 31 & 0 & \\
\hline 0.006 & 10 & 1 & 1 & 0 & \\
\hline 0.0039 & 10 & 2 & 3 & 0 & Clay \\
\hline 0.003 & 10 & 4 & 5 & 0 & \\
\hline 0.0019 & 10 & 8 & 10 & 0 & \\
\hline 0.0014 & 10 & 16 & 21 & 0 & \\
\hline 0.0009 & 10 & 32 & 42 & 0 & \\
\hline
\end{tabular}

Source: Shackley (1975)

TABLE 5.03. UNROTATED PRINCIPAL COMPONENTS LOADINGS FOR PARTICLE SIZE ANALYSIS

\begin{tabular}{|c|c|c|c|c|}
\hline & $\begin{array}{r}\text { Sedimentary } \\
\text { Process I }\end{array}$ & $\begin{array}{l}\text { Sedimentary } \\
\text { Process II }\end{array}$ & $\begin{array}{l}\text { Sedimentary } \\
\text { Process III }\end{array}$ & \\
\hline Variable & High Bank & Humidity & Aridity & Communality \\
\hline Time & -0.49 & -0.75 & 0.24 & 0.86 \\
\hline Flotation Material & 0.56 & -0.23 & -0.23 & 0.42 \\
\hline Very Coarse Sand & -0.4 & 0.57 & 0.67 & 0.93 \\
\hline Coarse Sand & -0.89 & -0.29 & -0.29 & 0.96 \\
\hline Fine Sand & -0.39 & 0.78 & -0.38 & 0.90 \\
\hline Silt & 0.92 & -0.04 & 0.39 & 1.00 \\
\hline Fine Silt and clay & 0.89 & 0.08 & -0.28 & 0.88 \\
\hline Variance & 0.47 & 0.24 & 0.15 & 0.85 \\
\hline
\end{tabular}

Important loading $>0.40$

\section{Geomorphic Process}

Sedimentary Process I (SED I), accounts for $47 \%$ of the variance, and exhibits a negative loading between all sand sizes, and the Silts and Clays. Since Time (level) correlated with sands, there is downward coarsening of the sediments. It will be referred to as the "High Bank" process. This means that as the sediment piles higher, more energy is required to lift suspended sediments onto the bank. We would expect to see a progression of finer sediments as the bank grows higher in relation to the normal river level. This expectation is fulfilled in Sedimentary Process I. 
An additional force shaping the High Bank process is channel movement. Sediments deposited at the confluence have pushed the main course of the Pedernales River northward, while moving Williams Creek to the east. As Brown noted above, archaeological surface features, as well as occupation frequencies (see Kerr, chapter 6) seem to support a bed shift. The high negative loading of Sands compared to Silts and Clays suggests that the depositional environment was changing through time in logical concert with channel shift. The sample from the lowest strata contained $127 \mathrm{~g}$ of Coarse Sand, more than all the other samples combined. Apparently during this earliest period the Pedernales River was very close to the site. As the channel moved away, fine sediments were more frequently deposited by overbank flooding.

\section{Climatic Processes}

With the basic geomorphic process of High Banking factored out, it is likely that the remaining two components are products of subtler biotic and climatic processes. Schumm (1965) has described principles of climatological, hydrological, and vegetational interaction and the sedimentary processes they produce. The effectiveness of these principles was tested and found to be workable on the Colorado River by Baker and Penteado-Orellana (1977). And since the Pedernales River is a tributary of the Colorado River, these principles may again be applicable.

Long-term climate on the Gulf Coastal Plain seems to be controlled by two principles to judge by analysis of modern climatic data (Gunn 1981, 1989; Gunn and Prewitt 1985). The first principle (P1), is that as the average temperature of the Northern Hemisphere increases, rainfall shifts from small amounts in the winter, through larger amounts in the spring and fall to very large amounts in the summer. The spring rains are most beneficial to vegetation while torrential summer rainfall is destructive. Also, winter precipitation is less than fully advantageous. Summer rainfall appears to be associated with arid climate, spring rains with humid climate, and winter precipitation with steppic climate.

The second principle (P2) is that as the average temperature of the Northern Hemisphere approaches $15-16^{\circ} \mathrm{C}$. an optimal balance develops between evaporation off the Gulf of Mexico, cloud cover, evapotranspiration, and Arctic frontal activity to produce a Moisture Optimum. This condition is associated with a year-round, warm, moist climate. In the following discussion, we will attempt to determine if the sedimentary processes can reasonably be assigned to one or the other of these principles.

Sedimentary Process II (SED II, Figure 5.03) accounts for 23.7\% of the variance in the samples. Very Coarse and Fine Sands correlated negatively with Time (see Table 5.03). Two processes can be suggested to account for coordinated behavior of sediments as different as Very Coarse Sand and Fine Sand. First, the increase of Fine Sand in the upper levels is probably indicative of increasing eolian deposition. The grain size of Fine Sand falls in the average transportable grain size for windblown 
materials. If the Fine Sands were the product of alluviation from the Pedernales River, there would be an increase in the amount of Silts and possibly Clays, but this is not the case.

\begin{tabular}{|cccc|}
\hline Climate & $\begin{array}{c}\text { Year around } \\
\text { Humidity }\end{array}$ & $\begin{array}{c}\text { Intermediate } \\
\text { Hum/Arid }\end{array}$ & $\begin{array}{c}\text { Year around } \\
\text { Aridity }\end{array}$ \\
Sediment & small quantities: & large quantities: \\
& Very Coarse Sand & Very Coarse Sand \\
& Fine Sand & Fine Sand \\
Dominant & Probably Alluvial & Colluvial \&/or \\
Process & & Emplied & Eolian \\
\hline
\end{tabular}

Figure 5.03. Sediments, Processes, and Implied Climate for Humidity/ Sedimentary Process II.

The increase in the amount of Very Coarse Sand indicates a second process in relation to the depositional environment. The Very Coarse Sands in the upper part of the section are so high it is unlikely they were deposited by the river. However, the Very Coarse Sands on the knoll to the south of the confluence are accessible. There are deep colluvial deposits of these sands at the base of the slope below the knoll. This, also, suggests that the sands were deposited colluvially from the knoll.

Increased eolianation with sparse vegetation cover implies a xeric climate that would have facilitated the movement of the Very Coarse Sands downslope. In particular, periods of episodic rainfall would have encouraged colluvial movement of the sands. Once again, the lack of correlated Silt and Clay suggests that deposition was not from the Pedernales River, but from the up slope area to the south.

We will assume for now that Sedimentary Process II represents the essential contrast between arid climate at one end $(+)$ and humid climate at the other $(-)$ (see Figure 5.03). It is an index of $\mathrm{P} 2$, the Moisture Optimum principle. This Arid-Humid continuum should correlate with other similar indicators, a topic that will be addressed in the next section of this chapter.

Sedimentary Process III (SED III, Figure 5.04), accounts for $14.7 \%$ of the variance. It was the only non-Time-related component. Very Coarse Sands and Silts correlated negatively against Fine Sands (see Table 5.03). The Silts can be taken to represent flooding. Heavy rains upstream would both increase the bed load and send the river over its banks. Once over the banks, the loss in velocity would result in deposition. Brown's discussion above suggests that the Silts would have been deposited from Williams Creek, while the Coarse Sand could have been brought in by the Pedernales River. However, sudden summer rains tend to be associated with arid climate and, by inference, sparse vegetation on the Coastal Plain (Gunn 1981). It 
is equally likely that the Coarse Sand was deposited as the result of slopewash from the sandy knoll to the south, as discussed previously.

\begin{tabular}{|ccc|}
\hline Climate & Aridity without & Aridity with \\
& floods, cool summers? & sumer floods \\
Sediment & Fine Sand & Very Coarse Sand \\
& Silt & Colluvial \\
Process & Elian & Flooding
\end{tabular}

Figure 5.04. Sediments, Processes, and Implied Climate for Aridity SED III.

The negative relationship of Very Coarse Sand and Silt to Fine Sand implies eolian activity without colluviation, indicating cool and dry climate (see Figure 5.04). The complementary relationships in Sedimentary Process III fit P1 very well. When average temperatures of the Northern Hemisphere rise above the Moisture Optimum, general aridity with summer flooding becomes the mean climate. These conditions would most resemble a warm steppe or desert. With movement of sediments during summer rains, which are in part related to the uplift of the Balcones Escarpment (Gunn and Prewitt 1985), the regime resembles the standard Basin and Range pattern of the Southwest.

The aridity without floods, which complements the above, probably represents the lowering of Northern Hemisphere temperatures below the Moisture Optimum. Reduced temperatures of sea water in the Gulf of Mexico reduce the amount of moisture. Rainfall is primarily off the Pacific in winter and not in great quantities. The more energetic atmospheric movements of cooler global climate stir the dust of the attendant cool steppe. The climate is probably that observed by Spanish Colonial period explorers and missionaries in Southcentral United States during the Little Ice Age (Gunn and Frkuska 1982).

To summarize, then, there appear to be three underlying processes that governed deposition of sediments at Moccasin Confluence. The first is High Banking, Sedimentary Process I, which is a natural result of increased depth of the sediment pile and is of little interest to this study except insofar as it is desirable to factor it out of the climatically related processes that it masks. The second process (Sedimentary Process II, Humidity) is associated with the amount of Very Coarse and Fine Sand accumulated by colluvial and eolian forces. It probably is an index of the Moisture Optimum.

The third process (Sedimentary Process III, Aridity) contrasts the movements of Silts and Very Coarse Sands to Fine Sands. Where there was one kind of Humidity, there are two kinds of Aridity, which would be expected from the model. Very dry summers associated with high temperatures and with torrential rainfall would 
increase the amount of colluvial (Very Coarse Sands) and flood deposits (Silts), and produce a coordinated movement of Very Coarse Sand and Silts. This most likely represents Altithermal and Altithermal-like climates.

The polar opposite of the Altithermal is the cool steppe with only eolian movement of Fine Sands. It can be expected to be associated with lower average temperatures, Little Ice Age-like climates. Dry and cold climates are known to produce eolian deposits from river beds (Saucier 1981) during the winter, and this may be applicable here.

Future research at Moccasin Confluence should include a high resolution examination of the sediment column. The interaction of the processes discussed above should correlate with projected climatic chronology discussed in chapter 1 .

\section{SEDIMENTS, GASTROPODS, AND ENVIRONMENT (Nash, Gunn)}

Once it was determined that certain components of the sediments reflected climatic variability, these data were integrated with molluscan data (Table 5.04) from the excavation levels to further define the environment of Moccasin Confluence. The hypothesis that guided this effort was as follows: the frequency and size of specific snail species is expected to correlate with the particle size of the sediments and lithic materials that they are associated. Analysis of this mix of sedimentary, human, and biotic measures would provide insights into the climatic conditions contributing to the development of the depositional sequence.

Three species of gastropods were identified. They were the Helicina orbiculata tropica, Polygyra texasiana texasiana, and Rabdotus sp. The gastropods collected from Test Pit 2 were weighed and counted by level (see Table 5.04).

The preferred environment of the Rabdotus sp. is arid or semiarid areas such as Northern Mexico and the Southwestern United States (Fullington and Pratt 1974:14). In living specimens, three species of Rabdotus are identified. R. dealbatus inhabits riparian woodlands. $R$. mooreaus is found in prairie habitats. $R$. alternatus are relatively abundant in mesquite chaparral and is found less often in a prairie type of habitat. They tend to prefer living in bushes and related forms of vegetation where they cling to the bark. During the winter, all species hibernate a few inches below the soil surface. In this study no attempt was made to separate the species, and there is some doubt as to whether they can be separated in non living specimens ( $R$. Neck, personal communication). A strategy for analysis of Rabdotus $\mathrm{sp}$. will be discussed later. 
TABLE 5.04. GASTROPOD ORIGINAL DATA

\begin{tabular}{|c|c|c|c|c|c|c|c|}
\hline LEVEL & $\begin{array}{c}\text { FRAG } \\
\text { WT }\end{array}$ & $\begin{array}{l}\text { RAB } \\
\text { NO }\end{array}$ & $\begin{array}{l}\text { RAB } \\
W T\end{array}$ & $\begin{array}{l}\text { POLY } \\
\text { NO }\end{array}$ & $\begin{array}{l}\text { POLY } \\
\text { WT }\end{array}$ & $\begin{array}{l}\text { HEL } \\
\text { NO }\end{array}$ & $\begin{array}{l}\text { HEL } \\
W T\end{array}$ \\
\hline $\begin{array}{l}1 \\
2 \\
3 \\
4 \\
5 \\
6 \\
7 \\
8 \\
9 \\
10 \\
11 \\
12 \\
13 \\
14 \\
15 \\
16 \\
16 \\
17 \\
18 \\
19 \\
20 \\
21 \\
22 \\
23 \\
24 \\
25 \\
26 \\
27 \\
28 \\
29 \\
30 \\
31 \\
32 \\
33 \\
34 \\
35 \\
36 \\
37 \\
38 \\
39\end{array}$ & $\begin{array}{r}.11 \\
.11 \\
.06 \\
.44 \\
.10 \\
1.15 \\
9.90 \\
1.40 \\
.22 \\
44.74 \\
.65 \\
4.80 \\
10.70 \\
13.26 \\
8.33 \\
17.30 \\
12.92 \\
16.69 \\
25.39 \\
30.61 \\
30.61 \\
13.20 \\
26.52 \\
7.34 \\
12.45 \\
28.28 \\
1.31 \\
0.00 \\
10.28 \\
.80 \\
2.76 \\
.00 \\
14.00 \\
7.60 \\
11.60 \\
9.68 \\
20.00 \\
3.40 \\
4.96 \\
1.16\end{array}$ & $\begin{array}{r}2 \\
0 \\
3 \\
1 \\
0 \\
0 \\
0 \\
2 \\
1 \\
8 \\
5 \\
17 \\
32 \\
23 \\
14 \\
25 \\
27 \\
32 \\
41 \\
17 \\
23 \\
21 \\
20 \\
1 \\
9 \\
32 \\
3 \\
1 \\
28 \\
0 \\
0 \\
4 \\
16 \\
20 \\
4 \\
12 \\
8 \\
0 \\
8 \\
8\end{array}$ & $\begin{array}{r}.95 \\
.00 \\
1.20 \\
.07 \\
.00 \\
.00 \\
.00 \\
1.77 \\
1.10 \\
3.89 \\
4.60 \\
1.63 \\
26.70 \\
20.20 \\
12.60 \\
26.32 \\
27.62 \\
41.57 \\
45.00 \\
17.07 \\
27.49 \\
16.24 \\
16.88 \\
2.24 \\
7.96 \\
45.04 \\
3.64 \\
.31 \\
44.64 \\
.00 \\
.00 \\
8.96 \\
15.80 \\
4.40 \\
1.88 \\
1.28 \\
2.80 \\
.00 \\
5.48 \\
6.04\end{array}$ & $\begin{array}{r}1 \\
3 \\
2 \\
0 \\
0 \\
0 \\
22 \\
5 \\
7 \\
63 \\
2 \\
112 \\
363 \\
235 \\
118 \\
181 \\
139 \\
170 \\
209 \\
107 \\
133 \\
61 \\
120 \\
18 \\
37 \\
52 \\
2 \\
1 \\
20 \\
20 \\
8 \\
0 \\
136 \\
160 \\
124 \\
276 \\
64 \\
8 \\
24 \\
0\end{array}$ & $\begin{array}{r}.11 \\
.30 \\
.20 \\
.00 \\
.00 \\
.00 \\
2.56 \\
.40 \\
.60 \\
6.19 \\
.19 \\
8.90 \\
28.20 \\
21.88 \\
10.36 \\
15.70 \\
12.11 \\
14.57 \\
19.05 \\
9.70 \\
12.30 \\
5.66 \\
10.92 \\
2.43 \\
3.52 \\
4.56 \\
.17 \\
.11 \\
1.92 \\
1.80 \\
.88 \\
.00 \\
10.16 \\
11.72 \\
8.88 \\
18.92 \\
4.44 \\
.56 \\
1.56 \\
.00\end{array}$ & $\begin{array}{r}1 \\
2 \\
2 \\
6 \\
3 \\
5 \\
37 \\
9 \\
19 \\
185 \\
6 \\
121 \\
447 \\
290 \\
143 \\
210 \\
136 \\
167 \\
180 \\
106 \\
84 \\
57 \\
65 \\
20 \\
17 \\
24 \\
4 \\
0 \\
0 \\
4 \\
8 \\
0 \\
0 \\
24 \\
0 \\
44 \\
4 \\
32 \\
52 \\
12\end{array}$ & $\begin{array}{r}.11 \\
.20 \\
.15 \\
.30 \\
.30 \\
.70 \\
7.10 \\
1.30 \\
3.30 \\
29.80 \\
1.00 \\
20.62 \\
73.24 \\
48.60 \\
23.80 \\
35.14 \\
24.58 \\
29.90 \\
32.55 \\
18.18 \\
15.55 \\
9.89 \\
11.46 \\
3.94 \\
3.53 \\
4.00 \\
.75 \\
.00 \\
.00 \\
.60 \\
2.80 \\
.00 \\
.00 \\
4.52 \\
.00 \\
6.76 \\
.88 \\
4.12 \\
8.00 \\
2.04\end{array}$ \\
\hline
\end{tabular}


Polygyra, by contrast, is found in prairie-forest ecotones, but not in deep woodlands or open prairie. They are primarily characterized as snails of humid country by Pilsbry (1940), and tend to live under dead wood, leaves or stones, and only come out at night or during rain. As with all snails they adapt to drought by sealing their apertures to prevent water loss (Cheatum and Fullington 1973). Survival in a given area depends on drought being shorter than the period individuals can survive in this dormant state.

Helicina is a species that ranges over most of the state of Texas, with the exception of far west Texas. Weeds and grasses in pasture lands, as well as protected woodland regions, are its preferred habitat. In the Dallas region Helicina has been observed ascending hackberry and elm trees (Cheatum and Fullington 1973), and, as with Polygyra, it possesses a certain amount of ability to survive short term drought.

Land gastropods have been used in the past to provide general environmental information. It has, however, been difficult to obtain precise climatic information from snail data due to nonspecific identification and probably their drought resistance. Sealing off their aperture to preserve internal moisture, they suspend growth and reproduction and become dormant.

We tried several ideas to see if reasonable climatic sequences could be obtained from the snails. In all experiments we assume that snails are a part of a multicausal system and that frequencies, weights, etc., must have non relevant patterns controlled out or partialled before climatic responses will become apparent. For example, the climatic component in snail frequencies cannot be observed until the effects of human occupation frequency have been numerically controlled; humans and snails apparently live in a positive feedback relationship.

We first tested the hypothesis that, if the snail species have preferred habitats, then the ratios between species should vary in accordance with changes in vegetation, that are governed by climate. Rabdotus is presumed to be more frequent in a drier climate, and Polygyra and Helicina more frequent in moister environments.

Second, we tested the idea that the size of snails responds in a general way to climate. Longer dry seasons or generally drier conditions would overtax the snail's drought-resisting capabilities, or simply reduce the amount of time for growth during the lifetime of snails. The net result, whatever the intervening causal factors, would be smaller average size in the population. R. Neck advises that this strategy is more applicable with Polygyra and Helicina, which have determinate growth, and is in theory less applicable to Rabdotus in which size analysis is complicated by indeterminate growth. The Rabdotus indicator is further complicated by the multiple unidentifiable species problem mentioned above. In this preliminary experiment we proceeded with the simple size/climate assumption with the understanding that during future research it would be desirable to tailor recovery and analysis methods to this design. This would include recovery of micro and small snails and attempts to speciate the Rabdotus population. 
The second hypothesis, that of snail size, seemed to be most productive with this data set. This may be in part due to the fact that the snails were collected from 1/8-inch dry screens, and the largest specimens would have been those often recovered. Wet screening with 1/16-inch screens would, without a doubt, yield a better collection capable of sustaining a more sophisticated analysis. Because of the method by which they were collected, the sample represented the upper end of the size range for Moccasin Confluence snails, and this may account for the better results obtained from the simple size hypothesis.

The principal components analysis that was calculated using the weight of snails appears in Table 5.05. The average snail size seemed to yield a reasonable analysis according to what is known about snail habitat preference. The correlated behavior of Polygyra and Helicina was as expected since they are reported to prefer moister conditions. The fact that Rabdotus are on another component indicates that it varies independently of Polygyra-Helicina rather than in a complementary fashion, which would be the case if they were on the same component but negatively correlated. Thus, the presence of small or large Rabdotus does not predict the size of the other two species. This complicated set of relationships may account for some of the frustration of previous attempts to use snail data as indicators of climate.

\section{TABLE 5.05. AVERAGE SNAIL SIZE PER EXCAVATION LEVEL: UNROTATED PRINCIPAL COMPONENTS ANALYSIS}

\begin{tabular}{cccc}
\hline & SNAI & SNAII & Communality \\
Level & -.27 & $.61^{\star}$ & .44 \\
Rabdotus Av. & -.05 & $.83^{\star}$ & .84 \\
Polygyra Av. & $.78^{*}$ & .32 & .58 \\
Helicina Av. & $.77^{\star}$ & -.05 & .59 \\
Variance & .32 & .29 & .61 \\
* indicates an important loading. & & \\
SNAI - Rabdotus and Level & & & \\
SNAII - Polygyra and Helicina & & & \\
\hline
\end{tabular}

\section{ANALYSIS OF SNAILS AND SEDIMENTS (Gunn)}

Since we are assuming that both snails and the sediments are related to the cultural and environmental system, analyzed together they should provide independent and mutual verification of environmental changes. To accomplish this the component scores (Nie et al. 1975:479) from the analysis of sediments-High-Bank (SED I), Humidity (SED II), Aridity (SED III), and the analysis of snails-Rabdotus and Level (SNAI), and Polygyra and Helicina (SNAII)-were joined into the same data set. Also, the lithic debris weights discussed in chapter 6 were included in the 
analysis as an indicator of the occupation intensity. This controls for any effect of humans on snail frequencies.

ENVI Human/Humidity. Component ENVI (Table 5.06) indicates a tendency for human occupation to increase with humid conditions. Polygyra-Helicina (SNAI) show no favorable response to humidity, and Rabdotus-Level (SNAII) have a strong negative response. The modest loading of the Aridity factor (SED III) indicates that occupation of Moccasin Confluence during periods of warm steppic or desert climate has something in common with periods of extreme humidity. Perhaps human activity increases near the stream as the uplands become more desiccated, or there is a real increase in population during arid intervals. A negative loading with Rabdotus-Level (SNAII) indicates that the pattern is late. Knowing which species of Rabdotus are present would be extremely helpful for the interpretation of this pattern. Presence of a prairie or riparian habitat would determine the model. As it is, it remains ambiguous.

TABLE 5.06. SEDIMENTS, SNAILS, AND LITHIC DEBRIS (UNROTATED PRINCIPAL COMPONENTS ANALYSIS )

\begin{tabular}{llccc}
\hline & ENVI & ENVII & ENVIII Communality \\
\hline SED I High-Bank & .01 & .32 & $.94^{*}$ & .98 \\
SED II Humidity & $.86^{*}$ & .23 & .04 & .79 \\
SED III Aridity & $.42^{\star}$ & $-.76^{*}$ & .18 & .79 \\
SNAI POIYgyra-Helicina & $.20^{*}$ & $.77^{*}$ & .01 & .63 \\
SNAII Rabdotus-Level & $-82^{*}$ & $.48^{*}$ & -.09 & .91 \\
Lithic Debris & $.73^{*}$ & $.50^{*}$ & -.27 & .86 \\
Variance & .36 & .30 & .17 & .83 \\
\hline
\end{tabular}

* indicates an important loading

ENVII Human/Cool Aridity. Component ENVII shares the variance in lithic debris with ENVI; note important loadings on both components. This indicates that there were two independent human responses to differing climates rather than one in which they withdrew in the face of adverse climate. Both snail components (SNAI and SNAII) show increases in the size of snails associated with human occupation. The component has a negative relationship to the Aridity factor (SED III). This means that it pertains to human occupation during periods of cool steppe rather than hot steppe or desert. It is probably associated with Late Holocene bison hunters. There is a related spectacular increase in occupation debris at both Moccasin Confluence and Hop Hill during the early Late Archaic (see chapters 3 and 4).

Component ENVIII relates only to the High Bank (SED I) phenomenon and is not relevant to our concern here. 


\section{HOLOCENE CLIMATE AND CULTURE CHANGE}

In the next few paragraphs we will attempt to relate the climatic sequence generated by this analysis to the central Texas archaeological sequence. For the sake of simplicity in comparing the components with the archaeological periods, ENVI will be referred to as the "Humidity" factor. It will be taken as an indicator of year-round humidity (positive) and aridity (negative). ENVII will be called the "Aridity" factor and indicates the type of seasonal drought. Its positive pole is winter drought with torrential summer rainfall. Its negative pole is summer drought associated with cooler climate.

The component scores for the Humidity and Aridity factors are plotted over the projection of climate discussed in the introductory chapter (Figure 5.05). Since no radiometric dates are yet available from Moccasin Confluence, the temporal correlation of the two chronologies is based on dates and diagnostics used by Prewitt (1981). While there seems to be a convincing coherence through the section between dates and diagnostics, the correlations have to be regarded with caution until independent confirmation of the dating is available. To achieve the correlation, period boundaries were established, and levels were apportioned increments between boundaries according to their relative thicknesses. This procedure assumes stable deposition rates during periods. The correlations are particularly tenuous at the bottom of the section since we have no way of knowing the date of the initial occupation of the site. An assumption was made that the Clovis-age occupation began at about 12,000 B.P. Levi Rockshelter (Alexander 1963) indicates that this date may be late.

In overall perspective it is interesting that the Humidity and Aridity factors cross at 4600 B.P. (see Figure 5.05). Around 4500 B.P. is a frequently mentioned date in prehistory that generally has to do with the beginning of the Late Holocene round of cultural activity. For instance, the old central Texas Archaic chronology began at about 4500 B.P. In most regions of the Southeast, the Late Archaic, explosively populated with intensive collectors who laid the groundwork for later sedentary developments, began during the third millennium B.C. This crossing in the graph suggests fundamental change in climatic conditions, a moistening of the environment and a shift away from Middle Holocene winter droughts.

Correlated the way they are, the samples collected during the 1982 field season span from about 5000-1500 B.P. with an 800-year break between 2900 and 2100 B.P. The Humidity factor during this period shows a moistening trend to the 3000-2000 B.P. period, followed by a sharp drop in moisture during the Late Archaic. Since the Late Archaic represents a stagnation and retraction of the Middle Archaic pattern, the cultural and climatic chronologies seem to correlate logically. Also, the Late Holocene moist period defined by Baker and Penteado-Orellana (1977) and referred to by Gunn and Prewitt (1985) as the "Colorado Subpluvial," corresponds to the period of moisture defined by the Humidity factor. The three lines of evidence make a compelling case for a moist Middle Archaic and a changed Late Archaic. 
They also fall during a period of stable and moderate volcanic activity and moderate global average temperatures, an 800-year period from about 2800 B.P. to 2100 B.P. During this time the climate model projects climatic conditions as being in the Moisture Optimum, a fourth independent line of evidence supporting the condition.

The Late Archaic is marked by a precipitous shift toward aridity on the Humidity factor. It is also notable for an extreme shift toward cool steppic climate on the Aridity factor. Dillehay (1974:183) documents the presence of bison in Texas during this period, as does the faunal material from Moccasin Confluence. This is the period of maximum occupation at Hop Hill, which is suggested in this report to be an overlook to bison fording the Pedernales River below the Johnson ranch house. Confluence.

Again, several lines of independent evidence support such a climatic regime. The climatic projection suggests that the cause is a period of substantially increased volcanic activity.

A comparison of sediment-snail responses at 3800 and 1900 B.P. indicates that responses to volcanicity were more radical during the period after the Moisture Optimum than before it.

The Humidity factor is consistently at or below the mean in the Early and Middle Holocene. In sample 6 the trend in Humidity is downward from the San Gabriel Subpluvial to the San Antonio dry interval. The Aridity factor is toward the warm steppe and/or desert end of the continuum which is as it should be. The response is not of the magnitude as that at 1800 B.P. The sampling may have obscured some of the magnitude. The problem of the Early to Middle Holocene transition deserves further research at higher resolution (Gunn 1996).

The relative aridity of central Texas during the Clovis period is of interest. A model based on reactions of the climate in the Southern Plains and central Texas to the Chichon volcanic eruption of 1982 predicts that central Texas would have been dried and the Southern Plains moistened by the highly volcanic Clovis period (Gunn 1983b, 1992). The Clovis period on the Plains is already known to be moist according to Wendorf (1975) and Bryant and Shafer (1977). This evidence can be taken as partial confirmation of the central Texas aspect of the problem. 


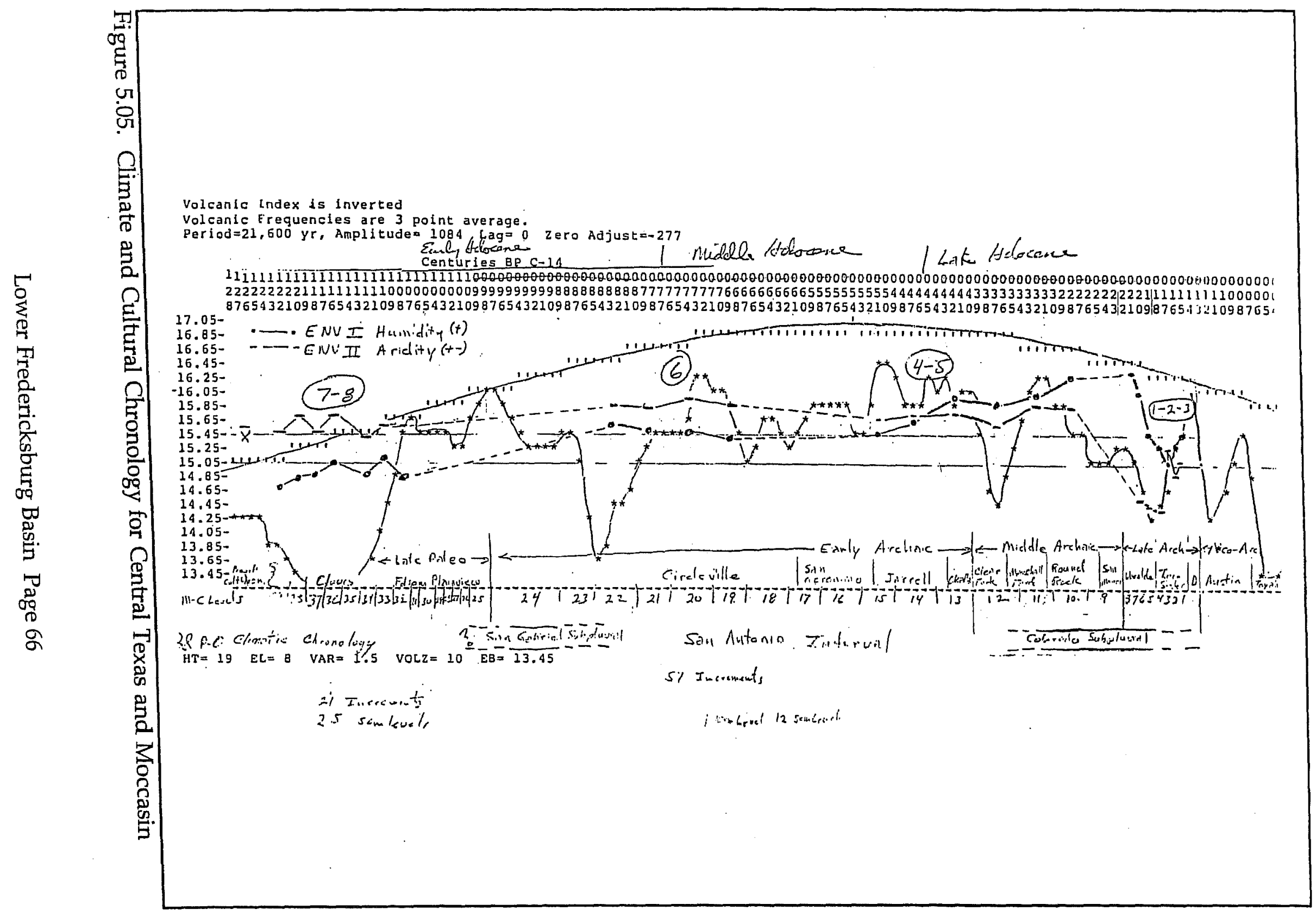




\section{CONCLUSIONS}

The Moccasin Confluence site is a deeply stratified site in the Edwards Plateau that has substantial geomorphological and climatic significance for the study of culture and climate change in the Late Quaternary. The study of sediments and snails through use of numerical analysis shows that, once non relevant factors are controlled out of the data, logical and convincing trajectories of climatic change can be drawn. The climatic trajectory indicates that centered about 4500 B.P. is a period of pivotal change from Early-Middle Holocene climate to Late Holocene climate. The samples that have been analyzed to date, coarse as they are, indicated a much more precipitous climatic pattern change in the Late Holocene, especially as pertains to global volcanicity. Such a pattern implies an equally precipitous pattern of cultural changes. 


\section{CHAPTER 6-CHRONOLOGICAL DEMOGRAPHY: VERTICAL CONCENTRATIONS OF LITHIC DEBRIS FROM MOCCASIN CONFLUENCE (Kerr)}

It required many millennia for successive human occupations to create the Moccasin Confluence site (41 BC 71). It is equally likely that it will take several reoccupations by archaeologists to gather sufficient data to understand all of the cultural processes that formed the site. The effort began with the 1982 test excavations. The present task is to evaluate what was recovered before proceeding with more excavations. This study involved the calculation of the vertical concentrations of lithic debris from three $1-\times 1-\mathrm{m}$ test pits. The test pits were located in order to examine various salient features of the site as is explained in chapters 2 and 3.

Once the vertical concentrations of lithic debris were determined for the three test pits under study, a comparison between pits was made to locate areas of occupation intensity. This analysis presupposes that lithic debris concentrations can be used as indicators of horizontal and vertical occupation intensity. We were interested to see if the camp locus changed through time and, if so, whether the change resulted from random movements or purposeful shifting. This was to be done by comparing chronologically equivalent modes on test pit histograms representing vertical debris frequencies. Modes showing similar relative frequencies of debris would indicate random camping at the site; uncorrelated modes would denote a purposeful shift. The trend across test pits with the highest concentrations would indicate the horizontal direction of the shift.

The random and/or systematic shift hypothesis was suggested by shovel tests conducted just prior to the excavation of the $1-\mathrm{m}^{2}$ test pits. Artifactual materials from the shovel tests indicated that older artifacts were coming from the southern (upstream along Williams Creek, Figure 3.01) portion of the site, and later materials were appearing further north. Furthermore, the geomorphologist (Brown) indicated that the channel of the Pedernales River shifted to the north as sediments deposited by Williams Creek accumulated at its confluence with the Pedernales River. The implication drawn from this was that the focus of occupation should have shifted northward with time. It was hoped that the analysis and interpretation of the concentrations of lithic debris would lend support to these tentative observations.

\section{METHOD}

The three test pits that were studied are designated by the numbers 6,4 , and 2 (see Figure 3.01). Test Pit 2 is located the closest to Williams Creek on the west bank and has the lowest surface elevation of the three units. Test Pit 4 is $47 \mathrm{~m}$ northwest of 
Test Pit 2 and has a surface elevation $46 \mathrm{~cm}$ higher than Test Pit 2. Test Pit 6 has the highest surface elevation, being $3.6 \mathrm{~m}$ above Test Pit 2, and is farthest from the creek, $109 \mathrm{~m}$ west southwest of Test Pit 2 .

"Lithic debris" for this study was defined as a platformed flake or chip weighing under $30 \mathrm{~g}$ individually. The debris from each excavation level was weighed as a unit. Then, since the excavation levels were not of equal thickness, the debris weight was divided by the level thickness, producing a grams-per-centimeter index. These indices were plotted as histograms to facilitate comparison (Figure 6.01 and Tables 6.01-6.03).

After the vertical frequency indices were plotted as histograms, a tentative chronology was assigned to each test pit sequence using associated diagnostic point types, which were graciously identified by Elton Prewitt. Prewitt's (1981:75-76) central Texas chronology was used to attribute the chronological periods of Paleoindian, Early, Middle, and Late Archaic to the various levels in the test units.

One problem became immediately apparent. The frequencies of diagnostics were not sufficient to produce the desired precise and refined chronology. This obscured the comparison of debris concentrations in the three test pits. The intended precise correlations of modes on the histograms were not possible, so the comparisons had to be interpreted in a more generalized manner.

\section{DATA}

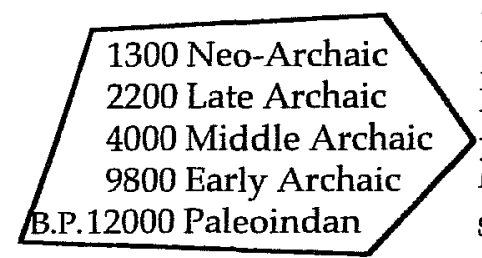

Figure 6.01 is a plot of the vertical lithic debris frequency indices for each test pit. Test Pit 6 has a high debris index in level 10. The presence of a Pedernales point designated this level as Middle Archaic. The succeeding level 9 has a slightly higher frequency and is marked as early in the Late Archaic by a Montell. The debris index drops with level 8 , which contained a Castroville, another Late Archaic point. The next three levels remain at the same moderate index level. Level 4, containing a Shumla, begins an upsurge of activity that peaks in level 3 . Levels 2 and 1, near the surface, show a rapid decline in debris frequency. Test Pit 6 is in the front yard of a house, and so the upper two levels may have been disturbed.

Test Pit 4 has a low intensity but fairly constant debris index during the Paleoindian period which ends with level 32 where a Plainview was recovered. Level 39 with no flakes or chips is exceptional. Level 30 is notably high in debris. The trend through the Early Archaic is one of an oscillating, but constant, rise in the debris frequency index. It reaches a peak in level 9, which contained a Taylor triangular point, an Early Archaic indicator. 


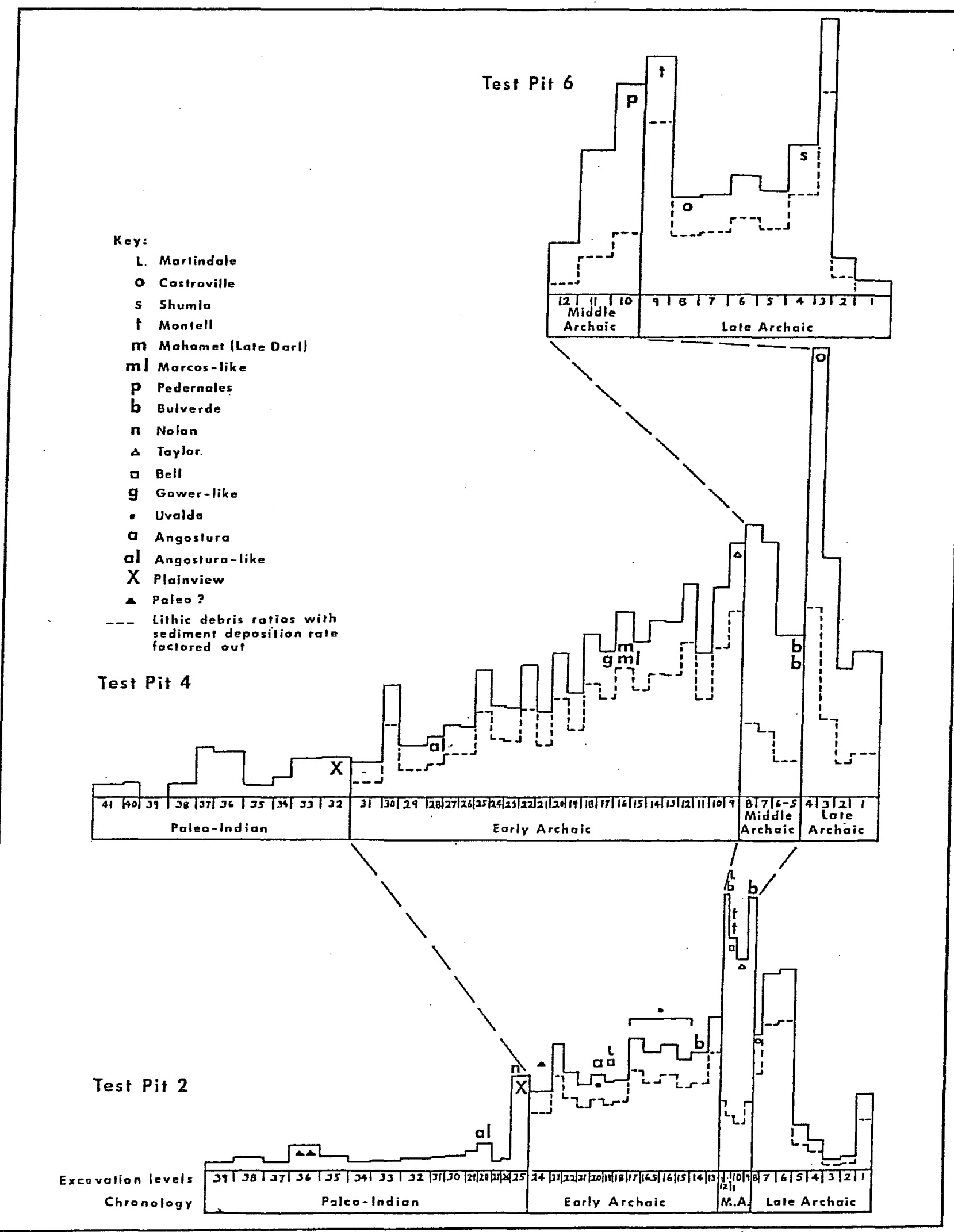

Figure 6.01. Moccasin Confluence Vertical Frequency Indices of Lithic Debris. 
A problem was encountered in determining the chronology in this test pit. The presence of later materials mixed with the early materials, particularly those located in levels 14-16, was troublesome. The field notes suggested bioturbation as a probable cause. The field notes have several descriptions of rodent burrows and specifically mention level 14. Microstratigraphic excavation, with the separation of burrow material, would be necessary to determine if the mixing is original to the point types involved or a product of some other sedimentary process such as deflation.

The Middle Archaic in Test Pit 4 is indicated by the presence of two Bulverde points in level 5. The debris from levels 5 and 6 was inadvertently mixed at some point and is represented as an average. There was a consistently high debris frequency in the Middle Archaic. In Level 4 there is a very high debris concentration, the highest at the site. This level contained a Castroville, placing it early in the Late Archaic. This is also the period of most intensive occupation at Hop Hill (chapter 4).

Test Pit 2, like Test Pit 4, has low debris indices for the Paleoindian period. This period extends to level 25 where there is an increase in frequency. Level 25 contained a Plainview point. During the Early Archaic, debris frequencies are considerably higher than the Paleoindian concentrations. Variation through the Early Archaic levels are not substantial. Overall there is a slight increase in debris as in Test Pit 4.

\section{TABLE 6.01. VERTICAL CONCENTRATIONS OF LITHIC DEBRIS IN TEST PIT 6}

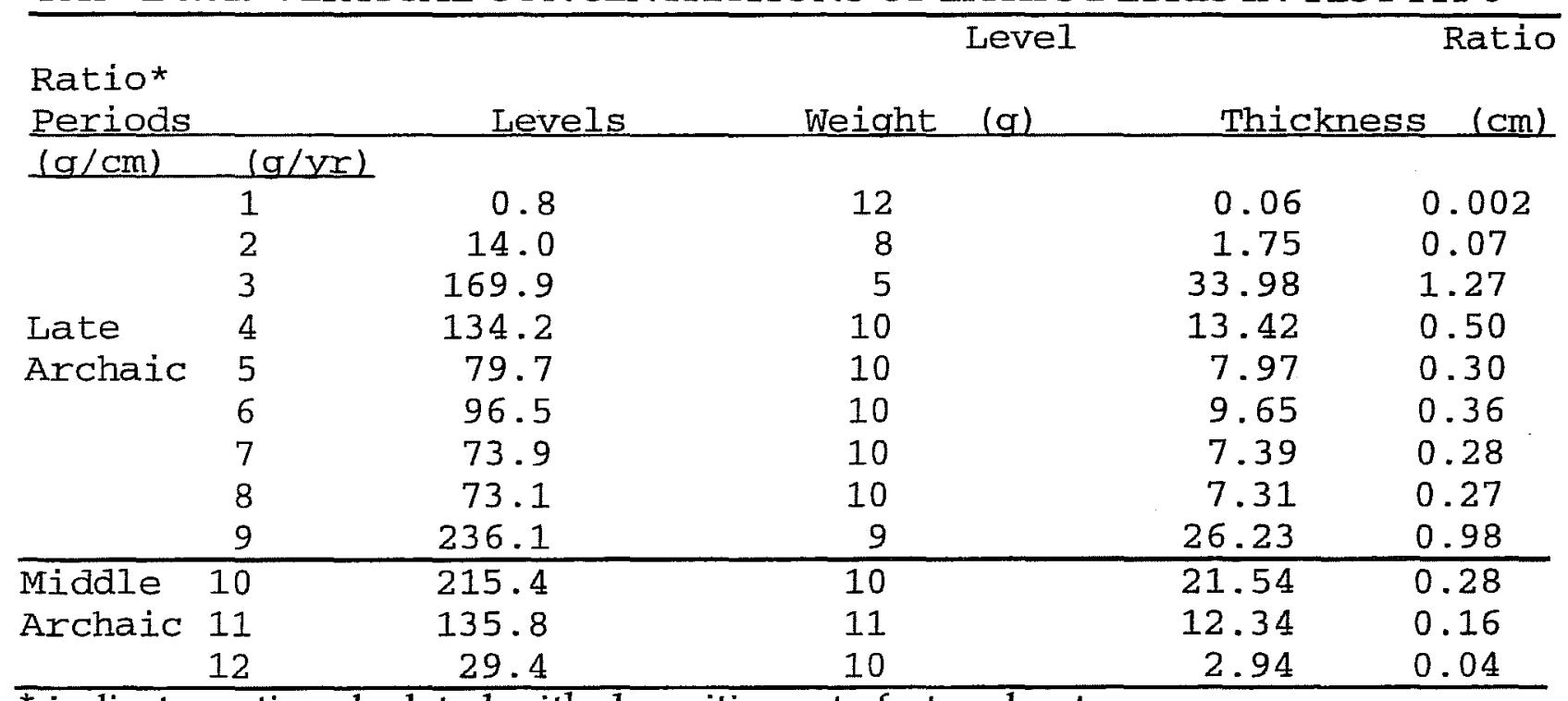

${ }^{*}$ indicates ratio calculated with deposition rate factored out 
TABLE 6.02. VERTICAL CONCENTRATIONS OF LITHIC DEBRIS IN TEST PIT 4

\begin{tabular}{|c|c|c|c|c|c|}
\hline Periods & Levels & Weight & $\begin{array}{c}\text { Level } \\
\text { (g) Thickness }\end{array}$ & $\begin{array}{l}\text { Ratio } \\
(\mathrm{g} / \mathrm{cm})\end{array}$ & $\begin{array}{l}\text { Ratio* } \\
\text { (g/yr) }\end{array}$ \\
\hline & 1 & 153.2 & 10 & 15.32 & 0.17 \\
\hline Late & 2 & 62.9 & 5 & 12.58 & 0.14 \\
\hline \multirow[t]{2}{*}{ Archaic } & 3 & 163.1 & 5 & 32.62 & 0.36 \\
\hline & 4 & 530.0 & 5 & 106.00 & 1.18 \\
\hline & 5 & 178.0 & 10 & 17.80 & 0.15 \\
\hline Middle & 6 & - & - & - & - \\
\hline \multirow{13}{*}{ Archaic } & 7 & 178.7 & 5 & 35.74 & 0.30 \\
\hline & 8 & 201.9 & 5 & 40.38 & 0.34 \\
\hline & 9 & 177.8 & 5 & 35.56 & 1.14 \\
\hline & 10 & 131.6 & 5 & 26.32 & 0.84 \\
\hline & 11 & 75.4 & 5 & 15.08 & 0.48 \\
\hline & 12 & 135.2 & 5 & 27.04 & 0.87 \\
\hline & 13 & 99.7 & 5 & 19.94 & 0.64 \\
\hline & 14 & 100.8 & 5 & 20.16 & 0.65 \\
\hline & 15 & 83.7 & 5 & 16.74 & 0.54 \\
\hline & 16 & 107.8 & 5 & 21.56 & 0.69 \\
\hline & 17 & 76.5 & 5 & 15.30 & 0.49 \\
\hline & 18 & 90.4 & 5 & 18.08 & 0.58 \\
\hline & 19 & 48.4 & 5 & 9.68 & 0.31 \\
\hline Early & 20 & 76.2 & 5 & 15.24 & 0.49 \\
\hline \multirow[t]{15}{*}{ Archaic } & 21 & 35.5 & 5 & 7.10 & 0.23 \\
\hline & 22 & 67.4 & 5 & 13.48 & 0.43 \\
\hline & 23 & 38.9 & 5 & 7.78 & 0.25 \\
\hline & 24 & 40.0 & 5 & 8.00 & 0.26 \\
\hline & 25 & 63.3 & 5 & 12.66 & 0.41 \\
\hline & 26 & 28.1 & 5 & 5.62 & 0.18 \\
\hline & 27 & 28.7 & 5 & 5.74 & 0.18 \\
\hline & 28 & 22.6 & 5 & 4.52 & 0.14 \\
\hline & 29 & 36.9 & 10 & 3.69 & 0.12 \\
\hline & 30 & 52.9 & 5 & 10.58 & 0.34 \\
\hline & 31 & 19.1 & 10 & 1.91 & 0.06 \\
\hline & 32 & 24.9 & 10 & 2.49 & \\
\hline & 33 & 23.9 & 10 & 2.39 & \\
\hline & 34 & 3.4 & 5 & 0.68 & \\
\hline & 35 & 1.1 & 10 & 0.11 & \\
\hline Paleo- & 36 & 32.1 & 10 & 3.21 & \\
\hline \multirow[t]{5}{*}{ Indian } & 37 & 17.9 & 5 & 3.58 & \\
\hline & 38 & 1.2 & 10 & 0.12 & \\
\hline & 39 & 0.0 & 10 & 0.00 & \\
\hline & 40 & 0.9 & 5 & 0.18 & \\
\hline & 41 & 0.9 & 10 & 0.09 & \\
\hline
\end{tabular}

* indicates ratio calculated with deposition rate factored out 


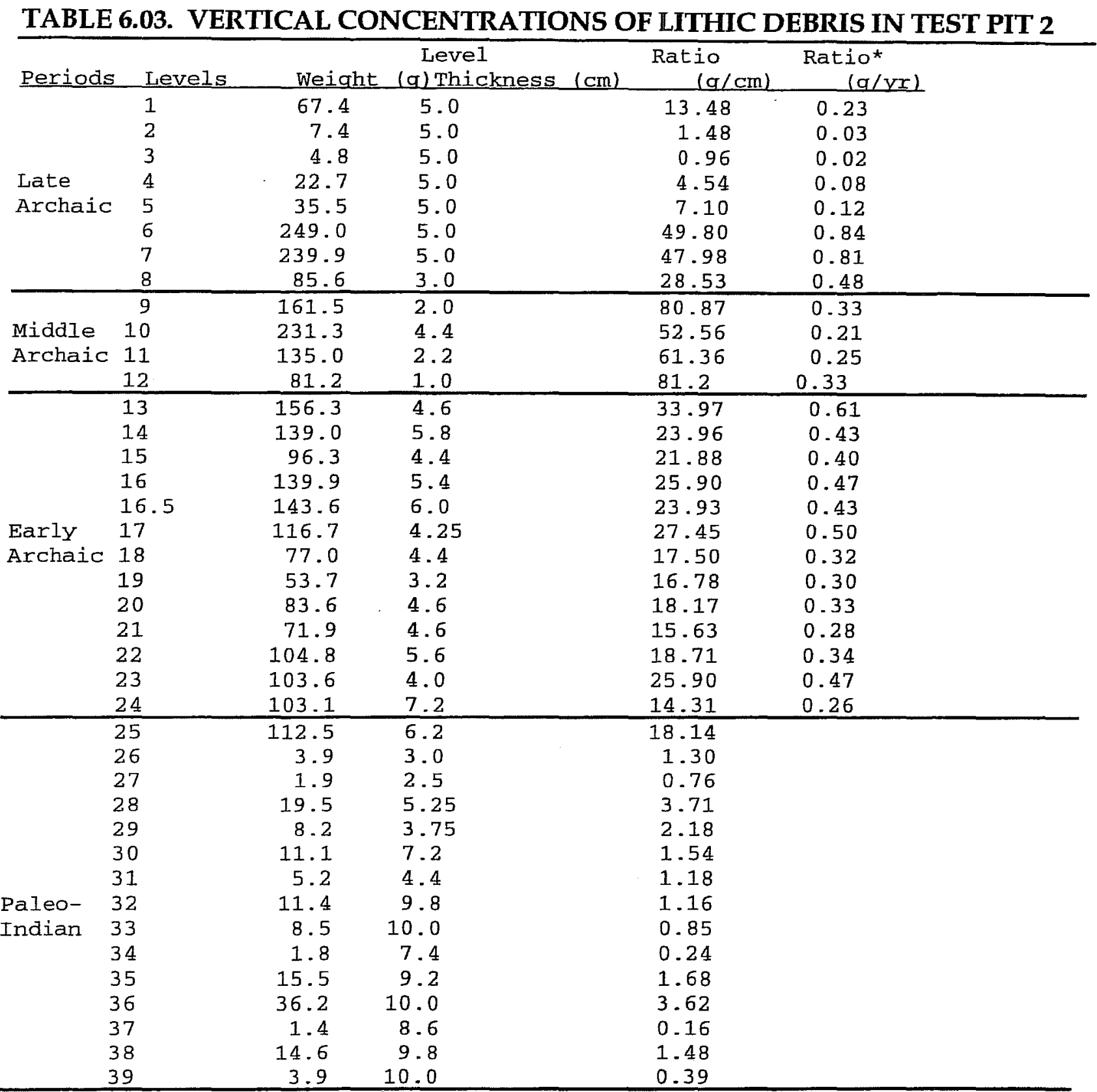

* indicates ratio calculated with deposition rate factored out

The Middle Archaic in Test Pit 2 is not clearly indicated by the presence of characteristic point types. However, Test Pits 1 and 3 , located immediately adjacent to Test Pit 2 on the east and west, did contain Bulverde points. (Note: Points in Test Pits 1 and 3 are indicated by symbols placed above the histogram, those for Test Pit 2 within the histogram.) The highest debris frequencies for Test Pit 2 occur in the levels designated as Middle Archaic. These levels also contained a midden of rocks which, according to Prewitt (1981:80), is a characteristic feature of Archaic sites. 
The Late Archaic in Test Pit 2 begins with level 8. There was a Castroville point present in this level. Debris concentration drops relatively low in level 5. Succeeding levels contained no diagnostics, so there is no clear upper bound on the chronology at this test pit or the others for that matter.

After the lithic debris concentrations were determined in the preceding manner, it seemed possible that differing rates of sediment deposition through time could contribute to the appearance of high or low concentrations. In essence, a low sediment deposition rate, coupled with repeated incidental accumulations of lithic debris, would lead to seemingly high debris concentrations within excavation levels. As a test, an average sediment deposition rate of years-per-centimeter was calculated for the Early, Middle, and Late Archaic for Test Pits 2, 4, and 6. These sediment deposition rates were factored out of the debris frequency indices. The pattern within periods did not change. However, a different picture of lithic debris concentration (which are indicated as small dashed lines on the histograms in Figure 6.01) emerged between periods. Provided the time spans were properly estimated, the Middle Archaic may actually have a much lower debris frequency relative to the Early and Late Archaic. The phenomenon suggested by the low adjusted Middle Archaic frequencies will be discussed below.

\section{INDICATIONS AND DISCUSSION}

Resolution of the problem of whether camp loci were randomly or purposely shifting seems to be resolvable in favor of a purposeful northward shift. Test Pit 2 to the south shows a sudden increase in popularity during Late Paleoindian times. After that, interest in the area remains relatively constant until the latter part of the Late Archaic after which it is largely ignored. Test Pit 4 to the north, and closer to the Pedernales River, shows a sustained increase of attention that culminates with spectacularly high, early Late Archaic frequencies. That the two test units represent two points within one camp area that was repeatedly occupied through time is supported by the fact that the same point types, including Plainview, Angostura, Taylor, Bulverde, and Castroville, occur in both places. The shift, then, probably concerned the changing location of activity areas within the camp from one occupation to the next rather than total relocation of the camp. Test pits further north of Test Pit 4 are needed to determine if the trend continues into later phases.

The Test Pit 6 area seems to be occupied for the first time in the Middle Archaic. The implication is that the camp area may have been expanded outward from the confluence suggesting a larger group was occupying the site. However, such an interpretation needs to be applied cautiously. There is little to support the assumption that the Test Pit 6 area was occupied concurrently with the Test Pits 4 and 2 area during the Middle Archaic. Test Pits 4 and 2 contain Bulverde points and no Pedernales points, and Test Pit 6 contains only one Pedernales point. This suggests that the elevated Test Pit 6 area was occupied at a slightly later time under possibly different conditions than Test Pits 4 and 2. 
Also, Test Pit 6 concentrations may not be reflective of actual occupation intensity because the peculiar geomorphic situation, deposition on a knoll, coupled with the sandier sediments, suggest that the area may have been subject to wind (eolian) deposition, thereby disturbing the lithic debris concentration. Precise temporal control of both the upper and lower bounds of the test pit chronology are lacking, so deposition rates could not be calculated with assurance.

Further information to be considered concerning the location of main Middle Archaic occupation comes from a survey and shovel test across Williams Creek on the east side. There was definite evidence of a deep rock midden indicating that the east bank may have been the main locus of Middle Archaic occupation. This implies that the west bank lithic debris concentrations for the Middle Archaic may not reflect actual intensity of occupation at the confluence as a whole. Prewitt (1981) and Weir (1976) indicate that the Middle Archaic was a time of dense population in central Texas. Prewitt (1981:80) cites lithic debris concentrations associated with rock middens as the identifying feature of the Middle Archaic phase in central Texas. Weir (1976:131) hypothesizes the Middle Archaic as a time of increased population with many small groups reoccupying sites more frequently for longer stays. This suggests that high frequencies of Middle Archaic lithic debris should be present. Either the 41 BC 71 sequence, when corrected for deposition rates, is extra ordinary for central Texas or the other side of the creek was more attractive.

The difficulties encountered during this use of lithic debris concentrations as an occupation intensity indicator prompted many thoughts on the processes by which concentrations were accumulated. All of them have a bearing on interpretation. Accumulation of lithic debris involves several variables including duration of stay, population size, frequency of return to the site, site function, and the nature of the particular tool assemblage. All of these variables would have operated in a systemic fashion. Environmental factors would have affected the relationship, and they would have been changing through time.

Further considerations have to be given to what happens to lithic debris accumulations after the site was abandoned (long before the archaeologists arrive to count them). Erosion by wind and rain has an affect. Rodents can rearrange the debris. A low sediment deposition rate inflates concentrations of lithic debris and therefore needs to be taken into account. All of this makes reliance on lithic debris concentrations alone as an indicator of occupation intensity an imprecise analytical tool. Lithic debris concentrations in concert with frequencies of tools, site boundaries, and as many other clues as it is possible are necessary to indicate intensity of occupation at a particular site during a particular time. 


\section{CHAPTER 7-POINT CHRONOLOGY AND SYSTEMATICS (Gunn, Craig)}

\section{INTRODUCTION}

The art of point analysis has progressed through the efforts of several analysts in the last decade. Thanks to the enduring interest in points, their analysis has come under scrutiny from various perspectives so that such efforts boast a growing body of literature and the status of a subdiscipline. A review of this literature can be followed by reference to Gunn and Prewitt (1975) and Benfer and Benfer (1981). Through a series of studies, ideas about measurement and analysis of points have been refined. In this study we suggest what appears to be a method of measurement and analysis that meets objections raised in previous studies as well as facilitates the study of points from the perspective of a theory of point function. Some of the subsystems of point morphology are time dependent in the LBJ State Historical Park collection.

Until recently most of the efforts to analyze points were essentially atheoretical. The peculiar problems and complexities of point morphology attracted interest in themselves. Little thought, however, was given to the functional implications of those morphologies. In Gunn (1982e) the senior author undertook the development of a theory of point function which is based on physical laws of levers. Such a perspective allows the researcher to examine points as an interacting system of morphological attributes that respond to cultural and environmental preconditions.

In the work cited, it was noted, for example, that in both Texas and Louisiana there are sequences of points that suggest a gradual adaptation of points, changing from dart to arrow weapon systems. The first step in that adaptation was to simply make dart points smaller. This, however, narrowed the penetration swath of points, presumably reducing their effect on game. This was corrected in the second stage of adaptation by exaggerating the barbs on the arrow points. In Texas, this sequence is represented by the Darl-Scallorn-Perdiz sequence; in Louisiana by the Gary-Small Gary- Catahoula sequence. In each case the adjustments are made by rearranging the proportions of the points to match the needs of the manufacturer and the peculiarities of the weapon system. The blade was shortened relative to the width, the stem was shortened relative to the blade, etc.

\section{METHODOLOGY}

Specific measurements of base width, blade length, neck width, etc., assume to a certain extent, that the analyst knows the morphological subsystems of point shapes 
and shape-related function. In this study we attempted to objectively define morphological subsystems (MSS) by numerical analysis. A method of measurement using polar coordinated radii was developed. Measurements made by this method presents a principal components analysis with a continuous array of data on the shape of the points. The principal components analysis then determines the MSS as statistically independent trends in the data. Nie et al. (1975) discuss the principal components method.

The best measurement method was selected by a set of experiments. Three different methods were evaluated by measuring the 39 relatively complete points from stratified contexts in LBJ State Historical Park. The first was the series of measurements used by Gunn (1982e, Figure 7.01a). The second was a set of 14 polar coordinate radii along which measurements were taken to the edges of the points (Figure 7.01b). Both of these produced analyses that in large part ignored the barbs. The final approach was to outline the point on a polar coordinate grid as is illustrated in Figure 7.01c.

This method, which we will refer to as the polar coordinate grid technique, records only half of the point. In other words, it assumes the point is symmetrical. This is a reasonable assumption, given the basically symmetrical nature of points, and it is often helpful since one or the other barbs of a point is frequently broken and has to be reconstructed. Each point was centered on the grid with the horizontal radii marking the blade- haft interface (on Ray 4). The blade-haft interface is the highest point on the tool that shows modification for hafting. In the instances of lanceolates, we follow Kelly (1977) and assume that the haft is no further up the point than the side with the shortest edge grinding.

The rays in the upper left quadrant are spaced at $30^{\circ}$ to measure the length of the blade (1), the convexity or concavity of the blade $(2,3)$, and the width of the blade (4). Rays 5-18 are arranged in three fans. They are closer together at the blade-haft interface to emphasize notches, barbs, etc. The locations of the radii are determined by Fibonacci's Series (Borissavlievitch 1958), a geometric series that has found wide applications in esthetics, architecture, etc., and works in this case to concentrate measurements in the turn of the notch. The series used was $5^{\circ}, 8^{\circ}, 13^{\circ}, 21^{\circ}, 34^{\circ}, 55^{\circ}$, and $89^{\circ}$. The location of each ray is determined by the sum of the previous two.

Figures 18a-c illustrate the use of the rays to measure points of various styles. The most extended use of the three fans of rays is demonstrated in Figure 18a, the case of the basally notched point. The first fan of rays, 5-8 measure the distances to the outside edge of the barb. The second fan of rays, 9-12, measures the inside of the barb, or outside of the notch. The third, 13-17, measures the stem or inside of the notch. Ray 18 measures the length of the haft. 


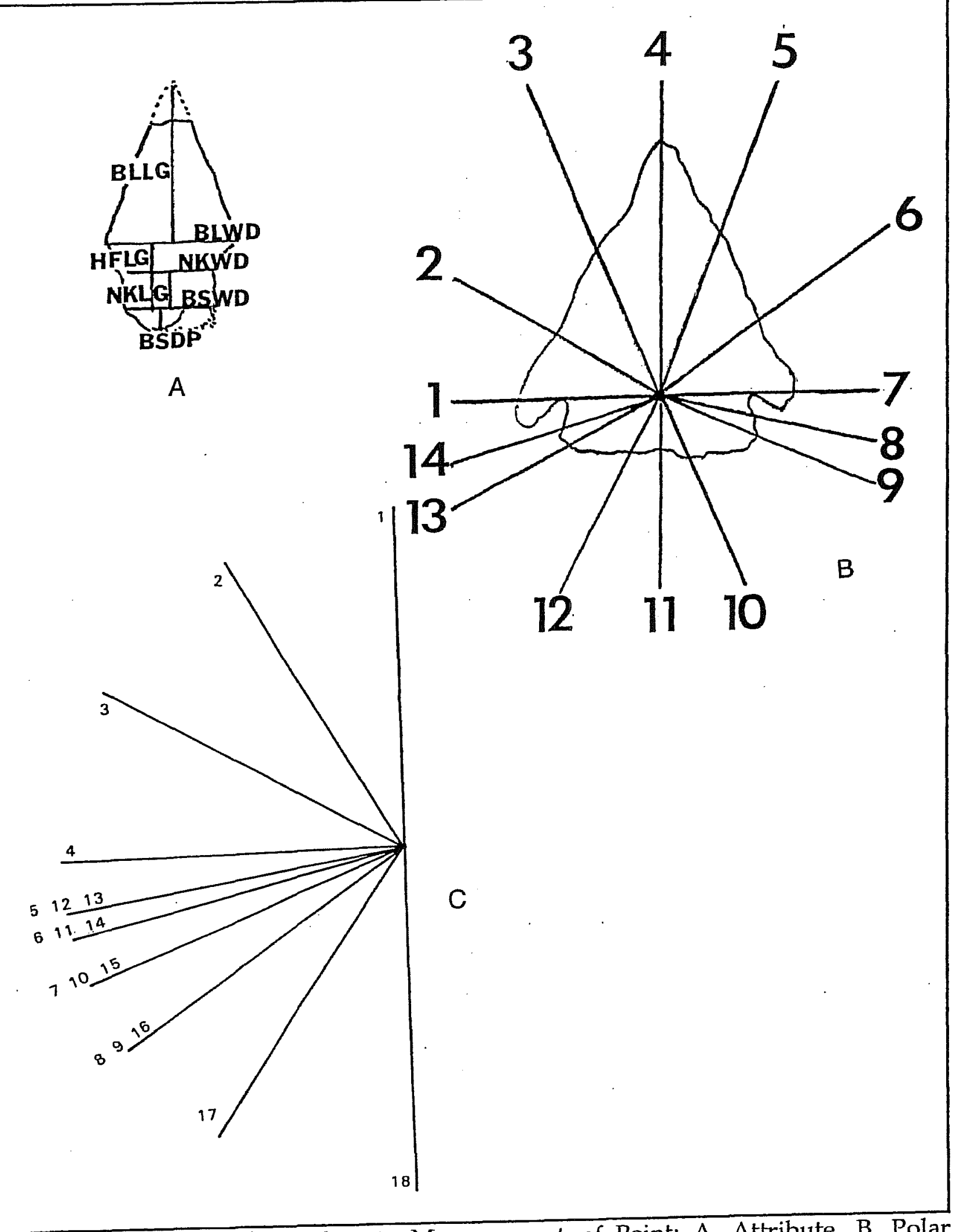

Figure 7.01. Approaches Taken to Measurement of Point; A. Attribute, B. Polar Coordinate, C. Polar Fan. 


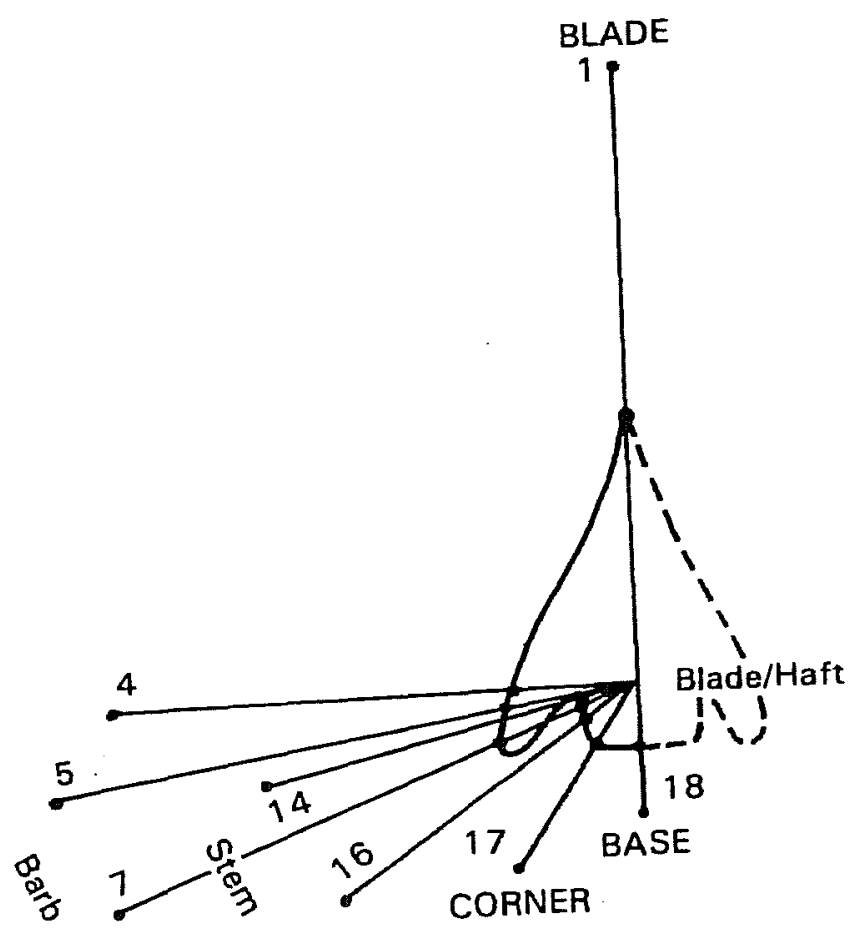

measure to

Figure 7.02. Methods of Measuring Three Types of Points with the Polar Fan; A. Basil Notch, B. Corner Notch, C. Lanceolate. 
The cases illustrated by Figure 18b-c are less complex in form. In those instances in which the rays cross an inside and outside edge, they function as they did with the basally notched point. Where there is no inside and outside, they assume the same values.

Benfer and Benfer (1981), as well as other investigators who have used the Gunn and Prewitt (1975) system of measurement, noted in their criticisms that angle measurements were difficult to replicate. Also, Benfer and Benfer (ibid.) felt that the angle measurements used in the original system were not completely appropriate. The polar coordinate grid system both dispenses with angles and involves only one judgement, the location of the blade-haft interface. As such it is as heuristic as a system of measurements can be expected to be.

\section{ANALYSIS}

Table 7.01 lists the 39 points along with their provenience, type, and presumed period; data appear in Appendix C. Twenty additional points too fragmentary for the analysis were recovered from Hop Hill and Moccasin Confluence during the 1978 and 1982 seasons. To find the systemic interactions of various aspects of point morphology for the LBJ State Historical Park collection, the polar grid data, along with thickness at the blade-haft interface, were processed through a principal components analysis. Each component from this analysis represents an independent process or morphological subsystem (MSS) of the total point morphology system represented by and sampled by the 39 points.

In practice it was not desirable to analyze all 18 rays. With this particular sample, measurements were frequently similar for the whole sample, particularly in adjacent rays. This redundancy or replication of information violates the assumption that measurements are independent of each other, and too much redundancy distorts the analysis. Of the pairs of rays with correlations above 0.80 , one was removed. The best pattern of rays to use for analysis of this sample seems to be the list of variables in Table 7.02, the unrotated principal components matrix for the data. Ray 1 characterizes the length of the blade. Rays 5 and 7 measure the outside aspect of the barb, while Rays 14 and 16 indicate the width dimensions of the stem. Note, by reference to Figure 7.02c, that Rays 5 and 7 are not measured on the same radii as Rays 14 and 16 . Rays 17 and 18 measure the stem length. Using this combination of rays guaranteed that, even in the case of a lanceolate, no two measurements are at the same location on the edge of the point. This combination of rays seems to eliminate most of the excess redundancy and is adequate for this particular collection. Other combinations of rays may be better for other collections. Each point collection must be subjected to the process of running all 18 radii and eliminating one of each set with a correlation greater than 0.80 . 
TABLE 7.01. POINTS RECOVERED IN PLACE FROM LBJ STATE HISTORICAL PARK

\begin{tabular}{|c|c|c|c|c|c|}
\hline Sequence & FN & Stage* & Type & Site & Season \\
\hline $\begin{array}{r}1 \\
2 \\
3 \\
4 \\
5 \\
6 \\
7 \\
8 \\
9 \\
10 \\
11 \\
12 \\
13 \\
14 \\
15 \\
16 \\
17 \\
18 \\
19 \\
20 \\
21 \\
22 \\
23 \\
24 \\
25 \\
26 \\
27 \\
28 \\
29 \\
30 \\
31 \\
32 \\
33 \\
34 \\
35 \\
36 \\
37 \\
38 \\
39\end{array}$ & $\begin{array}{r}88 \\
232 \\
233 \\
234 \\
344 \\
405 \\
407 \\
408 \\
433 \\
442 \\
471 \\
486 \\
508 \\
510 \\
513 \\
514 \\
517 \\
522 \\
537 \\
555 \\
559 \\
564 \\
576 \\
583 \\
584 \\
591 \\
608 \\
623 \\
654 \\
970 \\
972 \\
1007 \\
1016 \\
1030 \\
1042 \\
1048 \\
1081 \\
1127 \\
1243\end{array}$ & 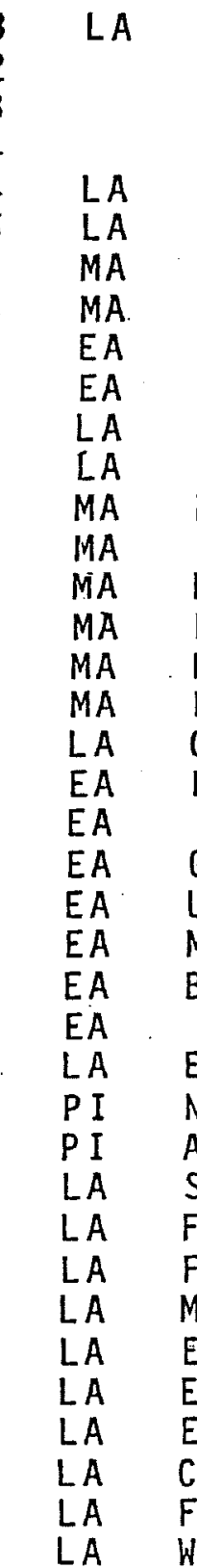 & 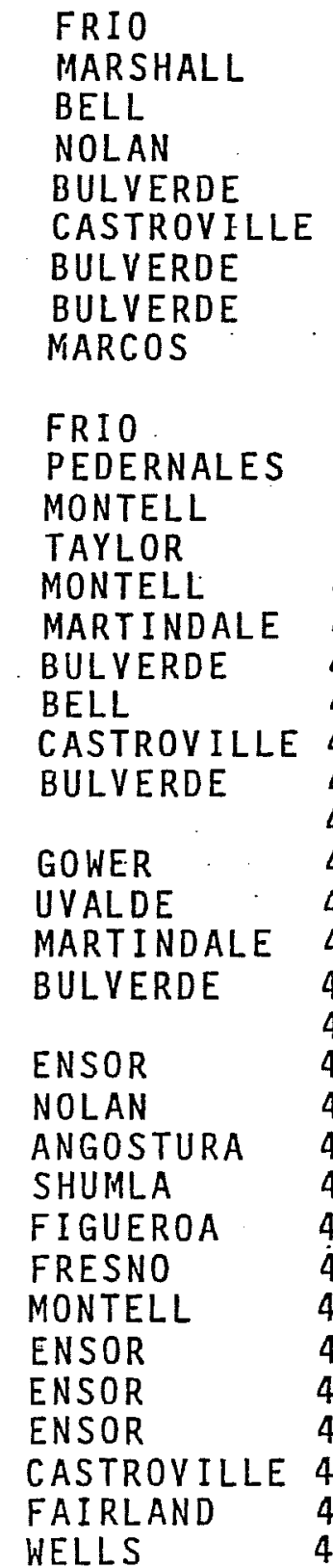 & $\begin{array}{lll}41 & \mathrm{GL} \\
41 & \mathrm{BC} \\
41 & \mathrm{BC} \\
41 & \mathrm{BC} \\
41 & \mathrm{BC} \\
41 & \mathrm{BC} \\
41 & \mathrm{BC} & 7 \\
41 & \mathrm{BC} & 7 \\
41 & \mathrm{BC} & 7 \\
41 & \mathrm{BC} & 7 \\
41 & \mathrm{BC} & 7 \\
41 & \mathrm{BC} & 7 \\
41 & \mathrm{BC} & 7 \\
41 & \mathrm{BC} & 7 \\
41 & \mathrm{BC} & 7 \\
41 & \mathrm{BC} & 7 \\
41 & \mathrm{BC} & 7 \\
41 & \mathrm{BC} & 7 \\
41 & \mathrm{BC} & 7 \\
41 & \mathrm{BC} & 7 \\
41 & \mathrm{BC} & 7 \\
41 & \mathrm{BC} & 7 \\
41 & \mathrm{BC} & 7 \\
41 & \mathrm{BC} & 7 \\
41 & \mathrm{BC} & 7 \\
41 & \mathrm{BC} & 7 \\
41 & \mathrm{GL} & 2 \\
41 & \mathrm{BC} & 7 \\
41 & \mathrm{BC} & 7 \\
41 & \mathrm{BC} & 7 \\
41 & \mathrm{BC} & 7 \\
41 & \mathrm{GL} & 2 \\
41 & \mathrm{GL} & 21 \\
41 & \mathrm{GL} & 2 \\
41 & \mathrm{GL} & 21 \\
41 & \mathrm{GL} & 21 \\
41 & \mathrm{GL} & 21 \\
41 & \mathrm{GL} & 21 \\
41 & \mathrm{BC} & 71\end{array}$ & $\begin{array}{ll}21 & 1982 \\
71 & 1982 \\
71 & 1982 \\
71 & 1982 \\
71 & 1982 \\
71 & 1982 \\
71 & 1982 \\
71 & 1982 \\
71 & 1982 \\
71 & 1982 \\
71 & 1982 \\
71 & 1982 \\
71 & 1982 \\
71 & 1982 \\
71 & 1982 \\
71 & 1982 \\
71 & 1982 \\
71 & 1982 \\
71 & 1982 \\
71 & 1982 \\
71 & 1982 \\
71 & 1982 \\
71 & 1982 \\
71 & 1982 \\
71 & 1982 \\
71 & 1982 \\
21 & 1982 \\
71 & 1982 \\
71 & 1982 \\
71 & 1982 \\
71 & 1982 \\
21 & 1978 \\
21 & 1978 \\
21 & 1978 \\
21 & 1978 \\
21 & 1978 \\
21 & 1978 \\
21 & 1978 \\
71 & 1982\end{array}$ \\
\hline
\end{tabular}

* LA=Late Archaic, MA=Middle Archaic, EA=Early Archaic, $P I=P a l e o-I n d i a n$ 
TABLE 7.02. MORPHOLOGICAL SUBSYSTEMS (MSS): UNROTATED PRINCIPAL COMPONENTS MATRIX FOR POINTS IN THE LBJ STATE HISTORICAL PARK COLLECTION

\begin{tabular}{|c|c|c|c|c|c|c|c|}
\hline & MSS I & MSS & MSS & III MSS IV & MSS V & \multicolumn{2}{|c|}{ 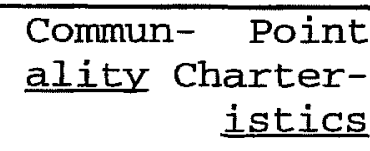 } \\
\hline Ray 1 & .4 & -.6 & .5 & .2 & .2 & .85 & Blade \\
\hline Ray 5 & .8 & .0 & .1 & -.4 & .2 & .90 & Barb \\
\hline Ray 7 & .8 & -.1 & -.0 & -.5 & -.1 & .90 & \\
\hline Ray 14 & .7 & -.0 & -.5 & .4 & .3 & .93 & $\overline{\text { Stem }}$ \\
\hline Ray 16 & .7 & -.3 & -.3 & .5 & -.4 & .93 & Width \\
\hline Ray 17 & .4 & .7 & .2 & -.0 & -.4 & .89 & Stem \\
\hline Ray 18 & .1 & .9 & -.2 & .1 & 3 & .94 & Length \\
\hline B-H Thick & .2 & .3 & .8 & .3 & 1 & .89 & Thickness \\
\hline Variance & .34 & .22 & .16 & .11 & .07 & .90 & \\
\hline
\end{tabular}

\section{Morphological Subsystems}

The following paragraphs discuss the characteristics and relationships between the morphological subsystems.

Morphological Subsystem I (MSS I). Except for the thickness and haft length ray (18), MSS I is a typical first principal component that captures size variance; all loadings are positive. With the effects of general size of artifacts removed to MSS I, the rest of the morphological subsystems can be assumed to pertain primarily to shape.

MSS I points with high deviation component scores have both wide stems and barbs (Figure 7.03A). Those points with low deviations component scores have both narrow stems and barbs. The points with scores near zero have other combinations of attributes, i.e., narrow stems and wide barbs, that will have high scores on other MSS pertaining to those trends.

As Table 7.03 indicates, MSS I has a statistically significant relationship to time. The positive beta (correlation) shows that points through time tended to become broader in the haft and lower blade. Such a broadening of the swath, the width of penetration (Gunn 1982e), probably reflects a growing use of points as projectiles rather than knives. 


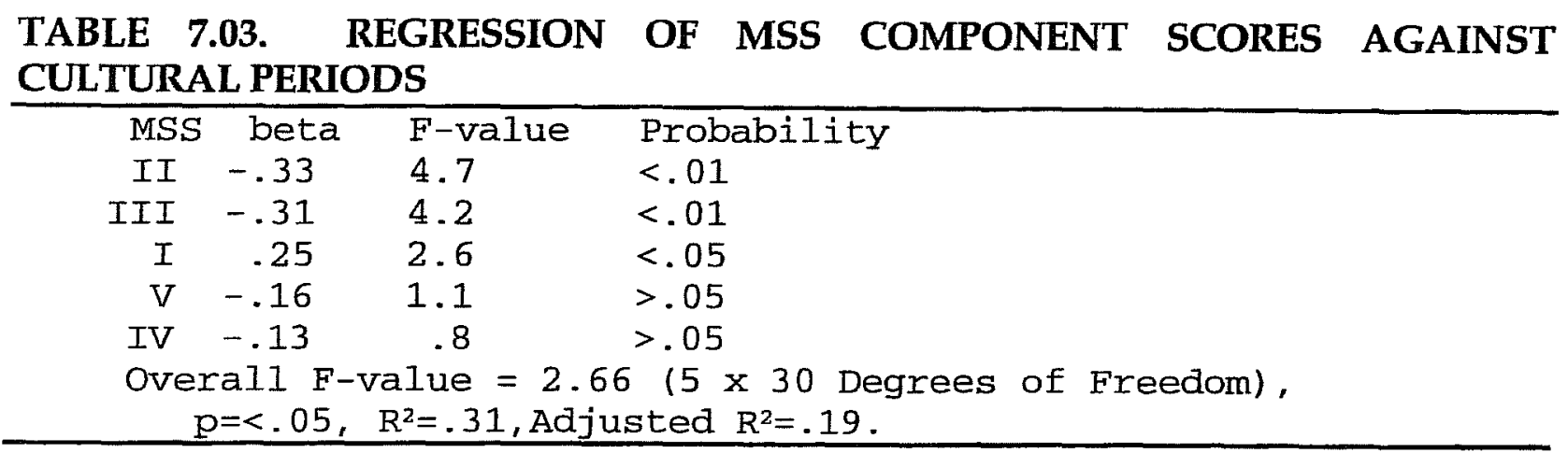

Morphological Subsystem II (MSS II). In MSS II there is a negative relationship between blade and stem length (see Table 7.02). As the blade lengthens, the stem becomes shorter and vise-versa.

The points with long stems and short blades had high positive deviation component scores (see Figure 7.03B). The points with short stems and long blades scored high negative deviations.

The systemic interaction of blade and stem has the strongest statistical relationship to cultural periods of any MSS (see Table 7.03). The negative beta indicates that through time stems become shorter and blades relatively longer. In the perspective of the leverage model, the shorter haft suggests less concern for lateral stress (Gunn 1982e). The longer blades may also suggest less resharpening. Both indicate a decreasing interest in using points as knives, lateral stress and resharpening being more characteristic of knives than projectiles. This correlates with an increased use of flakes as tools (chapter 10).

The analysis suggests that through time, points became specialized as projectile points and their function as knives decreased.

Morphological Subsystem III (MSS III). This subsystem contrasts blade length with the upper stem width (Ray 14). As the blade lengthens the upper stem narrows (see Figure 7.04C). As the blade shortens the upper stem widens. Through time there is a statistically significant tendency for blades to shorten and stems to widen (see Table 7.03).

The pattern is the well-recognized shift from a generalized lanceolate to a triangular pattern. 


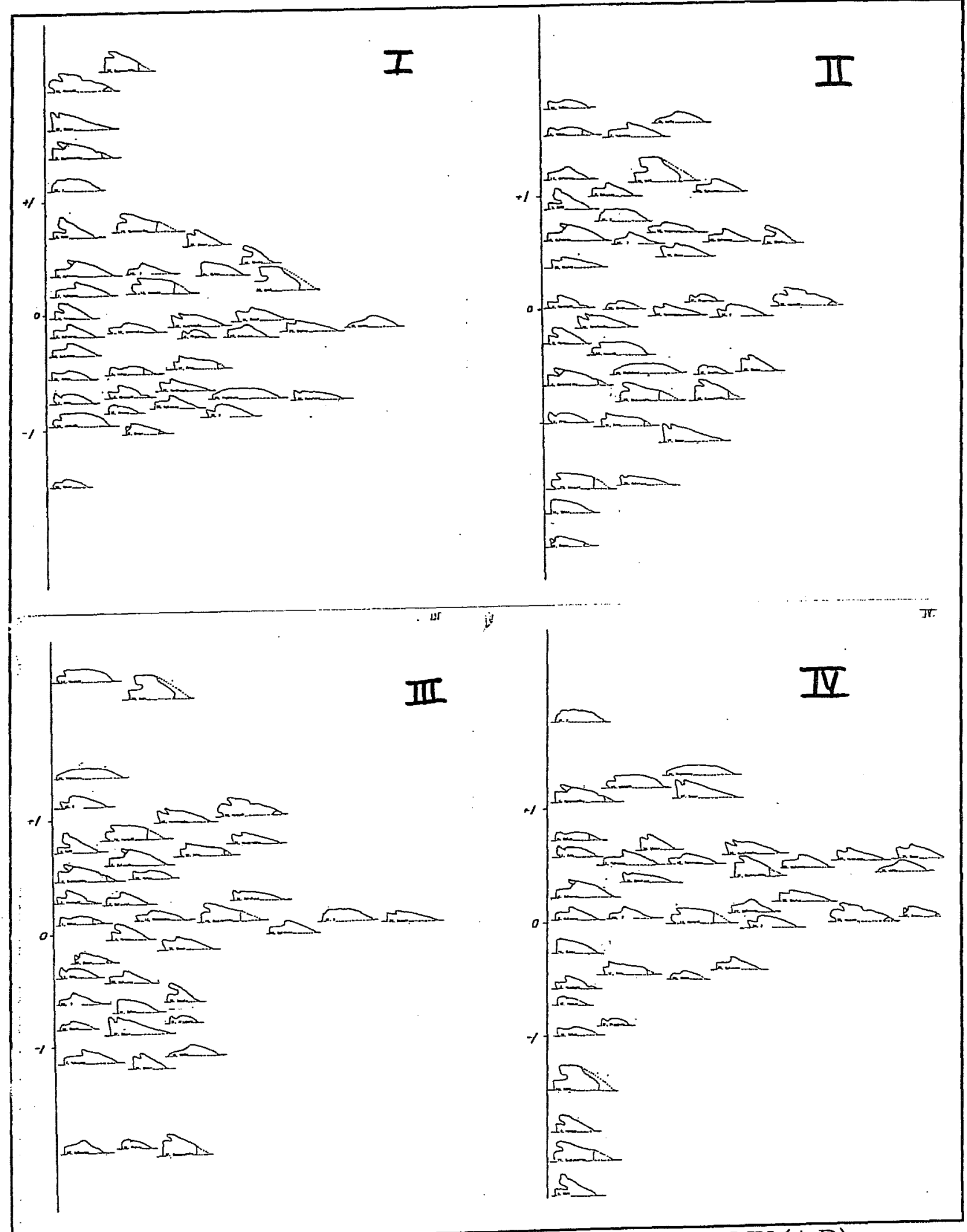

Figure 7.03. Single Dimension Component Score Plots for MSS I-IV (A-D). 
Morphological Subsystem IV (MSS IV). As the stem widens the barb shortens. This interesting MSS shows a tendency for width of the stem to interchange with barbs (see Figure 7.03D). Wider points have shorter barbs, while narrower points have wider barbs.

There is no relationship with time (see Table 7.03), which indicates a universal or time-independent relationship or process. It may be either an inherent difference between lanceolates and notched triangles, or it may be that resharpening of barbs produces this phenomenon. Observe for example, the two forms of Gower illustrated by Prewitt (1981:76), one no doubt the result of sharpening the other. Such sharpening sequences are quite common in Late Paleoindian assemblages (Goodyear 1974:26; Guy and Gunn 1983; Gunn 1984).

Morphological Subsystem V (MSS V). This subsystem shows a negative relationship between Rays 16 and 17, and Ray 14. The pattern suggests extension of the lower corner and retraction of the notches and lower stem. Side and basal notching is under-represented in the LBJ collection which probably accounts for the minimal impact of the component on the total system; it only accounts for seven percent of the variance in the data set. It does, however, bear a modest relationship to time (see Table 7.03).

There is a tendency for a segment of the point population to extend the basal corner.

Of the four major MSS it is no doubt important that three are related to time (MSS I, II, and III, see Table 7.03), and therefore, to some sort of cultural and technological evolution in central Texas points. Since the sample is biased toward the Archaic, with only two usable points from Paleoindian levels, it appears that most of this evolution took place in the Archaic. In brief, this evolution consisted of the following trends:

1. Points became wider, both in the blade and the stem.

2. As stems shortened, blades became longer relative to them. This seems to document the transition sequence from lanceolate, to early stemmed, and later to notched triangles that analysts have been aware of for some time.

3. As stems widened, blades became relatively shorter, a process of triangularization of lanceolates.

These trends seem to reflect a specialization of points away from multipurpose knife-projectile lanceolates that were designed to resist lateral stress, toward specialized, wide-swathed projectiles.

A fourth pattern is the retracting of barbs as stems become proportionally wider. Since this pattern has no time trend, it is presumed for now to be the product of variation in the barbs due to manufacturing peculiarities or resharpening. 


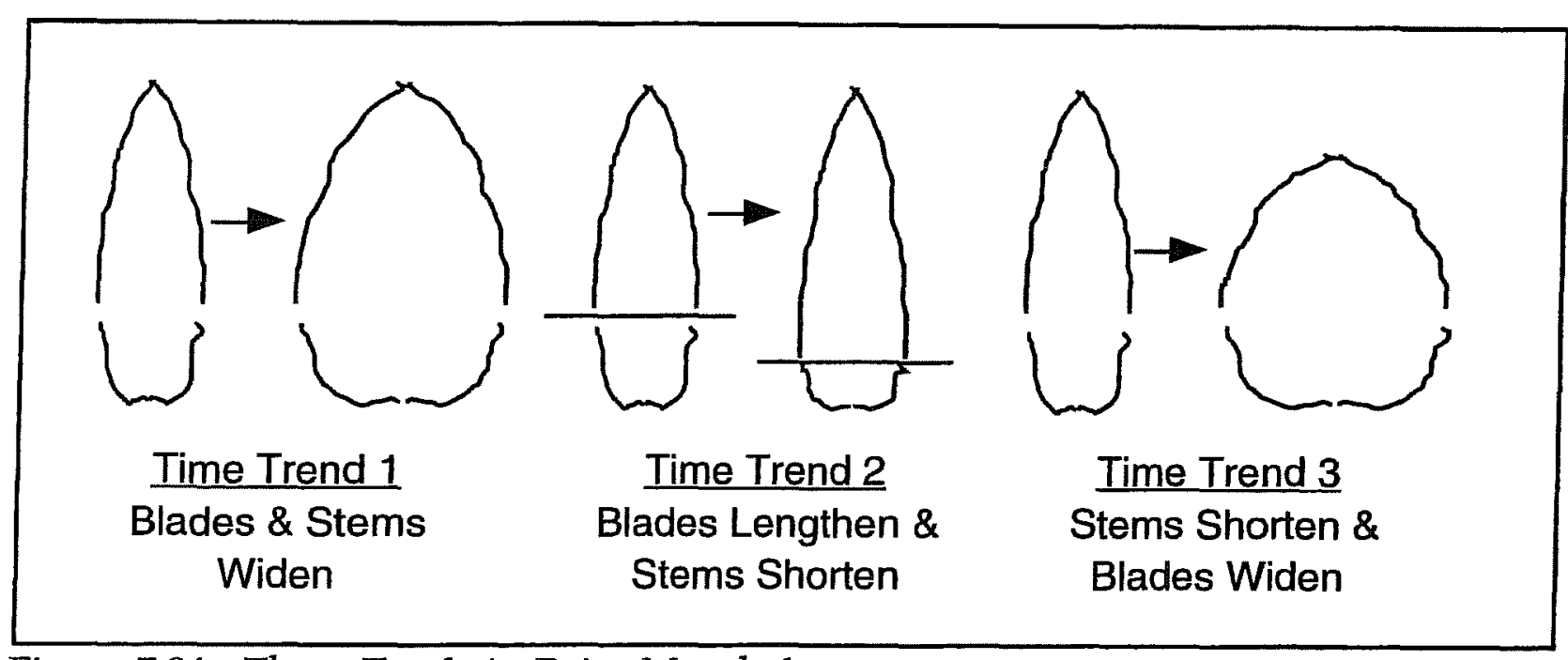

Figure 7.04. Three Tends in Point Morphology.

Component scores for the blade-stem (MSS III on horizontal axis) and barb-stem (MSS IV on vertical axis) are plotted in Figure 7.05. MSS III is one of the most time-dependent morphological subsystems (see Table 7.03). The plot demonstrates some of the strengths and weaknesses of ascribing chronological significance to morphological forms. Castroville points appear in clusters with Bell-Shumla, Martindale-Montell, or Ensor depending on their particular attributes. Ensors on the other hand, occupy a single quadrant of the plot, the upper left. The plot also shows that much of the barbing effect has to do with the contrast between basally notched pieces such as Bell and Shumla (bottom) and the various corner- and side-notched types (top). With notable exceptions, time trends are observable from old (on the right) to young (on the left).

\section{Point Transition Matrix Analysis}

It is safe to conclude from the above analysis that the points from LBJ State Historical Park have certain characteristics that can be used as time diagnostic markers, and, given a better sample, it would be possible to quantify those traits more securely. Given the minimal sample for such a long time range, the time transgressive nature of the traits can only be suggested as a statistically significant hypothesis. The next question is whether traditional typology effectively indicates time trends in the sample. Since typology is not inherently linear in structure a non-linear method must be used to test the typology's time-worthiness. Also, the size of the samples as compared to the number of years/strata is, again, a problem. A simple transition matrix, however, will serve to open the question to discussion.

Table 7.04 was constructed by noting all of the types of points found in LBJ State Historical Park along two sides of a square matrix. The order is taken from Prewitt (1981). In each case, where a point was found in a level, a mark was placed in the cell of the type of points occurring in the next level. Across the top the point types on the left are taken to be the older and the ones on the right the younger. If the 

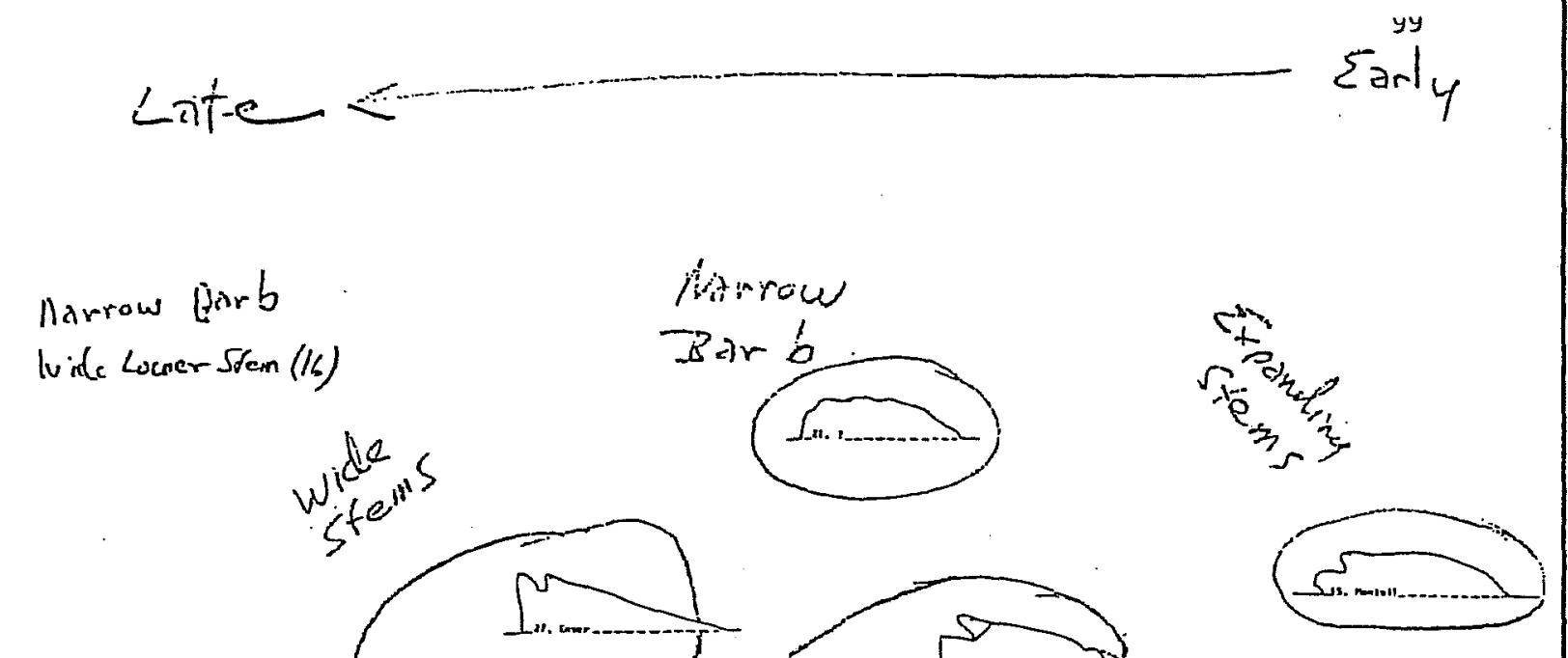

Wide Parb
narrow LuterStem (la)

Short $Q \ln a=$
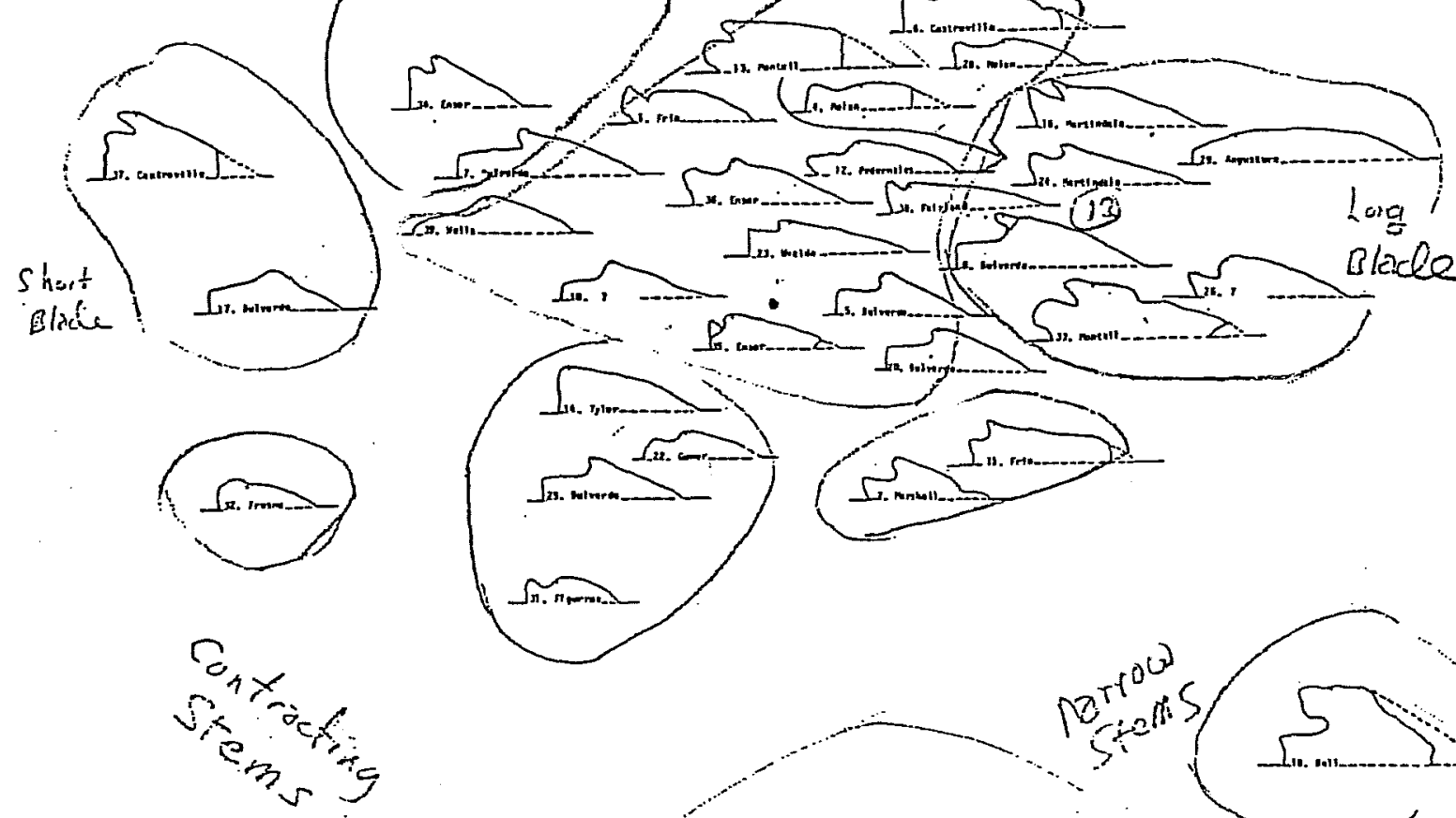

Wide linoer Stem(II)

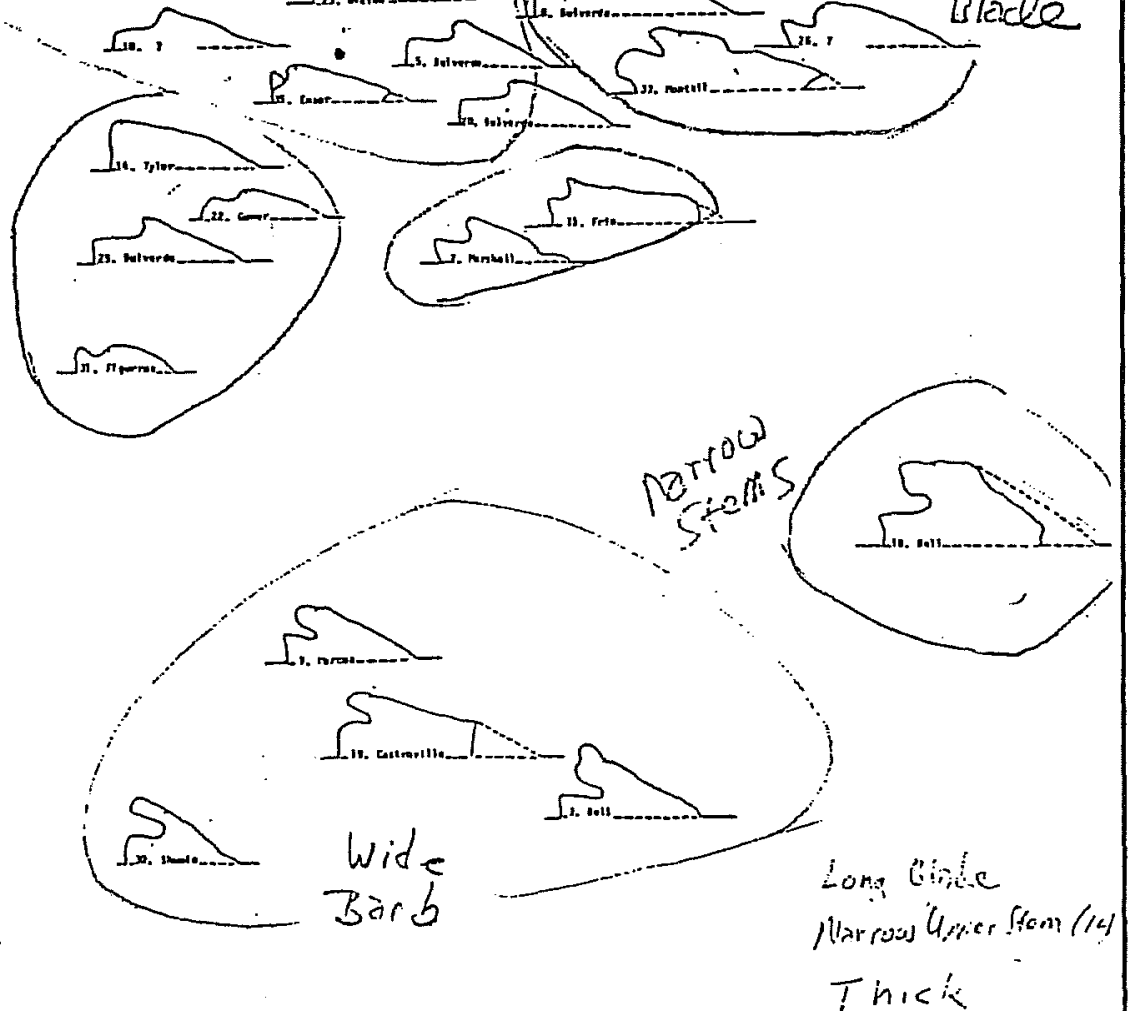

Figure 7.05. Blade-Stem (PC III, Horizontal) and Barb-Stem (PC IV, Vertical) Ordered on Component Scores. 
points were properly ordered by chronology, and there was no mixing of points in strata, all of the scores would appear immediately above the diagonal $\left(^{*}\right)$ of the matrix. For example, all transition from Plainview to Angostura would appear in cell two of row one. Two such occurrences were observed. The one transition from Plainview to Uvalde is out of order, perhaps in this case because of too many sterile strata between the two. Whether it is due to mixing or insufficient sample, its location off the diagonal suggests a problem.

TABLE 7.04. TRANSITION MATRIX FOR POINT TYPES FOUND IN PLACE IN LBJ STATE HISTORIC PARK, FIRST ORDERING OF TYPES YIELDS 21\%

\begin{tabular}{|c|c|c|c|c|c|c|c|c|c|c|c|c|c|c|c|c|c|}
\hline & $P$ & $\mathrm{~A}$ & $\mathrm{G}$ & $B$ & $M$ & $\mathrm{U}$ & $\mathrm{T}$ & $\mathrm{N}$ & $B$ & $\mathrm{P}$ & $\mathrm{M}$ & $F$ & $\mathrm{C}$ & $\mathrm{M}$ & $E$ & $\mathrm{M}$ & $S$ \\
\hline Plainview & $\star$ & 2 & & & & 1 & & & & & & & & & & & \\
\hline Angostura & 1 & * & 1 & 1 & 1 & & & 1 & & & & & & & & & \\
\hline Gower & & & $\star$ & & 1 & & & & & & & & & 1 & & & \\
\hline Bell & & & & $\star$ & & 1 & 1 & & 1 & & & & & & & & \\
\hline Martindale & & & & 1 & * & 1 & & & 1 & & 2 & & & & & & \\
\hline Uvalde & & & & 1 & 2 & * & & & 1 & & & & & & & & \\
\hline Taylor & & & & & & & * & & 3 & & & & 1 & & & & \\
\hline Nolan & & 1 & & & 1 & & & * & & & & & & & & & \\
\hline Bulverde & & & & 1 & 1 & & & & 1 & & 2 & & 1 & & & & \\
\hline Pedernales & & & & & & & & & & * & 1 & & & & & & \\
\hline Montel1 & & & & & & & 2 & & & & * & & & & & & \\
\hline Fairland & & & & & & & & & & & & * & 2 & & & & \\
\hline Castroville & & & & & & & & & & & & & * & & 8 & & 1 \\
\hline Marcos & & & & & & & 1 & & & & & & & * & & & \\
\hline Ensor & & & & & & & & & & & 4 & & & & 4 & & \\
\hline Mahomet & & & & & & & 1 & & & & & & & & & * & \\
\hline Shumla & & & & & & & & & & & & & & & & & * \\
\hline
\end{tabular}

* Diagonal cells

In this matrix $21 \%$ of the transitions are on the diagonal, i.e., from one point type to itself or from that point type to its nearest younger type.

Rearranging some of the types as in Table 7.05 brings $38 \%$ of the transitions onto the diagonal. To archive this improved performance, Martindale and Uvalde were reversed in order, and Marcos was moved before Fairland and Castroville; to discover if this new ordering of types truly improves understanding of type sequences, it would require additional research into the reasons why researchers have ordered types as they have, and if there are any doubts as to these orderings. It is presumably a better arrangement, at least perhaps for the LBJ park collection; is it possible for there to be reversed type sequences from region to region? It is also a small collection and therefore the experiment can only be considered a first approximation. As the collection is increased in size and more transitions are added, the correct sequence will become more secure. 
TABLE 7.05. REORDERED TRANSITION MATRIX: POINT TYPES FOUND IN
PLACE IN LBJ STATE HISTORICAL PARK WITH TYPES REORDERED TO BRING
THEM CLOSER TO THE DIAGONAL, 38\% ON THE DIAGONAL

\begin{tabular}{|c|c|c|c|c|c|c|c|c|c|c|c|c|c|c|c|c|c|}
\hline & $\mathrm{P}$ & $\mathrm{A}$ & $\mathrm{G}$ & $\bar{B}$ & $\mathrm{U}$ & $\mathrm{M}$ & $\mathrm{T}$ & $\bar{N}$ & $B$ & $P$ & $\bar{M}$ & $\mathrm{M}$ & $\bar{F}$ & $\mathrm{C}$ & $\bar{E}$ & M & $S$ \\
\hline Plainview & * & 2 & & & 1 & & & & & & & & & & & & \\
\hline Angostura & 1 & * & 1 & 1 & & 1 & & 1 & & & & & & & & & \\
\hline Gower & & & $\star$ & & 1 & & & & 1 & & & & & & & & \\
\hline Bell & & & & $\star$ & 1 & & 1 & & 1 & & & & & & & & \\
\hline Uvalde & & & & 1 & * & 2 & & & 1 & & & & & & & & \\
\hline Martindale & & & & 1 & 1 & * & & & 1 & & 2 & & & & & & \\
\hline Taylor & & & & & & & * & & 3 & & & & & 1 & & & \\
\hline Nolan & & 1 & & & & 1 & & * & & & & & & & & & \\
\hline Bulverde & & & & 1 & & 1 & & & 1 & & 2 & & 1 & & & & \\
\hline Pedernales & & & & & & & & & & * & 1 & & & & & & \\
\hline Montell & & & & & & & 2 & & & & * & & & & & & \\
\hline Marcos & & & & & & & 1 & & & & & * & & & & & \\
\hline Fairland & & & & & & & & & & & & & * & 2 & & & \\
\hline $\begin{array}{l}\text { Castroville } \\
\text { Ensor }\end{array}$ & & & & & & & & & & & 4 & & & * & $\begin{array}{l}8 \\
4\end{array}$ & & 1 \\
\hline $\begin{array}{l}\text { Ensor } \\
\text { Mahomet }\end{array}$ & & & & & & & 1 & & & & & & & & & * & \\
\hline Shumla & & & & & & & & & & & & & & & & & * \\
\hline
\end{tabular}

* Diagonal cells

\section{CONCLUSIONS}

The long sequence of points recovered from sites at LBJ State Historical Park suggests that several characteristics of points may qualify as time diagnostics. It may be that when the size of the sample is enlarged, defining morphological subsystems that indicate with some accuracy the time when a point was made will be possible. The evolutionary progress of points through the periods of the Texas Archaic appears to have been driven by a desire to specialize points for hunting functions. Technological innovations that altered morphological subsystems include broadening the points and adapting them to bear more penetration stress and less lateral stress. Given the present sample and the stratigraphic relationships obtained from excavations, time transitions defined by Prewitt (1981) account for only $21 \%$ of the stratigraphic order in the assemblage. Slight rearrangement of the points in time increases the transitions accounted for to $38 \%$. The unaccounted for $62 \%$ is apparently due to various causes, stratigraphic mixing, homologous types from different levels, gaps in the point type sequence from the park, and possible additional misarrangements in the order of the types. These various possibilities cannot be studied separately until more specimens have been recovered to eliminate gaps. 


\section{CHAPTER 8-TOOL MORPHOLOGY AND FUNCTION (Mock, Price, and Gunn)}

\section{INTRODUCTION (Gunn)}

There has been a determined effort on the part of most archaeologists to distinguish between tool morphology and function, morphology being assumed, at least in part, to be a product of stylistic preferences, and function relating to the use of tools. Normally morphology, the shape of tools, is studied through more or less traditional ideas of typology and classification. Use, and the wear that results from it, are studied by macroscopic and microscopic methods, most of which have been developed since 1960 .

In this chapter, both approaches are utilized to determine the stylistic and functional changes of tools at Moccasin Confluence and Hop Hill. Those stylistic and functional changes are then related to the central Texas chronology as proposed by Weir (1976) to show how the cultural changes relate to environmental conditions.

\section{BACKGROUND AND HYPOTHESIS (Mock and Price)}

The purpose of this chapter is to explore adaptive techniques and cultural changes evidenced in the chert tool assemblage of the prehistoric inhabitants of Moccasin Confluence (41 BC 71) and Hop Hill (41 GL 21).

Through analysis of the unifacial and bifacial tools recovered from the two sites, we hope to demonstrate how stylistic and functional changes relate to changing environmental adaptations during the central Texas Archaic. For this study the five phase division of the Edwards Plateau Aspect, proposed by Weir (1976:2), was followed.

According to Weir, the Archaic was characterized by large numbers of specialized stone implements, meeting the varied subsistence needs of Archaic peoples. Periodic environmental change influenced the subsistence related resources (Weir 1976:96). Each period reflects cultural adaptations to environmental changes, and we hope to find evidence of these oscillations in our analysis of the tool assemblage.

One of the variables that must be considered in the relationship between adaptation and environment is the location of the sites to be studied. The Edwards Plateau, with its diverse physiography, has been described as a distinct biotic province (Blair 1950:112). While the sites involved in this analysis are in the Balconian zone of the plateau (a more mesic environment evident on the eastern edge of the plateau), the central Texas area, in general, is a transition zone, or ecotone, between the mesic 
environments to the east, and the xeric environments to the west. As an ecotone this region exhibits characteristics of both environments.

Unpredictable physiography and climate probably contribute to the extreme variability within tool forms found in this region. The lack of standardization frequently causes problems in typology building and analysis. A problem often encountered is a lack of recognizable formal tools. Tools of convenience represent a minimum amount of energy expended in modification, but ordering them into morphological and functional categories requires an inordinate expenditure of energy on the part of the archaeologist.

In A Review of Central Texas Archeology, Suhm (1958:73) mentions limited tool varieties and highly variable tool types as one of the reasons for so many different interpretations of central Texas assemblages. Perhaps this lack of distinctive and recognizable tools types is due, in part, to the abundance of chert found in the region. For, as Sollberger (1969:232) has demonstrated in his replicative experiments, a newly struck, unmodified flake is often adequate for the job. A limited technology might also be expected from a mobile people who would have difficulty carrying a wealth of tools.

Ethnographic accounts of hunters and gatherers from the western desert of Australia (Hayden 1977:179) indicate a similar rarity of formal or retouched tools. If flint was nearby, a core flake was suitable for the job, and then discarded when the task was completed. Such comparative ethnographic accounts are useful because information on the indigenous central Texas people is lacking due to the invasion of Comanche and Apache groups, as well as the Spanish in historic times (Newcomb 1961). Stone tools are the main source of information concerning pre-existing subsistence patterns in central Texas because climatic and edaphic factors do not promote preservation of other cultural remains as they do in areas such as west Texas.

One aspect of the dependence upon stone tools as cultural indicators is the trajectory of the tools themselves. It is important to consider that such evidence of cultural activity was due to discarding, and may not represent all of the activities carried out at the site. Also to be considered is the possible development of an ecofact by bioturbation, wind and water erosion, or historic activities, such as root plowing. During the analysis, information can also become distorted due to remodification, recycling, or even multiple function.

Despite the theoretical handicaps, we hope to develop some information concerning the economic adaptations at these two sites, through the analysis of the stone tools in the assemblages.

Many current typologies of the central Texas region have been confusing or inconsistent because style and function were combined in the artifact descriptions, and ultimately the assemblage as a whole. In this analysis we attempt to research style and function as distinct aspects of tool manufacture and use. The first step, 
then, was to establish a typological model. According to Jelinek (1976:19), an artifact in its finished form embodies two distinct properties. The first, style, reflects choices made by the knapper from a number of possibilities. The study of style involved consideration of shape, size, different knapping abilities, materials used, or cultural preference.

The second property, function, is dependent on the intended task. Function was determined by an analysis of use-wear characteristics. All unifaces and bifaces, as well as fragments, were examined for wear-related edge damage. This approach has recently been posed as a fruitful technique for the study of previously and newly acquired lithic collections (Keeley 1980). The basic underlying assumption is that patterned evidence of "wear" indicates a "use" that is integral to the putative lifeway activities of prehistoric peoples.

\section{UNIFACE DESCRIPTIONS: MOCCASIN CONFLUENCE}

A uniface is defined as a tool that has been flaked or modified on one side only, and is created by the knapper according to a mental template. This definition originated in the classification of Upper Paleolithic tools and does not seem to apply to the majority of the unifacial tools in this assemblage. A mental template assumes an attempt on the part of the knapper to achieve a preconceived shape or form. The tools in this assemblage, however, appear to have been manufactured with a minimum expenditure of effort with the emphasis on an efficient working edge. Classification of these tools was determined by the classification system employed by Frkuska and Frkuska (1977:192-203) in which the artifact is divided into bit and haft ends, and categorized according to their dimensions. Brief comments follow some of the descriptions. Field numbers (FN) for tool categories and provenience appear in Table 8.01 .

\subsection{End Trimmed Unifaces, Small to Medium Haft/Small Bit $(\mathrm{N}=1)$}

This distinctive artifact (FN 645, Figure 8.01) has a broadly flared bit with concave and irregular nibbled edges. There is a lateral break in the haft end. It is manufactured from a dark, fine-grained chert and is possibly from the Paleoindian period. It is, in fact, at the next to the lowest level in the deepest test pit, Test Pit 2, level 38. The edge is marked by oblique flake scars and nibbling on the (arbitrarily determined) right corner. Polish was detected on both aspects, but primarily the outer surface. Its triangular shape suggests that it could have most likely been used for scraping or cutting activities. 


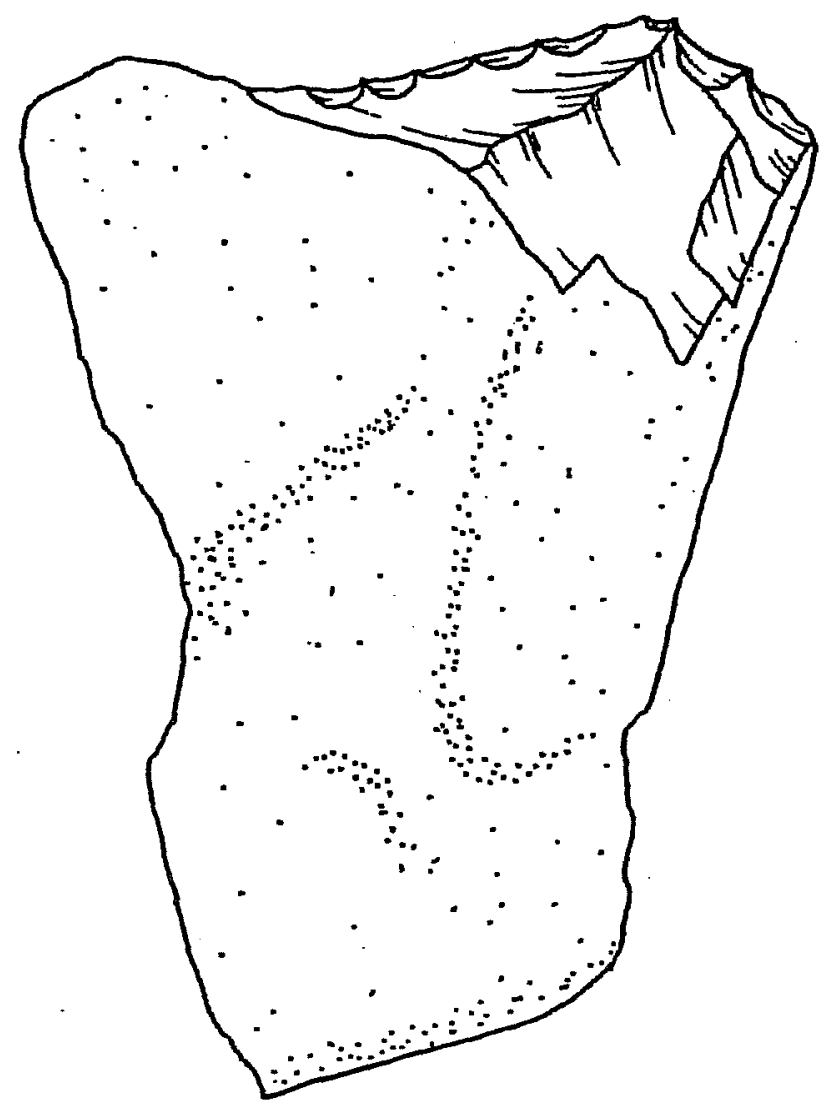

Figure 8.01. FN 645 Paleoindian Uniface from 41 BC 71 Test Pit 2, Level 38.

\subsection{Unilaterally Trimmed Unifaces, Medium Haft/Medium Bit ( $N=1)$}

FN 588-2 (see Figure 8.02) is a subtriangular specimen made from a core flake. One slightly beveled lateral edge has step and hinge fractures. Sometimes referred to as a side scraper, this tool is believed to have been used in hide, bone, and wood scraping, or plant processing.

\subsection{Unilaterally and End Trimmed Unifaces, Small Haft/Medium Bit ( $\mathrm{N}=2)$}

Specimen FN 560 exhibits lateral and distal flaking. The lateral edge is low edged and shows evidence of nibbling as well as stepping. It is probably a multipurpose tool. FN 537 has three distinct notches beside the bulbar end and the left lateral upper corner exhibits very fine nibbling and stepping.

\subsection{Bilaterally and End Trimmed Unifaces $(\mathrm{N}=7)$}

All of these specimens have been trimmed at the end opposite the platform of the flake and along both lateral edges. The shapes and sizes vary. 
TABLE 8.01. TOOL CATEGORY, FN, AND PROVENIENCE LIST OF UNIFACIAL TOOLS FROM 41 BC 71 AND 41 GL 21

\begin{tabular}{|c|c|c|c|c|}
\hline Category & FN & Level & Test Pit/Unit & Site \\
\hline 1.1 & $\overline{645}$ & 38 & 2 & $41 \mathrm{BC} 71$ \\
\hline 2.2 & 588 & -218 & 1 & $41 \mathrm{BC} 71$ \\
\hline 3.1 & 560 & 16 & 2 & $41 \quad \mathrm{BC} 71$ \\
\hline 3.1 & 537 & 10 & 3 & 41 BC 71 \\
\hline 4.1 & $454-2$ & 27 & 4 & 41 BC 71 \\
\hline 4.3 & 506 & 11 & 1 & $41 \mathrm{BC} 71$ \\
\hline 4.3 & 434 & 16 & 4 & 41 BC 71 \\
\hline 4.4 & 574 & 19 & 2 & 41 BC 71 \\
\hline 4.4 & $511-2$ & 12 & 1 & $41 \quad \mathrm{BC} \quad 71$ \\
\hline 4.5 & 467 & 36 & 4 & $41 \mathrm{BC} 71$ \\
\hline 4.5 & 966 & 3 & 6 & $41 \mathrm{BC} 71$ \\
\hline 5.0 & 505 & 7 & 3 & 41 BC 71 \\
\hline 6.0 & $451-2$ & 25 & 4 & $41 \mathrm{BC} 71$ \\
\hline 7.1 & 577 & 20 & 2 & $41 \quad \mathrm{BC} \quad 71$ \\
\hline 8.0 & $553-3$ & 16 & 1 & 41 BC 71 \\
\hline 8.0 & $524-2$ & 9 & 3 & $41 \mathrm{BC} 71$ \\
\hline 8.0 & 543 & 10 & 3 & 41 BC 71 \\
\hline 8.0 & $463-2$ & 33 & 4 & $41 \mathrm{BC} 71$ \\
\hline 8.0 & 532 & 11 & 2 & $41 \mathrm{BC} 71$ \\
\hline 8.0 & $1118-2$ & 13 & E931; N970 & 41 GL 21 \\
\hline 8.0 & $1040-4$ & 4 & E932; N971 & 41 GL 21 \\
\hline 8.0 & $1037-2$ & 2 & E932； N971 & 41 GL 21 \\
\hline
\end{tabular}

\subsection{Bilaterally and End Trimmed, Small Haft/Small to Medium Bit ( $N=1)$}

Specimen FN 454-2 (Figure 8.02) is a core flake tool. Opposite the platform end are a series of irregular notches and one small finely flaked graving tip. This protrusion exhibits bright polish and was possibly used on flesh or bone. A low edged right lateral area shows oblique flake scars and was possibly used as a cutting edge.

\subsection{Bilateral and End Trimmed Unifaces, Small Haft/Medium to Large Bit $(\mathrm{N}=2)$}

These crescent-shaped tools (Figure 8.03, FN 506, FN 434) with steeply beveled, concave edges and beaked points are quite distinctive. The concave edges exhibit relatively large step and hinge fractures; the convex edges are low angled and show microstep fractures. FN 506 is made from a fine gray chert and is a terminal end bit fragment. It is stratigraphically placed in the Early Archaic. FN 434 is complete except for the small missing tip. It is heat treated, slightly patinated, and also from the Early Archaic. These two specimens possibly functioned as composite tools, perhaps hafted and used for scraping activities. An intersite search of the tool assemblages revealed two similar tools. Jackson (1938:92) describes a dull, billed scraper, but fails to provide a drawing or photograph. 


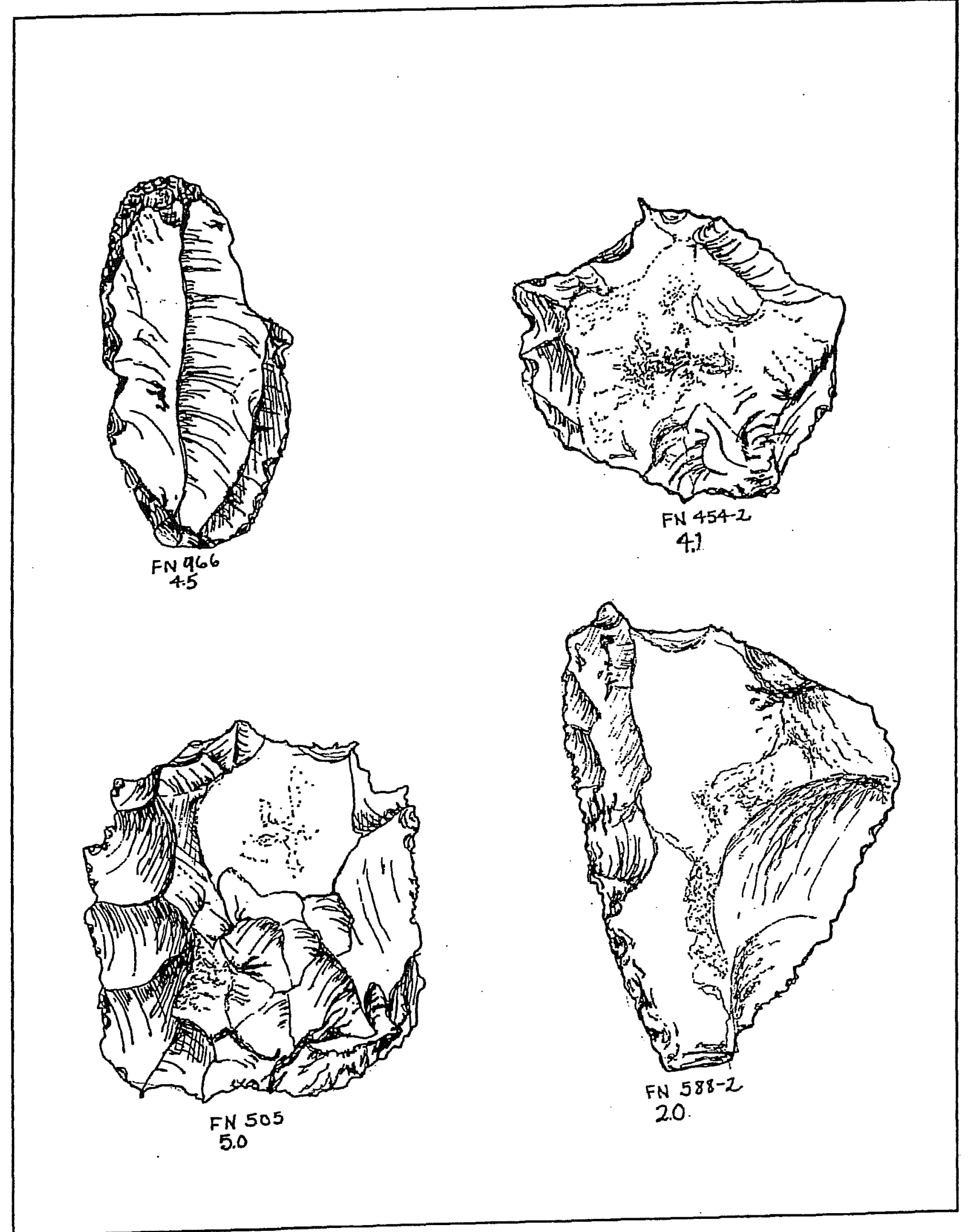

Figure 8.02. Unifaces. 

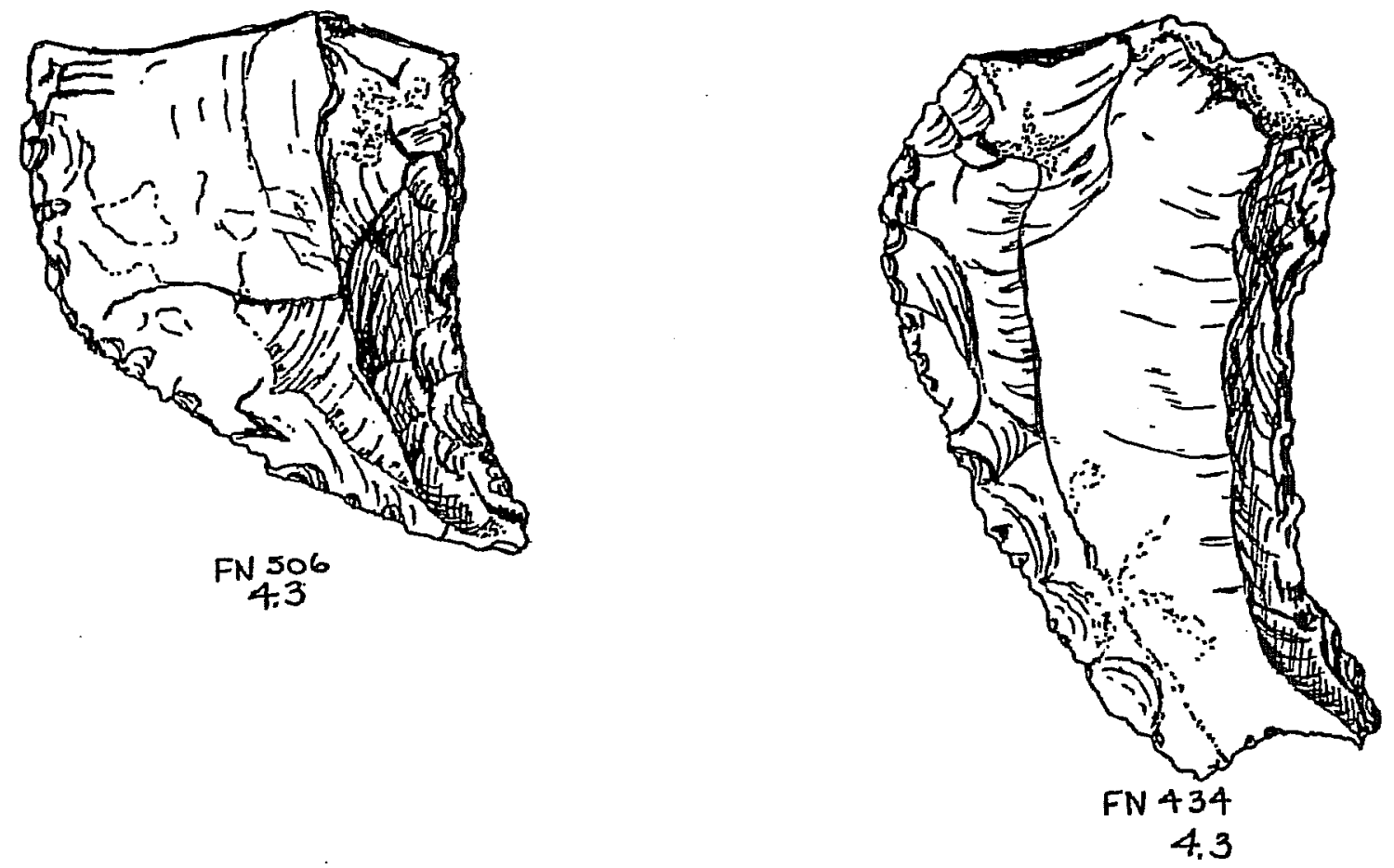

Figure 8.03. Bilaterally Trimmed Unifaces (Type 4.3). 


\subsection{Bilateral and End Trimmed Unifaces, Small Haft/Large Bit $(\mathrm{N}=2)$}

Specimen FN 574 is a modified flake with small beveled notches and nibbling along the right lateral edge. FN 511-2 (Figure 8.04) exhibits large hinge fracture scars along the steep left lateral edge. The preponderance of damage is found on the outer surface, indicating use as a scraper.
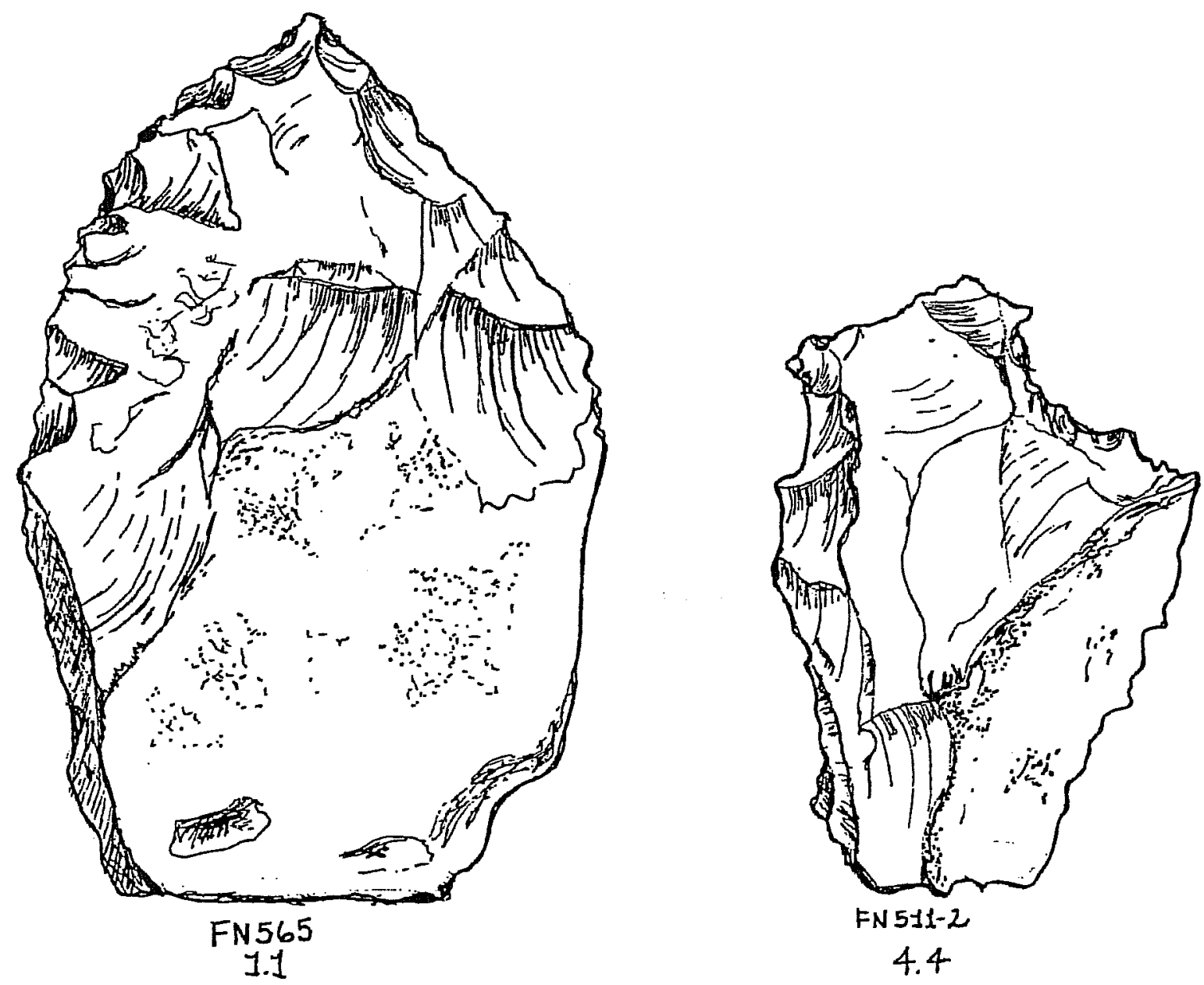

Figure 8.04. Bifaces.

4.5 Bilateral and End Trimmed Unifaces, Medium Haft/Medium to Large Bit $(\mathrm{N}=2)$

FN 966 (see Figure 8.02) is an example of a more "formal" tool type. It is commonly referred to as a blade end scraper. However, small step fractures are apparent on both the terminal end and the left lateral edge, which exhibited both polish and 
nibbling on the $35^{\circ}$ angle, strongly suggesting use on soft material. FN 467 shows heavy use on a lateral beveled edge opposite the platform.

\subsection{Circular Trimmed Uniface $(\mathrm{N}=1)$}

This fine grained dark gray chert specimen, FN 505 (see Figure 8.02), has a planoconvex cross section and highly beveled edges between irregularly scalloped ridges. It exhibits polish on both aspects, and nibbling and microstep fractures on both ends. Keeley (1980:24-63) found scalloping and rounding to be a wear attribute associated with animal butchering activities.

\subsection{Miscellaneous Trimmed Unifaces $(\mathrm{N}=1)$}

This small, stemmed flake, FN 451-2, exhibits polishing and nibbling on edges of various areas. It has a comparatively low edge-angle and was probably used for cutting soft material.

\subsection{Notched Trimmed Unifaces, Small to Medium Haft and Small Bit ( $N=1)$}

Specimen FN 577 is a distinctively pointed tool with heavy step fractures, polishing and nibbling on the high-angled left lateral edge. Notched pieces have been found to be associated with woodworking.

\subsection{Miscellaneous Incomplete Unifacial Fragments $(\mathrm{N}=5)$}

FN's 553-3, 463-2, and 524-2 are terminal, medial, and lateral flake fragments, respectively, and exhibit the traditional characteristics of end scrapers: high edge angle, polish, and nibbling concentrated on one aspect and tiny step fractures on the other. FN 543 is a platform end fragment with very little of the working edge remaining, but dulled at lateral points approximately opposite each other. It could have been hafted. FN 532 is a semicircular fragment with a peculiar jutting lateral area. It exhibits large step and hinge fractures on its rather dull edges. Of the three unifaces recovered from the Hop Hill site (41 GL 21), one, FN 1040-4, is a small, chunky proximal fragment with small step fractures ascending the outer aspect of both lateral edges. FN 1037-2 is complete and has a trimmed indentation on the platform end. Two projecting areas exhibit unifacial nibbling, indicating possible use as a scraper.

\section{BIFACE DESCRIPTIONS: MOCCASIN CONFLUENCE}

The biface collection was classified according to the Hop Hill criteria (Gunn and Ivey 1977), with only a few exceptions. Specimens are divided into groups according to proposed ideal forms or shapes determined by the steps a knapper takes to reach a predetermined tool type (Table 8.02). These ideal shapes are the square, the rectangle, and the triangle. Lithic material is assumed to be local unless otherwise noted. 
TABLE 8.02. TOOL CATEGORY, FN, AND PROVENIENCE LIST OF BIFACIAL TOOLS FROM 41 BC 71 AND 41 GL 21

\begin{tabular}{|c|c|c|c|c|}
\hline Category & FN & Leve1 & Test Pit/Unit & Site \\
\hline 1.1 & $40 \overline{6-2}$ & 5 & 4 & $41 \mathrm{BC} 71$ \\
\hline 1.1 & 565 & 16.5 & 2 & 41 BC 71 \\
\hline 2.0 & $420-2$ & 12 & 4 & $\begin{array}{lll}41 & \text { BC } 71 \\
\end{array}$ \\
\hline 4.0 & 246 & 6 & 2 & 41 BC 71 \\
\hline 4.0 & 343 & 8 & 1 & 41 BC 71 \\
\hline 4.0 & 667 & 39 & 2 & 41 BC 71 \\
\hline 4.0 & $422-2$ & 13 & 4 & 41 BC 71 \\
\hline 4.0 & $445-2$ & 20 & 4 & $41 \mathrm{BC} 71$ \\
\hline 4.1 & $467-2$ & 36 & 4 & $41 \mathrm{BC} \quad 71$ \\
\hline 5.1 & 618 & 21 & 3 & $41 \quad B C \quad 71$ \\
\hline 5.2 & $414-2$ & 9 & 4 & $41 \quad \mathrm{BC} \quad 71$ \\
\hline 5.2 & $447-2$ & 12 & 4 & 41 BC 71 \\
\hline 5.2 & $406-3$ & 5 & 4 & 41 BC 71 \\
\hline 5.2 & $597-3$ & 19 & 1 & 41 BC 71 \\
\hline 5.2 & 424 & 13 & 4 & 41 BC 71 \\
\hline 5.2 & $445-3$ & 20 & 4 & $41 \mathrm{BC} 71$ \\
\hline 6.1 & $597-5$ & 19 & 1 & $41 \quad \mathrm{BC} \quad 71$ \\
\hline 6.5 & 512 & 12 & 1 & $41 \mathrm{BC} 71$ \\
\hline 6.5 & 421 & 12 & 4 & 41 BC 71 \\
\hline 6.5 & 415 & 9 & 4 & 41 BC 71 \\
\hline 6.5 & 639 & 23 & 3 & 41 BC 71 \\
\hline 6.5 & 523 & 11 & 2 & 41 BC 71 \\
\hline 6.5 & $976-2$ & 9 & 6 & 41 BC 71 \\
\hline 6.5 & 426 & 14 & 4 & 41 BC 71 \\
\hline 6.5 & 624 & 25 & 1 & 41 BC 71 \\
\hline 6.5 & 423 & 13 & 4 & $41 \quad B C \quad 71$ \\
\hline 9.0 & $968-51$ & 4 & 6 & 41 BC 71 \\
\hline 10.1 & $563-3$ & 16.5 & 2 & $41 \quad B C \quad 71$ \\
\hline 10.1 & $429-2$ & 15 & 4 & 41 BC 71 \\
\hline 10.1 & $404-3$ & 4 & 4 & $41 \mathrm{BC} 71$ \\
\hline 10.1 & $503-4$ & 10 & 2 & $41 \mathrm{BC} 71$ \\
\hline 10.1 & $571-2$ & 18 & 2 & 41 BC 71 \\
\hline 10.1 & $411-2$ & 7 & 4 & 41 BC 71 \\
\hline 10.1 & $597-4$ & 19 & 1 & 41 BC 71 \\
\hline 10.1 & $553-2$ & 16 & 1 & 41 BC 71 \\
\hline 10.1 & 641 & 24 & 3 & 41 BC 71 \\
\hline 10.1 & $445-4$ & 20 & 4 & 41 BC 71 \\
\hline 10.1 & 533 & 12 & 2 & 41 BC 71 \\
\hline 10.2 & $458-2$ & 30 & 4 & 41 BC 71 \\
\hline 10.2 & $542-3$ & 13 & 2 & $41 \quad \mathrm{BC} 71$ \\
\hline 10.2 & $563-2$ & 16.5 & 2 & $41 \quad B C \quad 71$ \\
\hline 10.2 & $257-2$ & 18 & 1 & 41 BC 71 \\
\hline 10.3 & 582 & 22 & 2 & 41 BC 71 \\
\hline 10.3 & $500-3$ & 9 & 2 & 41 BC 71 \\
\hline 10.3 & $419-2$ & 11 & 4 & $41 \mathrm{BC} 71$ \\
\hline 10.3 & 410 & 6 & 4 & 41 BC 71 \\
\hline 10.4 & $585-2$ & 23 & 2 & 41 BC 71 \\
\hline 10.4 & $306-2$ & 7 & 2 & 41 BC 71 \\
\hline 10.4 & 428 & 14 & 4 & 41 ВС 71 \\
\hline 10.4 & $568-2$ & 17 & 1 & 41 BC 71 \\
\hline 10.4 & $306-209$ & 7 & 2 & $41 \mathrm{BC} 71$ \\
\hline
\end{tabular}


Table 8.02 (Continued)

\begin{tabular}{|c|c|c|c|c|}
\hline Category & $\underline{F N}$ & LeveI & Test Pit/Unit & Site \\
\hline 11.0 & 586 & 17 & 1 & 41 BC 71 \\
\hline 11.0 & 549 & 15 & 1 & 41 BC 71 \\
\hline 11.0 & 518 & 8 & 3 & 41 BC 71 \\
\hline 11.0 & $979-2$ & 10 & 6 & 41 BC 71 \\
\hline 11.0 & 340 & 8 & 2 & $41 \quad B C 71$ \\
\hline 11.0 & $605-2$ & 18 & 3 & 41 BC 71 \\
\hline 5.0 & $1037-4$ & 2 & E932; N971 & 41 GL 21 \\
\hline 5.0 & $1016-2$ & 3 & E932； N970 & 41 GL 21 \\
\hline 6.0 & $1058-1$ & 6 & E933; N970 & 41 GL 21 \\
\hline 7.1 & $1060-1$ & 8 & E933； N970 & 41 GL 21 \\
\hline 7.2 & $1072-4$ & 11 & E932; N970 & 41 GL 21 \\
\hline 8.1 & $1052-2$ & 3 & E933； N970 & 41 GL 21 \\
\hline 8.2 & $1043-2$ & 5 & E932； N971 & 41 GL 21 \\
\hline 10.1 & $1035-2$ & 1 & E932; N971 & 41 GL 21 \\
\hline 10.3 & $1007-3$ & 5 & E931; N970 & 41 GL 21 \\
\hline 10.3 & $1031-2$ & 7 & E932； N970 & 41 GL 21 \\
\hline 10.4 & $1037-3$ & 2 & E932； N971 & 41 GL 21 \\
\hline 10.4 & $1037-5$ & 2 & E932； N971 & 41 GL 21 \\
\hline 10.4 & $1074-1$ & 2 & E934； N970 & 41 GL 21 \\
\hline 10.4 & $1038-2$ & 3 & E932; N971 & 41 GL 21 \\
\hline 11.0 & $1069-2$ & 1 & E934； N970 & 41 GL 21 \\
\hline 11.0 & $1026-2$ & 5 & E932; N970 & 41 GL 21 \\
\hline
\end{tabular}

\subsection{Pointed Bifaces $(\mathrm{N}=2)$}

The bifaces in this category are trimmed to a beaked or rounded bit and untrimmed on the cortexed haft end. They are manufactured from small core cobbles, and the shape is irregularly triangular.

\subsection{Pointed Bifaces, Pick (N=2)}

The bit edges of this type are parallel, merging to a rounded point. The irregular flaked edges have widely spaced serrations. FN 565 (Figure 8.04), a tabular biface exhibits nibbling on the left lateral edge and light scalar stepping on the right. FN 406-2 is heavily stepped on both aspects at the bit end. Chopping on a fairly hard surface is indicated.

\subsection{End Biface $(\mathrm{N}=1)$}

This specimen, FN 420-2, was manufactured on a chert cobble. The base is narrow and has a cortex surface with the lateral edges expanding to a broad, crudely flaked bit. The edges are very sharp with no pattern of wear.

\subsection{Rectangular Bifaces ( $\mathrm{N}=5)$}

The members of this category are crudely flaked, irregular specimens that are greater than $1.5 \mathrm{~cm}$ in thickness. Four specimens have remnants of cortex, and one 
specimen with a concave base appears to have been a blank broken during manufacture.

\subsection{Rectangular Biface, Small $(\mathrm{N}=1)$}

FN 467-2 is a small thin specimen of coarse grained material, exhibiting mostly steep fractures on the edge, except for one small area of nibbling and polish on the left proximal corner. It is possible that this is a remnant of an edge that was lost in subsequent reduction. It was recovered in level 36 of Test Pit 4 suggesting it might be from the Paleoindian period.

\subsection{Round Bifaces $(\mathrm{N}=7)$}

These small bifaces are discoidal or subdiscoidal. All specimens exhibit crude, irregular flaking.

\subsection{Round Biface, Thin ( $\mathrm{N}=1)$}

The worked circumference of FN 518 is slightly beveled and irregularly notched. There is an area of cortex remaining on the slightly convex surface. Although the edge angle is relatively low (60R), there are indications of use on fairly hard surfaces. Nibbling is found on one of the bit corners, and scalar stepping is present on the edges bracketing the nibbling.

\subsection{Round Bifaces, Thick ( $N=6$ )}

All specimens are more than $1.5 \mathrm{~cm}$ in thickness, four specimens have cortex remnants, and one appears to have been heat treated. One specimen, FN 414-2, has a fairly low edge angle (50R) and exhibits a consistent pattern of polish and nibbling on all edges. FN 406-3 has the form of a flaked graver, i.e. a projecting pointed area, but there is no evidence of wear.

6.0 Oval Bifaces $(\mathrm{N}=10)$

The bifaces in this category are oval to suboval. On some of the specimens the haft and bit ends are indistinguishable. The group exhibits wide diversity in shape and flaking.

\subsection{Oval, Thick Biface ( $\mathrm{N}=1)$}

FN 597-5 is postulated to be a dart point preform, rejected as a result of technological difficulties. It is more than $1.5 \mathrm{~cm}$ in thickness, and has one thinner lateral side, and exhibits nibbling along the edge of that side. It was probably used in cutting activities on semisoft material.

6.5 Oval, Thin Bifaces (N=9) 
All specimens measure less than $1.5 \mathrm{~cm}$ in thickness and exhibit nibbling and small scalar stepping. One item, FN 426, has the characteristics of a point preform with a beveled lateral edge, and exhibits nibbling and minute step fractures on all edges. The largest, FN 423, has a form and thinness amenable to hafting, and the location of edge damage indicates that it may have been hafted. Four smaller bifaces are pointed, percussion flaked preforms with material flaws. The majority show evidence of use on a medium hard surface, i.e. scalar and nibbling. FN 976 has polish on its rather rounded tip.

9.0 Subtriangular Bifaces $(\mathrm{N}=1)$

FN 968-51 has a very uniform shape and a rather crudely beveled proximal end. Since damage was detected only on the lateral edges and tip (mostly nibbling and polish) it was possibly hafted.

10.0 Miscellaneous Fragments ( $\mathrm{N}=24)$

These biface fragments cannot be sorted into projected forms. They vary a great deal in size and workmanship.

\subsection{Miscellaneous Fragments, Tips ( $\mathrm{N}=11)$}

These fragments range from 8 to $25 \mathrm{~mm}$ in thickness; edge angles range only up to 50R. The predominant observed wear characteristic is nibbling, although those with lower edge angles (30-35R) exhibited obvious areas of polish. One bifacial perforator tip, possibly made from a broken projectile point, is finely pressure flaked. Only one lateral edge shows step fractures, the other is only slightly marred, and the tip exhibits no polish. Because of these characteristics, FN 533 was probably broken during manufacture.

\subsection{Miscellaneous Fragments, Medial (N=4)}

Specimens range from 7 to $28 \mathrm{~g}$; all four have edge angles of $50 \mathrm{R}$ or less and are characterized by the presence of polish and nibbling. All exhibit transverse or snap fractures.

\subsection{Miscellaneous Fragments, Haft $(\mathrm{N}=4)$}

Three specimens have edge angles of approximately 50R and exhibit nibbling and polish concentrated on the lateral edges. FN 410 is a fire-reddened drill base, broken in the middle of the neck. The lateral edges, however, measure at $40 \mathrm{R}$ and consistently show polish, even along the proximal edge.

\subsection{Miscellaneous Fragments $(\mathrm{N}=5)$}

The items in this group cannot be assigned to any of the above categories, but all are apparently what could be termed "lateral" fragments. They follow the previous pattern of low edge angle (60R or less), and polish and nibbling was observed. 


\subsection{Flake Core Tools $(\mathrm{N}=6)$}

Members of this category are large, thick core remnants with step and hinge fractures on the utilized edges, if any. They are commonly referred to as chopper tools, and are believed to have been used on hard contact surfaces. Some may simply be expended cores, however, since very few exhibit nibbling.

\section{BIFACE DESCRIPTIONS: HOP HILL}

There were 17 bifaces recovered from this site, subdivided into six categories. All are dated to the Late Archaic.

\subsection{Round Bifaces, Thin ( $\mathrm{N}=2)$}

These small bifaces, discoidal, or subdiscoidal in shape, exhibit crude irregular flaking. FN 1037-4 is of superior dark chert, with a suggested shoulder notch. Slight nibbling was noted on one lateral edge, and heavy scalar stepping on the haft edge. Damage is unifacial due to a transverse fracture. FN 1016-2 is pyramidal in extraplanar shape. Only stray flake scars mar its otherwise pristine edge.

\subsection{Oval Biface $(\mathrm{N}=1)$}

The single example of this category is actually suboval. There is a cortex remnant on the lateral edges, along with polish and nibbling, but the damage is intermittently spaced along the edges. Perhaps the specimen was too thick in relation to its size for further reduction.

\subsection{Ovoid Biface, Small Thinned ( $\mathrm{N}=1)$}

FN 1060-1 is 9 mm thick, fire-reddened, and potlidded, which makes wear observation difficult. There is a cortex remnant and it appears to have been in the latter stages of reduction before discarding.

\subsection{Ovoid Bifaces, Large, Thick $(\mathrm{N}=1)$}

FN 1072-4 exhibits one small area of scalar stepping on a protrusion at the distal end.

\subsection{Triangular Biface, Small $(\mathrm{N}=1)$}

FN 1052-2 is $7 \mathrm{~mm}$ thick, finely flaked and resembles an arrow point preform of the Late Prehistoric period. It exhibits polish and nibbling along one lateral edge, and the edge angle is 50R, indicating use in cutting activities.

8.2 Triangular Biface, Large $(\mathrm{N}=1)$ 
FN 1043-2 exhibits polish along one lateral edge. Due to its thinness (9 mm), it would be suitable for use in cutting activities, especially in semisoft material.

\subsection{Miscellaneous Fragments, Tip ( $\mathrm{N}=1)$}

FN 1035-2 appears to be a knife tip. It is beveled on both surfaces, with regularly serrated edges exhibiting mostly polish. Long beveled knives have been found in levels dated to the Late Prehistoric period at other sites, and are part of the Plains cultural tradition.

\subsection{Miscellaneous Fragments, Haft $(\mathrm{N}=2)$}

Two of the fragments have low edge angles and exhibit polishing and nibbling. The other exhibits only nibbling.

\subsection{Miscellaneous Fragments $(\mathrm{N}=4)$}

Three of these fragments are badly broken and are unclassifiable. FN 1038-2, however, is interesting because it has a badly damaged area, i.e. grossly rounded, but nibbled on this previously abraded edge.

\subsection{Core Flake Tools $(\mathrm{N}=2)$}

Both of these tools were manufactured from chert cobbles. FN 1026-2 exhibits a broad utilized bit with extensive notching. FN 1064-2 has a narrow cortexed proximal end and a broad thick flaked bit with step and hinge fractures.

\section{MORPHOLOGICAL INTERPRETATION (Mock)}

The morphological studies performed on the flint tools from the Archaic levels at Moccasin Confluence indicate the following interpretations. Weir's (1976) studies of central Texas sites characterized the San Geronimo phase (8000-4500 B.P.) as a warm period, with a broad based exploitative pattern. During the Early Archaic a broad technological inventory would have been essential to support the varied subsistence activities. Test Pits 1, 2, and 3 bear this out. In the middle of the Early Archaic levels are clusters of bifaces, (Table 8.03) unifacial tools such as scrapers and gravers, and an unusual crescent-shaped composite tool (see Figure 8.03, FN 506). This diversity points to varied activities and a diverse economy.

Clusters of tools in the Early Archaic levels correspond to fluctuations in the lithic debris concentrations. This suggests episodic occupations by small groups as part of a nomadic subsistence pattern. Their activities probably varied in intensity with Middle Holocene climatic conditions as discussed in chapter 5. 


\section{TABLE 8.03. FREQUENCIES OF UNIFACES AND BIFACES AT MOCCASIN CONFLUENCE IN TEST PITS 1-3 BY TEST PIT 2 LEVELS.}

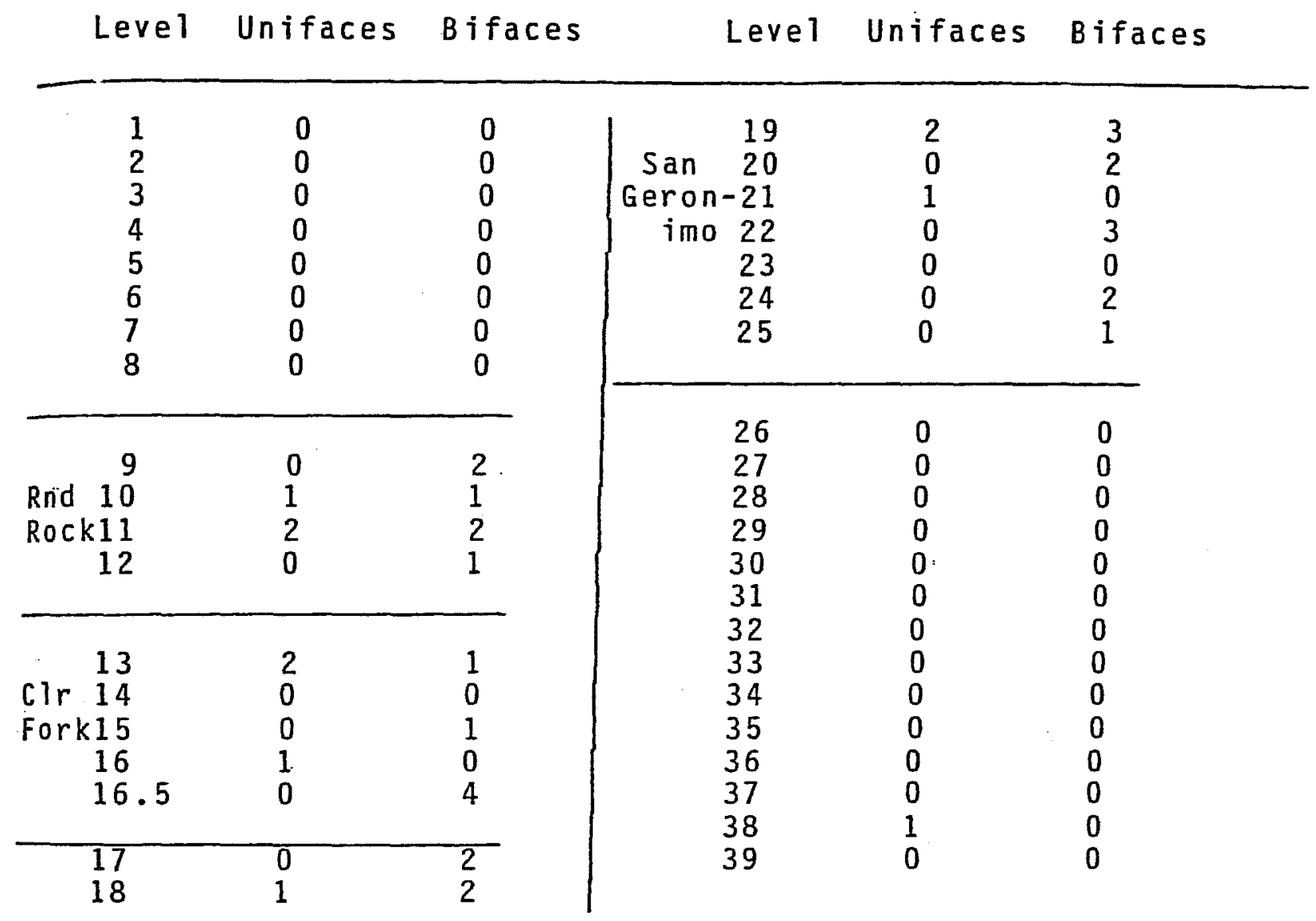

After 5000 B.P. the Clear Fork phase is characterized by more numerous, large sites, with a distinctly different artifact inventory. A more focal subsistence pattern (Weir 1976) is attributed to more abundant resources, rather than technological innovation, a hypothesis supported by the climatic analysis in chapter 5 .

In Test Pit 4, there is a dramatic increase in the number of bifaces for the Clear Fork levels. Three of the bifaces recovered from these levels appear to be manufacturing discards, given the breakage patterns. They appear to be what are commonly called "blanks." Lithic raw materials were close to the site, and reduction of these materials could have been a primary activity, although it most likely would have been in conjunction with food collecting.

Test Pits 1, 2, and 3 generally show a decline in the number of unifaces and bifaces for the Clear Fork levels (Table 8.03). This seems to correspond with the lithic debris concentrations, and perhaps indicates a change in site function within the overall subsistence pattern. 
The Round Rock phase (4200-2600 B.P.), corresponding to the Colorado Subpluvial, marks a change to a more mesic, warm environment for the region (see chapter 5). Weir (ibid.) suggests that this prompted a more focal subsistence pattern, as resources flourished. We would expect that under these conditions the tool assemblages would be less diverse and more specialized.

There are indications of change in the manufacture and use of tools. In Test Pit 4 there are fewer bifaces for the Round Rock levels, while Test Pits 1,2, and 3 show an increase in bifaces and unifaces from the previous phase. The change in the character of the artifact assemblage may be due to a change in site function in response to environmental changes or organizational restructuring. In general, there is a higher ratio of debris to tools in Test Pits 1, 2, and 3, possibly indicating an increase in tool manufacturing. Assuming that wood was a more prominent feature of the landscape during this mesic period, and that the wooden artifacts were an integral part of the cultural inventory, it follows that woodworking would appear as a more prominent feature of tool function. Woodworking dictates the use of sharp tools, and we would assume that the tools used in woodworking would exhibit extensive resharpening. There were a large number of tools exhibiting stepping found in the wear pattern studies, suggesting use on a hard surface, such as wood (see below).

The tool and debitage assemblage from Moccasin Confluence for the Archaic presents a picture of adaptation involving changes in tool use for resource exploitation, and also in the manufacture and maintenance of tools. There was a decreasing emphasis on tools and an increasing reliance on utilized flakes, "tools of convenience," for vegetable processing or butchering.

\section{CONCLUSIONS}

The morphological analysis of the tool assemblage from Test Pits 1, 2, 3, and 4 indicates a change in adaptation from the earlier phases through the later phases of the Archaic that correlates with changes in environment. The frequencies of tool types shifted within the site through time suggesting changes in site-specific activities. In general, style and form are the result of a "mental template" of a flint knapper, and also the response of the cultural and technological system to environment. As there are climatic shifts, there is a resulting impact on available resources. Such environmental stimulation will eventually influence the style and form of tools.

\section{USE-WEAR ANALYSIS OF BIFACES AND UNIFACES (Price)}

A functional analysis of bifacial and unifacial artifacts from Moccasin Confluence (41 $B C 71$ ) was undertaken to establish the types of activities predominant at the site 
through time. Both macroscopic and microscopic observations were made on working edges of the assemblage, based on the concepts and techniques suggested by Keeley (1980); Hayden and Kamminga (1979); and Ahler (1979). These included the analysis of wear patterns such as edge damage (nibbling, step and hinge fractures) as well as polish.

The actual recording of the observations can be complex. Short of literally counting fracture scars and designating the dominant form of damage on one or both aspects, observations can become almost arbitrary. This is a particular problem if the observer is inexperienced, or does not have the time for extensive replicative experiments. Following the recommendations of many researchers, considerable time was spent preparing and examining each specimen. Semenov (1973), for instance, advises close attention to details such as the orientation of striations, the cross sections of the utilized edges, and the extent of polish, even noting whether the polish is present in the hollows of fracture scars as well as on the ridges.

With regard to the interpretation of wear patterns, various attendees of the first Conference on Lithic Use-Wear, held in 1977, have pointed to several sources of edge damage other than "use" that could confound interpretation, e.g. manufacture, mechanical transport (downslope movement), eolian polish, excavation damage, and "bag" damage. There was even a report of debitage trampling by moccasined feet that produced modification remarkably similar to "established morphological categories." It was also noted that raw material was a factor in edge damage resulting from use, and that high magnification equipment is not uniformly available to all researchers.

These factors are particularly important when attempting to distinguish grades of wear polish, the occurrence of which has been related to use on such disparate contact materials as wood, bone, meat, and hide. Keeley (1980) pointed out that differences in illumination with microscopes can create "serious observation differences."

In view of these admitted difficulties in microscopic data collection and interpretation, several researchers have proposed that other morphological attributes of lithic tools may be more "objective" and more readily obtainable to complement and supplement the microscopic observations. Edge angle, for example, has been included in various schemes of functional analysis (Wilmsen 1968; Odell 1979) and has been shown to be an important factor in distinguishing motions required for certain tasks (e.g., cutting and scraping Keeley 1980). Weight of the artifact was found to be a useful diagnostic attribute in the work of Cantwell (1979) on the settlement system of the midwest Havana tradition. It was found that there was a significant difference in weight between two groups of scrapers divided into categories on the basis of wear pattern alone. Thickness, too, would logically be a factor in determining use, especially in such activities as chopping and adzing, and has been recorded as an integral attribute (albeit not a determining one) in an analysis of hardwood scrapers by Hester et al. (1973). These three variables, then- 
edge angle, weight, and thickness-will be related to types of edge damage in an attempt to establish values of what Cantwell (1979) has called "diagnostic criteria" for this collection.

\section{The Sample}

The sample consisted of 40 unifaces and bifaces selected from those documented above. Selection of the sample was based on the relative "completeness" of the artifacts. Each artifact was placed flat side down and the most pointed side toward the top of the page on a grid of eight equally spaced radii, and a measure of edge angle, as well as observations of wear, were made for each edge segment bounded by two radii. Measures for weight $(\mathrm{g})$ and thickness $(\mathrm{mm})$ were also recorded, and each edge segment was examined with a stereoscopic microscope for evidence of microwear (Table 8.04).

\section{Wear}

Observations were recorded for each edge segment as to the presence of, or absence of, polish, nibbling, or stepping. Stepping was observed as large and invasive step and hinge fractures. These three wear characteristics were taken to indicate use on progressively harder materials: polish for use on succulents or other vegetable matter; nibbling for use on medium-hard materials, such as soft woods, bone, or antler; and stepping for use on hardwoods, or activities requiring greater force. Table 8.05 shows the relative frequency of their occurrence: on artifacts from the various chronological periods. With two exceptions, the pattern remains basically the same through all periods. Stepping is infrequent except in the Middle Archaic, where it represents $64 \%$ of the total observations. The Paleoindian period is notable for lowest incidence of stepping, only $21 \%$.

\section{TABLE 8.05. PERCENTAGE OF WEAR BY PERIOD}

\begin{tabular}{lcccc} 
& Paleo- & Early & Middle & Late \\
& Indian & Archaic & Archaic & $\begin{array}{c}\text { Archaic } \\
\text { Polish }\end{array}$ \\
\cline { 2 - 5 } Nibbling & 24 & 18 & 13 & 18 \\
Stepping & $55^{*}$ & 47 & $* 23$ & $45^{*}$ \\
Number of Tools & 29 & 146 & $64 *$ & 27 \\
\hline
\end{tabular}


TABLE 8.04. TOTALS BY LEVEL OF UNIFACES AND BIFACES AT MOCCASIN CONFLUENCE IN TEST PITS 1-3 USING TEST PIT 2 LEVELS

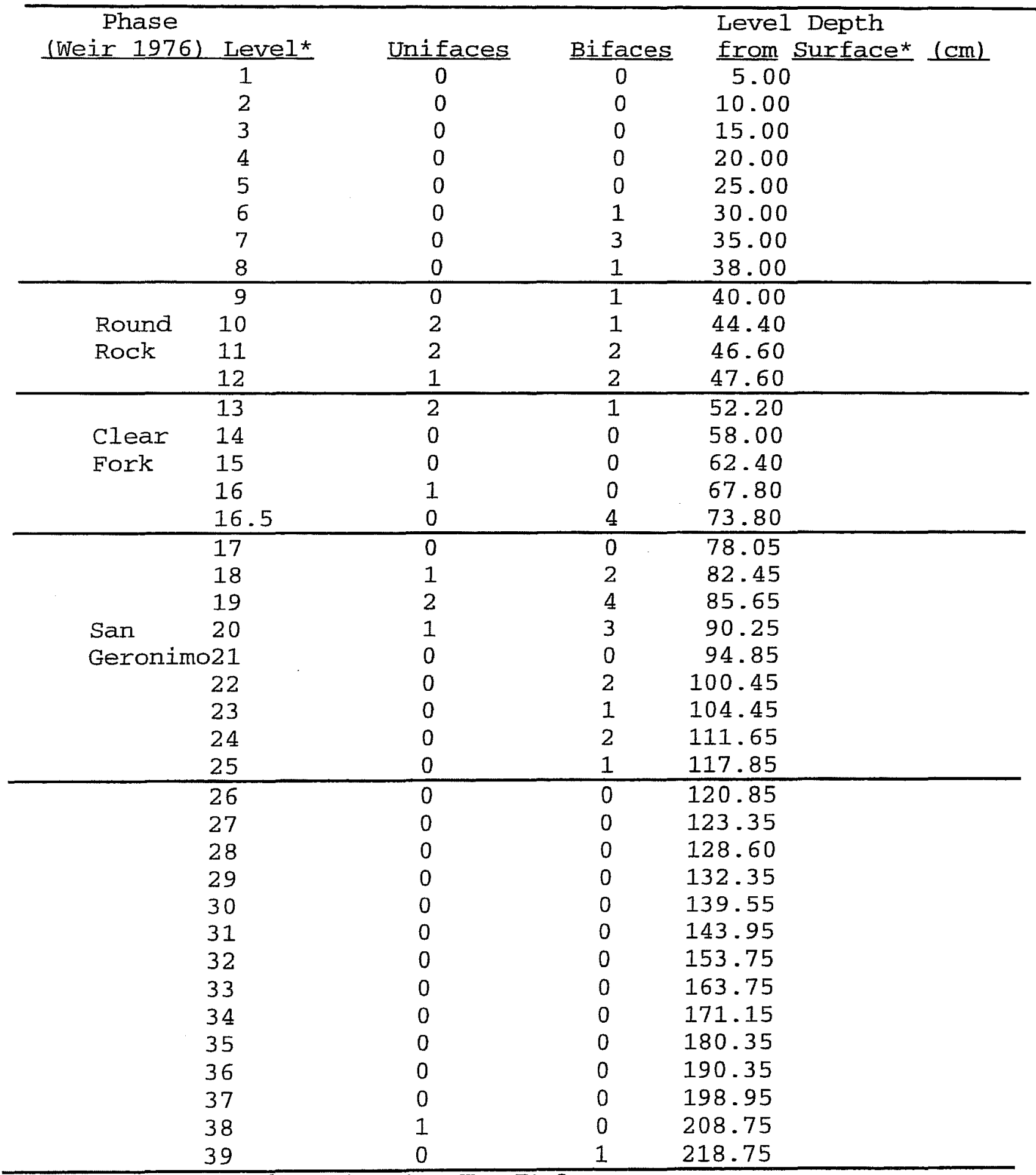

${ }^{\star}$ Levels and level depths are based on Test Pit 2.

The climate during the Middle Archaic has been characterized as predominately warm and moist (Gunn, Sims, La Rocca, Chapter 5) and would have contributed to 
the propagation of a woodland type of environment in the central Texas region. The high proportion of stepping may reflect increased exploitation of woodland resources. The ratios of the other periods probably represent a successful economic strategy that persisted among the inhabitants of the site during less moist intervals.

\section{Weight}

The mean weight of the entire sample was determined to be $86.2 \mathrm{~g}$ (standard deviation 73.6, range 279). When weight was tested between the three types of edge wear with a two-tailed t-test, no significant difference was found between the means of wear categories. These results could be explained by the rather disparate nature of the collection, as indicated by the wide standard deviation. There is a slight tendency for weight of stepped pieces to be heavier that reinforces the use hypothesis. The fact that differences in thickness are significant (see below) must be taken as an indicator of which variable is important to heavy use.

\section{Thickness}

Calculation of the mean for the 40 measurements of thickness gave a value of 18.32 $\mathrm{mm}$. The standard deviation was 8 , and the range 35 . The mean for the occurrence of polish was $15.6 \mathrm{~mm}$; that of nibbling, $15.8 \mathrm{~mm}$; and stepping $18.7 \mathrm{~mm}$. A significant $t$-test indicated a difference between the mean thickness of artifacts with stepping, and those with polish and nibbling. The mean thickness for artifacts with polish and nibbling were almost identical. It would seem that thickness is not a discriminating variable for activities where force is not a factor. The significant association of thickness with stepping, however, adds a meaningful dimension to the Middle Archaic, apparently woodland assemblage.

\section{Edge Angle}

Measurements for edge angle were taken in all eight segments of each artifact with a contact goniometer. The mean value for all the observations was $66.5^{\circ}$ (standard deviation 11.3); and the values range from $40^{\circ}$ to over $90^{\circ}$. A t- test on the edge angles between polish and nibbling was not significant. However, tests for differences between the mean edge angle on artifacts with polish and that of stepping, and the mean of those with nibbling and that of stepping were significant at the .005 level. These results, along with those for the other variables, indicate that, statistically, weight, thickness and edge angle can not be used to discriminate between activities resulting solely in polish and nibbling.

If, however, the values for polishing and nibbling are pooled and compared with the values associated with stepping, significant levels are found for thickness (.01) and edge angle (.001). The combination of polish and nibbling into one category was suggested by Keeley's. (1980) report of wear damage resulting from experimental 
replication. Thin, low edge angled scrapers exhibited polish and microscopic fracture scars; thicker, high edge angled scrapers exhibited polish and large, shallow fracture scars.

The test for differences between means for weight did not reach the criterion value. It does not seem to be a diagnostic attribute, at least not for this sample.

It is interesting to note that with regard to edge angle, the mean for stepping $\left(71.9^{\circ}\right)$ is close to those found by Cantwell (1979) in the analysis of the hardwood "Havana" scrapers $\left(70.7^{\circ}\right)$ and by Hayden and Kamminga (1979) in their report on Australian woodworking tools $\left(70.0^{\circ}\right)$.

It is worth noting that weight, thickness, and edge angle show a clear progression toward better discrimination of use, which is in accord with the original hypothesis of the study. The failure of weight to perform as an indicator is probably due to its indiscriminate characterization of the whole mass of the artifact. As can be seen in Figure 8.05A thickness discriminates only stepping. Edge angle, on the other hand, shows three distinct frequency peaks for each type of use-wear (Figure 8.05B). This suggests a two-staged blank production process for various intended uses. In the first stage a blank of appropriate thickness was prepared. In the second stage the edge angle was adjusted to the prospective use.

We propose, then, that these results support the idea that the morphological characteristics of thickness and edge angle can be used as supplementary indicators of tool function along with use-wear on contact surfaces. In conjunction with other data concerning available resources, these characteristics could help determine use. Furthermore, the frequency signature, the distributions of the thickness and edge angle attributes against types of use, can be used as ecological indicators and probably produce information on the cultural origins of groups on a given occupation level.

\section{CONCLUSIONS (Price, Gunn)}

It is proposed that the Archaic cultural system existed in a homeostatic balance with its environment, in spite of structural and functional changes brought about by climatic shifts. Foods being exploited changed through time, but within a marginal, or optimal, environment food was available. In our tool analysis studies the importance of hunting must not be overemphasized. Plant food sources certainly were an integral and even more reliable part of the prehistoric peoples diet. 

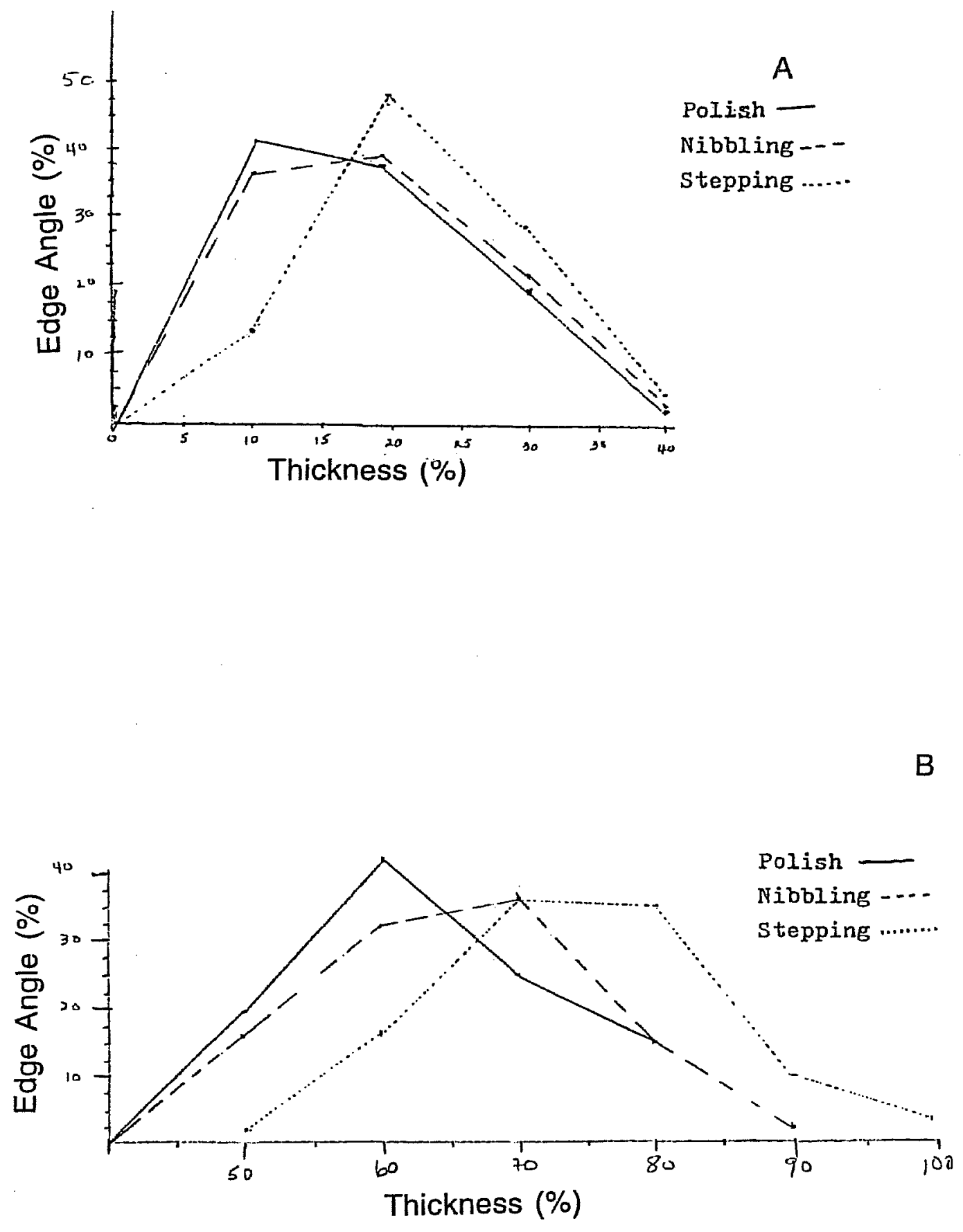

Figure 8.05. Edge Wear and Other Attributes: A. Percentage Frequencies for Thickness Measurements for Observed Polish ( $n=43)$, Nibbling ( $n=101)$, and Stepping $(n=84)$, B. Percentage Frequencies for Edge Angle for Polish $(n=28)$, Nibbling $(\mathrm{n}=99)$, and Stepping $(\mathrm{n}=84)$. 
A comparative study of other sites and assemblages in this area of Texas indicated reoccurring patterns in tool assemblages and proposed site attributes. However, the reports on the Enchanted Rock area (Assad and Potter 1979) and the Fall Creek site (Jackson 1938) were mainly surface survey reports. The evidence from test pits at 41 BC 71 and 41 GL 21 are promising and more extensive excavations could ultimately contribute much to our understanding of environmental change, and its impact on culture in central Texas. 


\section{CHAPTER 9-FLAKE MORPHOLOGY AND CULTURE CHANGE (Gunn, Probst, Syverson)}

This chapter reports on the study of culture change as evidenced by lithic technology, specifically through the analysis of platformed flakes, at Moccasin Confluence. Unlike points and tools, flakes are found in all levels and, therefore, provide a continuous, high resolution monitor of cultural change.

\section{OBSERVATIONS AND METHODOLOGY}

Platformed flakes were targeted for study because they contain the most diagnostic attributes of the various technological modes and accurately represent the amount of lithic-related activity at the site. Platformed flakes are, literally, a "blow-by-blow" description of a site's lithic history. The number of broken or "shattered" pieces has a random component that depends on the number of fragments into which a flake breaks. The total amounts of lithic debris including shatter ("chips") are discussed in Kerr (chapter 6).

The flakes came from the levels of Test Pits 2, 4, and 6. Each level had an assigned field number (FN). Flakes were washed and sorted into platformed and nonplatformed classes. Platformed flakes were measured and observed on 32 variables. The information recorded from each flake was then keyed into computer readable format. The results were evaluated, and the information obtained is the subject of this report.

Test Pit 6 contained 385 flakes from 12 levels. All platformed flakes from the test pit were processed. In Test Pit 2, 564 flakes were sampled from levels 1 through 39. If less than 50 flakes were recovered from a level, all were processed. If more than 50 flakes were recovered, they were sequenced from largest to smallest and a random sample of 50 flakes was drawn by reference to a table of random numbers. Two-hundred flakes were processed from the lower levels (19-41) of Test Pit 4, the Paleoindian and the early half of the Early Archaic period. All of the levels contained less than 50 flakes.

Figure 9.01a shows the flake manufacturing process and describes the flake terminology used in this report (Gunn and Mahula 1977b; Gunn 1982d). Figure 9.01b illustrates the morphological characteristics of a platformed flake. Each of these components must be recognized before a flake can be evaluated. 


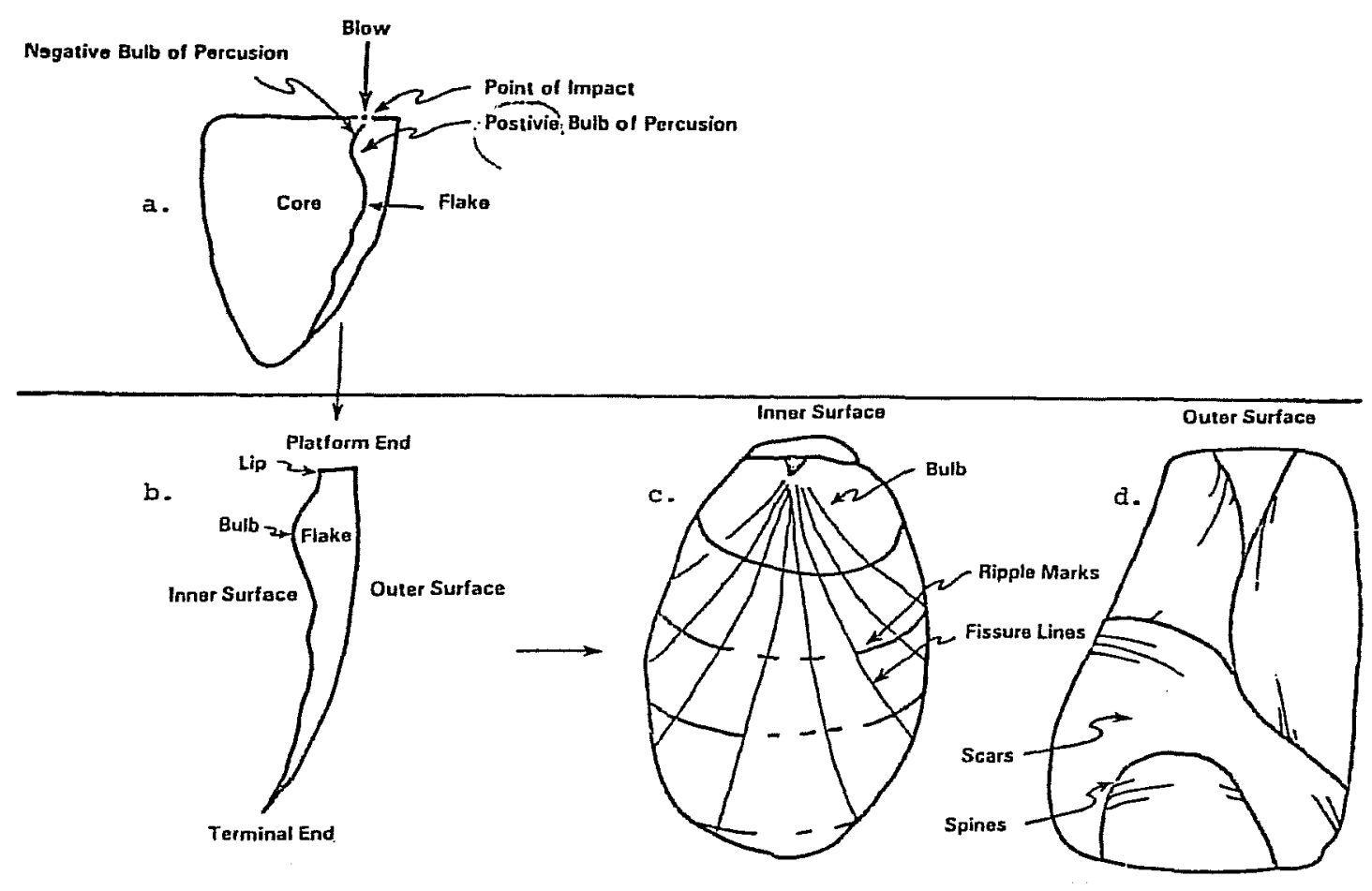

\section{Figure 9.01. Flake Terminology.}

Fifteen participants in the anthropology laboratory course (ANT 4403), at UTSA in the fall of 1982, assisted in the analysis. Each was assigned a coder number. These numbers were recorded on each form as the individual completed the 32 observations and measurements. Test and reviews were conducted by the instructor and lab supervisor to reduce reporting error.

The individual characteristics of each flake were recorded on a flake technology/morphology form (Figure 9.02). The variables of each flake were recorded in the following manner:

1. Time-time at which the observations began.

2. FN-permanent field specimen number assigned by level. This number along with the artifact sequence number and site number, $41 \mathrm{BC} 71$, was inked onto each flake.

3. Sequence Number-a unique number assigned to each flake within a level. 


\section{LBJ PARL PROJECT}

Flake Technology/Morphology-JG-60CT 2

Zero=missing data, Blank=not observed

$$
\text { in } a
$$

$1=$ Elake $2=$ blade $3=$ bif Lo $4=b$ if $W i$

$1=$ translucent $2=e d g e$ trans. $3=$ opaque

$1=\tan 2=$ grey $3=$ white $4=$ black $5=$ red $6=y e l l o w$

$1=a b s e n t \quad 2=p r e s e n t$

$1=1$ ight $2=$ medium $3=$ dark $4=v e r y$ dark

$1=v e r y$ fine $2=$ fine $3=$ medium $4=$ coarse

$1=$ none $2=s l i g h t ~ 3=p r o m i n e n t$

$1=f l a t, 2=$ triangular

1 =none 2 =facet $3=$ ground $4=$ hvy ground

$1=$ flaked $2=b i$ tpat $3=1 / 2$ pat $4=$ pat $5=b$ itcort

$6=1 / 2 \operatorname{cort} 7=$ cortex

$1=$ feathered 2 =hinged $3=$ runoff $4=f l a t \quad 5$ outhang

$7=$ outdent $8=$ indent $9=$ truncation

$1=$ none $2=n i b b l e d \quad 3=$ scalled $4=$ stepped $5=$ notched

$1=$ none $2=$ reddened $3=$ potlided 4 =crazed

\section{$\mathrm{mm}$ \\ $\mathrm{mm}$ \\ $\mathrm{mm}$ \\ $\mathrm{mm}$ \\ $.1 \mathrm{~mm}$ \\ - $1 \mathrm{~mm}$ \\ $.1 \mathrm{~mm}$ \\ $.1 \mathrm{~mm}$ \\ - Igrams \\ $\log \mathrm{mm}$}

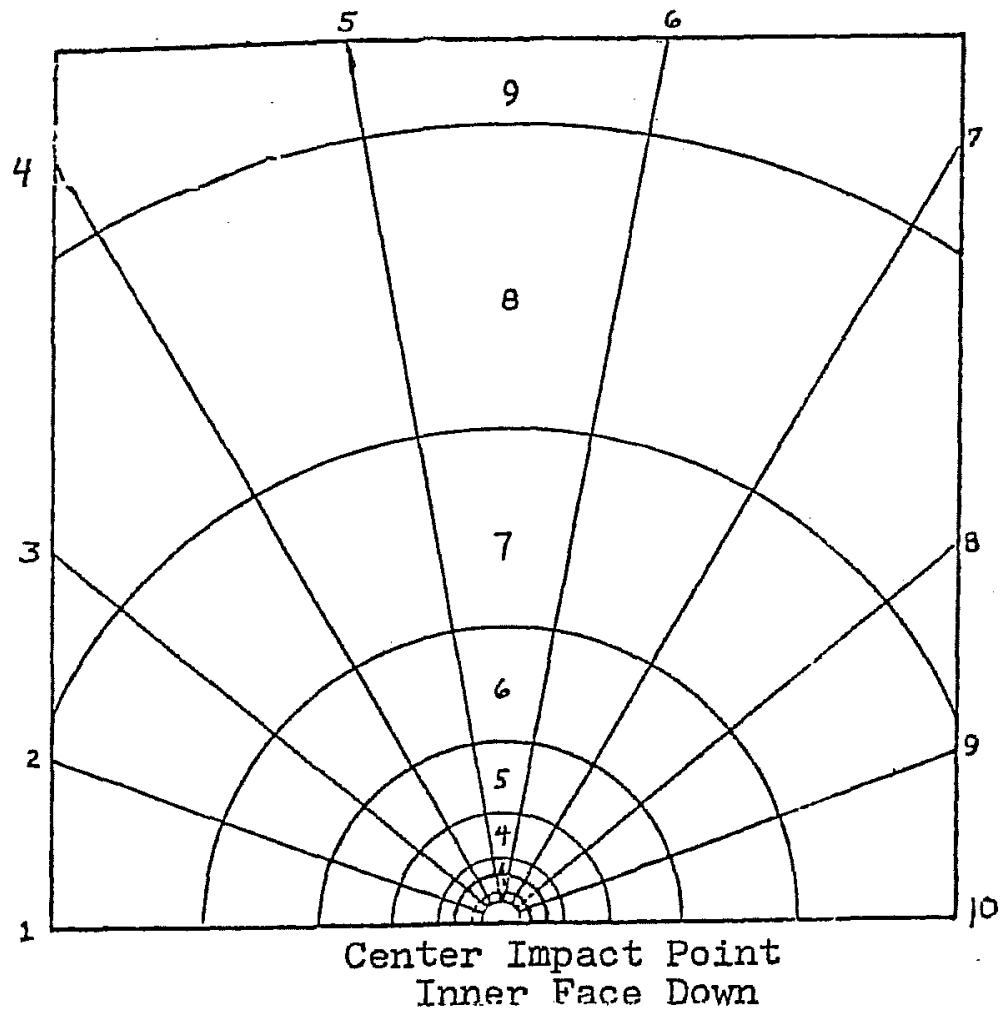

Platform Shape

$$
\text { Time }
$$

EN\#

Sequence \#

Technotype

Translucence

$7=$ brown

Colar

Mottling

Value

Grain

Platform Preper

Outer Surface

$6=$ inhang

Termination

Altered

Eired

Length

width

Platform Width

tform Thickness

Bulbar Thickness

Length Thickness

Width Thickness

Terminal Thick Weight

Ist Ray

2nd Ray

3 rd Ray

4 th Ray

5th Ray

6 th Ray

7th Ray

8th Ray

9th Ray

10th Ray

Test pit

Depth

Level

Coder

Inspector

Time

DISK $=U \bar{N} I \bar{V} ;-L \overline{I T H} . F R$

Figure 9.02. 
4. Technotype-The technological mode by which flakes are removed from the parent material; 1 =flake, $2=$ blade, $3=$ biface long, $4=$ biface wide.

5. Translucence-A variable representing the light transmitting characteristic of the material; 1 =translucent, $2=$ =dge translucent, $3=$ opaque

6. Color-A rating of the color of the material; $1=\tan , 2=$ gray, $3=$ white, $4=$ black, $5=$ red, $6=$ yellow, $7=$ brown.

7. Mottling-Significant color variation in the material; $1=a b s e n t, 2=$ present.

8. Value-A rating of four states intended to measure the gray scale of the material; $1=$ light, $2=$ medium, $3=$ dark, $4=$ very dark.

9. Grain-A rating of the material texture; $1=$ =very fine, $2=$ fine, $3=$ medium, $4=$ coarse.

10. Lip-A rating describing the character of the lip on the inner edge of the platform; $1=$ none, $2=$ slight, $3=$ prominent.

11. Platform shape-A variable describing the profile of the platform (Figure 9.03c); $1=$ flat, $2=$ triangular.

12. Platform Preparation-The extent and kind of special modification used to prepare the platform for further work; 1=none, 2=faceted, 3=ground, 4=heavy ground. (Faceting indicates a retouching of the platform in order to alter the shape. Grinding is accomplished by rubbing a coarse grained rock across the platform. A ground platform is usually detected by drawing a fingernail across the platform. If the fingernail is shaved, or catches, no grinding has been done.)

13. Outer Surface-A description of the outer surface of the flake; $1=$ flaked, $2=$ bit patinated, $3=1 / 2$ patinated, $4=$ patinated, $5=$ bit cortex, $6=1 / 2$ cortex, $7=$ cortex. (Outer surface shows primary, secondary, or tertiary nature of the flake.)

14. Termination-A description of the terminal end of the flake; $1=$ feathered, $2=$ hinged, 3 =runoff, $4=$ flat, $5=$ outhang, 6 =inhang, 7 =outdent, 8 =indent, $9=$ truncation. (Figure 9.04d illustrates the various terminations.)

15. Altered-The presence or absence of alteration or retouching; 1-none, $2=$ nibbled, $3=$ scaled, $4=$ stepped, $5=$ notched.

16. Fired-A rating of the degree of heat alteration; 1=none, 2=reddening, $3=$ potlidded, $4=$ crazed.

17. Length-A measurement taken perpendicular to the platform (mm).

18. Width-A measurement taken parallel to the platform ( $\mathrm{mm}$ ). 

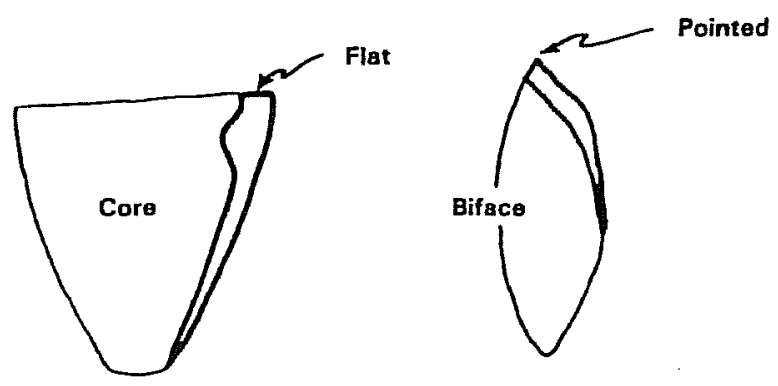

\section{Platform Profile}

Figure 9.03. Platform Shapes.

19. Platform Width-A measurement taken across the platform, parallel to width $(\mathrm{mm})$.

20. Platform Thickness-A measurement taken from the lip to the outer edge of the platform (mm).

21. Bulbar Thickness-A measurement taken from the most salient point on the bulb of percussion to the outer surface $(.1 \mathrm{~mm})$.

22. Length Thickness-A measure taken with the assistance of vernier calipers, by allowing the platform and terminal ends to touch one arm, and the highest point on the outer surface to touch the other $(.1 \mathrm{~mm})$.

23. Width Thickness-A measurement made approximately halfway down and perpendicular to the length $(.1 \mathrm{~mm})$.

24. Terminal Thickness-A measurement taken at the terminal end of the flake (.1 $\mathrm{mm}$ ). 


\title{
TERMINATIONS
}

\author{
a. HISGED
}

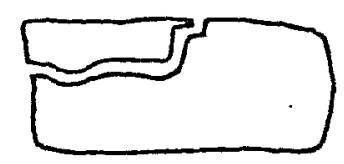

b. FEATHERED

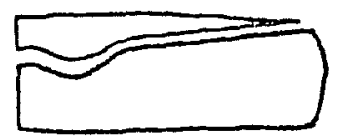

c. RUNOFF

\section{BREAKS}
a. $F[A T$
e. OUTDENT
f. OUTHANG
g. INDENT
h. IPMANG
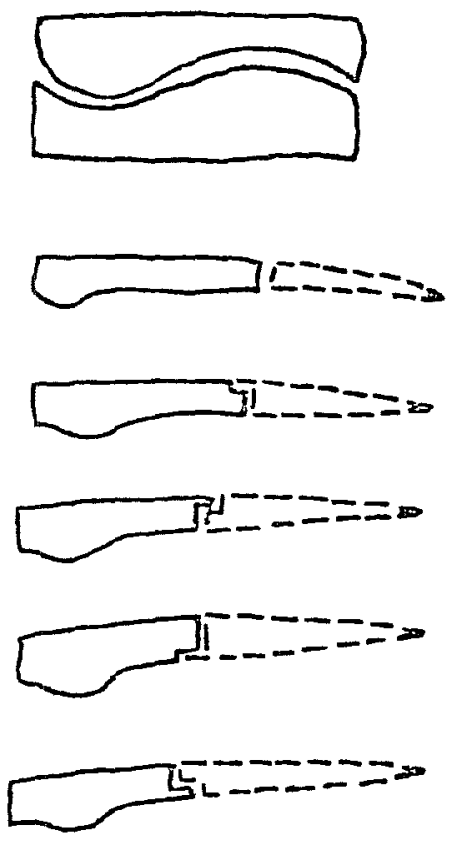

Figure 9.04. Flake Terminations. 
25. Weight-A measurement of the weight of a flake on a balance scale $(0.1 \mathrm{~g})$.

26. First to Tenth Ray Length-A system of 10 polar coordinates designed to represent the shape of the flake. The point of impact at the platform end of the flake is centered at the origin, inner face down, while a pencil line is drawn around the flake. Measurements (log scale) are taken on the 10 rays.

27. Test Pit-Identifies by number the test pit from which the material was recovered.

28. Depth-The depth, in centimeters, of the unit/level from which the artifact was recovered.

29. Level-A sequential listing of the excavated levels from top to bottom.

30. Coder-A unique number assigned to an individual coder.

31. Inspector-The number of the lab supervisor/instructor who has received and confirmed the recorded information.

32. Time-Time at which flake observations were completed.

As each level was completed, the sheets for all flakes in that level were entered into a computer. A principal components analysis was calculated for interval variables and contingency tables for the nominal variables.

\section{ANALYSIS}

Three trends were identified in the data by correlating variables with level numbers:

1. Technology versus Level-the change in flake type and manufacturing suggest shifts through time.

2. Size versus Level-the width of flakes changed through time.

3. Quality of Material versus Level-Grain and translucence changed through time.

The remainder of this report will deal with these three trends, paying particular attention to variation during the Archaic period. The information gathered from. Test Pit 6, located on the sandy knoll above the confluence, will be examined first. The sediments on the sandy knoll were temporally limited to the Middle and Late Archaic, based on point typology. Test Pit 6 is of interest because it records a transition from Middle to Late Archaic that involved several dimensions of material and technique. It shows that flake morphology is a valuable adjunct to diagnostics as an indicator of cultural change. There was a negligible amount of 
material in levels 1 and 2, so they were combined with level 3. Level 12 was added to level 11 for the same reason.

The overall trends in the Test Pit 6 assemblage (Table 9.01) are as follows.

Components I and VI pertain to the size and material of the flakes.

Component I represents the general size of flakes. Only translucence of the material shows any relationship to size. Larger flakes are sometimes made of more opaque materials. Opaqueness is frequently associated with poorer quality materials, with coarse grain, because opaqueness is caused by nonsiliceous inclusions such as clay, carbonates, etc. This is an almost normal observation in flake assemblages. Larger flakes and decortication flakes, in particular, are usually of coarse grain.

Component VI is concerned with material. More opaque and grainy material occurs in the older, Middle Archaic, levels. Finer grained and more translucent material is in the Late Archaic. If we assume Binford's (1978, 1980) logistical model as an explanation for material quality, this pattern conforms with the semisedentary to nomadic transition thought to have occurred in the Middle to Late Archaic. The more mobile Late Archaic bison hunters would have had more access to high quality material because of greater mobility and access to more chert resources.

Components III-V pertain to core and bifacing technology.

Component II has a loading greater than 0.4 for the variable Level and is therefore related to time. Rays 3-6 (flake length) of the polar coordinate grid appear on the component. There is a tendency for flakes to be longer in the older levels, as well as exhibiting heavy grinding on the platform. It suggests that Middle Archaic bifacing technology tended to produce longer flakes, probably a product of attempts at biface thinning, which requires that flakes proceed past the halfway line from both sides in order to thin the middle of the biface. A higher degree of platform preparation (heavy grinding) would be expected on such bifacing flakes.

Components III and IV evolve around the lipping on flakes, a phenomenon normally associated with bifacing. Component III shows that lipping on the platform is related to the platform width of the flakes, Rays 1-2 and 10. An inverse relationship to weight indicates that flakes with wider platforms and prominent lips are lighter, i.e., very thin. While unlipped flakes have narrow platforms and tend to be heavier, i.e., core flakes.

Taken together, Components II and III represent two modes of biface production. One is thinning as discussed in Component II which produces long narrow flakes. The other, Component III, is not so well defined in the literature but is readily observable in assemblages of bifacing flakes. The process involves short wide flakes that transcend a ridge near the edge of the biface. A beveled edge is characteristic of such a flake but could be produced in a number of other operations. The principal 
components analysis demonstrates that they are two statistically independent and definable processes in the assemblage.

TABLE 9.01. UNROTATED PRINCIPAL COMPONENTS ANALYSIS OF TEST PIT 6 FLAKE MORPHOLOGY

\begin{tabular}{|c|c|c|c|c|c|c|}
\hline Components & $I$ & II & III & IV & $\overline{\mathrm{V}}$ & $\overline{V I}$ \\
\hline \multicolumn{7}{|l|}{ Variables } \\
\hline Level & .2 & $.5 *$ & .3 & .0 & -.0 & $.4 *$ \\
\hline Translucence & $.4^{\star}$ & -.3 & .1 & -.1 & -.3 & $.5 *$ \\
\hline Value & -.3 & -.3 & .1 & -.1 & .1 & .2 \\
\hline Grain & .3 & -.0 & .2 & -.2 & -.2 & $.7 *$ \\
\hline Lip & .1 & .2 & $.4^{*}$ & $.4^{*}$ & .3 & .1 \\
\hline Platform Shape & -.2 & -.3 & .2 & .3 & $.4 *$ & .2 \\
\hline Platform Preparatio & 1.0 & $.4^{*}$ & .1 & .2 & $.5 *$ & .1 \\
\hline Use Alteration & .2 & .2 & -.3 & -.2 & .1 & $\overline{-.2}$ \\
\hline Fire Alteration & -.0 & .0 & .1 & -.1 & $.5 *$ & .3 \\
\hline Length & $.8 *$ & .2 & -.3 & .1 & .0 & .0 \\
\hline Width & $.9 *$ & .1 & -.0 & -.1 & -.1 & .0 \\
\hline Platform Width & $.5 *$ & -.1 & $.4^{*}$ & .1 & -.0 & -.0 \\
\hline Platform Thickness & $.7 *$ & -.3 & .1 & .2 & .0 & -.1 \\
\hline Bulbar Thickness & $.9 *$ & -.3 & -.1 & .2 & -.0 & .0 \\
\hline Length Thickness & $.9^{\star}$ & -.2 & -.2 & .2 & .0 & .1 \\
\hline Width Thickness & $.8 *$ & -.3 & -.3 & .3 & .0 & .1 \\
\hline Terminal Thickness & $.6^{\star}$ & -.1 & -.1 & -.2 & -.0 & .2 \\
\hline Weight & $.7 *$ & -.2 & $-.4^{*}$ & $.5 \star$ & .1 & .1 \\
\hline Ray Length 1 & $.5 *$ & -.1 & $.5^{\star}$ & .2 & -.1 & -.3 \\
\hline Ray Length 2 & $.6 *$ & .1 & $.5 *$ & .1 & -.3 & -.2 \\
\hline Ray Length 3 & $.6 *$ & $.4^{*}$ & .3 & .0 & -.3 & -.1 \\
\hline Ray Length 4 & $.7^{*}$ & $.5^{*}$ & .1 & -.1 & -.3 & -.0 \\
\hline Ray Length 5 & $.7^{\star}$ & $.5^{\star}$ & -.2 & -.1 & -.0 & -.0 \\
\hline Ray Length 6 & $.8 *$ & $.4 *$ & -.3 & -.1 & .1 & .0 \\
\hline Ray Length 7 & $.7^{\star}$ & .2 & -.1 & $-.4^{*}$ & .3 & -.0 \\
\hline Ray Length 8 . & $.7 *$ & -.1 & .1 & $-.5^{\star}$ & .3 & -.1 \\
\hline Ray Length 9 & $.6 *$ & -.3 & .3 & $-.4^{*}$ & .3 & -.2 \\
\hline Ray Length 10 & $.6 *$ & $-.4^{*}$ & $.4^{*}$ & -.0 & .2 & -.1 \\
\hline
\end{tabular}

${ }^{*}$ Indicates important loadings

Component IV indicates that small, unlipped flakes tend to vector to the right. There is probably a tendency for right-handed knappers to vector bifacing flakes to the right. Larger lipped flakes, however, tend not to go to the right. These are probably core flakes.

Component $\mathrm{V}$ indicates that platforms with triangular profiles, such as bifacing flakes, usually have platform preparation (grinding). They also are more frequently severely fire altered. The ray loadings are not important by usual standards but appear to have a pattern. Rays 2-4 move in the opposite direction of Rays 7-9. Thus, platform prepared flakes tend to be shorter on the right and longer on the left. In other words there is a tendency for platform prepared flakes to vector to the left. It also implies that flakes with unprepared platforms vector to the right. The process of lithic production that is responsible for this pattern is as yet undefined. Oddly 
enough, the more preparation and vectoring to the left, the more frequently the flakes are found to be of heat altered chert. This may indicate a special function that was carried out near fires.

These six processes characterized lithic technology in the Late and Middle Archaic on the knoll. Two processes relate to material. Larger flakes are made of opaque, coarse material (Component I). There is a distinct shift from coarse, in the Middle Archaic, to fine-grained materials in the Late Archaic (Component VI). The remaining four processes concern aspects of lithic technology. The Middle Archaic flint knappers produced long and narrow flakes, while the Late Archaic artisans made relatively short and narrow pieces (Component II). Since the dimensions of flakes are associated with platform preparation, it is likely that these characterize the shift from a bifacing to a core flaking mode of production. Lipping figures prominently but is only slightly not related to time. Lipped flakes tend to have wide platforms and are light weight (Component III). Unlipped flakes also tend to be light and to vector to the right (Component IV). And flakes with triangular shaped, prepared platforms are frequently fire altered (Component VI).

Statistical verification of the trends in bifacing, material and size suggested by the principal components analysis were sought as follows. In Table 9.02, technotypes "flakes" and "blades" were combined into one category, core. The "biface long" and "biface wide" flake types were combined into the category, biface. In this way categories were grouped according to overall technological type rather than technological subtypes.

There is an approximately 2:1 ratio of core to biface technology in levels 3- 6, the Late Archaic levels. The core to biface ratio in levels 7 and 9 changes significantly, but not consistently, toward bifacing. Levels 10 and 11 complete the transition with a shift to biface technology. The chi-squared values are highly significant at less than .001 .

TABLE 9.02. COLUMN PERCENTAGES AND CONTINGENCY TABLE ANALYSIS OF TECHNOLOGY BY LEVELS IN TEST PIT 6

\begin{tabular}{|c|c|c|c|c|c|c|c|c|c|}
\hline \multirow[b]{2}{*}{ Technology } & \multicolumn{9}{|c|}{ Level } \\
\hline & 3 & 4 & 5 & 6 & 7 & 8 & 9 & 10 & 11 \\
\hline Core & 68 & 69 & 67 & 69 & 50 & 90 & 65 & 25 & 3 \\
\hline Biface & $\begin{array}{r}32 \\
\mathrm{Cl}\end{array}$ & $\begin{array}{l}31 \\
-\mathrm{Sc}\end{array}$ & $\begin{array}{c}33 \\
\text { lare }\end{array}$ & $\begin{array}{l}31 \\
\text { (X2 }\end{array}$ & $\begin{array}{l}50 \\
=45\end{array}$ & $\begin{array}{r}10 \\
\mathrm{p}\end{array}$ & $\begin{array}{l}35 \\
00\end{array}$ & 75 & 65 \\
\hline
\end{tabular}

In Table 9.03, the two fine-grained categories, very fine and fine, are combined into a single category of fine. Medium and coarse grain are combined into coarse. Levels $3-8$ contain $75 \%$ or more fine grained flakes while levels $9-11$ are less than $75 \%$ fine 
grained flakes. The logistic model of Late Archaic procurement of higher quality chert is supported by statistical analysis.

TABLE 9.03. COLUMN PERCENTAGES AND CONTINGENCY TABLE ANALYSIS OF GRAIN BY LEVEL IN TEST PIT 6

\begin{tabular}{rrrrrrrrrr} 
Grain & 3 & 4 & 5 & 6 & 7 & 8 & 9 & 10 & 11 \\
& & & & & & & \\
Fine & 85 & 90 & 88 & 75 & 81 & 85 & 73 & 55 & 71 \\
Coarse & 15 & 10 & 12 & 25 & 19 & 15 & 27 & 45 & 29 \\
& Chi-Square & $(\mathrm{X} 2)=22$ & $\mathrm{p}=.004$ & \\
\hline
\end{tabular}

Figure 9.05 shows the deviation of each level flake width from the grand mean flake width for Test Pit 6 . There are two distinctive groups of flakes in relation to width. Width is taken to be an indicator of bifacing (wide) and core flaking (narrow). Levels 3-8 fall in the negative range of standardized level means. Levels 9-11 range into the positive deviations. These differences generate an analysis of variance significance level of $p=.001$. The extraordinary shift between levels 8 and 9 suggests a marked change in technology, and probably pinpoints the change from Middle to Late Archaic. 


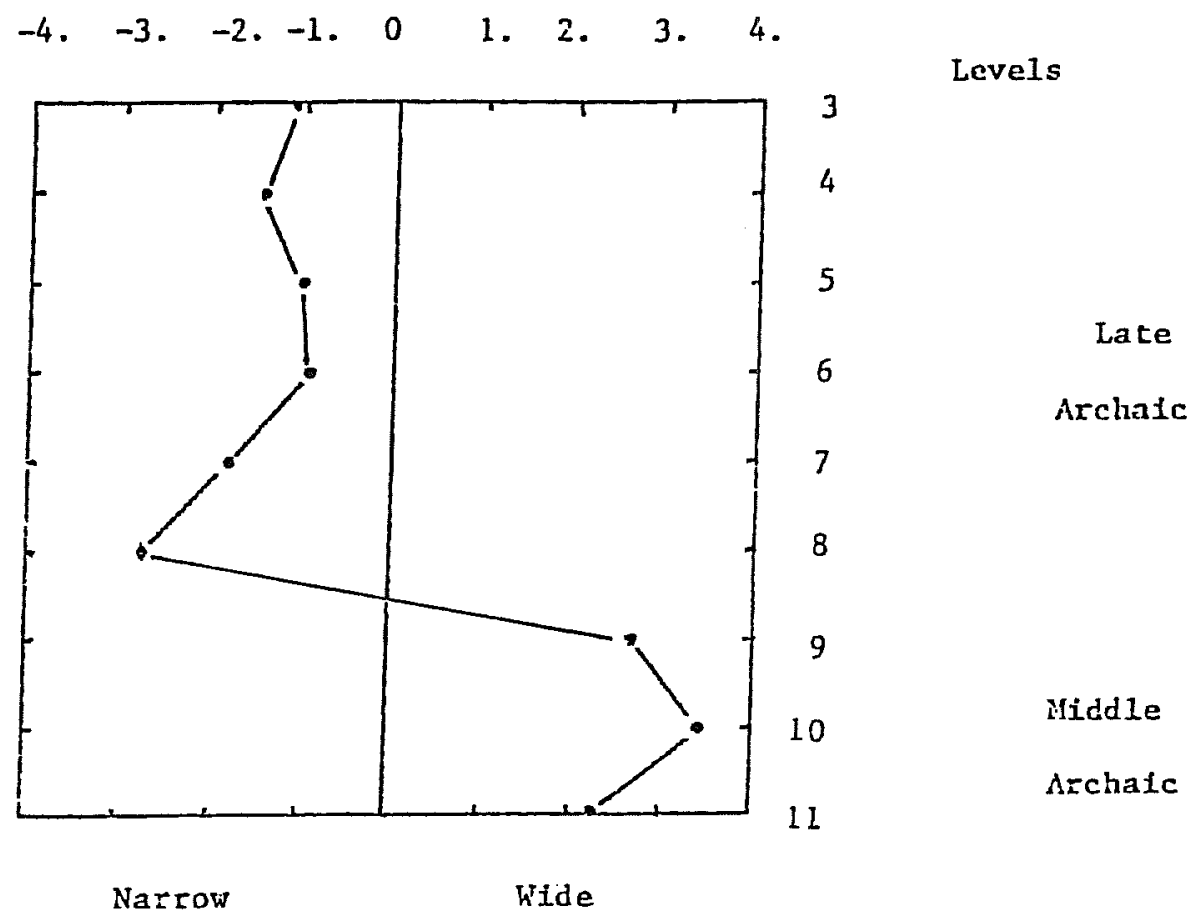

Figure 9.05. Mean Flake Width Range of Variation in Test Pit 6.

\section{Test Pit 6 Summary}

All evidence from Test Pit 6 indicates a major cultural transition between levels 8 and 9. Increases in the numbers of bifacing flakes, increases in the size of flakes, and the presence of more coarse material all at the same time leads us to believe that this is where the Late and Middle Archaic meet.

Based on three diagnostics, Kerr (chapter 6) placed the transition at level 10. But the distinct characteristics of the larger number of flakes indicate a more reliable placement of level 8. We are not suggesting that flake morphology can replace points as time markers. They can, however, in conjunction with a point chronology, provide a much more resolved definition of period boundaries. The points "ball-park" the dates, while flake morphology provides specific temporal definitions.

In levels 3-8 there is a trend to smaller flakes. Some bifacing flakes are present, but the majority of the flakes are core flakes exhibiting flat platforms. The material is generally translucent and fine grained. 


\section{Test Pits 2 and 4 Summary}

Test Pits 2 and 4 are located in the confluence about 42 meters apart. Test Pit 2 is 40 $m$ further upstream along Williams Creek and nearer the bank of the creek. The dominant technology, as represented by the percentage of bifacing flakes, and the percentage of fine-grained flakes are shown in Table 9.04 for all test pits at Moccasin Confluence. The sharp and consistent drop in bifacing technology observed in Test Pit 6 from the Middle to the Late Archaic does not appear in Test Pit 2. This suggests two things: the Late Archaic was not entirely dominated by a core flaking technology and that there was functional differentiation between areas of the site during the Late Archaic or a possible postdepositional disturbance (see Labadie, chapter 10).

There is an increase in the use of fine-grained cherts during the Late Archaic in Test Pit 2. As has been noted before, this suggests an increase in mobility and a solution to the logistical problems of nomads. It also compares favorably, and thus affirms, the similar shift to the use of fine- grained cherts as was posited for the late sequence in Test Pit 6. Various findings associating bison hunting with the Late Archaic, including bison bone from this site (Hafernik, Appendix A) are consistent with nomadic lifeways. The course grained character of lithics in the Middle Archaic levels is, likewise, indicative of a more settled lifeway.

The multiple classification analyses for three test pits are illustrated in Figure 9.06. In comparable levels the trends found in Test Pit 6 are not entirely replicated in Test Pit 2. Test Pit 2 flake widths show considerably more oscillation between narrow to wide within both the Late and Middle Archaic. Wider flakes tend to dominate in the Early Archaic levels. Test Pit 2 may have material from the Late Prehistoric but no diagnostics were found. 
TABLE 9.04. PERCENTAGE OF BIFACING FLAKES AND FINE-GRAINED FLAKES FROM TEST PITS 2, 4, AND 6 (bif = biface)

\begin{tabular}{|c|c|c|c|c|c|c|c|}
\hline \multirow[b]{2}{*}{ Period } & \multirow{3}{*}{$\frac{\text { Level }}{3}$} & \multicolumn{2}{|c|}{ Test Pit 2} & \multicolumn{2}{|c|}{ Test Pit 4} & \multicolumn{2}{|c|}{ Test Pit 6} \\
\hline & & 器if & offine & 告bif & gfine & 学bif & 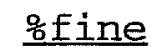 \\
\hline & & 67 & 100 & & & 32 & 80 \\
\hline & 4 & 56 & 88 & & & 30 & 90 \\
\hline & 5 & 80 & 95 & & & 33 & 88 \\
\hline Late & 6 & 75 & 80 & & & 31 & 75 \\
\hline \multirow[t]{2}{*}{ Archaic } & 7 & 67 & 88 & & & 50 & 81 \\
\hline & 8 & 59 & 61 & & & 10 & 85 \\
\hline & 9 & 80 & 60 & & & 35 & 73 \\
\hline Middle & 10 & 76 & 76 & & & 75 & 55 \\
\hline \multirow[t]{8}{*}{ Archaic } & 11 & 76 & 83 & & & 65 & 71 \\
\hline & 12 & 74 & 78 & & & & \\
\hline & 13 & 80 & 78 & & & & \\
\hline & 14 & 71 & 79 & & & & \\
\hline & 15 & 72 & 85 & & & & \\
\hline & 16 & 96 & 68 & & & & \\
\hline & 17 & 62 & 78 & & & & \\
\hline & 18 & 72 & 74 & & & & \\
\hline Early & 19 & 83 & 85 & 61 & 83 & & \\
\hline \multirow{13}{*}{ Archaic } & 20 & 89 & 91 & 54 & 54 & & \\
\hline & 21 & 52 & 73 & 46 & 64 & & \\
\hline & 22 & 79 & 90 & 65 & 53 & & \\
\hline & 23 & 72 & 70 & 47 & 80 & & \\
\hline & 24 & 46 & 27 & 33 & 53 & & \\
\hline & 25 & 60 & 52 & 27 & 27 & & \\
\hline & 26 & 67 & 33 & 30 & 80 & & \\
\hline & 27 & 89 & 44 & 27 & 55 & & \\
\hline & 28 & $\wedge$ & ^ & 67 & 83 & & \\
\hline & 29 & 50 & 75 & 50 & 79 & & \\
\hline & 30 & $\wedge$ & $\wedge$ & 56 & 78 & & \\
\hline & 31 & $\wedge$ & ^ & 50 & 70 & & \\
\hline & 32 & 44 & 67 & 15 & 54 & & \\
\hline \multirow{8}{*}{$\begin{array}{l}\text { Paleo- } \\
\text { Indian }\end{array}$} & 33 & ^ & n & 21 & 71 & & \\
\hline & 34 & 56 & 63 & $\hat{\imath}$ & $\hat{\imath}$ & & \\
\hline & 35 & ^ & $\hat{\imath}$ & 1 & 1 & & \\
\hline & 36 & 44 & 72 & & & & \\
\hline & 37 & 15 & 69 & Combi & ined & & \\
\hline & 38 & $\hat{\imath}$ & $\hat{\imath}$ & & & & \\
\hline & 39 & 50 & 30 & & & & \\
\hline & $\frac{40}{r e(x 2)}$ & $\frac{\hat{n}}{86}$ & $\frac{\wedge}{97}$ & 21 & 21 & 45 & 22 \\
\hline \multicolumn{2}{|c|}{ Chi-Square (X2) } & $<.001$ & & .11 & 10 & $<.001$ & .004 \\
\hline
\end{tabular}




\section{Lower Levels}

Both Test Pits 2 and 4 were analyzed for the Paleoindian and Early Archaic periods. Sparse frequencies of lithics in Test Pit 4 below level 33 reflect the relative unimportance of the north side of the site in earlier times. The levels below 33 in 


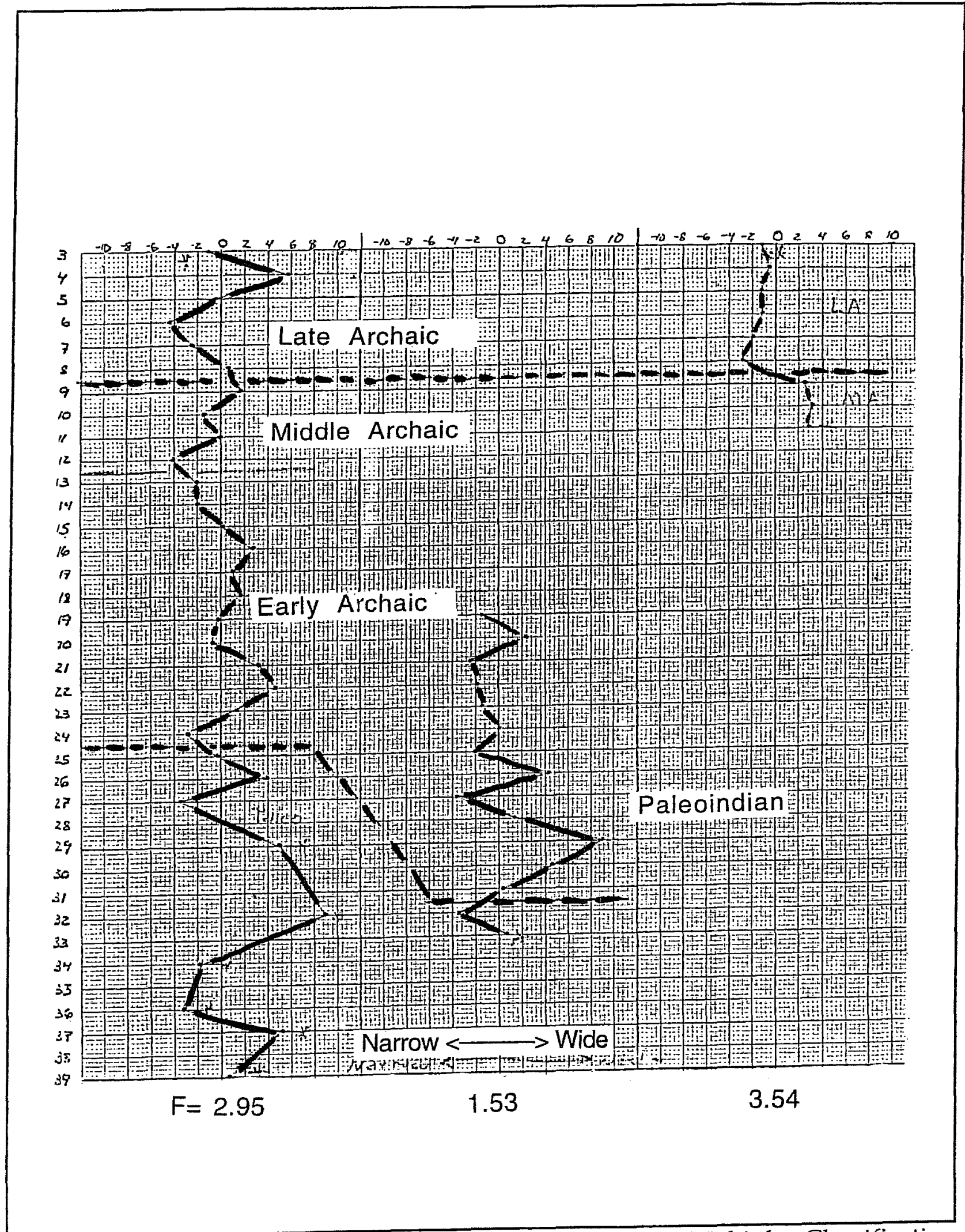

Figure 9.06. Flake Width Mean Departure F-Values for Multiple Classification Analysis. 
Test Pit 4 were summed into level 33 to increase the numbers because of inadequate frequencies for statistical analysis.

Both test pits show significant periods of wide flakes during the Paleoindian and Early Archaic. It is possible that the peaks of wide flakes correlate. However, the sparse diagnostics found during the excavation appear to indicate that they do not.

Flaking through the Early Archaic period appears to represent medium width flakes rather than the extremes. This is perhaps another generalized aspect of the varied Early Archaic tool kit (Weir 1976; Gunn and Weir 1976). However, an alternative is suggested by studies of Indian activities during the Historic period. The ethnic composition of the Edwards Plateau changed on an annual basis depending on the severity of the winter which effected the movement of bison and those pursuing them (Gunn and Frkuska 1982). It is, therefore, not unlikely that these near-mean values represent frequent visits by various groups during the Middle Holocene.

Returning again to the idea that grain indexes mobility, Figure 9.07 illustrates the percentage of fine-grained material for all levels analyzed in Test Pits 2, 4, and 6. Test Pit 2 shows a marked tendency toward less fine grained material and more coarse grained material during the Late Paleoindian period. Diagnostics indicate that the Paleoindian period begins about level 24 in Test Pit 2. Finer grained materials again dominate the assemblage until the Middle Archaic/Late Archaic interval. The Middle Archaic period has been thought for some time as an interval of sedentary lifeways (Weir 1976). However, the idea that Late Paleoindians were at least semisedentary is recent. Morse (1975) first suggested it in the Mississippi River Valley when he discovered a Dalton cemetery. The vast numbers of points at the Wilson-Leonard site (Young 1983) in central Texas accompanied by a burial suggests that sedentism may have extended to the Balcones Fault zone. The flake material from Moccasin Confluence appears to support a similar conclusion. The reason for this period of intense Late Paleoindian occupation are discussed in Gunn (1983b).

\section{CONCLUSIONS}

1. Flake morphology refined definition between test pit levels of the transition between the Middle and Late Archaic periods over that which was possible by diagnostics alone. Indications from material and core-bifacing studies support similar conclusions.

2. It seems likely that during the Middle Holocene (Early Archaic) the site was visited by a range of groups that homogenized the flake assemblage. Prewitt (1981) arrived at similar conclusions from the number of point types in the Middle Holocene (Early Archaic).

3. If the frequency of fine-grained flakes can be taken as an indicator of mobility, mobility was reduced during the Late Paleoindian period. 


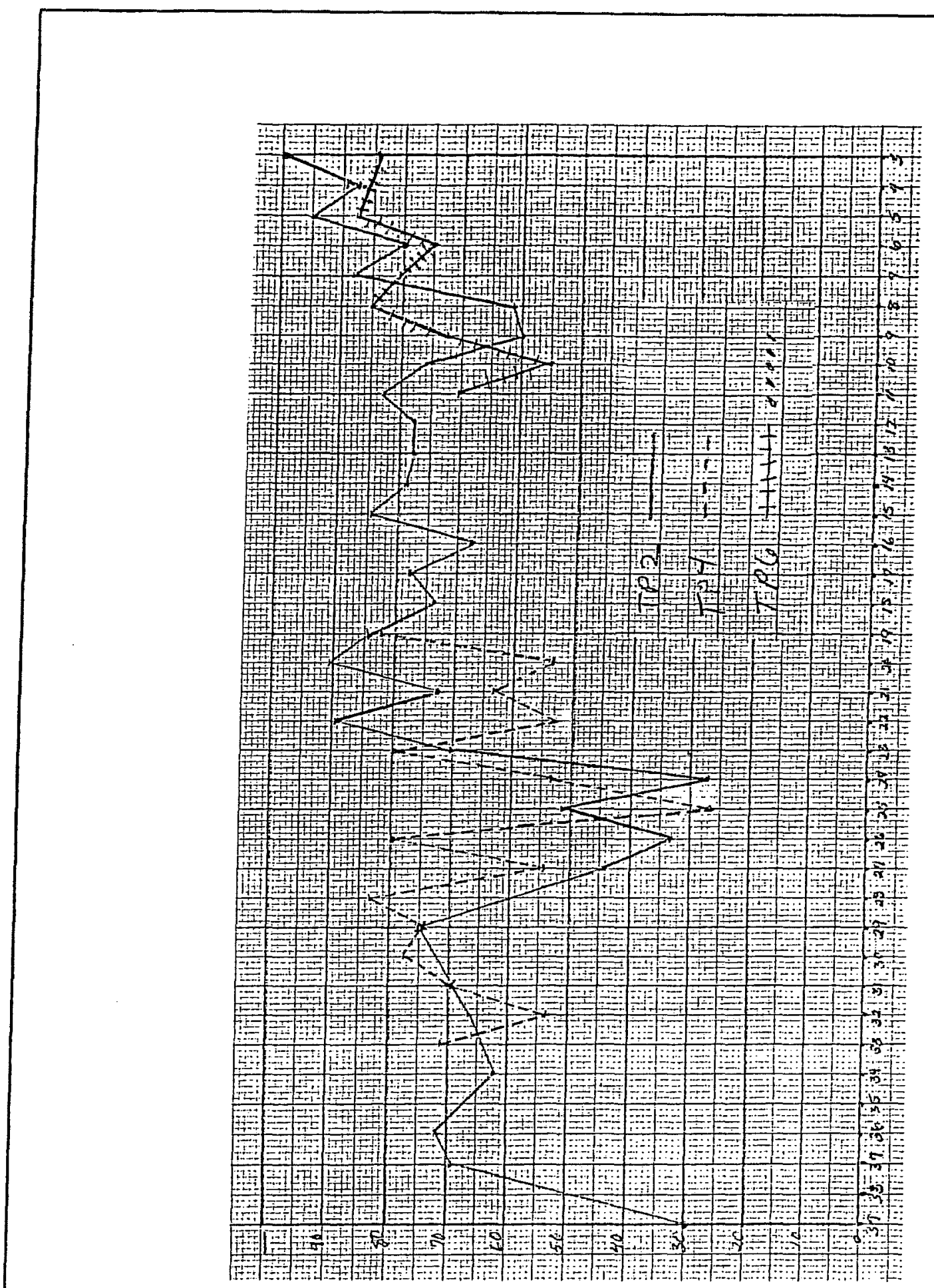

Figure 9.07. Percentage of Fine Grained Material from Test Pits 2, 4, and 6. 


\section{CHAPTER 10-FUNCTIONAL STUDIES OF FLAKES AT MOCCASIN CONFLUENCE AND HOP HILL (Labadie, Craig, Gunn)}

\section{INTRODUCTION (Gunn)}

This chapter surveys the use of flakes as tools and the changes in the patterns of those uses at Moccasin Confluence and Hop Hill. The results indicate relationships between climate and culture.

The amount and kind of use is measured by the observable wear on the flakes. Wear can be observed macroscopically, without the use of microscopes, as well as microscopically. Microscopic observations fall into two general categories because of the increasing difficulty of observing wear patterns under progressively higher powers. Below about 80 power magnification (80X) observations are not difficult with a binocular microscope and can be done without substantial preparation of specimens and problems of interpretation. Above $80 \mathrm{X}$, problems of specimen preparation, time of interpretation, and difficulty of observation complicate the observation process. Increasing the detail of observation requires proportionally more sophisticated interpretive aids such as experimental replication of the use of specific lithic materials on equally specific target materials.

The studies conducted for this project include observations made macroscopically, and microscopically at high and low magnification. However, since this is the first study of wear patterns in the LBJ Park, area there was a major emphasis on macroscopic and low power studies because of the preliminary nature of the effort. More sophisticated studies should follow now that the generalities of site wear patterns are understood.

\section{LITHIC USE AT MOCCASIN CONFLUENCE AS A FUNCTION OF BIOLOGICAL VARIATION IN THE ENVIRONMENT (Labadie)}

Stone tools and lithic debris are often all that remain to indicate the presence of prehistoric humans. The reduction of stone to functional tools allowed early people to exploit a variety of biotic resources that, in their natural state, were otherwise unusable. Knives, choppers, and scrapers composed the early tool kits and enabled humans to pursue and process a diversified diet. Biotic diversity, tempered by cultural norms for preferred resources, may have served as limiting factors for the variety and size of the tool kits.

This study assumes that tool kits for a nonsedentary group may have been limited further by their highly mobile lifestyle. Caching tools would have been possible for 
groups that could depend on returning to the same location year after year. It is believed that large or heavy tools (choppers, hammerstones) were not, as a matter of routine, transported from campsite to campsite, especially in areas where lithic resources were known, or plentiful. On-site manufacture of tools produced lithic debris, as did the resharpening of dulled tools. Detached flakes usually have sharp edges of varying thickness, edge angle, and length. Depending on the task at hand, these flakes could function as ad hoc or expeditious tools without any secondary modification. It could, therefore, be expected that highly mobile groups would use flakes and chips for augmenting simple, portable tool kits. By contrast, semisedentary groups could be expected to utilize debris to a less intense degree while having a more task-specialized and complicated tool kit comprising in part, heavier tools.

In this study the hypothesis will be examined that lithic traditions for the manufacture of chipped stone tools have a directional meaning relative to the changing habitat and inhabitants of the region. Several investigators (Hester 1971; Gunn and Mahula 1977a; Thoms, Montgomery, and Portney 1981; and Lukowski 1983) have previously addressed this issue. The Plains lithic tradition is thought of as primarily a core-flaking technology because of a nomadic lifeway favoring simple, generalized, and light tools. This lifeway was highly mobile because it involved the hunting of migratory animals. The Eastern Woodlands lithic tradition is posited to have a larger component of a bifacing technology, assumed to be a cultural response to the biotic diversity typical in a woodland biome, and thus, sedentism and a higher incidence of potentially heavier bifacial tools (Gunn 1982d). These two lithic traditions are spatially separated by an ecotonal boundary, with the Plains tradition generally found to the west (grassland biome) and the Woodland tradition to the east (forest biome). Climatic conditions are primarily responsible for decreasing biotic diversity, as well as density, from east to west, and the transition from one biome to the other has shifted substantially over the 10,000-year history of this site (see chapter 5).

Furthermore, it may be assumed that a bifacing technology inherently produces a greater amount of debitage than the core technique. This is because the products from chipping from a core are targeted for use, while they are waste products from a biface. In the context of use-wear analysis then, we expect to see a higher ratio of used lithic pieces during periods when core production is favored. Periods of high percentages of use of lithic pieces, then, should correlate with dry intervals. Periods of low use percentages should correlate with moister periods.

To test this idea the unmodified (no intentional secondary modification after initial removal) flakes and chips (total $=5754$ ) were examined both macroscopically and microscopically for evidence of use-wear edge alteration. In many cases use-related edge alteration was eliminated principally on the basis of the size or technotype of platformed flakes. This report presents the results of a computer-generated analysis of the differences and similarities found among the four cultural periods 
represented at Moccasin Confluence using wear and lithic frequencies as criteria for comparison. These data are supplemented by a similar analysis from Hop Hill.

\section{USE-WEAR ANALYSIS OF FLAKES AT MOCCASIN CONFLUENCE (Labadie)}

Artifact recovery strategy at Moccasin Confluence provided a high resolution recovery of cultural remains. Excavation in 5 or $10 \mathrm{~cm}$ levels within homogeneous strata was supplemented by the use of microstratigraphic excavation techniques in cultural levels. In the cultural levels all artifacts were mapped in place, providing detailed recording of discrete occupation floors. Screening was through $1 / 4$ - or 1/8-inch mesh, with some limited water screening performed in Williams Creek. This practice was soon abandoned because of frequent sightings of moccasins in the creek.

The analysis of lithic use wear at $41 \mathrm{BC} 71$ involved the application of one research design to two divisions of the tool assemblage. All lithic debitage, platformed flakes and nonplatformed chips, were placed into one of the following categories:

1. Utilized-evidence of edge alteration due to abrasion during use;

2. Modified-evidence of edge alteration produced by purposeful retouch;

3. Unmodified-no evidence of edge alteration after manufacture.

The unmodified and utilized categories will be discussed in this chapter. Modified flakes, tools, and tool fragments are discussed by Mock and Price (chapter 8).

In order to elicit behavioral information from the debitage at Moccasin Confluence a two-pronged approach was used. The first phase explored replicative experimentation with tools and materials. From this a basic understanding of the mechanics of platform preparation, and the flaking process itself was gained. Flakes removed from cores in this phase of the analysis were not modified. The objective of the experiment was to produce flakes of a uniform size and shape. The second phase involved the use of these flakes in a replicative edge damage experiment. These flakes formed the basis for a comparative collection, against which the artifacts from Moccasin Confluence could be examined. This experimental data was integrated with data gleaned from several sources (Shafer and Holloway 1977; Gibson and Gunn 1982; Keeley 1980; Hayden 1977; Odell 1980), to form a comparative collection.

Contact materials were for the replicative edge damage study that would provide similar flake edge damage to what is encountered at Moccasin Confluence. The task was complicated by the fact that the site had been occupied periodically over the last 10,000 years. That time encompassed many varied environments (chapter 5). Against this backdrop of vast potential adaptive variability was a desire to keep the 
number of contact material classes manageable. The number of material classes was narrowed by archival research (Schuetz 1960, 1963) and several trips to view the comparative collections at the Witte Museum, San Antonio, Texas. At the Witte Museum, the curator allowed perishable assemblages to be examined. Most of the materials were from dry cave sites in the Trans-Pecos region (Shumla, Damp, and Centipede Caves) that were dated to the Archaic and/or Paleoindian periods. Assemblages examined included a woven pouch with flake inside (Figure 10.01, see also Martin 1933), as well as, sandals, matting, cordage, basketry, bundles of unprocessed plant fibers, pointed and shaped sticks and tree branches. Bone artifacts included awls, drills, and probable cutting tools. Sotol (Dasylirion sp.), lechuguilla (Agave lecheguilla), yucca (Yucca sp.), and sacahuisti grass dominated the preferred plant construction materials. The species of wood and animal bone were not determined. The wood, however, is believed to be typical hardwood (possibly live oak or mesquite).

Additional artifacts from Hinds Cave, Val Verde County, Texas, were microscopically examined. These artifacts were unique in that they still retained organic residue on the working surfaces from the materials worked thousands of years ago (Hayden 1977). Sotol and lechuguilla fibers have been identified among the organic debris preserved on the artifacts. These fibers were processed using artifacts in a cutting and/or slicing motion with polish and smoothing of the edges as a result of contact with plant material (Shafer and Holloway 1977; Hayden 1977). Nibbling was obliquely oriented relative to the working edge on several of the specimens.

\section{METHODOLOGY}

An Olympus stereomicroscope was used to isolate wear patterns because of its ability to produce what is, essentially, a 3-D image (high depth of field relative to the specimen size). The depth of field allowed by the stereomicroscope is an asset in this type of study. The use of maximum magnification is a liability, as above 80X the depth of field becomes a substantial problem. Part of the objective was to identify specific microwear polishes, i.e. as being from bone, wood, plants. For theoretical and practical reasons this study was construed to be a first pass, low resolution endeavor. Determinations of use were limited to wear damage produced by contact with either hard (step and hinge scars) or soft (polish) materials. Contact with materials of intermediate hardness and/or softness was characterized by nibbling and scaling of the working edges.

All flakes and chips from all levels of Test Pits 2 and 6 were examined macroscopically for edge alteration. A flake that showed anything other than a relatively straight edge (usually a by-product of manufacture) was suspected to have related damage. Once selected, these flakes and chips were examined microscopically at low (40X or lower) power magnification. This examination was intended to determine if the damage was the result of nonuse related damage 


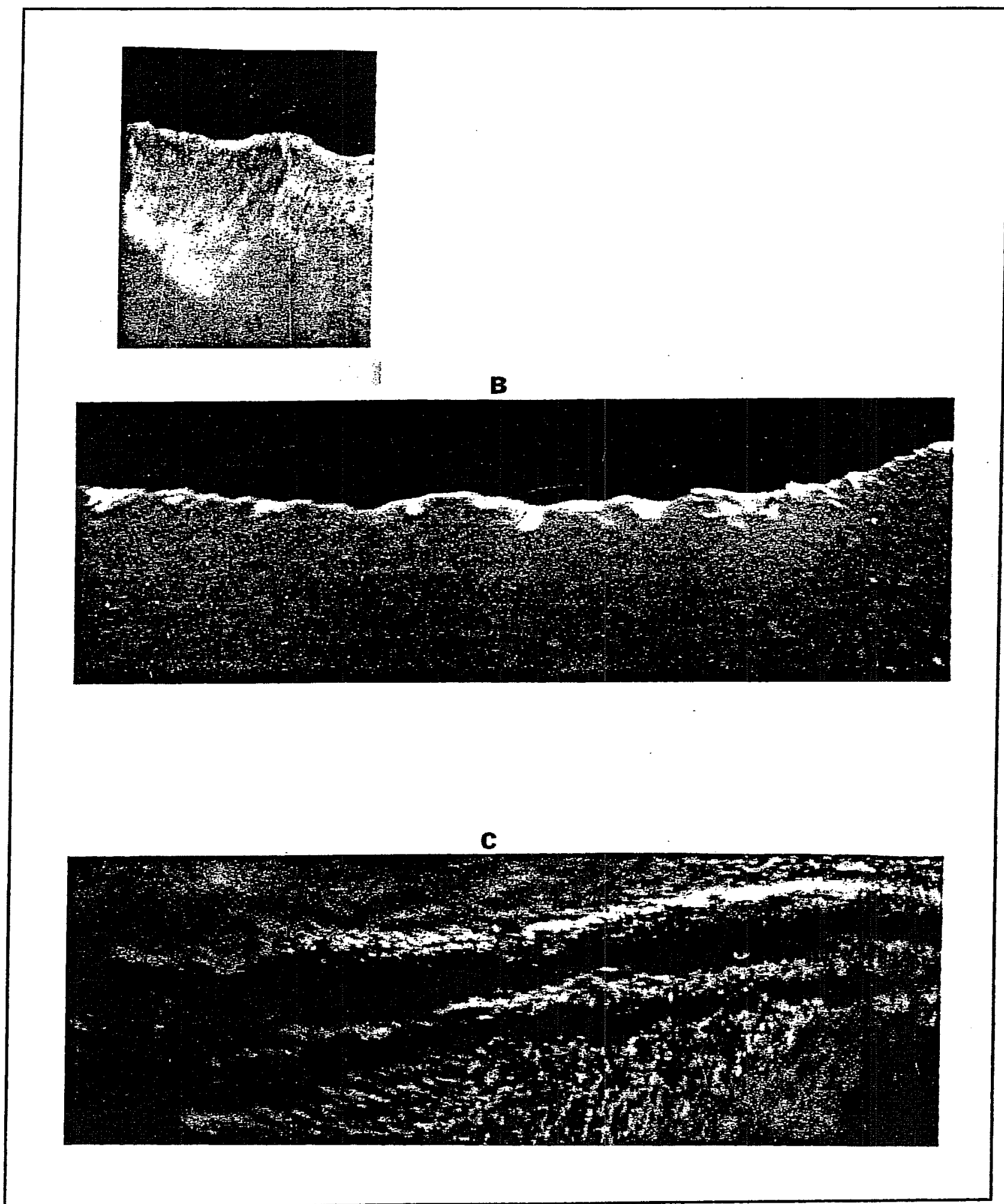

Figure 10.01. Edge-wear Scar Patterns and Organic Residue: A. Scaled Flake Scars, B. Nibbled Edge with Randomly Oriented Flake Scars, C. Sotol Fibers on an Artifact from Hinds Cave. 
incurred during manufacture or after deposition. Great care was taken in this determination, particularly on edges that were nibbled or scaled.

In many cases nibbling appeared on edges with prominent hackling. These projections along the terminus of the edge, at times, showed a random pattern of breakage. This was interpreted as the product of postdepositional damage from trowels, screening and bag damage. If there was symmetry or definable patterning to the breakage of a hackled edge, it was interpreted (subject to several other qualifications, i.e., type of breakage initiation) as damage resulting from use.

Flakes or chips with otherwise straight edges, without prominent hackling, that displayed nibbling, scaling, or step and hinge termination flake scars were also examined at low power magnification. The object was to eliminate flakes and/or chips with nonuse-wear related damage. As part of the background replicative experiments, a group of flakes and/or chips were placed on a concrete or dirt floor and walked on, then examined under the microscope at low magnification. Edges typically displayed randomly located and spaced unifacial removals. If the removal was in the area of a former projection along the edge it often produced a "C-" or "D-" (Odell 1979) shaped nibble or scale. Usually there was no symmetry to the location of the scars, but in a few cases, symmetry was present and may be attributable to the evenness of the pressure exerted along the edge as it was stepped on while resting on the floor (this occurred on both dirt and concrete).

In many cases, use-related edge alteration was confidently ruled out based principally on size and technotype of platformed flakes. In some levels of Test Pit 2 (Early Archaic and Paleoindian) some biface-wide flakes and beveling flakes (associated with the retouch of a dulled, bifacial edge) were so small that up to five flakes could be placed on a penny without totally obscuring the face of the coin. Examination of wear on these flakes concentrated on the outer surface near the platform. Frequently these areas had step- and/or hinge-terminated flake scars.

Platform wear on resharpening flake platforms is an area of study with much potential, especially in a case where tools were carefully resharpened, maintained, and carried away for use at other sites. However, these scars could be the product of original manufacture or retouch maintenance instead of the result of use-related damage that dulled the edge and necessitated retouch and beveling to return the edge to its original sharpness. If platform preparation was required prior to retouching of the dulled edge, use damage (already present) would be obliterated by grinding. Nonuse-related patterning would be produced on the prominent scar ridges that were already smoothed by use. The amount of experimental replication necessary to discriminate between these three "theoretical planes of edge damage" was judged to be beyond the scope of the project, and the effort was left for later studies.

In cases where polish was suspected, the artifact was rewashed with vinegar and water (or in some cases hot soapy water or methyl alcohol). Polish, somewhat 
surprisingly, was rarely isolated, and was never associated with areas of the flake that pertain to hafting, e.g. spurs, haft edges, etc.

\section{RESULTS}

\section{Test Pit 6}

Test Pit 6 is located further from Williams Creek than any of the other test pits, and likewise is at the highest elevation (see Figure 3.01). The 1-m2 test unit was excavated to $115 \mathrm{~cm}$ by $10 \mathrm{~cm}$ levels, and all matrix.was screened through $1 / 4$-inch mesh. A hand-operated post hole digger was then used to dig a test probe down to $160 \mathrm{~cm}$. No artifacts were found in the test probe.

Based on diagnostics, levels 1-9 of Test Pit 6 were dated to the Late Archaic, and levels 10-12 to the Middle Archaic (chapter 6). Since no points or other diagnostic materials were found in the test probe, the lower temporal boundary could not be confidently established.

\section{Discussion}

Each flake and chip that was not deliberately modified after manufacture was examined for use-related damage. Table 10.01 shows descriptive statistics per period. The percentages of pieces attributable to the three modes of utilization remain about the same except that polishing appears in the Late Archaic. This implies extended use of the tools, a trait that would be logically consistent with more nomadic lifeways. There is, contrary to the hypothesis, more unmodified debitage in the Late Archaic. As we shall see, this probably reflects a special use status for the top of the knoll.

TABLE 10.01 LATE AND MIDDLE ARCHAIC USE-WEAR OBSERVATIONS IN TEST PIT 6

\begin{tabular}{|c|c|c|c|c|c|}
\hline & Polish & Nibbling & Stepping & Unmodified & Total \\
\hline Late Archaic & $5(4$ 号) & 116 (88\%) & 11 (8号) & 791 [868] & 923 \\
\hline Middle Archaic & $0 \quad(-1)$ & $52 \quad(918)$ & $5 \quad(98)$ & 189 [77\%] & 246 \\
\hline Total & $5 \quad(38)$ & $168(89 \%)$ & $16(88)$ & $980 \quad\left[844^{\circ}\right]$ & 1169 \\
\hline
\end{tabular}

Note: Row Percentages of utilization mode () and unmodified [].

Of the 1169 pieces of chert in Test Pit 6, overall percentage of utilization was $16 \%$. Comparison of the difference in the frequencies for utilized pieces between the Middle and Late Archaic levels (Table 10.02) shows an interesting trend through time. The $16 \%$ figure is representative of the expected rate of utilization for most levels. The Middle Archaic values all exceed $16 \%$ indicating an increase in 
utilization. The Late Archaic levels fall below the expected value, suggesting that the assemblage is more dominated by lithic production. These findings did not conform to the proposed model of higher frequencies for utilized flakes in the Late Archaic.

\section{TABLE 10.02. PERCENTAGE OF UTILIZATION BY LEVEL FOR TEST PIT 6}

\begin{tabular}{|c|c|c|c|c|c|c|c|c|c|c|c|c|}
\hline \multicolumn{4}{|c|}{ Middle Archaic } & \multicolumn{5}{|c|}{ Iuate Archaic } & & \multirow[b]{2}{*}{3} & \multirow[b]{2}{*}{2} & \multirow[b]{2}{*}{1} \\
\hline Level & 1211 & 10 & 9 & 8 & 7 & 6 & 5 & 4 & & & & \\
\hline \multicolumn{4}{|l|}{ Percentage of } & & & & & & & & & \\
\hline Utilization & $\begin{array}{r}22 \quad 24 \\
\text { verall }\end{array}$ & $\begin{array}{l}41 \\
\text { uti }\end{array}$ & $\begin{array}{l}30 \\
1 \mathrm{iza}\end{array}$ & $\begin{array}{l}13 \\
\text { on }\end{array}$ & & 10 & $\begin{array}{l}12 \\
16\end{array}$ & 19 & & & 60 & 0 \\
\hline
\end{tabular}

Further, used as a chronological criterion, high utilization in level 9 suggests that it should be included with the Middle Archaic, rather than the Late Archaic, as was determined by the point chronology. Level 2 need not be considered an exception to this as only five flakes were recovered. The phase values in Table 10.01 were calculated to reflect this decision, e.g. using levels 9-12 for the Middle Archaic and Levels 1-8 for the Late Archaic.

As is shown in Table 10.03, during both the Late and Middle Archaic the platformed flakes were consistently preferred over chips for use as expedient tools. This probably reflects the more robust character of the platform end of flakes. It also suggests that the flake morphology study (chapter 9) gathered most of the important variation in the flakes that were used as tools.

TABLE 10.03. PERCENTAGE OF FLAKES AND CHIPS UTILIZED BY LEVEL IN TEST PIT 6

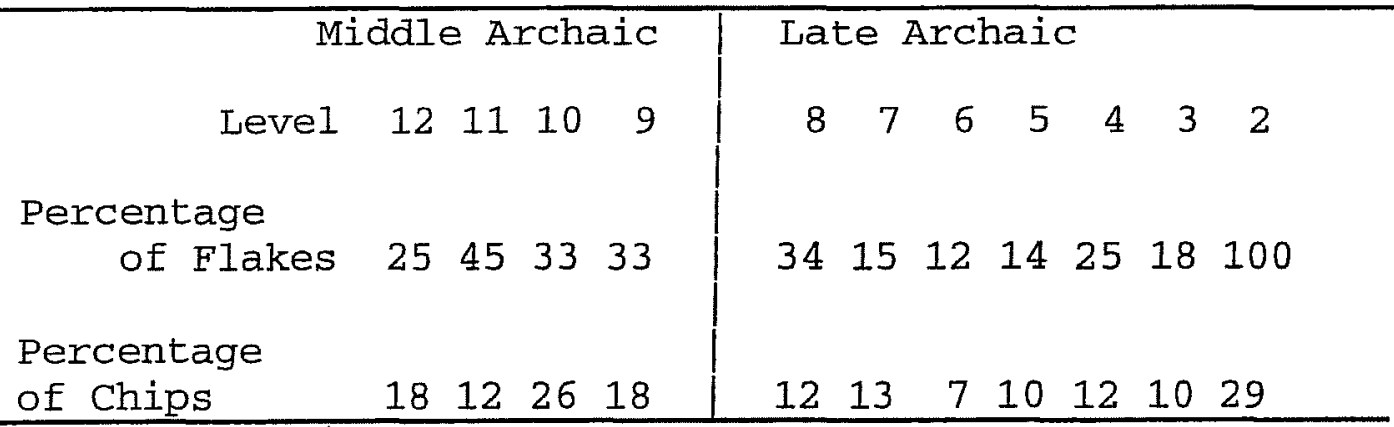

Most utilized flakes had use-related wear characterized by nibbling and scaling on one or both lateral edges; platform end alteration was infrequent. The edge angles rarely exceeded $20 \%$, with the mode of use (slicing, chopping, etc.) usually 
undefinable. Few edges had flake scars oriented perpendicular to the edge; most scars were obliquely oriented with no preference noted for terminal-to-platform or platform-to-terminal mode of use. Because of the lack of artifacts with identifiable polish (Figure 10.02), it is believed that the majority of the flakes and chips were utilized for short duration functions that required a sharp, low-angle working edge.

\section{Test Pit 2}

Test Pit 2 consisted of 39 levels divided into two periods, Archaic (Late 1-8, Middle 9-12, and Early 13-24) and Paleoindian (25-39). Late Paleoindian is considered to be from $25-33$ for the purposes of this analysis, but there is, as yet, no radiometric or typological evidence to support such a separation relative to standard Paleoindian chronology (see Kerr, chapter 6, for discussion). Most of the levels were excavated in 5 or $10 \mathrm{~cm}$ arbitrary levels, although several cultural floors were excavated using the microstratigraphic "rock bottom" excavation technique (Mahula 1977), which allowed for the "in-place" mapping, photographing, and recording of artifacts.

\section{Discussion}

The results of the microwear analysis of the 5753 flakes and chips recovered from Test Pit 2 produced results quite different from those in Test Pit 6 (Tables 10.04 and 10.05). The overall utilization rate was $3.4 \%$, which is considerably lower than the $16 \%$ at Test Pit 6 . As was the case with Test Pit 6, the most common type of edge damage was nibbling and scaling of the lateral edges (75\%). Terminal modification was rare. Damage characterized by step and hinge termination flake scars accounted for $23 \%$ of the utilization, and polish was confidently identified in $2 \%$ of the cases (Table 10.06).

The frequencies of classes of wear vary from period to period. Eliminating the Paleoindian sample as too small, the important difference seems to be a shift to nibbling during the Late Archaic. The reduced appearance of stepping in Late Archaic is what would be predicted by our model because of a reduction in forest biome components in the vegetation. The relatively high incidence of stepping during the Early Archaic is not what would be expected by our simple model if Early Archaic peoples were nomads in an arid environment. Further examination of the model is needed to explain this case.

The mean frequency per level is highest during the early part of the Late Archaic (Figure 10.03), and in the Middle Archaic possibly reflecting more intense occupation. Wear occurs more frequently in the Late Archaic than in either the Middle or Early Archaic. 


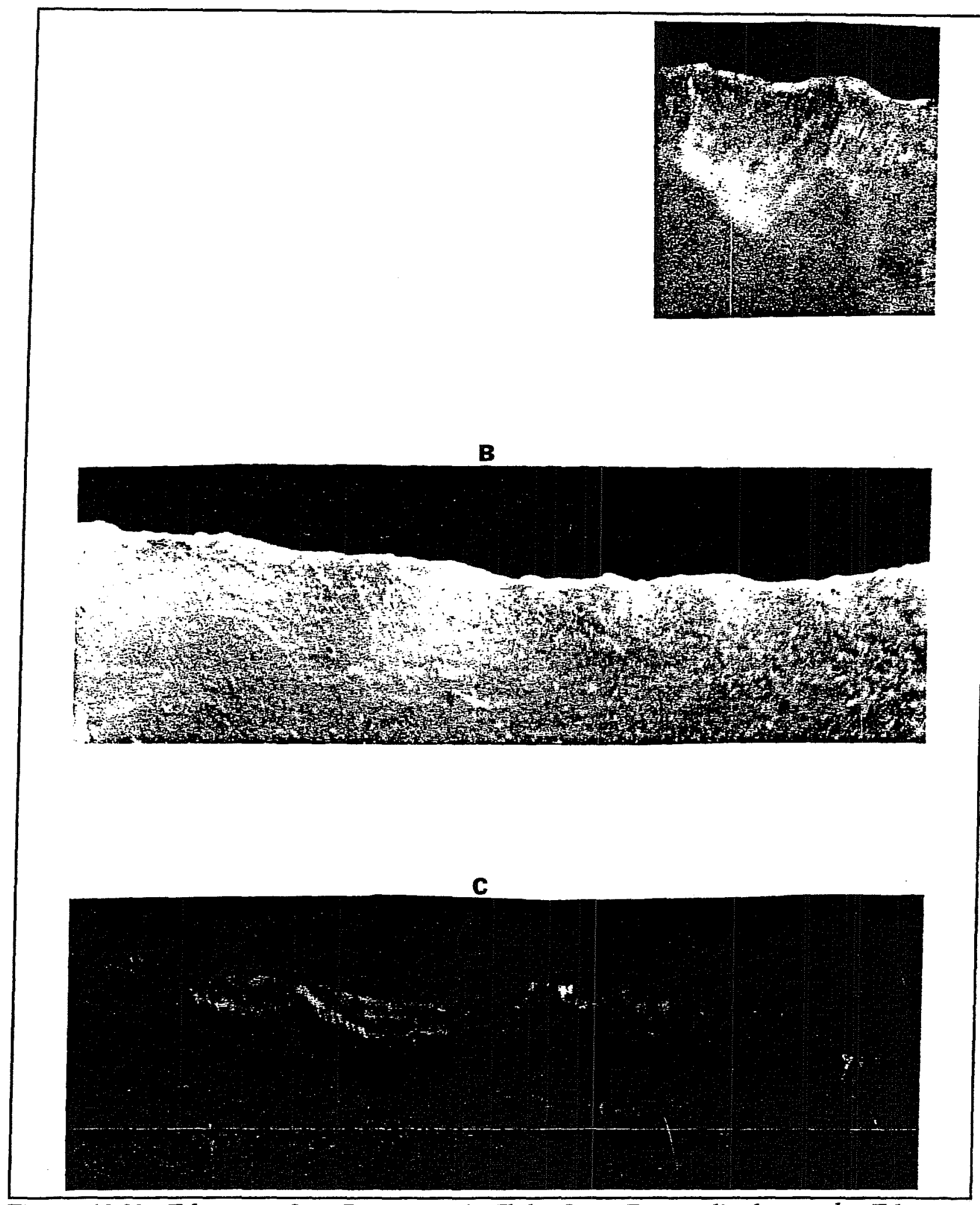

Figure 10.02. Edgewear Scar Patterns: A. Flake Scars Perpendicular to the Edge. B. Polished Edge with Smoothed Scar Ridges. C. Scaled and Hinged Flake Scars. 
TABLE 10.04. TEST PIT 2 PLATFORMED FLAKE UTILIZATION FREQUENCIES

\begin{tabular}{|c|c|c|c|c|c|}
\hline $\begin{array}{l}\text { Test Pit/ } \\
\text { FN/Sequence }\end{array}$ & Polish & Nibble & Step/Hinge & Unmodified & Total \\
\hline $2-301-2$ & 0 & 0 & 1 & 5 & $\overline{6}$ \\
\hline $2-302-3$ & 0 & 1 & 0 & 3 & 4 \\
\hline $2-303-4$ & 0 & 2 & 1 & 11 & 14 \\
\hline $2-304-5$ & 0 & 1 & 1 & 20 & 22 \\
\hline $2-305-6$ & 0 & 14 & 5 & 157 & 176 \\
\hline $2-306-7$ & 0 & 7 & 0 & 199 & 206 \\
\hline $2-307-8$ & 0 & 6 & 0 & 37 & 43 \\
\hline $2-500-9$ & 0 & 6 & 0 & 51 & 57 \\
\hline $2-503-10$ & 0 & 9 & 1 & 228 & 238 \\
\hline $2-515-11$ & 0 & 0 & 3 & 96 & 99 \\
\hline $2-528-12$ & 1 & 1 & 3 & 132 & 137 \\
\hline $2-542-13$ & 0 & 2 & 1 & 167 & 170 \\
\hline $2-547-14$ & 0 & 6 & 2 & 94 & 102 \\
\hline $2-552-15$ & 0 & 2 & 0 & 43 & 45 \\
\hline $2-558-16$ & 0 & 4 & 2 & 45 & 51 \\
\hline $2-563-16.5$ & 0 & 6 & 1 & 50 & 57 \\
\hline $2-568-17$ & 0 & 4 & 1 & 45 & 50 \\
\hline $2-571-18$ & 0 & 0 & 0 & 60 & 60 \\
\hline $2-573-19$ & 0 & 1 & 0 & 56 & 57 \\
\hline $2-575-20$ & 0 & 1 & 0 & 35 & 36 \\
\hline $2-579-21$ & 0 & 1 & 0 & 29 & 30 \\
\hline $2-581-22$ & 0 & 0 & 0 & 41 & 41 \\
\hline $2-585-23$ & 0 & 1 & 1 & 26 & 28 \\
\hline $2-587-24$ & 0 & 0 & 1 & 11 & 12 \\
\hline $2-590-25$ & 0 & 0 & 0 & 3 & 3 \\
\hline $2-599-27$ & 0 & 0 & 0 & 3 & 3 \\
\hline $2-602-28$ & 0 & 0 & 0 & 8 & 8 \\
\hline $2-606-29$ & 0 & 0 & 0 & 4 & 4 \\
\hline $2-609-30$ & 0 & 0 & 0 & 3 & 3 \\
\hline $2-615-31$ & 0 & 0 & 0 & 6 & 6 \\
\hline $2-621-32$ & 0 & 0 & 0 & 9 & 9 \\
\hline $2-629-33$ & 0 & 0 & 0 & 6 & 6 \\
\hline $2-630-34$ & 0 & 0 & 0 & 8 & 8 \\
\hline $2-631-35$ & 0 & 0 & 0 & 23 & 23 \\
\hline $2-632-36$ & 0 & 0 & 0 & 2 & 2 \\
\hline $2-637-37$ & 0 & 0 & 0 & 1 & 1 \\
\hline $2-644-38$ & 0 & 1 & 0 & 6 & 7 \\
\hline$\underline{2-647-39}$ & $\underline{0}$ & 0 & 0 & 3 & 3 \\
\hline Total & 1 & 76 & 24 & 1750 & 1851 \\
\hline
\end{tabular}


TABLE 10.05. TEST PIT 2 CHIP UTILIZATION FREQUENCIES

\begin{tabular}{|c|c|c|c|c|c|}
\hline FN/Sequence & Polish & Nibble & Step/Hinge & Unmodified & Total \\
\hline $2-301-2$ & 0 & 3 & 0 & 12 & 15 \\
\hline $2-302-3$ & 0 & 1 & 0 & 1 & 2 \\
\hline $2-303-4$ & 0 & 7 & 3 & 59 & 69 \\
\hline $2-304-5$ & 0 & 1 & 1 & 29 & 31 \\
\hline $2-305-6$ & 0 & 6 & 1 & 398 & 405 \\
\hline $2-306-7$ & 0 & 6 & 2 & 689 & 697 \\
\hline $2-307-8$ & 0 & 16 & 2 & 81 & 99 \\
\hline $2-500-9$ & 0 & 12 & 4 & 110 & 126 \\
\hline $2-503-10$ & 0 & 1 & 0 & 373 & 374 \\
\hline $2-515-11$ & 0 & 0 & 0 & 155 & 155 \\
\hline $2-528-12$ & 1 & 0 & 1 & 283 & 285 \\
\hline $2-542-13$ & 0 & 3 & 1 & 402 & 406 \\
\hline $2-547-14$ & 0 & 6 & 1 & 169 & 176 \\
\hline $2-552-15$ & 0 & 1 & 3 & 95 & 99 \\
\hline $2-558-16$ & 0 & 2 & 1 & 145 & 148 \\
\hline $2-563-16.5$ & 0 & 3 & 0 & 82 & 85 \\
\hline $2-568-17$ & 0 & 1 & 1 & 97 & 98 \\
\hline $2-571-18$ & 0 & 0 & 0 & 99 & 99 \\
\hline $2-573-19$ & 0 & 0 & 1 & 49 & 50 \\
\hline $2-575-20$ & 0 & 1 & 0 & 75 & 76 \\
\hline $2-579-21$ & 0 & 0 & 0 & 77 & 77 \\
\hline $2-581-22$ & 0 & 1 & 1 & 104 & 106 \\
\hline $2-585-23$ & 0 & 0 & 0 & 29 & 29 \\
\hline $2-587-24$ & 0 & 0 & 0 & 61 & 61 \\
\hline $2-590-25$ & 0 & 0 & 0 & 32 & 32 \\
\hline $2-594-26$ & 0 & 0 & 0 & 2 & 2 \\
\hline $2-599-27$ & 0 & 0 & 0 & 5 & 5 \\
\hline $2-602-28$ & 0 & 0 & 0 & 28 & 28 \\
\hline $2-606-29$ & 0 & 0 & 0 & 4 & 4 \\
\hline $2-609-30$ & 1 & 0 & 0 & 4 & 5 \\
\hline $2-615-31$ & 0 & 0 & 0 & 3 & 3 \\
\hline $2-621-32$ & 0 & 0 & 0 & 4 & 4 \\
\hline $2-629-33$ & 0 & 0 & 0 & 5 & 5 \\
\hline $2-630-34$ & 0 & 0 & 0 & 5 & 5 \\
\hline $2-631-35$ & 0 & 0 & 0 & 20 & 20 \\
\hline $2-632-36$ & 0 & 0 & 0 & 9 & 9 \\
\hline $2-637-37$ & 0 & 0 & 0 & 2 & 2 \\
\hline $2-644-38$ & 0 & 0 & 0 & 7 & 7 \\
\hline $2-647-39$ & $\underline{0}$ & $\underline{0}$ & $\underline{0}$ & 3 & $\underline{3}$ \\
\hline Total & 2 & 71 & 22 & 3807 & 3902 \\
\hline
\end{tabular}


TABLE 10.06. PALEOINDIAN TO LATE ARCHAIC USE-WEAR OBSERVATIONS IN TEST PIT 2

\begin{tabular}{|c|c|c|c|c|c|}
\hline & Polish & Nibbling & Stepping & Unmodified & Total \\
\hline Late Archaic & $0(-)$ & $71(81 \%)$ & 17 (198) & 1701 [958] & 1789 \\
\hline Middle Archaic & $2(58)$ & $29(678)$ & 12 (28各) & $1428 \quad[97 \%]$ & 1471 \\
\hline Early Archaic & $0(-)$ & $46 \quad(73 \%)$ & 17 (27\%) & 2186 [978] & 2249 \\
\hline Paleoindian & $1(508)$ & $1(508)$ & $\underline{0}(-1$ & $242[998]$ & $\underline{244}$ \\
\hline Total & $3(2 \%)$ & 147 (75\%) & $46 \quad(238)$ & $5557 \quad[97 \%]$ & 5753 \\
\hline
\end{tabular}

Note: Row Percentages of utilization modes () and unmodified [].

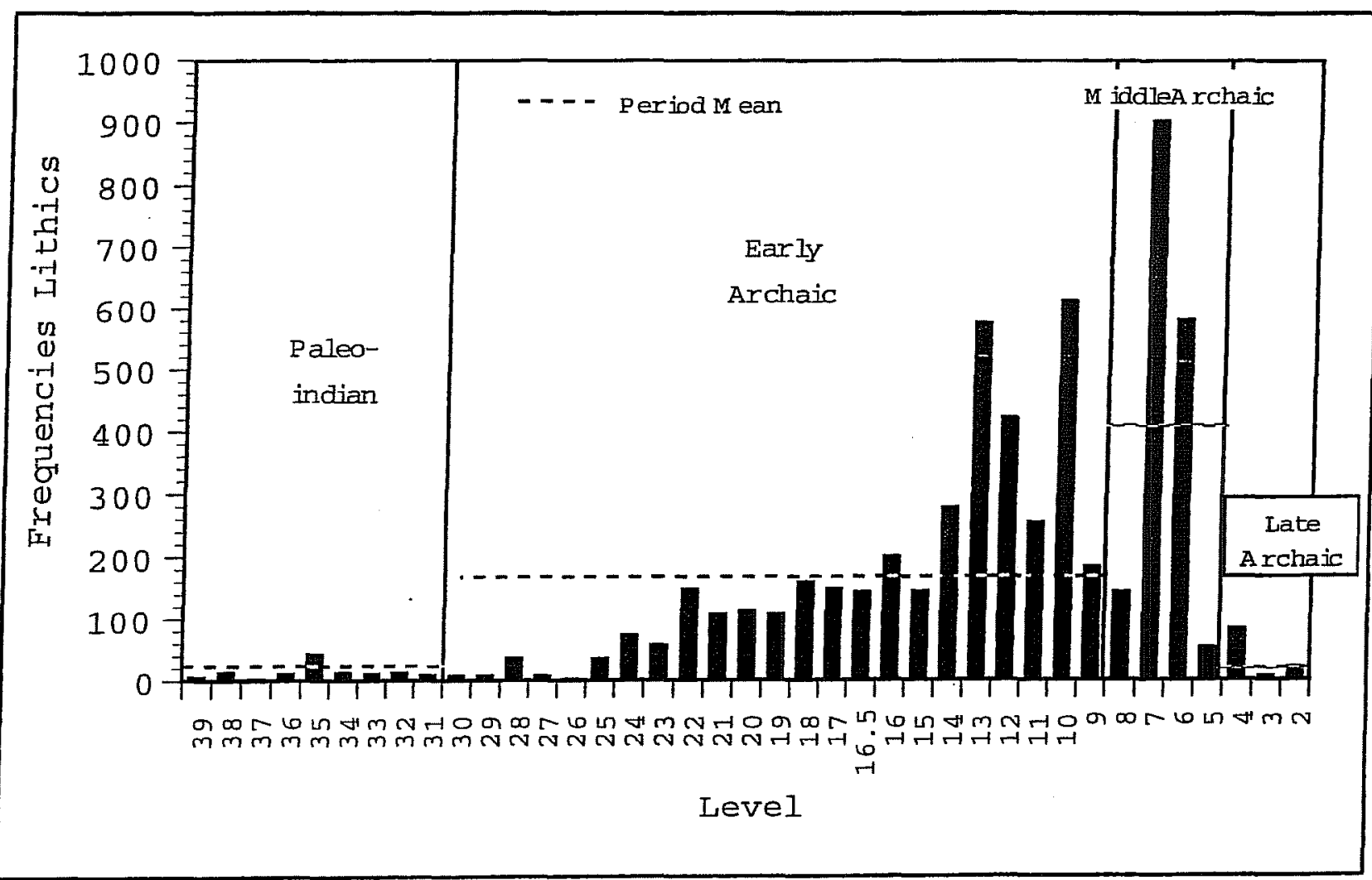

Figure 10.03. Total Lithics by Level, PER X = period Mean Frequency Per Level.

The percentage of utilization of debris in each period was computed (see Table 10.6, inverse of unmodified debris). The utilization of debris steadily increased from Paleoindian to Late Archaic. In general this trend indicates that the site was used less as a lithic workshop, and more as a lithic "use shop." It is not inconceivable that this trend was fostered by the increased difficulty of obtaining good lithics as 10,000 years of exploitation made good quality cryptocrystalline rocks more difficult to obtain. Whatever the reason, a fundamental change in the philosophy of lithic use developed. Within periods there are some fluctuations about the period mean utilization score (Figure 10.04). 


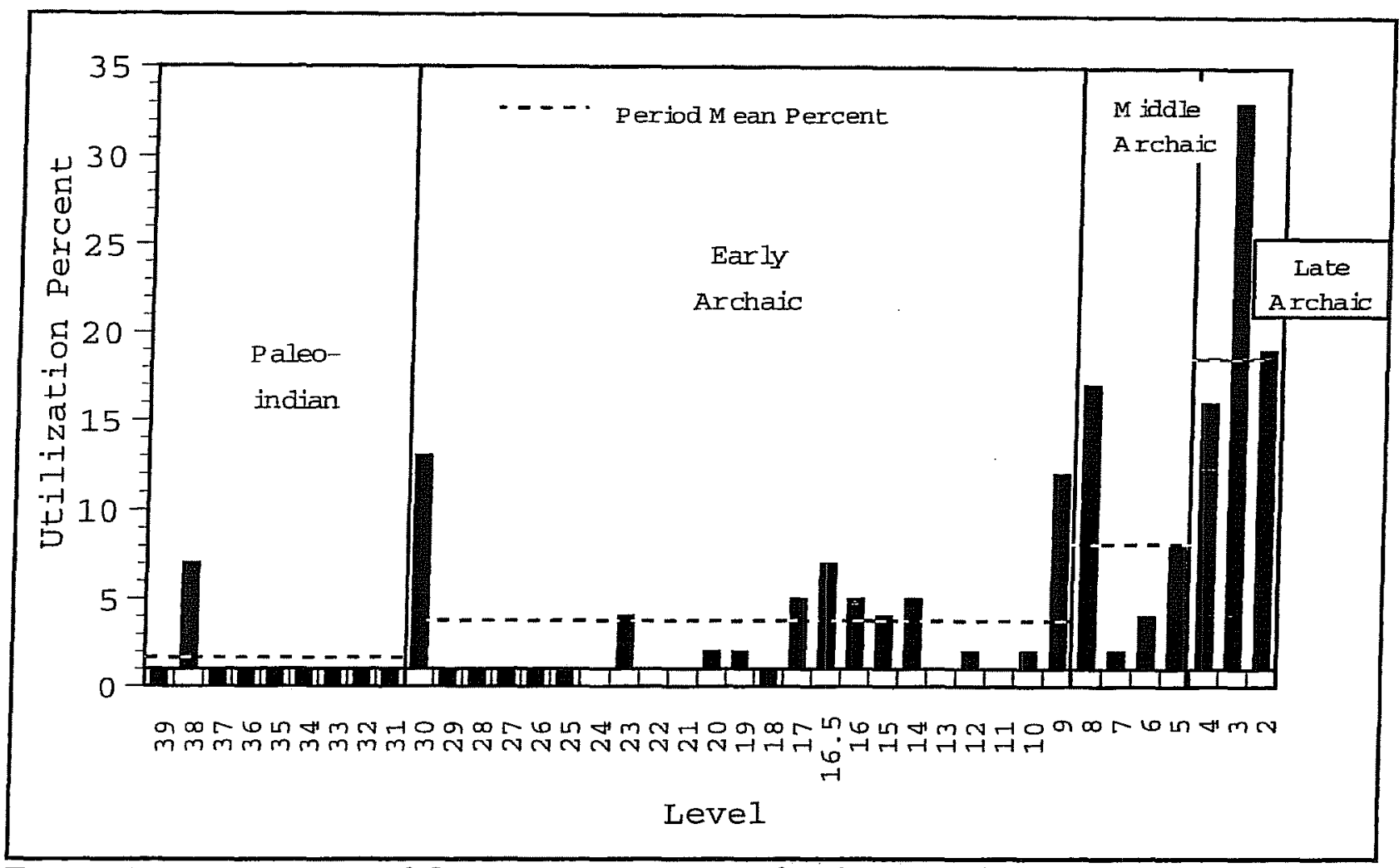

Figure 10.04. Intensity of Occupation, Percent of Lithics Used as Tools.

Comparison of the Late Archaic components in Test Pit 6 (levels 1-8) and Test Pit 2 (levels 1-8) showed a reversal in the use trend noted earlier. Late Archaic use in Test Pit 6 is consistently below the $16 \%$ expected value. In Test Pit 2 use is consistently above the expected 3.4\% value (see Figure 10.04). This probably indicates internal differentiation of use areas within the site.

The Middle Archaic components in Test Pit 6 (levels 9-12) are consistently above the $16 \%$ utilization rate. The Middle Archaic component in Test Pit 2 (levels 9-12) also shows this utilization rate above the expected value $3.4 \%$ (see Figure 10.04). A consistent pattern of use seems to have occurred over the currently known areas of the site during the Middle Archaic.

The Early Archaic component in Test Pit 2 begins at level 13 and extends to level 24 . Almost all of the levels have a utilization rate below the expected 3.4\%. Most of the flakes and chips are very small, with biface-wide and beveling flakes as the dominant technotypes for platformed flakes. Flakes with the potential (width, length, and edge angle) for use as expeditious tools are almost wholly absent. During the Early Archaic and Paleoindian periods, the use of flakes and chips in subsistence activities is minimal. From the types of platform flakes present, it is clear that during both periods the retouching and resharpening of tools dominates over manufacture. 


\section{Summary}

From the data collected on the 6922 flakes and chips recovered from Test Pits 2 and 6 , the use of flakes and chips without secondary modification can be demonstrated. Overwhelmingly, sharp, low edge-angled, platformed flakes were the preferred choice through all time periods in both test pits.

In Test Pit 6 a definite pattern exists from the Late and Middle Archaic. During the Late Archaic the Test Pit 6 area functioned more as a manufacturing locus, while the Middle Archaic shows more evidence of being an area in which both manufacture and use of stone tools were practiced.

Test Pit 2 has an overall utilization rate much lower (3.4\%) than is seen in Test Pit 6 $(16 \%)$. In overall perspective, then, more manufacturing was done by the stream than away from it. The elevated location of Test Pit 6 may have been preferred for resource processing.

The Paleoindian components in Test Pit 2 (levels 25-39) show little evidence for the use of platformed flakes and chips in subsistence activities. Most of the material examined were the by-products of tool rejuvenation. This is consistent with Binford's (1980) logistic model as applied to Paleoindians. That is, the far-ranging Paleoindian preferred to carry high quality, workable flint with them, rather than chance local materials. The continuation of this tradition into the Early Archaic is consistent with similar findings cited in the literature for the southern Plains and the Southeast (Mahula 1982).

One major question raised by the analysis involves the context of materials in Test Pit 2. There is an elevational difference between Test Pits 2 and 6 of approximately $3.8 \mathrm{~m}$. Whether this is a sufficient gradient to allow for sheetwash between these two areas is a significant question which needs to be addressed by geomorphological investigations. If, during the Early Archaic period, when the climate was characterized as hot and dry, there would, in all likelihood, have been less surface vegetation to slow runoff, thus increasing the potential for erosion. The first materials eroded downhill would be the smallest. This may account for the near absence of flakes and/or chips that have the potential for use.

\section{USE WEAR ANALYSIS AT HOP HILL, 41 GL 21 (Gunn, Craig)}

At Hop Hill (41 GL 21) the lithics from a 1-m2 (E101-N102) excavated in the summer of 1982 were examined for signs of microwear. This area of the site was in a buried gully that was apparently used as a trash pit or perhaps a natural cooking pit during the Late Archaic (see chapter 3). The purpose of this analysis was to determine the frequency of use of the flakes and/or chips through time. The analysis was conducted on all lithic debris recovered from E101-N102. Lithic debris was defined as platformed flakes and nonplatformed chips, that had not been purposely retouched. 
The debris was examined with the same methodology discussed for Moccasin Confluence.

The debris was divided into four categories: (1) None, no apparent evidence of microwear; (2) Polish, caused by contact with soft materials; (3) Nibbling and Scaling, caused by contact with an intermediate material such as leather, or short term contact with a hard material such as wood or bone; and (4) Step and Hinge fractures, caused by contact with hard materials.

Twenty levels were excavated in E101-N102 (Table 10.07) with a total of 3735 pieces of lithic debris found, of these only $2 \%$ showed signs of wear. In all of the levels there were large amounts of potlidded, crazed, or otherwise thermally altered debris. This alteration made the identification of wear difficult.

As judged by point chronology, the levels represent three phases: the San Marcos (2600-2250 B.P. corrected radiocarbon), Uvalde (2250-1750 B.P.) and Twin Sisters (1400-1750 B.P.) (Prewitt 1981). Each phase will be discussed in detail below.

The San Marcos phase at Hop Hill is not well defined because only a minimum of prehistoric activity was apparent, and no diagnostic points were found. The periodization is inferred from stratigraphic position relative to the Uvalde phase. There was no apparent utilization on any of the 99 pieces of lithic debris. This suggests that the area was used only as a lithic procurement station.

The Uvalde phase at Hop Hill was defined by Castroville points. During this time there was a decrease in effective moisture (chapter 5), and the drying may have forced the prehistoric inhabitants to broaden their subsistence base into upland areas such as Hop Hill. This is supported by an increase in density of lithic debris, and therefore increased occupation of the site during the Uvalde phase. In the Uvalde phase there are 1225 pieces of lithic debris. Out of this number $1.6 \%$ of the pieces showed signs of use wear. Of those pieces utilized, $80 \%$ showed signs of stepping and/or hinging. Increased occupation and broadening of activities is suggested.

In the Twin Sisters phase there are 2411 pieces of lithic debris. Of this assemblage $3 \%$ exhibit utilization. The phase was defined by the presence of Ensor points. Of the pieces utilized, 85\% showed signs of nibbling and/or scaling, and 15\% showed signs of stepping and/or hinging. The percentage of debris utilized almost doubles that of earlier levels. This increase might, again, be interpreted as an increase in occupation and use of the site for a broader range of activities.

In summary, the amount of debris indicates an increase of activity at Hop Hill during the Late Archaic. The utilization of lithic debris doubled through the period. The progression of increase in amount of debris and use of debris suggests an increasing range of activities, specifically workshop and occupation. The change in relationship between nibbling/scaling and step/hinge variables through the Uvalde and Twin Sisters phases, points to a change in site function, perhaps in response to changing environmental conditions. 
TABLE 10.07. HOP HILL UTILIZED FLAKE \& CHIP FREQUENCY AND PERCENTAGE

\begin{tabular}{|c|c|c|c|c|c|c|c|c|c|}
\hline \multirow[t]{2}{*}{ Phases } & \multirow[t]{2}{*}{ FN/Sequence } & \multicolumn{3}{|c|}{ Flakes } & \multicolumn{3}{|c|}{ Chips } & \multirow{2}{*}{$\begin{array}{l}\text { Total } \\
\text { Debris }\end{array}$} & \multirow{2}{*}{$\begin{array}{l}\text { Total } 8 \\
\text { Utilized }\end{array}$} \\
\hline & & $\mathrm{A}-\mathrm{U}$ & $\mathrm{T}$ & 8 & $A-U$ & $\mathrm{~T}$ & 8 & & \\
\hline & $1035-1$ & 2 & 29 & 7 & 1 & 201 & 1 & 230 & 1 \\
\hline & $1037-2$ & 15 & 75 & 20 & 13 & 627 & 1 & 702 & 3 \\
\hline & $1038-3$ & 3 & 83 & 4 & 5 & 258 & 2 & 341 & 2 \\
\hline Twin & $1040-4$ & 4 & 88 & 5 & 5 & 280 & 2 & 368 & 2 \\
\hline \multirow[t]{7}{*}{ Sisters } & $1043-5$ & 5 & 38 & 13 & 3 & 135 & 2 & 173 & 5 \\
\hline & $1044-6$ & 4 & 36 & 11 & 2 & 125 & 2 & 161 & 4 \\
\hline & $1045-6.5$ & 2 & 59 & 3 & 3 & 91 & 3 & 150 & 3 \\
\hline & $1047-7$ & 4 & 62 & 6 & 5 & 224 & 2 & 286 & 3 \\
\hline & $1053-8$ & 2 & 47 & 4 & 0 & 185 & 0 & 232 & 1 \\
\hline & $1056-9$ & 1 & 52 & 2 & 2 & 108 & 2 & 160 & 2 \\
\hline & $1063-10$ & 1 & 66 & 2 & 0 & 183 & 0 & 249 & 0.4 \\
\hline \multirow[t]{6}{*}{ Uvalde } & $1071-11$ & 1 & 23 & 4 & 1 & 61 & 2 & 84 & 2 \\
\hline & $1073-12$ & 0 & 29 & 0 & 0 & 72 & 0 & 101 & 0 \\
\hline & $1082-13$ & 1 & 37 & 3 & 0 & 66 & 0 & 103 & 1 \\
\hline & $1111-14$ & 2 & 26 & 4 & 1 & 79 & 1 & 105 & 3 \\
\hline & $1113-15$ & 2 & 43 & 5 & 1 & 148 & 1 & 191 & 2 \\
\hline & $1117-16$ & 0 & 18 & 0 & 0 & 46 & 0 & 64 & 0 \\
\hline San & $1123-17$ & 0 & 2 & 0 & 0 & 14 & 0 & 16 & 0 \\
\hline \multirow[t]{2}{*}{ Marcos } & $1124-18$ & 0 & 0 & 0 & 0 & 19 & 0 & 19 & 0 \\
\hline & $1125-19$ & 0 & 0 & 0 & 0 & 0 & 0 & 0 & 0 \\
\hline \multicolumn{10}{|c|}{$\begin{array}{l}\text { \% indicates percentage } \\
\text { A-U - Amount Utilized } \\
\text { T - Total }\end{array}$} \\
\hline
\end{tabular}

The concept, central to Primary Forest Efficiency (Caldwell 1958), that techniques developed within a period of broad spectrum resource exploitation will become intensified toward the end of that episode, can be applied in this case as a vehicle for interpretation. It is worth noting that the lithic frequencies and use indicate a coordinated burst of activity at Hop Hill and in the Test Pit 4 area at Moccasin Confluence.

Intensive occupation at Hop Hill ends with the Twin Sisters phase, which supports the inference of some sort of cultural trauma during or before the following Driftwood phase. This corresponds approximately the A.D. 536 event that produced worldwide climatic and population changes (Baillie 1994). 


\section{CONCLUSIONS (Gunn, Labadie)}

The rather cursory discussion of lithic use-wear presented in this chapter demonstrates dramatically the potential of such studies to discover the character of past lifeways. At the beginning of this study, we proposed that when the frequency of utilized flakes exceeds the period means, it indicates dry climatic and/or biotic intervals. During these periods the region would be favored by Plains people adapted to drier conditions, nomads who are conservative with their carefully selected lithics. The increase in the percentage of utilization early in the Late Archaic correlates with the onset of drier conditions during the San Marcos phase.

The less-than-expected use of lithics during the Middle Archaic indicates a less nomadic people who were less selective of materials and, more inclined to a bifacing technology to produce the heavier tools necessary for life in the woodlands. The evidence from Test Pit 2 supports this model, while that of Test Pit 6 does not. Intrasite patterning is likely a factor to be considered in future interpretations.

A steady increase in the use of lithics from Paleoindian to Late Archaic marks a basic shift of lithic use philosophy over time. The earlier groups apparently preferred to use tools in the formal sense, leaving only resharpening flakes as residue. During the later periods emphasis shifts to the use of flakes as expeditious tools.

There is a marked increase in the proportion of lithics used at the beginning of each period in the chronology (see Figure 10.04). This probably represents the immigration of people from other regions, most usually east Texas, which is noted by Prewitt (1981), at the beginning of each period. It is logical that new arrivals in a region would be unfamiliar with local lithic resources, and they would therefore be more careful to curate and utilize what they brought with them, probably on hunting expeditions. As local resources were discovered and utilized and they settled into the local niche as residents, less emphasis would be placed on curation and utilization and more on local production. Also, at the beginning of each period, and therefore at the beginning of the optimization of the efficiency process, new arrivals would, of necessity, be more mobile than during more sedentary times after they familiarized themselves with a broad spectrum of local resources. These data constitute the best evidence that central Texas ecology acted repeatedly as a cultural "anvil," first enticing and then crushing cultural structures. The archaeology suggests a parallel case to that of Labrador (Fitzhugh 1972) discussed in chapter 1. In this perspective the use of lithics as tools can be seen as a part of the Broad Ecotone adaptation processes that draw in cultural groups during optimum conditions, necessitate adaptation to local conditions, and then place them under severe stress during periods of radical climatic change (Gunn and Prewitt 1983). 


\section{CHAPTER 11-OCCUPATION FLOORS AND FIRE AREAS AT MOCCASIN CONFLUENCE (Meskill, Gunn)}

\section{INTRODUCTION}

As is amply demonstrated in Kerr (1983), occupation floor patterns are a growing interest among archaeologists of the south-central United States. Such excavations yield examples of stratigraphically unmixed behavior patterns of prehistoric peoples. These units of analysis can be used to study the information content of prehistoric technological systems as Kerr did, to isolate associations of typological diagnostics as Prewitt (1981) and Goodyear (1974) demonstrate, and to delineate use-wear patterns (Gunn 1982f; Johnson 1982). While no large areas were opened at Moccasin Confluence, a 1 by $3 \mathrm{~m}$ excavation revealed enough of the occupation floors to justify a preliminary study. This chapter can serve as a guide for future research and also demonstrates the integrity of the floors at the site.

\section{A METHOD FOR HEARTH DEFINITION}

There is more than adequate ethnographic, ethnohistoric and archaeological evidence that activities in a camp lifestyle are centered around hearths (Yellen 1977, Binford 1983, Leroi-Gourhan and Brezillon 1966). Therefore, the definition of a fireplace is the first priority in the study of occupation floor patterns and activities. Charcoal is generally used in archaeological sites to locate prehistoric hearths. The scarcity of charcoal at Moccasin Confluence (probably due to the alluvial/colluvial character of the site) posed a problem for the identification of fire-related areas. Following Gunn (1982f), a model was developed to spatially define the location of fires at the site without the benefit of charcoal. In each test pit and level targeted for study, data was compiled on the quantity and condition of fire-altered materials recovered. Field observations, visual documentation, mapped floors, and photographs were integrated to identify hearths and related occupation floor features. Analysis of these traces of ancient life suggested certain possibilities for interpretation. "Interpretation" is used here as museum science uses it, visualization of a scene from some basic facts or an outline.

The search for interpretive clues focused on the patterning of physical features: shape, repetition, and size of rock patterns. Also, the rocks themselves were observed and studied. These structural elements became valuable diagnostic tools.

The amount of fire-altered lithics was used to locate fires. Fire-altered material was determined by visual examination in the laboratory; assumptions were conservative. Lithics, including tools, flakes, chips, and fire spalls from chert 
nodules, bone, burned limestone, the small amounts of charcoal collected, and any other pertinent materials were selected for their burned condition, then counted and weighed. Totals for each category were recorded by level.

Reddening of lithic materials (limestone, chert) and the "dishwatery" appearance normally associated with heat alteration of chert were considered inadequate criteria for location of fires. These attributes were viewed as ambiguous with respect to the placement of hearths, since intentional thermal alteration can affect these changes. Prehistoric artisans presumably placed blanks and cores under campfires in sand or soil (Crabtree and Butler 1964), then removed the material after heating for further modification. The possibility of transfer of these materials from the immediate area of heating eliminates color change as a reliable indicator of fire position.

Primary indicators of fire were crazing and potlidding. In the absence of charcoal, these conditions were viewed as being the most direct evidence of fire. Accidental exposure to fire was assumed as items may have been dropped into a fire, or a fire built over them after they were discarded. Although poor control of intentional heating can cause these characteristics (Patterson 1979), it is a less likely and certainly a less frequent occurrence. Should potlidding and crazing both be present, the item is categorized as crazed. Crazing is taken to signal direct contact with fire, while potlidded items are viewed as being on the periphery of the fire.

Fire spalls, large, firecracked fragments of flint, were interpreted as fractured boiling stones. They might be found inside or outside the fire. Fracturing occurred during heating (inside the fire) or when taken from the fire and placed in water and exposed to an abrupt temperature change. When removed from the boiling container they would probably be discarded outside the fire. Burned limestone, probably also used as boiling stones, would have been discarded outside the fire for the same reason.

Wilson and Davis (1978) assert that burned, blackened, and calcimined bone results when bone pieces are thrown or spat into the fire as a means of efficient garbage disposal and are not the by-products of cooking. Cooking could cause a small amount of leaching, or charring of ends, if exposed when roasting. And bone buried beneath a fire would be charred and blackened due to the reducing environment (Wilson and Davis 1978). Charred and blackened bone, then, is seen as being inside the fire.

The totals of burned materials for the occupation floors from Test Pits 1, 2, and 3 are shown in Table 11.01. The crazing and potlidding ratios are presented on occupation floor maps as pie diagrams above each square, " $\mathrm{C}$ " indicating crazed and "PL" potlidded. Evidence of a hearth for the later Archaic floors is determined by the presence of $20 \mathrm{~g}$ or more of burned material. On lower floors the square with the greatest weight of burned material indicates a hearth area. 


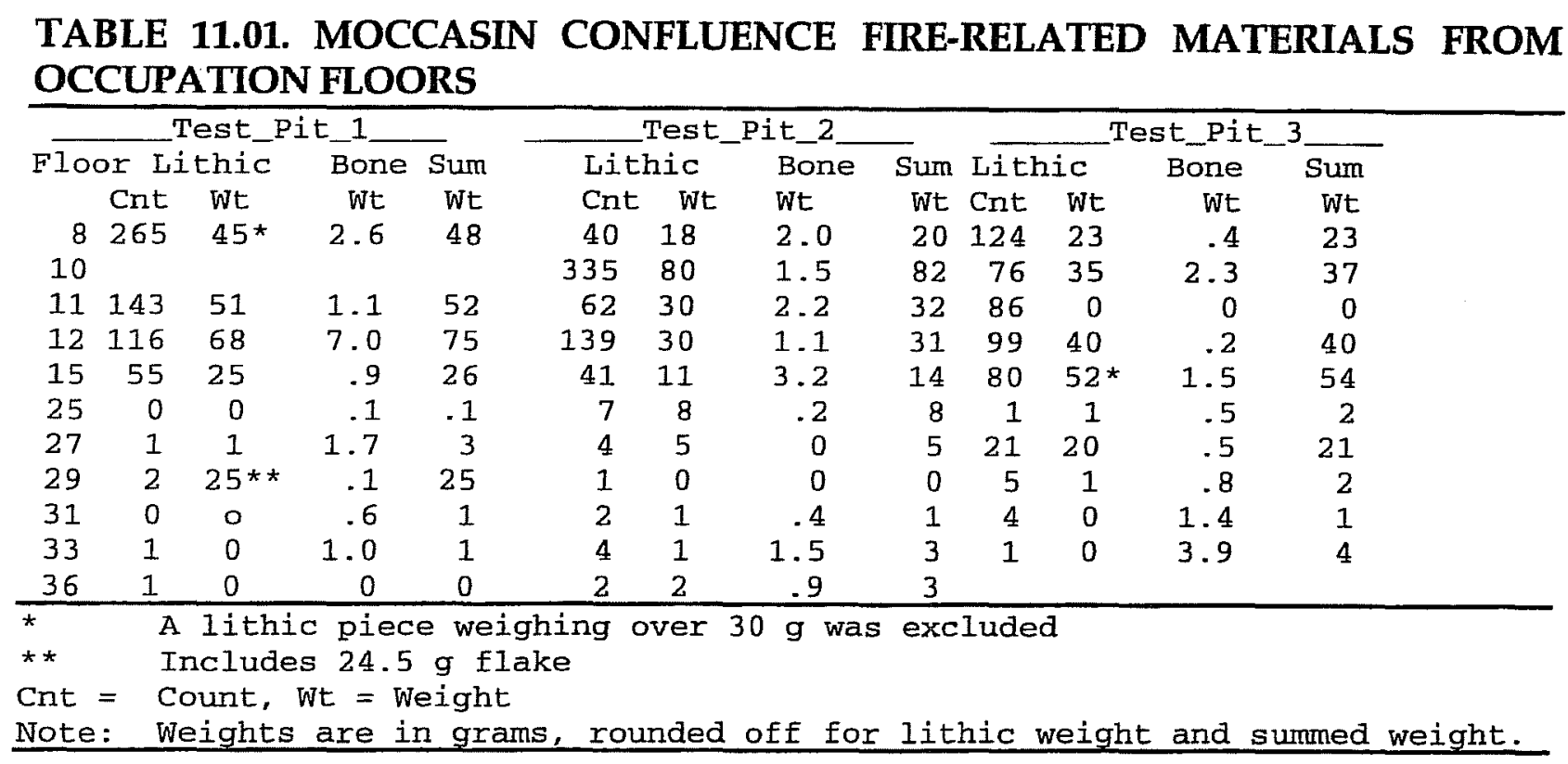

\section{METHOD FOR INTERPRETATION OF OCCUPATION FLOORS}

At Moccasin Confluence there was a wealth of features peripheral to hearths. Probably most of the Middle Archaic activity was at the midden across Williams Creek. The area excavated at $41 \mathrm{BC} 71$ provided uncluttered examples of midden producing activity where there was less accumulation of the dense jumble of debris usually associated with burned rock middens. This greatly facilitated interpretation.

Test Pits 1, 2, and 3 were excavated in 40 levels/microstrata. It would have been neither useful nor possible to interpret all possible occupation floors. Eleven floors were selected for intensive study and interpretation. Generally, selected floors contained large numbers of artifacts that were mapped and photographed in detail. Some occupation floors with few artifacts were not mapped, but were included in the interpretation because of important diagnostic artifacts. Study of these floors considered on totals of burned materials and other statistical data, notations from the field, and inferred subsistence patterns. Since there was no evidence to indicate otherwise, the interpretations based on these data assume very little or no depositional or postdepositional disturbance.

Floors with substantial amounts of cultural material were excavated with the greatest care. The technique of "rock bottom excavation" (Gunn and Mahula 1977a; Gunn 1982f), i.e. excavation with a control face to the bottom of rocks in horizontal association, hypothetically enables the excavator to expose a consistent cultural level. The occupation floor thus exposed is then mapped and photographed. The vertical location of the floors can be seen in Figure 5.03. Horizontal proveniencing 
of diagnostics on an occupation floor is at one centimeter resolution, other artifacts are provenienced to one meter.

The initial step in interpretation was spatial ordering of observed features of mapped floors. Photographs provided the clearest evidence of patterns, upon which functional assessments were recorded. Statistical data were used to support these interpretations. Such data act, at times, as an activity indicator, and at other times as a corrective to interpretation. Gunn's (1982e) concept of an "episode," as related to functional discreteness, supported the diagnosis. Historical and archaeological references (see discussion of acorn utilization below) to methods of food preparation were investigated, and inferences drawn.

A system of rock patterns, first noted in the field by the primary author, and further defined from photographs during laboratory analysis, suggested the interpretation of the midden floors. Patterns of repeated interconnecting circular forms seemed the logical result of a single activity episodes. An unusually explicit example appears in Figure 11.01. Investigation of historical references (Turner 1977a) to the forms observed suggested that the patterns might be associated with stone boiling. Kroeber (1932:276) describes a Patwin acorn boiling episode this way:

Acorn soup or gruel, YIWIT, required three baskets to cook well. The hot stones were picked up with two sticks and first dipped into the acorns. They were removed from this with two paddles, TS'IWIK, of oak, a foot and a half long, with blades the size of a palm. Then the gruel was carefully poured into another basket so as to leave behind the fragments of rock that had become detached.

Note the indication of multiple boiling containers. This procedure is consistent with the rock patterning observed on the midden floors at Moccasin Confluence. Circular or ovate rock groups, perhaps used as support for baskets or boundaries for skin "bowls," are seen adjacent to hearth areas in which the stones could have been heated. The use of rock patterns is particularly applicable to the Middle Archaic midden floors. Using the data, a systematic search was made of each floor for circles and ovals, seen as voids on living floors and immediately accessible to fire, where they would be expected if the stone rings were put to such a use.

Additional support for the interior of stone rings being discrete functional zones is found in the fact that they were apparently cleared of debris before use. The general absence of materials within the circles is supplemented by the fact that provenienced artifacts were often on the periphery or outside of the circular rock forms.

Examination of the occupation floors in the Eagle Hill II report (Gunn and Brown 1982) at similar time depth and the Hop Hill report (Gunn and Mahula 1977a) seem to suggest the presence of these forms (see southeast section, Occupation Plane 2.13, Gunn 1982f:328). The interpretation of the stone rings as features associated with stone-boiling and acorn processing (Turner 1977a), suggests the occurrence of such activities at Moccasin Confluence. 


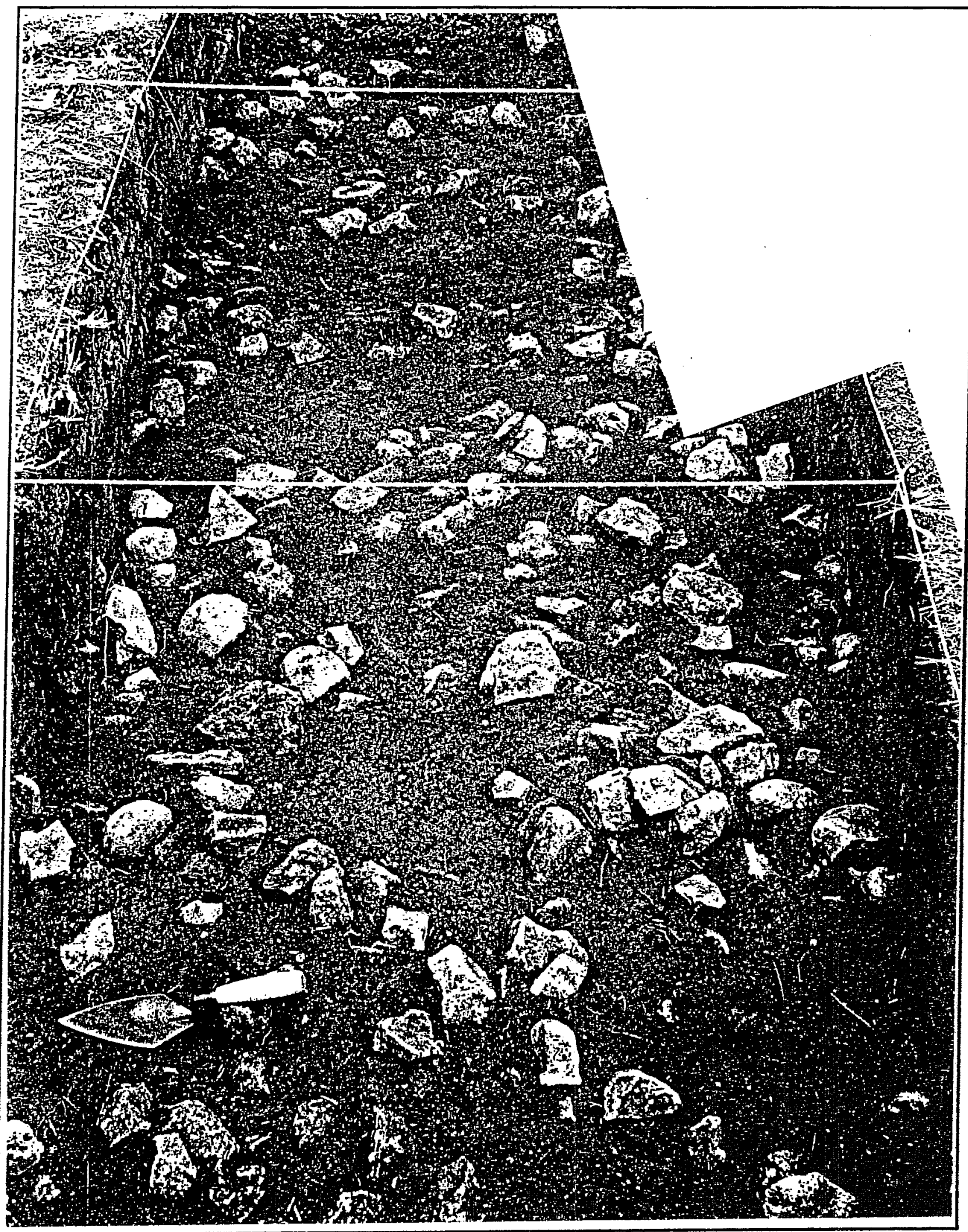

Figure 11.01. Occupation Floor 8, View East. 


\section{ROCK SIZE THROUGH TIME}

An informative overview of the use of rocks during the 10,000 year occupation interval of the site can be seen in Table 11.02. The circumferences of rocks mapped on occupation floors we measured and divided by the number of rocks per square to get the average circumference for a floor. It was assumed that the size selection of rocks, and possibly shape, was a product of a culturally determined, mental template. This selection would have been influenced by availability, but the primary consideration would have been which rocks best suited the current preferred mode of food preparation.

\begin{tabular}{|c|c|c|c|c|c|c|c|c|}
\hline \multicolumn{3}{|c|}{ Test Pit 1} & \multicolumn{3}{|c|}{ Test Pit 2} & \multicolumn{3}{|c|}{ Test Pit 3} \\
\hline Unit $\mathrm{FN}^{*}$ & $\begin{array}{l}\text { N. of } \\
\text { Rocks }\end{array}$ & Cir. & Unit $\mathrm{FN}^{*}$ & $\begin{array}{l}\text { N. of } \\
\text { Rocks }\end{array}$ & Cir. & Unit $\mathrm{FN}^{\star}$ & $\begin{array}{l}\text { N. of } \\
\text { Rocks }\end{array}$ & Cir. \\
\hline $1-257-8$ & 24 & 17 & $2-306-7$ & 21 & 26 & & & \\
\hline $1-258-9$ & 28 & 18 & $2-307-8$ & 22 & 19 & $3-338-5$ & 24 & 22 \\
\hline $1-259-10$ & 44 & 17 & $\begin{array}{l}2-500-9 \\
2-503-10\end{array}$ & $\begin{array}{l}16 \\
62\end{array}$ & $\begin{array}{l}25 \\
20\end{array}$ & $\begin{array}{l}3-345-6 \\
3-501-7 \\
3-507-8\end{array}$ & $\begin{array}{l}19 \\
50 \\
36\end{array}$ & $\begin{array}{l}18 \\
21 \\
21\end{array}$ \\
\hline $\begin{array}{l}1-504-11 \\
1-511-12\end{array}$ & $\begin{array}{l}39 \\
\text { stain }\end{array}$ & 19 & $\begin{array}{l}2-515-11 \\
2-528-12\end{array}$ & $\begin{array}{r}40 \\
9\end{array}$ & $\begin{array}{l}16 \\
21\end{array}$ & $\begin{array}{l}3-524-9 \\
3-529-10\end{array}$ & $\begin{array}{l}24 \\
31\end{array}$ & $\begin{array}{l}18 \\
17\end{array}$ \\
\hline $1-517-13$ & 7 & 14 & $2-542-13$ & 5 & 18 & $\begin{array}{l}3-544-11 \\
3-544-12\end{array}$ & $\begin{array}{l}8 \\
8\end{array}$ & $\begin{array}{l}24 \\
23\end{array}$ \\
\hline $1-504-14$ & 6 & 18 & $\begin{array}{l}2-552-15 \\
2-568-17 \\
2-571-18 \\
2-594-26\end{array}$ & $\begin{array}{r}3 \\
6 \\
5 \\
23\end{array}$ & $\begin{array}{l}24 \\
27 \\
25 \\
20\end{array}$ & & & \\
\hline $1-627-26$ & 17 & 24 & $2-615-31$ & 5 & 41 & $\begin{array}{l}3-648-27 \\
3-662-30\end{array}$ & $\begin{array}{r}19 \\
7\end{array}$ & $\begin{array}{l}25 \\
27\end{array}$ \\
\hline
\end{tabular}

${ }^{*}$ Unit FN = Test Pit-Field Number-Level, N. = Number, Cir. = Average Circumference

The table shows that large counts of rocks near the surface clearly indicate the presence of midden floors. Below the midden floors rocks become generally larger and remain so, with the exception of Occupation Floor 26. Visual examination of the occupation floor maps supports the figures in Table 11.02 and suggests a clear change in rock size and shape preference during the Late Paleoindian period. Though not temporally documented, a similar pattern of change was noted by Gunn and Mahula (1977a) at Hop Hill.

The presence of smaller rocks in Test Pit 1, nearer the stream, through all levels is probably a function of slope. The bank of Williams Creeks begins to slope at Test Pit 1 and it probably represents broken and discarded or rolled rocks. 


\section{OCCUPATION FLOOR INTERPRETATIONS}

The following sections detail interpretations of targeted occupation floors.

\section{Occupation Floor 8}

This midden floor is dated to the Late Archaic, based on the presence of a Castroville point from the central unit (Figure 11.02). Evidence of a hearth, based on the analysis method, is present in all three pits. The pie diagram (see Figure 11.02) for this floor points to Test Pit 3 as being the most likely hearth area with a higher proportion of crazed (C) than potlidded (PL) material. However, Test Pit 1 also has a relatively high proportion of crazing and the weight and count of fire-altered materials were greater there.

Circular forms in Test Pit 3 (evident in the lower part of the photograph, see Figure 11.01) are adjacent to a mass of large rocks at the juncture with Test Pit 2, conforming to the pattern associated with stone boiling. A broken mano from Test Pit 3 and a second mano (tentatively identified in the photograph), suggest the grinding of some plant or nut resources indigenous to the area. A likely position for the "cook" would be in the void just below the east edge of Test Pit 3. Prehistoric women, we assume, were tending the fire and boiling meals in baskets, or perhaps roasting nuts or meat as additions to the boiled food. Tools and fragments of white-tailed : deer bone in Test Pit 1 suggest the presence of meat, and that it was being severed from the bone and cut up to the west of the fire. An expended tabular core and a burned cortex flake found in the southwest quadrant of Test Pit 2 suggest a possible minor workshop area. Flint knapping may have been the product of immediate need. Use-wear figures show a high proportion of utilization relative to other floors. Twenty-three flakes and chips show signs of nibbling (plant-animal processing), and two show step wear (use on harder substance such as bone or wood).

The edge of an ovate form at the east edge of Test Pit 1 suggests a satellite hearth described in Weir's (1976) Hearth Type 5 category, where a large hearth, three to eight feet in diameter, is surrounded by satellite hearths. These subsidiary hearths are 12-36 inches across and consist of only a few burned rocks located three to ten feet from the parent hearths (ibid.). The parent hearth type might have been used for the roasting of large game, and the satellite hearths may represent stone-boiling activities. Also recovered in Test Pit 1 were 14 very small pieces of rolled quartzite and a nut fragment, possibly pecan.

\section{Occupation Floor 10}

Weight and count of burned material in Test Pit 2 are the highest of all the units analyzed on this occupation floor, a strong indication of a hearth (Figure 11.03). 


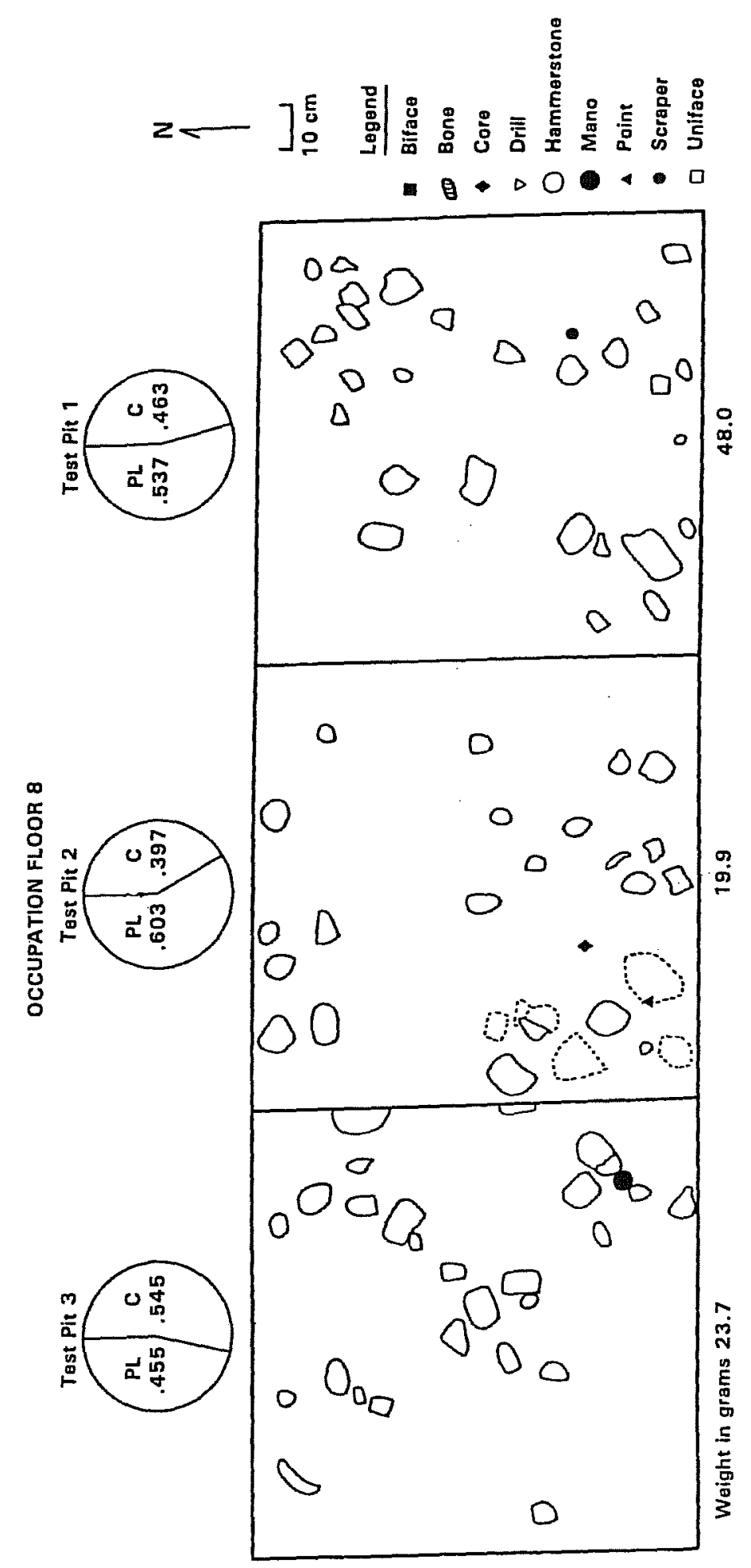

Figure 11.02. Occupation Floor 8. 


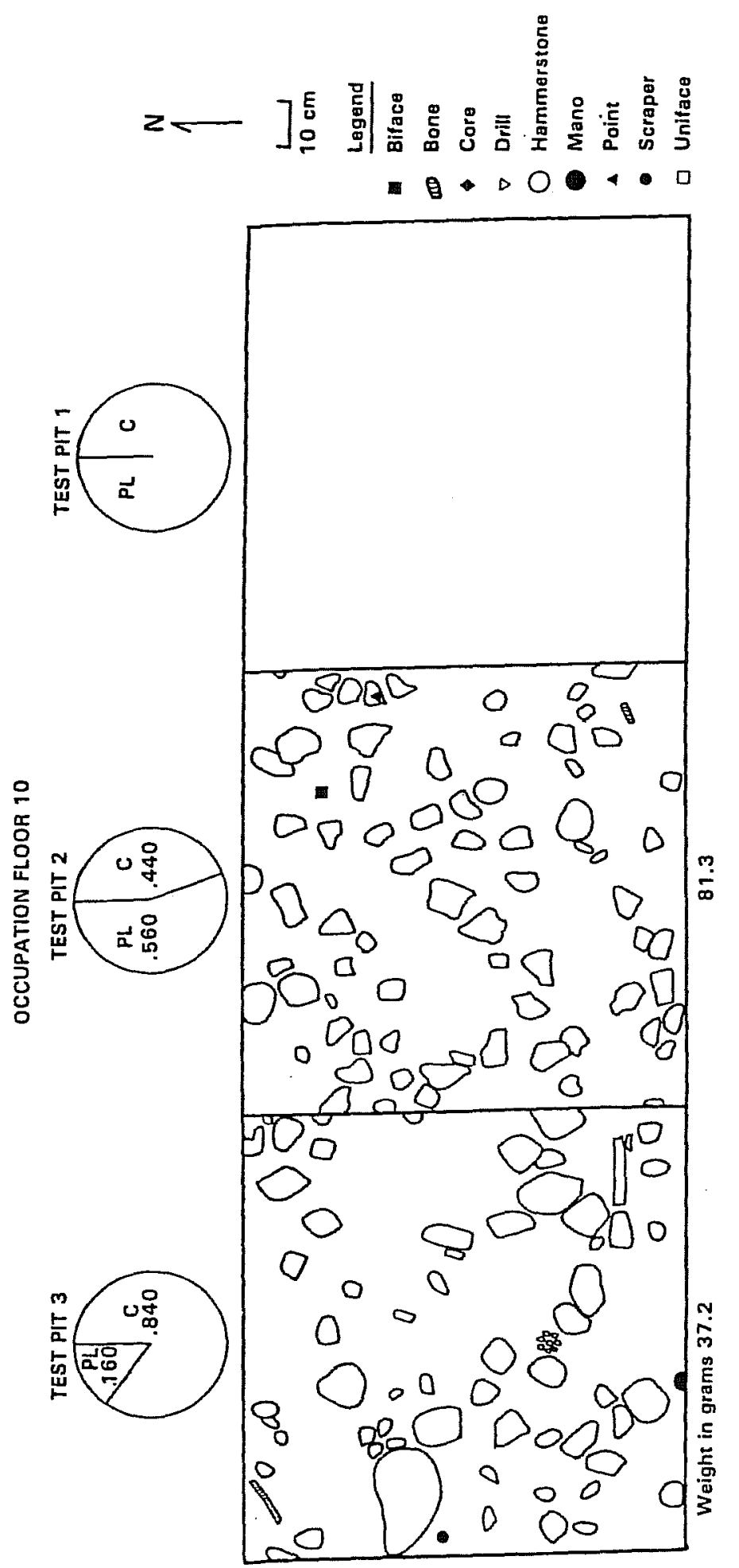

Figure 11.03. Occupation Floor 10. 
This is, however, inconsistent with the higher proportion of crazing to potlidding in Test Pit 3. Four discrete patterns radiate from the hearth area in the southeast quadrant of Test Pit 3, the same position suggested on the earlier midden floor, Occupation Floor 8 (see Figure 11.02). The stone-boiling analytical device is again applicable. An incident of some interest is suggested in the northwest area of the unit. A metate, a discoid denticulated scraper and a large piece of bone appear together outside the aboriginal "firepot." A woman, leaning over, grinding plant food or nuts, scraping meat off bone, and adding these ingredients to the baskets or skins is easily imaginable from the disposition of these artifacts and features. The relationship is inferred from Iroquois and Algonquin use of acorns, as reported by Parker (1910) and Merriam (1918): A broken mano is in the south wall of the unit.

A triangular point, a Taylor or Baird, was recovered from Test Pit 2. Evideñce of a hearth is strong in this pit: of 612 flakes and chips recovered, 335 were burned. Ten lithic pieces exhibit nibbling, and one has step fractures. The number of burned chips is extremely high relative to the count of burned flakes-a pattern seen repeatedly through this period. A severely burned biface was situated in the northeast quadrant of Test Pit 1, possibly indicating a subsidiary hearth.

\section{Occupation Floor 11}

A Bell point from Test Pit 2 (Figure 11.04) marks this floor as a possible Early Archaic occupation. Circular patterning of rocks, observed in the field and more clearly observable in the photograph (Figure 11.05), precipitated the pursuit of the rock pattern study. Attempts to account for the forms observed led to the stone boiling concept. Note the placement of tools on the periphery of the circle (see Figure 11.04).

The crazing proportion is highest in Test Pit 1 , which is consistent with the high count of burned material. However, the greatest weight of burned material is in Test Pit 3, where crazing is over 50\%. Perhaps the dense, more random rock scatters represent destroyed hearths. Test Pit 1 yielded one of the rare traces of charcoal. This unit is located at the top of the embankment sloping toward Williams Creek to the east, and may indicate that earlier occupations were to the west.

A biface and a scraper on the east side of Test Pit 2 suggest a cutting and scraping episode. Use-wear analysis shows only three utilized flakes, all evidencing step wear. These flakes may have been damaged in the same task as the core tool found in the west end of the unit. The marked shift from utilized flakes in Occupation Floor 8 to tools in Occupation Floor 11 is characteristic of the whole sequence as is discussed in Labadie's use-wear analysis (chapter 10). Paleoindian and Early Archaic peoples favored formal tools while later Archaic residents relied on flakes as tools. A rather enigmatic yellow rock found at the bottom of Test Pit 2 could be a hammerstone. Outside the circular pattern of rocks, in the north portion of Test Pit 1, a crescent scraper (see Figure 8.03, FN 506) was found. The large amount of lithic debris in this area suggests that some prehistoric flint knapper might have sat on the edge of the slope, resharpening his tools. 


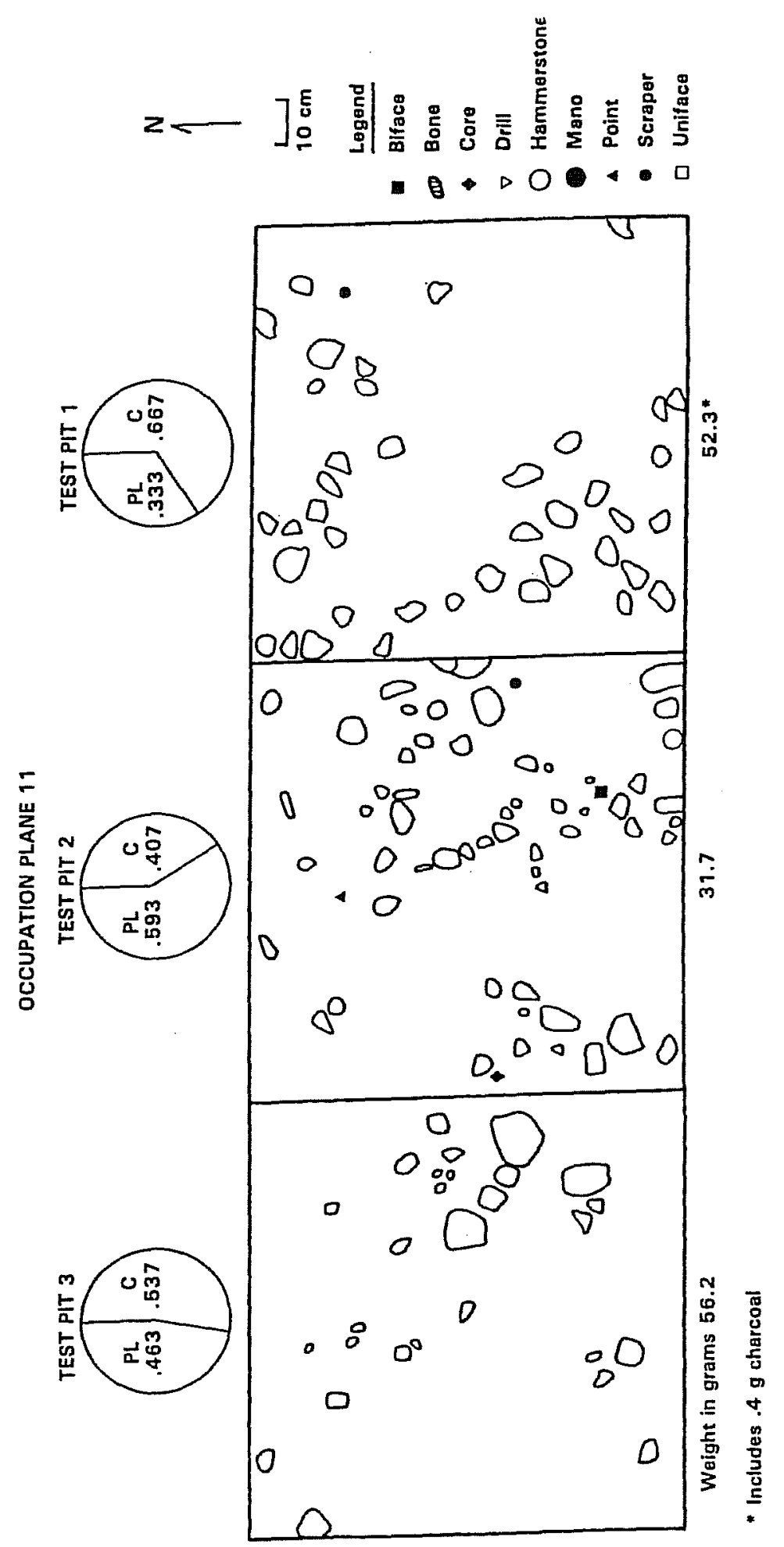

Figure 11.04. Occupation Floor 11. 


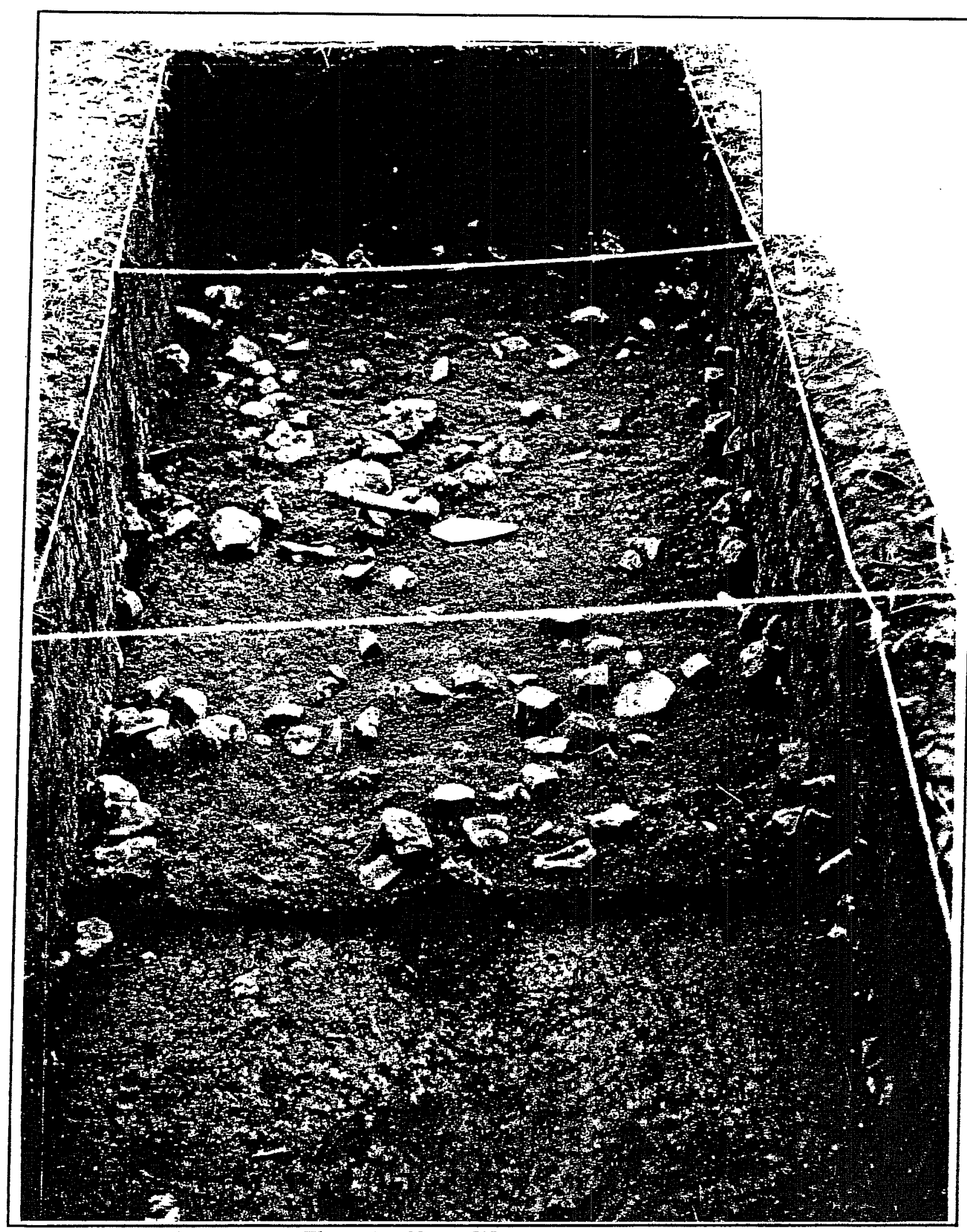

Figure 11.05. Occupation Floor 11, View West. 
In Test Pit 3 a concentration of terrestrial snails was noted in the northeast quadrant.

\section{Occupation Floor 12}

This occupation floor provokes particular interest, with four points, a Montell, a Martindale, a Bulverde, and an untyped point, having been recovered from Test Pit 1 , in close context with a drill positioned on the upper right of Test Pit 2 (Figure 11.06). The tooth of a large herbivore, apparently that of a small bison, was also located in this pit. The Martindale is noted as having an apparent impact fracture at the tip. A probable post mold between Test Pits 1 and 2 suggests some sort of shelter or structure (shaded area, Figures 11.06). It is $15 \mathrm{~cm}$ in diameter, $25 \mathrm{~cm}$ deep and a rock was found at the bottom, perhaps to stabilize the post.

Another interpretation suggests the roasting or steaming of the meat on the spot and a single, but contemporaneous, hide-working episode in the vicinity of Test Pit 2. The Bulverde point on the left is potlidded, but the bone beneath it was not burned, nor were the other points. The counts of burned material were high in all three pits, and the weight greatest in Test Pit 1 . The crazing relationship, taken alone, would have pointed to Test Pit 3 as the most likely hearth area. The proportion of crazed materials was highest in Test Pit 3 , and possible boiling stones and fragments were found, indicating a hearth, or a disposal of hearth-related debris. A biface, a scraper fragment, and the basal fragment of a point were also recovered.

Burned materials were frequent in Test Pits 2 and 3 , and the concentration of rocks in the westernmost area of the pit suggests a hearth. A complement of tools, two uniface cutting tools and a scraper, were recovered next to the concentration of rock. The cobbles are distinguished by their consistent size, a characteristic not noted on any other floor.

Labadie's use-wear analysis for Test Pit 2 (chapter 10) shows hard wear, with four artifacts exhibiting step fractures, one with polish and only one piece evidencing nibbling. Subsistence on this floor seems to be oriented towards the exploitation of animal, rather than plant, resources.

\section{Occupation Floor 15}

This floor represents an Early Archaic occupation (Figure 11.07). The amount of lithic materials has decreased as compared to the upper levels. The relative lack of artifactual materials in this level prompted the use of $5 \mathrm{~cm}$ levels sloped with the strata. The floor maps reveal a minimum of visual information. A rodent bone was found in Test Pit 2 and two probable deer teeth in Test Pit 3, while an exhausted core was found in Test Pit 1.

A trace of charcoal, a fire spall, and a fairly large quantity of bone, some of it burned, came from Test Pit 2. The proportion of crazing to potlidding is high in Test Pit 2, 


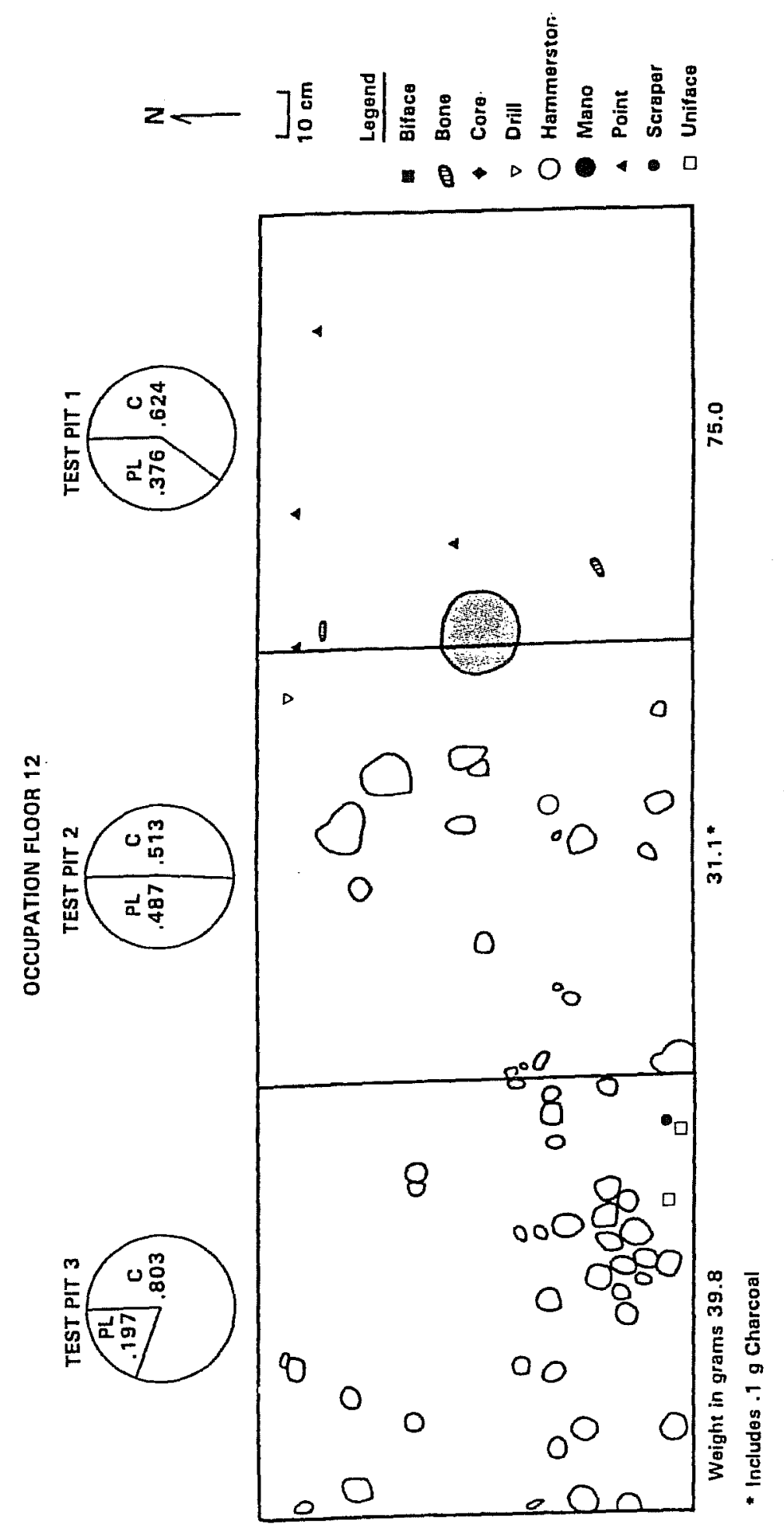

Figure 11.06. Occupation Floor 12. 


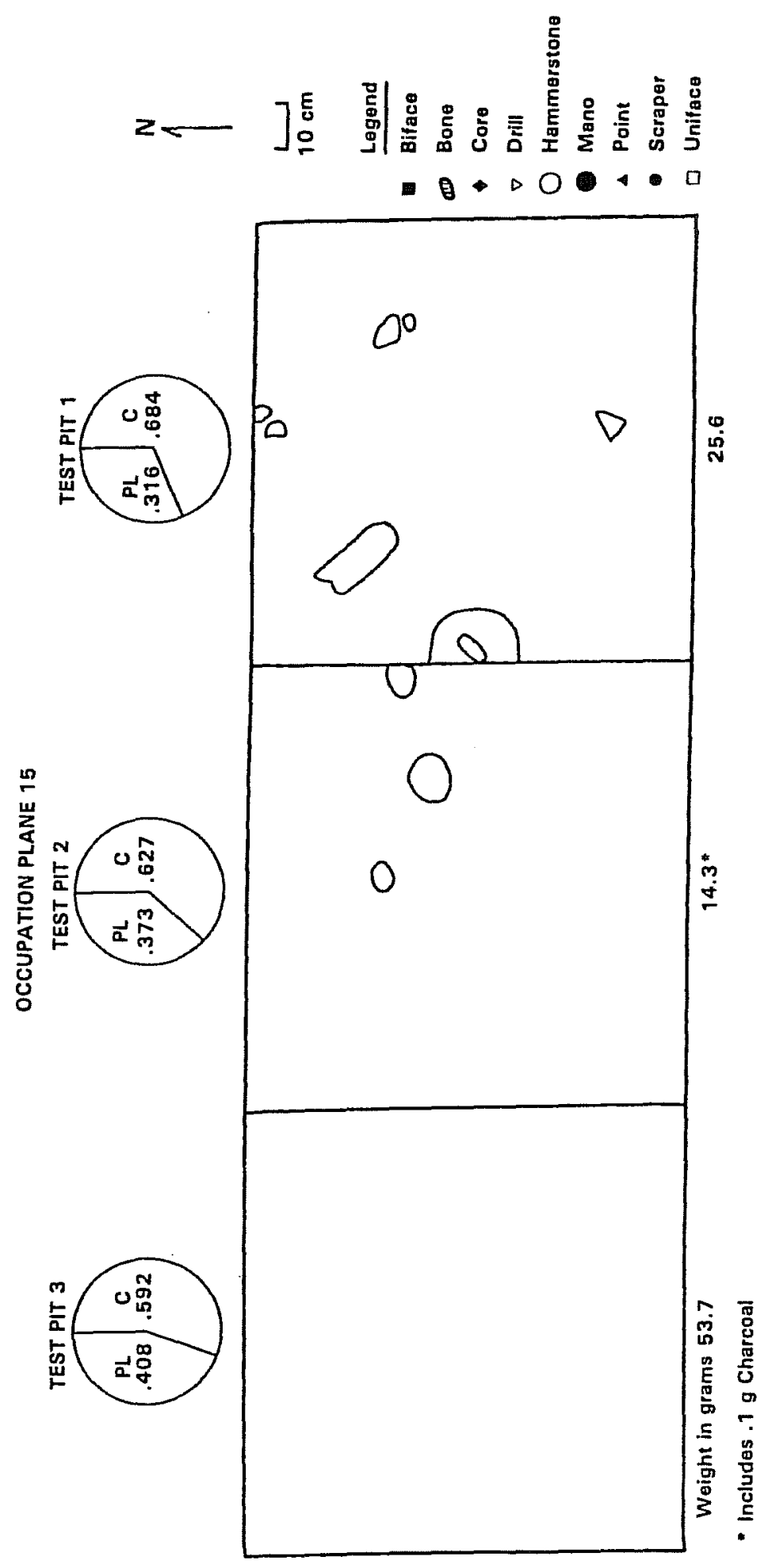

Figure 11.07. Occupation Floor 15. 
although the amounts of burned material are rather low. Three flakes and chips show signs of soft wear (nibbling), and three chips evidence harder wear (step fracturing). The weight and count of burned material is highest in Test Pit 3 , where a crazed, unidentified point, a point fragment, and a beveled tool were found. Aquatic shell appears on the occupation floor.

\section{Occupation Floor 25}

A possible Plainview point marks this as the first Paleoindian floor. The Paleoindian levels were generally excavated in 5 or $10 \mathrm{~cm}$ levels, lacking the midden structure necessary for the rapid microstratigraphic excavation appropriate to a testing operation. The diagnoses are, therefore, more generalized, but certain qualitative suggestions can still be made.

Perhaps some generally applicable remarks would be helpful. The amount of lithic materials recovered from these lowest levels was greatly reduced compared to the upper levels. Any large weights are derived from the presence of either a large flake or fire spalls. The percentage of burned material for these floors is high relative to the total amounts, and the recovery of bone is greater relative to lithic material. The burned/not burned relationship for bone is also higher. The proportion of crazing to potlidding becomes ineffective as a diagnostic devise because of the small amounts of lithics. Rocks mapped on the floors are large, with but one exception, in Test Pit 2, level 26. The matrix was screened through 1/4-inch mesh screen, with the exception of the southwest quadrant of Test Pit 2, which was screened through 1/8-inch mesh as a control. Indications are of short-term occupation, camping by the water, cooking game, moving on, making this site in essence, a Paleoindian stop-over spot.

Test Pit 2 exhibits the best evidence for a hearth feature. Notations made in the field report a large number of flat rocks in this unit, and a possible Plainview point was located here. Five fractured chert nodules may be associated with stone boiling.

Test Pit 1 yielded an edge-ground Nolan point and a biface, but no burned chips or flakes, and only one piece of burned bone. Test Pit 3 had only one crazed chip, and five pieces of bone, all burned.

\section{Occupation Floor 27}

This floor was selected for analysis because of a mapped (Figure 11.08) and photographed (Figure 11.09) feature, recognizable as a hearth in Test Pit 1 . The amount of burned flint and bone in association with this feature is quite low, a seeming anomaly within our analytical model. A strict analytical examination of these units would probably not have pointed to the existence of this feature, and this points again to the validity of visual observation as an additional analytical tool. The discrete pattern and low material count reflect a short-term occupation, possibly 


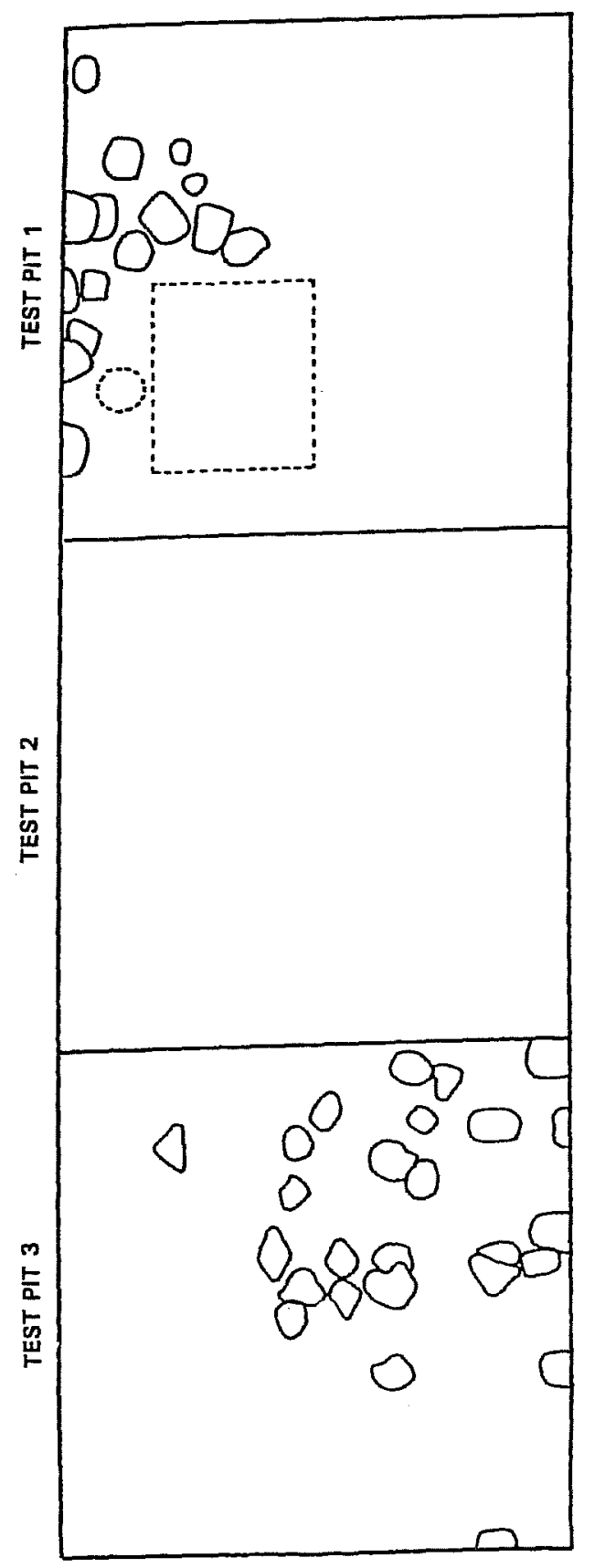

Figure 11.08. Occupation Floor 27. 


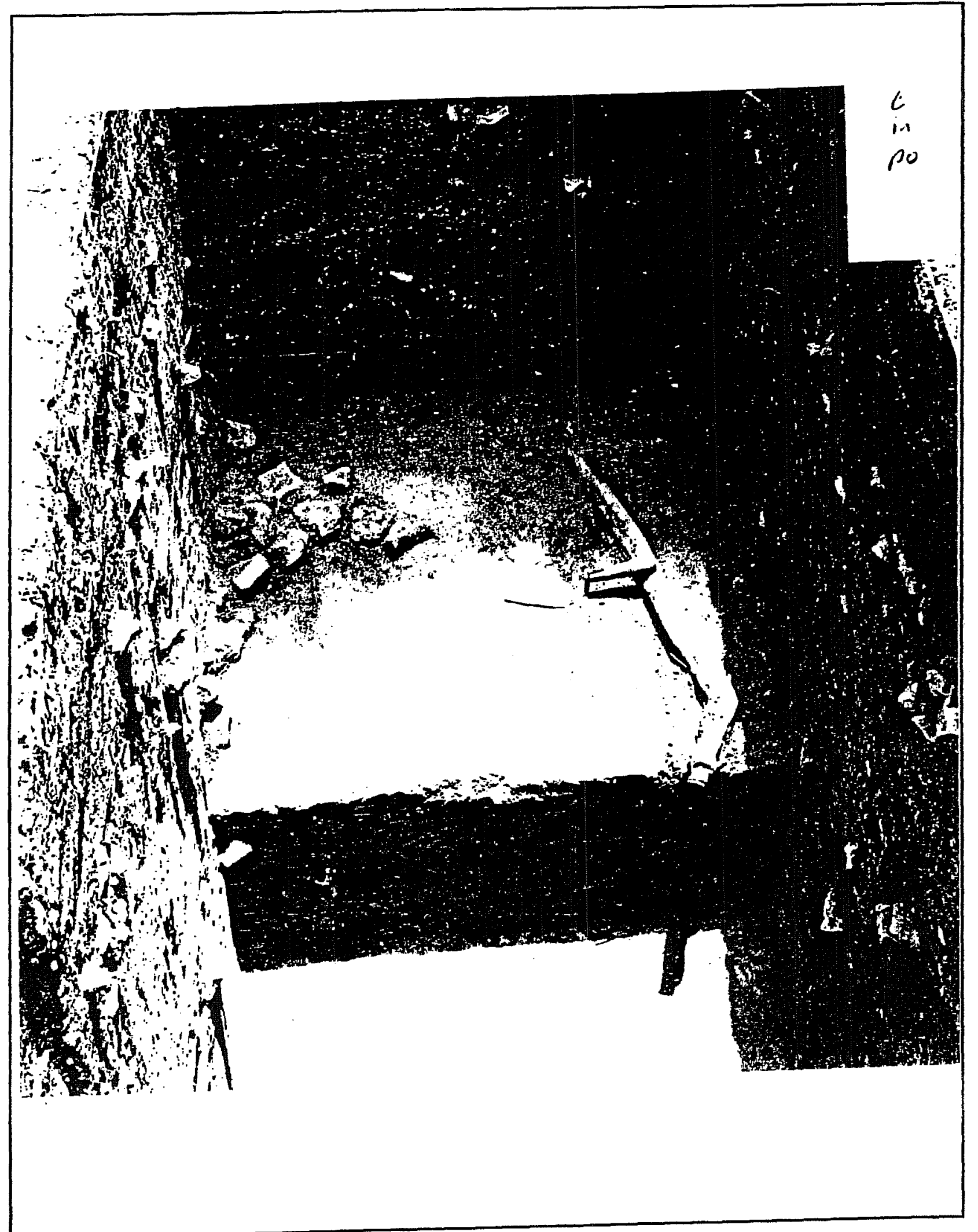

Figure 11.09. Occupation Floor 27, View East. 
just an overnight stay. The area within the dotted lines in Test Pit 1 (see Figure 11.08) was excavated as an arbitrary level with a shovel.

The lithic debris from Test Pit 3 contains the highest count of fire-altered flakes and chips from any of the excavated Paleoindian levels. Three fire spalls, two quite large, and both aquatic and terrestrial snails are present. The somewhat dispersed nature of the rocks could indicate a disturbed hearth. Rocks in the two features in Test Pits 1 and 3 are very similar in size and shape. A point of interest: on the level above, in Test Pit 2, a hackberry seed was found.

\section{Occupation Floor 29}

An Angostura point was recovered from this Paleoindian floor in Test Pit 1, the unit closest to Williams Creek. The high weight of fire-altered materials would probably mark it as a hearth area. The amount for the weight of fire-altered material is somewhat skewed, however, by the presence of a large $(24.5 \mathrm{~g})$ crazed flake. Two chert fragments of moderate size and a piece of charred bone were also found.

Only one burned lithic piece came from Test Pit 2. Test Pit 3 yielded five crazed and potlidded flakes and chips and ten fragments of bone, four charred.

\section{Occupation Floor 31}

This Paleoindian floor shows a pronounced difference from the upper levels. It contains (Figure 11.10) a rectangular, or square-shaped feature, which suggests a different cultural pattern. The cultural pattern of this period may have differed from that of later periods, but it is unknown whether this also reflects different subsistence strategies. The rock partially exposed in Test Pit 2 appears to be the result of an intentional disruption of the pattern. This flat rock was possibly removed from the corner of the fireplace and then used as a metate. A large $(43.6 \mathrm{~g})$ potlidded chip was present as well as rolled quartz pebbles. The placement of the feature is to the north and no material was recovered from the southwest quadrant.

Notations made on Test Pit 1 indicate that large pieces of flat rock were present at the bottom of the level, perhaps indicating the presence of associated hearthstones. Two very large fire spalls and one piece of charred bone were recovered.

\section{Occupation Floor 33}

An Andice-like tip in Test Pit 1 was recovered from Occupation Floor 33. The weight of burned bone, with fire spalls eliminated, now exceeds that of the remaining lithic material. Almost $4 \mathrm{~g}$ of bone came from Test Pit 3 alone. The scarcity of lithic materials suggests a short stay at the site, probably just a visit to exploit the faunal resources of Moccasin Confluence. 


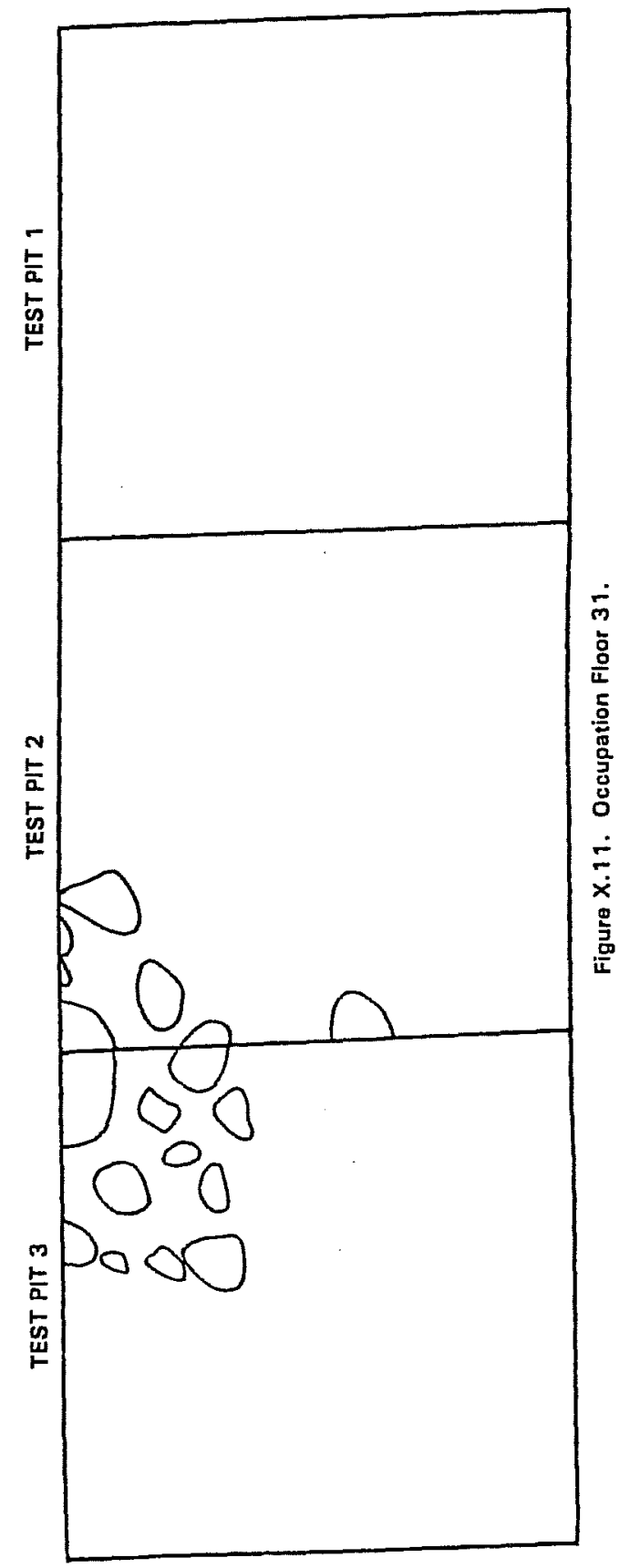

Figure 11.10. Occupation Floor 31.

Lower Fredericksburg Basin Page 169 


\section{Occupation Floor 36}

A possible Paleoindian point fragment was recovered from Test Pit 2, as were terminal tool fragments. The point fragment was a medial section, heavily patinated and, was located in the southwest quadrant with a trimmed flake. Notations from the field indicate the presence of burned rock. Charred bone was noted below the point fragment. This would suggest the presence of a hearth. Test Pit 1 yielded a single potlid. Test Pit 3 was not excavated down to this level.

\section{DISCUSSION}

The circular patterns of rock noted on midden floors appears repeatedly. Gunn (1977b:223) stated that a systematic hypothesis of midden structure would aid in delineating their functional character. It is suggested that the rock patterning observed at Moccasin Confluence could be such a structure, and could serve as a generalizable interpretive devise.

The patterns of repeated, interconnecting circles seen in the photographs (Figures. 11.01 and 11.04) of the midden floors were suggested to be the product of multiple and simultaneous activities, and also to be the result of a specific function, that of stone boiling. The observations from the limited area opened in the 1982 excavations relative to the size of the site is suggestive as a glimpse of the scope of such activity: As an hypothesis we propose the mass processing of an indigenous resource such as that frequently reported in the ethnographic record.

In addition to the discussion of acorn utilization by Kroeber (1932), mentioned in the early paragraphs of this chapter, a look at historical observations of acorn utilization also provide some interesting insights into the presumed aboriginal subsistence patterns at Moccasin Confluence.

The acorn has been used almost universally for sustenance. Spatially, the utilization of this resource in the Old World extended from Iberia in the West to New Guinea in the east (Gifford 1936). In the New World, at the time of European contact, acorns formed a substantial part of the diet of Indians from California to the Eastern Woodlands.

Ethnographic reports point to the widespread practice of boiling acorns to remove the tannic acid, before final processing. In the eastern woodlands Gifford (1936) reports that boiling of whole acorns was the common method of leaching. In some areas in California the acorns were first ground, and then the meal was boiled in a basket by the stone boiling method.

To the native Indians of California, the acorn was the staff of life (Merriam 1918). Of high nutritive value, and often the principal component of the diet, the effect of the 
acorn as a staple food is attested to by a population of over 300,000 individuals at the time of European contact.

The acorn also played an important role in the subsistence patterns of the Iroquois, the Algonquins, and the Hurons in the eastern woodlands (Merriam 1918). Although, "their former employment remains only a memory," the Iroquois use of acorns was recorded by Parker (1910). They would boil the acorns in wood ash (lye) as a means to leach the bitter tannic acid and render the acorns palatable. The nuts were then roasted and ground and, after several washings, cooked with meat to make a soup or pudding. The fact that acorns have been found in Hopewellian mounds and refuse pits (Streuver 1962) shows something of the age of the custom.

Merriam's (1918) observation of a ceremony for the dead points to the abundance and importance, of the acorn. He reports two cooking and five leaching places in active operation for several days. He counted 50 baskets, containing one to two bushels each, of freshly cooked acorn mush, and at least 50 loaves of acorn bread. He also reports the use of acorns for bread and oil by the Algonquins in the east. A Jesuit account of buying 500 bushels of acorns from an Algonquin tribe illustrates the abundance and importance of the acorn to these people. Also noted was the establishment of acorn camps, to which the groups returned each season.

Newcomb (1961) cites usage by such Texas tribes as the Comanche, the Tonkawa, the Caddo and the Bidais. The possibility of such occurrences during the prehistoric period are almost certain in the central Texas region at the time of the ubiquitous burned rock middens. The system of rock patterning observed on the midden floors at Moccasin Confluence may reflect activities associated with boiling and/or leaching in baskets, skins, or trays. The location is near oak groves (see chapter 5) and water, the two essential ingredients. The midden exhibits a large quantity of burned rock, and the association of acorn processing and the development of these middens is logical.

In addition to ethnographic support for the acorn hypothesis, archaeologists have pointed out further logical support from prehistoric sites themselves. Hester (1973) notes the proximity of major sites to oak groves. Weir (1976) and Turner (1977a) have associated the presence of middens with acorn utilization for various reasons. The presence of deer bone, which subsist in part on acorns, further supports this conclusion.

Presumably, then, communal gatherings were held to process large crops of acorns in the fall. Women and children might have collected acorns on the ground, and the men often reportedly assisted in obtaining acorns by climbing trees (Driver 1961). Skins or waterproof baskets were on or inside the rock features. Large amounts of limestone rocks were being heated nearby to be used as boiling stones or possibly leaching agents, as suggested by Turner (1977a). Sodium ash could also be used to leach the tannic acid from the acorns to make them more palatable (Driver 1961). The skins or baskets were filled with water from the nearby creek, and then the acorns were placed in the water. Boiling stones and a leaching agent (possibly the 
same, Turner 1977a) were added. The acorns were simultaneously cooked and leached of their tannic acid. The limestone rocks were then discarded, and an accumulation of these could create an aboriginal dump as suggested by Hester (1971). The dense midden structure around Test Pit 4 at Moccasin Confluence might represent just such a "dump." The procedure described above would have been repeated until the entire crop was processed.

\section{CONCLUSIONS}

Two distinctive periods of rock use are apparent in the Moccasin Confluence levels. The first is associated with the midden. The midden floors date from the Late Archaic to the later phases of the Early Archaic. Amounts of lithic artifacts are high, as is the proportion of crazed and potlidded chips to those not fire altered. Information from visual observation is interpreted in relation to possible subsistence patterns. Evidence from spatial patterning, observations noted, and artifacts collected indicate reliance on some sort of plant resource, which we suggest to be acorns. The utilization of faunal resources seems centered on the exploitation of white- tailed deer, based on the assemblage of bone recovered. Gunn (1983a) and Weir (1976) propose a model relating the moist period, the Colorado subpluvial (chapter 5) when these middens were under development, to the movement of people from the east following the encroachment of oak woodlands.

An older pattern appears on Occupation Floor 12, the end of the Early Archaic. The indications of the presence of large herbivores (bison), the introduction of different diagnostic artifacts, and a difference in the spatial ordering and consistency of rock size probably indicates a different character of the local and regional biotic system, as well as a cultural change.

No clear pattern emerges through the remaining Early Archaic period. Lithic material is much less evident. There is still evidence of hearths, although analysis of more floors is needed to deduce the overriding patterns for this period.

Occupation Floor 25 begins the Paleoindian occupation. The amount of lithic materials drops sharply when compared to later periods. The percentage of burned pieces is high relative to the totals, and rocks mapped are large. A very distinctive pattern, the square hearth, appears on Occupation Floor 31. Diagnostics suggest a Plains influence on these Paleoindian floors. Throughout the floors was a consistently high proportion of burned chips to crazed and potlidded flakes.

In conclusion, influence from the east and west is evident. Prehistoric peoples from both areas followed the shifting ecotone to arrive at the Moccasin Confluence area. A reliance on the local fauna was noted, and a possible dependence on acorns for subsistence was suggested. Further intensive recovery of micro and macro faunal and floral remains are needed to confirm the specific character of the activities being performed at the site as suggested by this preliminary analysis. 


\section{CHAPTER 12-SETTLEMENT PATTERNS IN THE LOWER FREDERICKSBURG BASIN (Gunn)}

\section{INTRODUCTION}

With the exception of the 1976 excavation season at Hop Hill, efforts during succeeding periods of the project have included a focus on understanding the settlement pattern in the LBJ State Historical Park and the surrounding area. In 1978 a survey was made along a $20 \mathrm{~km}$ (13 mile) strip south of the Pedernales River. The strip extends from the river to the uplands toward the south. The study area was centered on the park and, through questioning of residents, 13 sites in the area neighboring the park were located. In 1982 all of the sites in the park east of Hop Hill were tested. Both of these exercises contributed to what is now understood about the arrangement and distribution of archaeological sites within the park and the park vicinity. Limited inferences can be made about the functional relationship between sites in the park and those in the park environs, using the location and content of these sites. This chapter reports on these findings. The results can be taken as ideas for further testing during future work in the Fredericksburg area at large. This chapter also focuses on, and makes use of, much of the research reported in previous chapters.

\section{PHYSIOGRAPHY OF THE PARK ENVIRON}

Figure 12.01 is a map of the Pedernales River, a tributary of the Colorado River. Fredericksburg, Texas, in the western portion of the valley, is the largest town in the valley and as of 1980 incorporated a population of 5536 persons. Johnson City at the east end of the valley has 932 inhabitants. Fredericksburg was settled in 1846 by German emigrants and is notable for peaceful relations with the Comanches. Johnson City was established later by Anglo settlers and is the town in which Lyndon B. Johnson was educated. The LBJ Ranch is between the two towns near the community of Stonewall, and on the north side of the river. The Lyndon B. Johnson State Historical Park is opposite the ranch on the south side of the river. Williams Creek marks the eastern end of the park. The study area was selected to center on the park and extends from Rocky Creek in the east and South Grape Creek in the west. The study area is between the towns of Rocky Creek, and Luckenbach, Texas. 


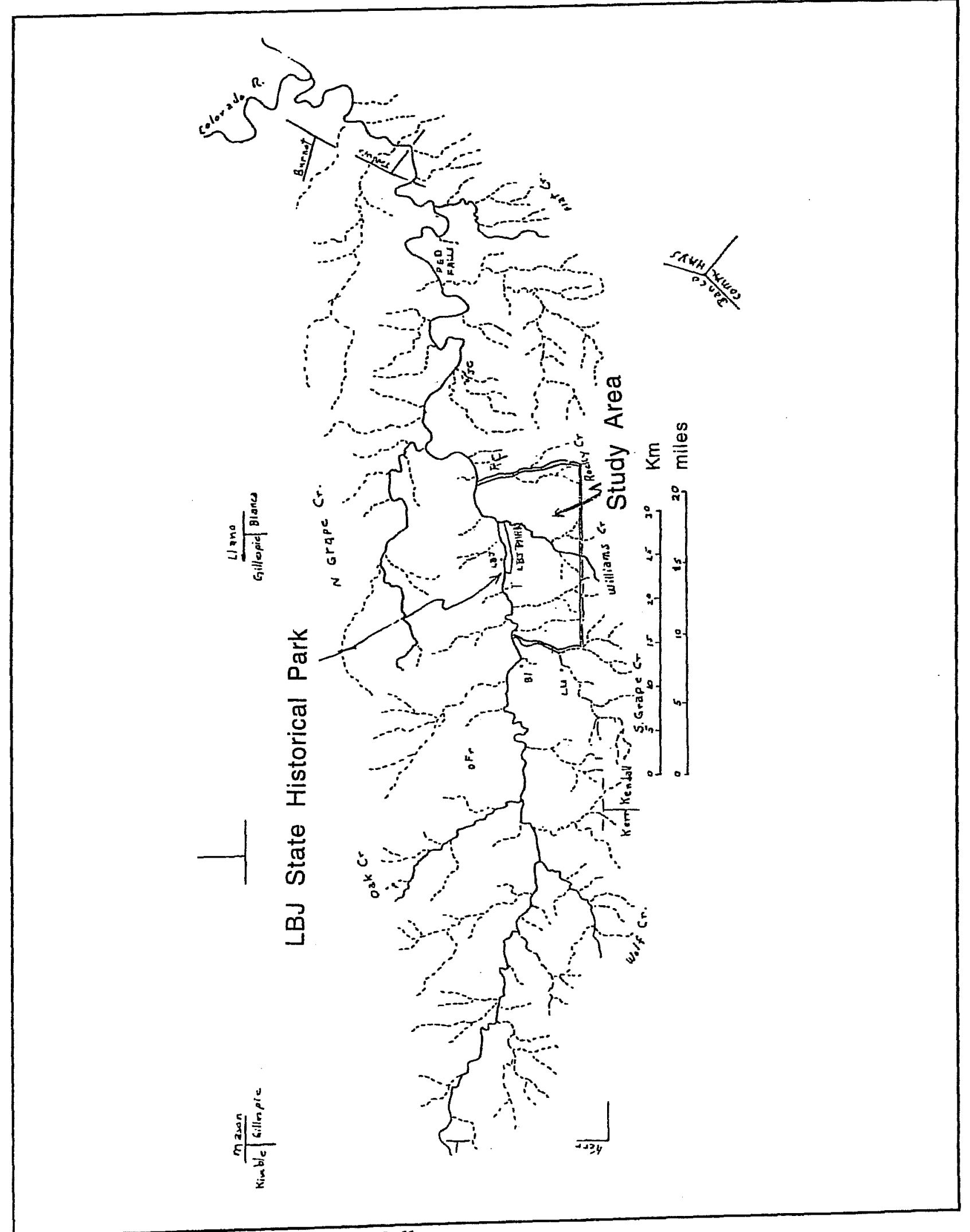

Figure 12.01. Pedernales River Valley. 
A remnant of resistant Pre-Cambrian rock extends from the Central Mineral Region of Texas south to the Pedernales River between Rocky Creek and Johnson City (Renfro, Feray, and King 1973, see geology in chapter 5). This creates an upland and a choke between Rocky Creek and Johnson City that gives the upper Pedernales Valley its basin shape. The Fredericksburg basin is a rich agricultural region. It is particularly noted for the excellent quality of its peaches, a commodity for which Stonewall is famous. Residents attribute the quality of the peaches to the minerals contributed by the central mineral region which the Pedernales River, in part, drains.

In the east at Rocky Creek the elevation is 1300 feet above mean sea level (amsl). At Grape Creek the elevation is 1460 feet amsl, a gradient of 12 feet per mile. Above the floodplain to the south the countryside rises to about 1500-1600 feet amsl (Figure 12.02). The highest point in the study area is 1831 feet on the Mayer property. We were privileged to visit this place in the company of Mr. and Mrs. Mayer, and it affords a spectacular view of the entire study area as well as evidence of prehistoric occupation.

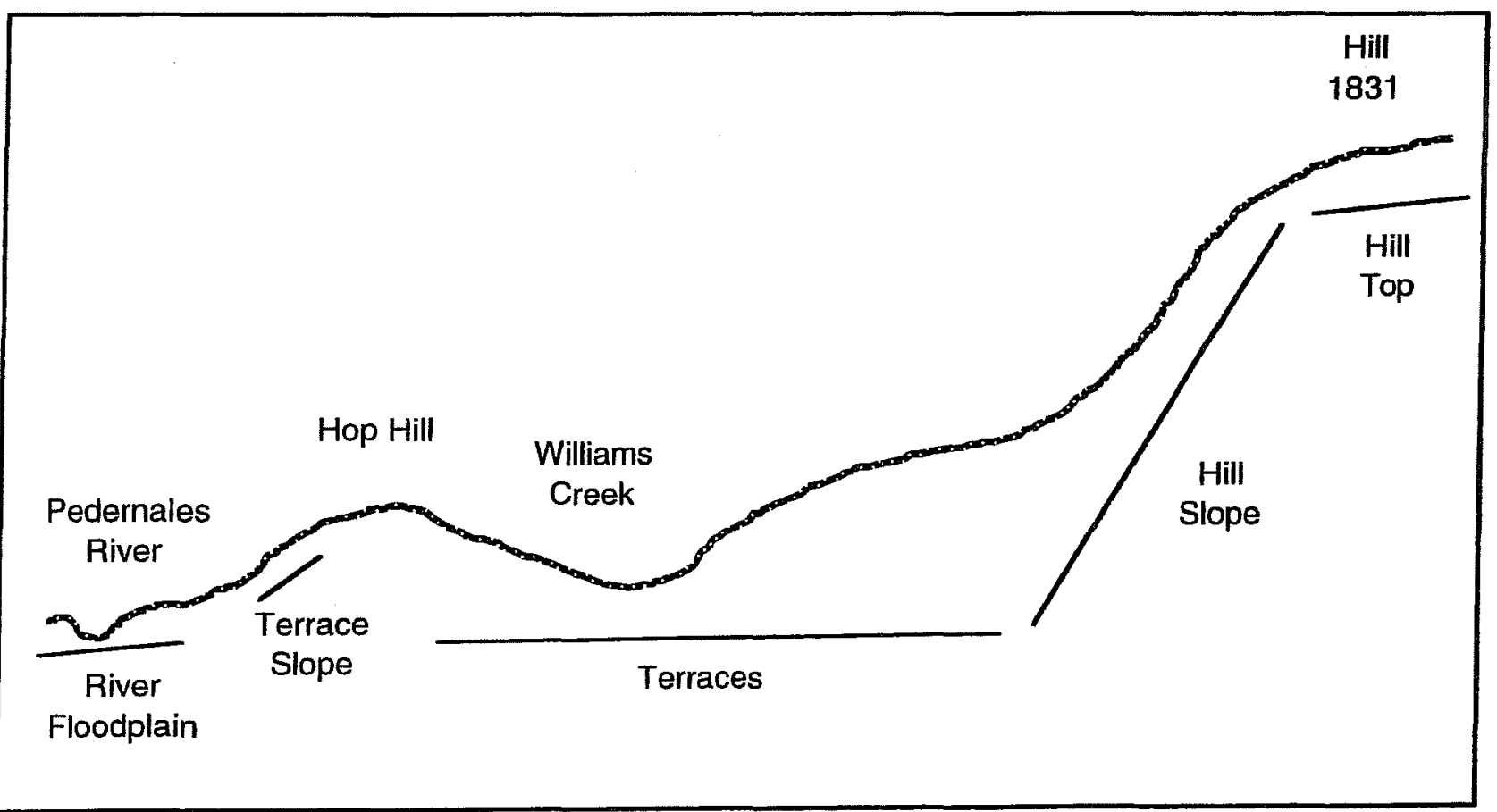

Figure 12.02. Transect of the Study Area, Hop Hill to Hill 1831.

Occasional low spots or swamps are found in the lower terraces and floodplain. In dry years they are farmed. In wetter years they fill with water and provide habitat for migratory birds. 


\section{Geomorphic Observations}

A few observations can be added to those made by Brown in chapter 5 on the geomorphology of the study area. The river floodplain deposits appear to be underlain by a gravel bed as can be observed near the Grape Creek Highway 290 bridge. The gravels are covered by up to three meters of alluvial sediments and soils. An erosional incision near the park headquarters shows this very well. The terraces are overlain by a red soil, the Luckenbach-Pedernales- Heatly Association (Figure 12.03) under which is generally a caliche zone or limestone bedrock. This applies to everything from the terrace margin (see Figure 12.02) immediately adjacent to the river, as at Hop Hill, to the break in topography at the hill slope. Modern land use consists of farming the sandy loams of the river floodplain and lower terraces. Grain crops are grown in the higher terraces. The bulk of the terraces and hills are grazing land.

\section{Hydrologic Observations}

The year 1978, when the environs were surveyed, was very dry. One person reported that up to the time of the survey (late June) they receive 30 inches of rain in good years. That year there were only 6 inches of rain by June. The archaeological crews lost no days to rain during the summer. Creeks that normally flow through the summer were reduced to holes of standing water and one individual thought the Pedernales River would stop flowing by mid July at the study area. Mr. Althaus, who showed us his land immediately upstream from Johnson City, indicated that a spring in the Pedernales River water course on his property never ceases to flow; it becomes the headwaters of the Pedernales River during dry years. This suggests that the area upstream from Johnson City, i.e., the Stonewall area, may be a particularly sensitive area to moist and dry conditions since anyone living there in prehistoric dry intervals would have had limited, if any, access to water. (Before the 1952 flood, which scoured out much of the valley, there was a mound near the Althaus spring that contained Paleoindian points.)

Springs at the heads of Rocky Creek, Williams Creek, Three Mile Creek, and South Grape Creek infrequently cease to flow; so they are also indicators of aridity of the climate. F. Mayer, who lives at the head of Williams Creek, has reopened the springs on his place with a bulldozer and found that even in dry years there is plenty of subsurface water. G. Lindig reports that the now dry gullies east and west of Hop Hill (41 GL 21) in the park flowed most of the year up to the 1920s. Now only the one to the east flows and only in moist years. Lindig's grandfather settled the land in the 1850s. 
Figure 12.03 removed 


\section{Vegetation}

The present-day vegetation is generally composed of live oak and mesquite which appears in decreasing frequency all the way to the hill tops. Several residents reported that about 100 years ago there was only grass outside the floodplains of permanent streams. Vegetation along the Pedernales River tributaries was dominated by hackberry and elm. Hickory groves were reported close to the river.

Whitworth reported that his grandfather burned off some part of his land each year, perhaps half, as a pest control measure. Burning off the land reduced the tick and locust problems in that and subsequent years. An additional effect was to reduce the brush and tree vegetation.

We have not determined if the Indian populations of the area burned off land during proto- and prehistoric times. The Comanches only occupied the area briefly before the coming of the Germans, from perhaps the latter decades of the $1700 \mathrm{~s}$ (John 1975; Gunn and Frkuska 1982). Comanches were not friendly with the Apaches or Tonkawas they were displacing, so it is unlikely they would have acquired and passed on their customs. However, the Germans were quite well acquainted with the Comanches, exchanging treaties and goods with them (Turner 1977b). It would be interesting to know if the land burning technology was developed by the settlers or passed from the natives and, therefore, a custom of long standing. The earliest German settlers were not farmers by trade. They had left Europe because of upheaval over religious beliefs, and were also isolated from other European settlements in Texas until about 1849, the beginning of the gold rush. The German settlers were, therefore, inclined to adopt whatever was useful from the Indian culture.

F. Merz, a lifelong resident of the Williams Creek area, reported that watercress grew in that stream early in the 1920s, but since then the grazing of sheep, which eat the watercress, has reduced its frequency.

\section{Wildlife}

The tributaries of the Pedernales River in the Stonewall area are not polluted by modern economic activities except that there is an increase of sediment load from farming activities. This seems to have started in 1917 in the terraces, and the effects are evident in the upper levels of Test Pits 1, 2, and 3 at Moccasin Confluence. Nevertheless, all of the streams we observed contained fish, catfish, perch, bass, and sucker. These were observed far up into the hill slopes.

Cottontail rabbit and jackrabbit, red squirrel, armadillo, raccoon, and fox were observed by the survey crews. Various kinds of small rodents, snakes, and lizards were also seen in numbers. Some of the hilltops have rattlesnake dens that are visited on occasion by the residents. 
Wild turkey, buzzards, various hawks, kill-dee, cardinals, mockingbirds, etc., were present, and migratory ducks were mentioned by the residents.

White-tailed deer are present throughout the study area. They are seen much more frequently in the more rugged terrain of the Rocky Creek drainage in the eastern part of the study zone, the uplift of Pre-Cambrian rock. G. Lindig (a third-generation resident of the area) says there were no deer in the 1930s and corn could be grown then. The deer have become so numerous since that it is difficult or impossible to grow corn. There is money to be made from deer leases.

The 1982 field season was the third in a series of moist summers. The quantities of wildlife, particularly deer, rabbits, and armadillos appear to have increased by about fourfold on the strength of two moist summers. This can be taken as indicative of the significant responsiveness of wildlife to environmental conditions.

\section{SURVEY METHODOLOGY}

In 1978 an informant survey was conducted in the park environ by students of The University of Texas at San Antonio, Summer Field Course in Archaeology. Informants, usually land owners, were sought by driving the roads in the study area and visiting the farm and ranch houses wherever they were encountered. The amount of area sampled depended on who was at home when the surveyors drove by. However, residents were generally very cooperative and in some cases, when they were missed, they sought us out to report on sites. The areas for which owners were found are mapped on Figure 12.04. Thirty-nine percent of the $250 \mathrm{~m}^{2}$ squares in the study area received coverage in this manner. Various forms were filled out for each informant and site reported. The locations, which at present qualify as sites, were reported to Texas Archeological Research Laboratory in Austin and assigned state numbers. Table 12.01 lists the sites, that were assigned the names of the land owners, the drainage, physiographic context, elevation, and the most characteristic artifacts of each site. The sites are ordered from the Pedernales River by drainage.

\section{PRESENT DAY SETTLEMENT PATTERN}

The floodplain of the Pedernales River is very wide toward the west and narrows considerably toward the east. Within the floodplain, farmers grow peaches, cotton, sorghum, corn, etc., on plots of ground from a few acres to hundreds of acres. Residents of Stonewall pride themselves on living in the peach growing capital of Texas and hold an annual Peach Jamboree and Rodeo in honor of peach growing. At progressively higher altitudes the uplands are dominated by larger and larger ranches ranging up to 2000-3000 acres. Cattle, sheep, and goats are raised. Also, lands are leased to deer hunters from adjacent urban areas, a practice that contributes substantially to local incomes. 


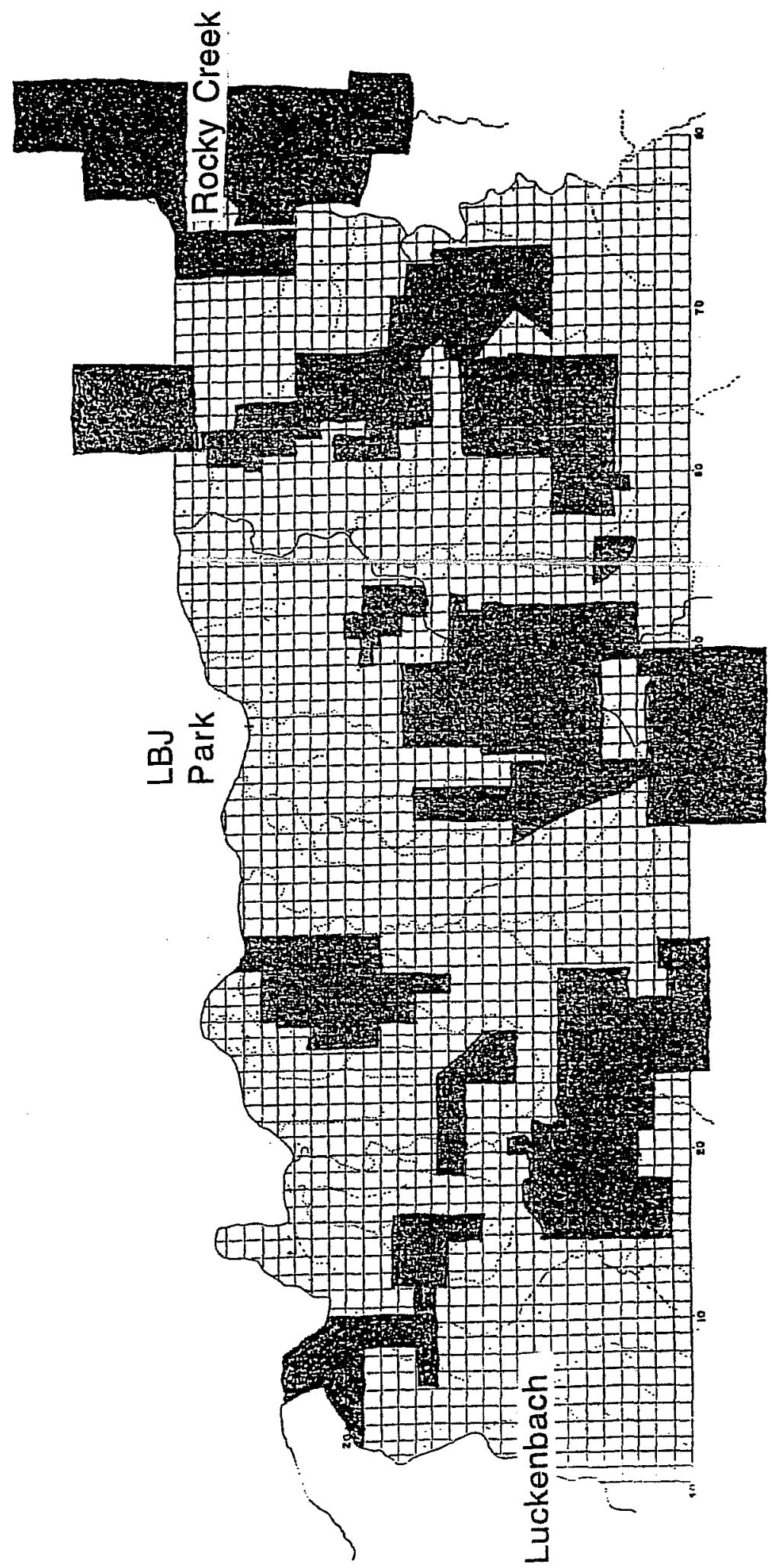

Figure 12.04. Properties on which Landowners were Contacted. 


\section{TABLE 12.01. SITES REPORTED BY INFORMANTS IN THE PARK AREA}

\begin{tabular}{|c|c|c|c|c|c|}
\hline Site Name & State 1 & Number & Artifacts & Elevatior & Physiography \\
\hline \multicolumn{6}{|l|}{ Rocky Creek } \\
\hline W. Lindig & $41 \mathrm{BC}$ & 90 & burned rock & 1380 & $\begin{array}{l}\text { terrace, small bluff over } \\
\text { creek }\end{array}$ \\
\hline Lange \#1 & $41 \mathrm{BC}$ & 89 & burned rock & 1460 & $\begin{array}{l}\text { terrace, West rock Fork } \\
\text { floodplain }\end{array}$ \\
\hline Lange \#2 & $41 \mathrm{BC}$ & 88 & points & 1490 & $\begin{array}{l}\text { terrace, foot of hill } \\
\text { slope }\end{array}$ \\
\hline Mayer \#2 & $41 \mathrm{BC}$ & 87 & flakes & 1560 & hill slope valley, narrow \\
\hline Mayer \#1 & $41 \mathrm{BC}$ & 86 & flakes & 1831 & $\begin{array}{l}\text { hill top, highest in } \\
\text { study area }\end{array}$ \\
\hline \multicolumn{6}{|l|}{ Williams Creek } \\
\hline $\begin{array}{l}\text { Moccasin } \\
\text { Confluence }\end{array}$ & $41 \mathrm{BC}$ & 71 & burned rock & 1380 & $\begin{array}{l}\text { alluvial, confluence with } \\
\text { Pedernales River }\end{array}$ \\
\hline---- & $41 \mathrm{BC}$ & 63 & burned rock & 1380 & $\begin{array}{l}\text { alluvial, confluence with } \\
\text { Pedernales River }\end{array}$ \\
\hline Basse & 41 GL & 144 & burned rock & 1460 & $\begin{array}{l}\text { terrace, Williams Creek } \\
\text { floodplain }\end{array}$ \\
\hline Merz \#2 & $41 \mathrm{GI}$ & 143 & cores & 1460 & $\begin{array}{l}\text { terrace, Williams Creek } \\
\text { floodplain, confluence }\end{array}$ \\
\hline Merz \#1 & 41 GL & 142 & manos & 1480 & $\begin{array}{l}\text { terrace, foot of hill } \\
\text { slope }\end{array}$ \\
\hline \multicolumn{6}{|c|}{ Three Mile Creek } \\
\hline Weinheimer & 41 GL & 138 & burned rock & 1500 & $\begin{array}{l}\text { terrace, edge of } \\
\text { farmlands }\end{array}$ \\
\hline $\begin{array}{l}\text { Kusenberger } \\
\# 1\end{array}$ & 41 GL & 139 & burned rock & 1580 & $\begin{array}{l}\text { terrace, foot of hill } \\
\text { slope }\end{array}$ \\
\hline $\begin{array}{l}\text { Kusenberger } \\
\# 2\end{array}$ & 41 GL & 140 & burned rock & 1560 & hill slope valley, wide \\
\hline \multicolumn{6}{|c|}{$\begin{array}{l}\text { Pedernales River } \\
\text { Moccasin see above } \\
\text { Confluence }\end{array}$} \\
\hline Hop Hill & $41 \mathrm{GL}$ & 21 & choppers & 1430 & terrace margin \\
\hline Burg & $41 \mathrm{GL}$ & 141 & choppers & 1450 & floodplain \\
\hline Pickett & 41 GL & 137 & choppers & 1480 & terrace margin \\
\hline
\end{tabular}

The Williams Creek floodplain provides an avenue for agriculture leading away from the Pedernales River. Its rich and mature floodplain allows the practice of farming up to the town of Albert which is on the southern margin of the study zone. The farming is associated with the Frio-Guadalupe soil association (see Figure 12.03).

\section{Collectors in the Study Area}

Usually residents of the study area are interested in "arrowheads" or points and collect them from their own land. This occurs usually after plowing and rains. J. Porter reported that the best time for finding points on unplowed land is at the end 
of the winter before the grass begins to grow. Residents consistently reported that points were found regularly up to about 20 years ago. After that time they become much harder to find. Once a serious interest in collecting developed, surface finds disappeared.rapidly. This reflects the thinness of the terrace soils over the bedrock and the consequent shallowness of the sites.

Several collectors allowed us to look at collections from their property and in some cases outlines of points were made. Ida Feldstead has lived in the vicinity of the Hye Post Office (eastern sector of the study area) all of her life (83 years as of 1978) and has collected points off the floodplain for about 45 years. Her collections are mostly from east of Stonewall and in the Pedernales River floodplain. She has about 2000 points, some of which were collected in other parts of the United States.

Warren Smith does not live in the study area. However, he dug a site on the W. Lindig property and retains most of the collection labeled with an " $\mathrm{L}$ " for Lindig.

\section{Collectors and Prehistoric Occupation Density}

Aside from knowing the location of sites on their own land, land-owners usually are aware of the best places to collect in the area. People in the study area generally recognize a site on the F. Merz property as the best place to collect. Apparently the same rich soils that attract modern farmers to settle away from the Pedernales River along Williams Creek also attracted prehistoric interest. The Hop Hill locality is also widely recognized. As mentioned above, I. Feldstead collected near Hye, Texas, and W. Smith in the Rocky Creek area. We were not able to locate any collectors who frequented the area west of Stonewall in the Three Mile and Grape Creek drainages. Our surveying seemed to confirm a lack of significant sites. However, the pattern has to be qualified with one observation. C. Weinheimer never found a point on his place in the Three Mile Creek drainage west of Stonewall until a few years ago when he had a water reservoir constructed. In the construction process a substantial site was unearthed. Victor Nixon from Fredericksburg reported heavy collecting of artifacts from about Blumenthal (west of the study zone, Figure 12.01) to Harper (west of Fredericksburg).

J. Ohlenburg (District Conservationist, Fredericksburg) has worked all over west Texas and thinks that the concentration of artifacts in the Fredericksburg area is greater than any he has seen elsewhere.

The pattern of occupation as seen from collector's eyes, then, is one of intense occupation around Fredericksburg and the Williams-Rocky Creek areas with little between the two concentrations. In the intervening area are Three Mile and Grape Creeks that are low lying and may have been unattractive for more permanent occupation for that reason, or the sites may be buried under the floodplains. 


\section{Prehistoric and Modern Occupation Density}

One very interesting fact came out of the survey interviews. Persons occupying terrace land for the purpose of subsistence in areas in which sites occurred frequently showed us at least two sites on their property. This includes people who were very helpful and willing to spend any amount of time showing us around. Those who did not, often spoke of minor or destroyed sites. It is likely that prehistoric sites occur in a ratio of 2:1 to modern property holdings. The reason for this relationship must have something to do with the amount of land present-day property owners acquire along streams, since most sites occur along semipermanent tributaries. Also, when the great variation in the size of farms and ranches in the study zone is considered, it suggests that the frequency of sites on properties is related to carrying capacity in the same way that modern economy dictates the distribution and size of farms and ranches.

At this time I can offer no explanation for the concentration of sites around Fredericksburg. It should be made a matter of study. However, the attraction to the lower basin around Williams and Rocky Creek may have been the convergence of the river with the Pre-Cambrian uplands. This convergence produced a profusion of habitats in a narrow space, all of which was well watered during moist climatic episodes. As is typical the world over, a variety of resources next to water attracts human occupation. Since the area is above the only permanent spring at Johnson City, however, it must have been occupied by relatively sedentary people on a periodic basis depending on climate.

\section{SETTLEMENT PATTERN AND SITE FUNCTION IN THE PARK AND ITS ENVIRONS}

The settlement pattern in the park is known in great detail because of surveys performed by the Texas Parks and Wildlife Department in 1975 and 1977 (reported in the previous research sections of chapter 2), and testing of all of the sites found in the eastern half of the park during 1982 are reported in previous chapters. Moccasin Confluence at the juncture of Williams Creek and the Pedernales River has all the marks of long-term occupation by many cultures. The intensity of occupation indicates base camp or semipermanent status. During the Late Archaic this intensity of occupation was supplemented by an even more intense occupation of Hop Hill, a probable bison overlook site. Various other sites in the terrace margin and terrace slopes near Moccasin Confluence appear to be lithic workshop stations, based on the appearance of the lithics. An occasional piece of ground stone indicates other activities, as do occasional chopping tools.

Characteristic tools from the sites in the park environ likewise suggest some possible site functions. Choppers were found in great numbers at Hop Hill (Gunn and Ivey 1977), and the sites revealed by the survey along the Pedernales River (see Table 12.01) are reported to be characterized by bifaces and choppers. The heavy 
nature of the choppers suggests that they were being used to work wood in the riparian zone. Sites in the terraces typically contain middens of burned rock. Current wisdom associates middens with nut and deer processing, a not unreasonable, but yet to be substantiated, inference. However, as Larson (1980) points out, deer are most frequent at the edge of the riparian zone as are the most productive oaks and hickories. It is therefore likely that if the middens were being used for deer and nuts, they would be located just where they were located.

Perhaps the most interesting site, with respect to function, is the Merz \#1 site (41 GL 142 shown on Figure 12.C 4). F. Merz reports that he has collected a bucketful of manos (and metates) from the field every year since it was first plowed in 1917. He has fenced his yard with these manos and metates. The site is located at the break in topography between the terraces and the hill slopes. Presumably the hills would always have been more prone to grassy vegetation than the rest of the topographic features in the basin. Indians observed ethnohistorically in the western United States typically awaited the coming of may/ricegrass seed in the late spring with great interest since they were usually running short of food and the maygrass was the second most important edible plant product after pine nuts (Thomas 1973:164; Steward 1938:104). Harvest sometimes began as early as May (Steward 1938:96). Since the manos appear in such great profusion at a well-watered place at the juncture of the lowlands and highlands, it is likely that they were there for some sort of grass or weed-related seed collecting, perhaps the maygrass. At 41 GL 142 such seed processing was carried out in great numbers. Manos and metates appear less frequently in terrace and floodplain sites. One metate seems to be the norm.

From the information collected from within and without the park, a seasonal round of activities can be inferred for the prehistoric inhabitants of the park. They would have preferred to live at Moccasin Confluence most of the time. However, they would have retired up Williams Creek in the spring to collect and process seeds into cakes, perhaps storing enough flour or cakes to last the year. The later summer would have involved maturing native fruits, berries, and wild vegetables. In the fall they would have worked the middle ground between the hills and river for nuts and deer. All parts of the year they would have supplemented their diet with small game, root crops, cactus, etc.

As yet we know little about the time structure of these activities. Widespread burned rock middens in the study area suggest that between 2000-3000 years ago the year-round activities would most have resembled those outlined in the previous paragraph. During the Paleoindian period about 10,000 years ago and in the last 1000 years those activities would have been supplemented or replaced by big game hunting, bison in most cases. Further research in the sites away from the river would be necessary to discover times when the differing approaches to diet and survival were taken. 


\section{REFERENCES CITED}

Ahler, S. A.

1979 Functional Analysis of Nonobsidian Chipped Stone Artifacts: Terms, Variables, and Quantification. In Lithic Use-Wear Analysis, edited by B. Hayden, pp. 301-328. Academic Press, New York.

Alexander, H. L.

1963 The Levi Site: A Paleoindian Campsite in Central Texas. American Antiquity 28:510-528.

Assad, C. and D. R. Potter

1979 Intensive Archaeological Survey of Enchanted Rock State Natural Area. Center for Archaeological Research, The University of Texas at San Antonio, Archaeological Survey Report 84.

Baillie, M. G. L.

1994 Dendrochronology Raises Question about the Nature of the AD 536 DustVeil Event. The Holocene 3:212-217.

Balée, William

1989 The Culture of the Amazon Forests. Advances in Economic Botany 7:1-21.

1993 Indigenous Transformation of Amazonian Forests: An Example from Maranhao, Brazil. L'Homme XXXIII:231-254.

Baker, V. R. and M. M. Penteado-Orellana

1977 Adjustment to Quaternary Climatic Change by the Colorado River in

Central Texas. Journal of Geology 85:395-422.

Barnes, V. E.

1964 Geology of the Hye Quadrangle, Blanco, Gillespie, and Kendall Counties,

Texas. Geologic Quadrangle Map 27, Bureau of Economic Geology, The University of Texas at Austin.

1965 Geology of the Stonewall Quadrangle, Gillespie and Kendall Counties,

Texas. Geologic Quadrangle Map 31, Bureau of Economic Geology, The University of Texas at Austin.

1981 Llano Sheet. Geologic Atlas of Texas. Bureau of Economic Geology, The University of Texas at Austin.

Beardsley, R. K., D. Holder, A. D. Krieger, B. J. Meggers, J. B. Rinaldo, and P. Kursche

1956 Functional and Evolutionary Implications of Community Patterning. In Seminars in Archaeology, edited by R. Wauchope, pp. 129-155. Memoirs of the Society for American Archaeology 11.

Benfer, R. A. and A. N. Benfer

1981 Automatic Classification of Inspectional Categories: Multivariate Theories of Archaeological Data. American Antiquity 46(2):381-396.

Bernabo, J. C.

1981 Quantitative Estimates of Temperature Changes over the Last 2700 Years in Michigan Based on Pollen Data. Quaternary Research 15(2):143-159.

Binford, L. R. 
1978 Nunamiut Ethnoarchaeology. Academic Press, New York.

1980 Willow Smoke and Dogs' Tails: Hunter and Gatherer Settlement Systems and Archaeological Site Formation. American Antiquity 45(1):5-15.

1983 In Pursuit of the Past: Decoding the Archaeological Record. Thames and Blair, W. F. Hudson, New York.

1950 The Biotic Provinces of Texas. The Texas Journal of Science 2(1):93-117. Blum, Michael D., Rickard S. Toomey III, and Salvatore Valastro Jr.

1994 Fluvial Response to Late Quaternary Climatic and Environmental Change, Edwards Plateau, Texas. Paleogeography, Paleoclimatology, Paleoecology 108:1-21.

Blum, Michael D., Salvatore Valastro Jr.

1989 Response of the Pedernales River of Central Texas to Late Holocene Climatic Change. Annals of the Association of American Geographers 79:435-456.

Borissavlievitch, $\mathrm{M}$.

1958 The Golden Number. Philosophical Library.

Brakenridge, G. R.

1980 Widespread Episodes of Stream Erosion During the Holocene and Their Climatic Cause. Nature 283:655-656.

Bryant, V. M., Jr.

1977 A 16,000 Year Pollen Record of Vegetational Change in Central Texas. Palynology 1:143-156.

Bryant, V. M., Jr. and H. J. Shafer

1977 The Late Quaternary Paleo-envirnoment of Texas: A Model for the Archaeologist.

Bulletin of the Texas Archeological Society 48:1-25.

Bryson, R. A. and B. M. Goodman

1980 Volcanic Activity and Climatic Changes. Science 207:1041- 1044.

Caldwell, J. R.

1958 Trend and Tradition in the Prehistory of the Eastern United States. American Anthropological Association, Memoir 88.

Campbell, D. H.

1962 Petrography of the Cretaceous Hensel Sandstone, Central Texas. Unpublished Masters Thesis, Department of Geology, University of Texas at Austin.

Campbell, T. N.

1975 The Payaya Indians of Southern Texas. Southern Texas Archaeological Association, Special Publication 1.

Cantwell, A. M.

1979 The Functional Analysis of Scrapers: Problems, New Techniques, and Cautions. Lithic Technology 8:5-11.

Cheatum, E. P. and R. W. Fullington

1973 The Aquatic and Land Mollusca of Texas, Part 2: The Recent and Pleistocene Members of the Pupillidae and Urocoptidae. Dallas Museum of Natural History, Bulletin 1. 
Crabtree, D. E.

1972 An Introduction to Flintworking. Occasional Papers of the Idaho State University Museum 28.

Crabtree, D. E. and B. R. Butler

1964 Notes on Experiments in Flint Knapping: 1 Heat Treatment of Silica Materials. TEBIWA 7(1):1-6.

Cuyler, R. H.

1931 Travis Peak Formation of Central Texas. Unpublished Ph.D. Dissertation, Department of Geology, The University of Texas at Austin.

Dillehay, T. D.

1974 Late Quaternary Bison Population Changes on the Southern Plains. Plains Anthropologist 19(65):180-196.

Dittemore, W. H., Jr. and J. E. Allison

1979 Soil Survey of Blanco and Burnet Counties, Texas. USDA Soil Conservation Service.

Driver, H. E.

1961 Indians of North America. University of Chicago Press.

Fitzhugh, W. W.

1972 Environmental Archaeology and Cultural Systems in the Hamilton Inlet, Labrabor. Smithsonian Contributions to Anthropology 16.

Flannery, K. V., editor

1976 The Early Mesoamerican Village. Academic Press, New York.

Frkuska, E. and A. Frkuska

1977 Hop Hill Lithics: Uniface Analysis. In Hop Hill: Culture and Climatic Change in Central Texas, edited by J. Gunn and R. Mahula, pp. 189-203. Center for Archaeological Research, The University of Texas at San Antonio, Special Report 5.

Fullington, R. W. and W. L. Pratt, Jr.

1974 The Aquatic and Land Mollusca of Texas, Part Three. The Dallas Museum of Natural History, Bulletin 1.

Gibson, E. C.

1981 Archaeological Investigations in Zavala and Dimmit Counties, Texas: The Internorth Pipeline Project. Center for Archaeological Research, The University of Texas, Archaeological Survey Report 110.

Gibson, E. C. and J. Gunn

1982 Use-Wear Analysis. In Eagle Hill: A Late Quaternary Upland Site in Western Louisiana, edited by J. Gunn and D. Brown, pp. 312- 316. Center for Archaeological Research, The University of Texas at San Antonio, Special Report 12.

Gifford, E. W.

1936 California Balanophagy. In Essays in Anthropology Presented to A. L. Kroeber, edited by R. H. Lowie, pp. 87-98. University of California Press, Berkeley.

Goodyear, A. C.

1974 The Brand Site: A Techno-Functional Study of a Dalton Site in Northeast Arkansas. Arkansas Archeological Survey, Research Series 7. 
Gunn, J.

1979 A Hypothesis for the Use of Cryptocrstalline Raw Materials Among Paleoindian Groups of North America. On file at Institute of Archeology and Anthropology, Research Manuscript, Series 156, University of South Carolina, Columbia.

1977a Envirocultural System for Central Texas. In Hop Hill: Cultural and Climatic Change in Central Texas, by J. Gunn and R. Mahula, pp. 257-276. Center for Archaeological Research, The University of Texas at San Antonio, Special Report 5.

1977b Analysis of Occupation Floors. In Hop Hill: Culture and Climatic Change In Central Texas, by J. Gunn and R. Mahula, pp. 223-234. Center for Archaeological Research, The University of Texas at San Antonio, Special Report 5.

1979a Impact of Climate Change: Working Papers. Research by Center for Archaeological Research, The University of Texas at San Antonio for the Ewing Halsell Foundation of San Antonio and the United States Bureau of Reclamation.

1979b Occupation Frequency Simulation on a Broad Ecotone. In Transformations: Mathematical Approaches to Culture Change, edited by C. Renfrew and K. Cooke, pp. 257-274. Academic Press, New York.

1981 General Coastal Seasonal Dynamics Climatic Model. On file at ECS Corp, Box 290097, San Antonio.

1982a Paleoclimatology of the Gulf of Mexico Coastal Plain. In Eagle Hill: A Late Quaternary Upland Site in Western Louisiana, by J. Gunn and D. Brown, pp. 74-118. Center for Archaeological Research, The University of Texas at San Antonio, Special Report 12.

1982b Form and Environment: Historical and Cultural Landscape Study of the San Antonio Missions. On file at San Antonio Missions National Historic Park and at ECS Corp, Box 380373, San Antonio.

1982c Excavation Activities and Techniques at Eagle Hill. In Eagle Hill: A Late Quaternary Upland Site in Western Louisiana, by J. Gunn and D. Brown, pp. 45-72. Center for Archaeological Research, The University of Texas at San Antonio, Special Report 12.

1982d Biface and Core Technology. In Eagle Hill: A Late Quaternary Upland Site in Western Louisiana, by J. Gunn and D. Brown, pp. 238-242. Center for Archaeological Research, The University of Texas at San Antonio, Special Report 12.

1982e Points as a Functional System. In Eagle Hill: A Late Quaternary Upland Site in Western Louisiana, by J. Gunn and D. Brown, pp. 242-254. Center for Archaeological Research, The University of Texas at San Antonio, Special Report 12.

1982f Interpretation of Occupation Plane Patterns. In Eagle Hill: A Late Quaternary Upland Site in Western Louisiana, by J. Gunn and D. Brown, pp. 318-343. Center for Archaeological Research, The University of Texas at San Antonio, Special Report 12. 
1983a Holocene Climatic Sequence for the Circum-Caribbean. In Culture and Climate Change in the Gulf-Caribbean Basin, edited by J. Gunn and V. Carbone. In preparation.

1983b Culture and Climate Change in the Paleoindian Period of Southcentral United States. Paper presented at the Paleoindian Lifeways Symposium II, Lubbock.

1984 Points from Peason Ridge and Nearby Areas. In Occupation and Settlement in the Uplands of West-Central Louisiana, edited by J. Gunn and A. C. Kerr, pp. 135-147. Center for Archaeological Research, The University of Texas, Special Report 17.

1988 Mobility Patterns in Central Texas. In Aboriginal Central Texas: Culture Change along the Central Texas Ecotone, edited by J. Fox, submitted for review.

1989 Regional Climates of Texas. MS on file, Garrow \& Associates, Inc., Chapel Hill.

1991 Influences of Various Forcing Variables on Global Energy Balance During The Period of Intensive Instrumental Observation (1958-1987) and Their Implications for Paleoclimate. Climatic Change 19:393-420

1992 Regional Climatic Mechanisms of the Clovis Phase on the Southern Plains. In Probocidians and Paleoindian Interactions, edited by J. Fox, C. Smith and K. Wilkins, pp. 171-190, Baylor University Press.

1994 Global Climate and Regional Biocultural Diversity. In Historical Ecology, edited by Carole L. Crumley, pp 67-97. School of American Research, Santa Fe.

1996 A Framework for the Paleoindian-Early Archaic Transition. In The Paleoindian and Early Archaic Southeast, edited by D. Anderson, and K. Sassaman, University of Alabama Press, Tuscaloosa.

Gunn, J. and R. E. W. Adams

1981 Climatic Change, Culture, and Civilization in North America. World Archaeology 13(1):85-100.

Gunn, J. and D. O. Brown

1982 Eagle Hill: A Late Quaternary Upland Site in Western Louisiana. Center for Archaeological Research, The University of Texas at San Antonio, Special Report 12.

Gunn, J. and A. Frkuska

1982 Climatic Effects on Mission History. In Form and Environment: Historical and Cultural Landscape Study of the San Antonio Missions, by J. Gunn, pp. 65-72. On file at San Antonio Missions National Historic Park and at ECS Corp, Box 380373, San Antonio.

Gunn, J. and J. E. Ivey

1977 Face Flaking Model - Bifacing (Curvilinear Technospatial Analysis). In Hop Hill: Culture and Climatic Change in Central Texas, by J. Gunn and R. Mahula:163-183. Center for Archaeological Research, The University of Texas at San Antonio, Special Report 5.

Gunn, J. and R. Mahula 
1977a Hop Hill: Culture and Climatic Change in Central Texas. Center for Archaeological Research, The University of Texas at San Antonio, Special Report 5.

Gunn, J. and R. Mahula, continued

1977b Flake Technology. In Hop Hill: Cultural and Climatic Change in Central

Texas, by J. Gunn and R. Mahula, pp. 235-252. Center for Archaeological

Research, The University of Texas at San Antonio, Special Report 5.

Gunn, J. and E. R. Prewitt

1975 Automatic Classification: Projectile Points from West Texas. Plains Anthropologist 20(68):139-149.

1985 Theory of Culture Change on Broad Ecotones. Ms. on file, Center for Archaeological Research, University of Texas at San Antonio.

Gunn, J. and F. Weir

1976 Tool Kit Hypotheses: A Case of Numerical Induction. Newsletter of Lithic Technology 5(3):131-135.

Gunn, J. and D. R. White

1977 Clustering of Technological Types (Non-Linear Technospatial Analysis,

Resov 4). In Hop Hill: Culture and Climatic Change in Central Texas, by J.

Gunn and R. Mahula, pp. 209-221. Center for Archaeological Research,

The University of Texas at San Antonio, Special Report 5.

Gunn, Joel D., and Anne Kerr (editors and contributors)

1984 Occupation and Settlement in the Uplands of West-Central Louisiana.

The University of Texas at San Antonio Center for Archaeological

Research Special Report 17.

Gunn, Joel, and Carole L. Crumley

1991 Global Energy Balance and Regional Hydrology: A Burgundian Case

Study. Earth Surface Processes and Landforms 16:579-592.

Gunn, Joel, William J. Folan, and Hubert R. Robichaux

1995 A Landscape Analysis of the Candelaria Watershed in Mexico: Insights into Paleoclimates affecting Upland Horticulture in the Southern Yucatan Peninsula Semi-Karst. Geoarchaeology 10:3-42.

Guy, J. and J. Gunn

1983 Settlement Patterns in the Ft. Polk Region. On file at Center for Archaeological Research, The University of Texas at San Antonio. Harris, M.

1979 Cultural Materialism: The Struggle for a Science of Culture. Random House, New York.

Hayden, B.

1977 Stone Tool Functions in the Western Desert. In Stone Tools as Cultural Markers: Change, Evolution and Complexity, edited by R. Wright, pp. 178-188. Australian Institute of Aboriginal Studies, Canberra.

Hayden, B. and J. Kamminga

1979 An Introduction to Use-Wear: The First CLUW. In Lithic Use- Wear Analysis, edited by B. Hayden, pp. 1-13. Academic Press, New York.

Hester, T. R. 
1971 Archeological Investigations at the La Jita Site, Uvalde, Texas. Bulletin of the Texas Archeological Society 42:51-148.

1973 The Formation of a "Burned Rock Midden": A California Example. The Record, Dallas Archaeological Society 29(3):4.

Hester, T. R., D. Gilbow, and A. Albee

1973 A Functional Analysis of Clear Fork Artifacts for the Rio Hughes, J. Grande Plains, Texas. American Antiquity 38:90-96.

1949 Investigations in Western South Dakota and Northeastern Wyoming. American Antiquity 14(4):266-277. Jackson, A. T.

1938 The Fall Creek Sites. Annual Report of WPA and The University of Texas Archeological Research, Lake Buchanan, 1936-1937, edited by J. E. Pearce. The University of Texas Publications 3802:11-118.

Jelinek, A. J.

1976 Form, Function, and Style in Lithic Analysis. In Cultural Change and Continuity: Essays in Honor of James Bennett Griffin, edited by Charles John, E. A. H.

Cleland, pp. 19-33. Academic Press, New York.

1975 Storms Brewed in Other Men's Worlds. Texas A\&M Press, College Station.

Johnson, E.

1982 Paleoindian Bone Expediency Tools: Lubbock Lake and Bonfire Shelter. Kelly, T. C. Canadian Journal of Anthropology 2(2):145-157.

1977 Analysis of Arrow and Dart Points. In Hop Hill: Culture and Climatic Change in Central Texas edited by J. Gunn and R. Mahula, pp. 185-188. Center for Archaeological Research, The University of Texas at San Antonio, Special Report 5.

Keeley, L. H.

1980 Experimental Determination of Stone Tool Uses. University of Chicago Press, Chicago.

Kerr, A.

1983 Information Theory Applied to Discerning General Adaptive Trends in Culture. Manuscript on file at Center for Archaeological Research, The University of Texas at San Antonio.

Klinger, T. C.

1978 Lowland Environmental Variability and Prehistoric Settlement Behavior in the Lower Mississippi Valley. Midcontinental Journal of Archaeology Kroeber, A. L. 3(2):285-331.

1932 The Parwin and Their Neighbors. University of California Publications in American Archaeology and Ethnography 29:253- 423.

Kukla, G. J.

1975 Missing Link Between Milankovitch and Climate. Nature 253(5493):600-603. 
Landscheidt, Theodor

1987 Long-Range Forecasts of Solar Cycles and Climate Change. In Climate: History, Periodicity, And Predictability., edited by M. Rampino, pp. 421-445, Van Nostrand Reinhold Company, New York.

Larson, L. H.

1980 Aboriginal Subsistence Technology on the Southeastern Coastal Plain during the Late Prehistoric Period. University of Florida Presses, Gainesville, Florida.

Leroi-Gourhan, A. and M. Brezillon

1966 L'habitation Magdalenienne No. 1 de Pincevent pres Montereau (Seine-et-Marne). Gallia Prehistoire, Fouilles it Monuments Archeologiques en France Metropolitain 9(2):263-385.

Lukowski, P. D.

1983 An Investigation of Cultural Changes During the Archaic and Late Prehistoric Central Texas. Manuscript on file at Center for Archaeological Research, The University of Texas at San Antonio.

Mahula, R.

1977 Recovery Procedures. In Hop Hill: Culture and Climatic Change in Central Texas, by J. Gunn and R. Mahula, pp. 121-136. Center for Archaeological Research, The University of Texas at San Antonio, Special Report 5.

1982 Lithic Period. In Eagle Hill: A Late Quaternary Upland Site in Western Louisiana, by J. Gunn and D. Brown, pp. 190-230. Center for Archaeological Research, The University of Texas at San Antonio, Special Report 12.

Martin, G. C.

1933 Archaeological exploration of the Shumla Caves: report of George C. Martin expeditions. Big Bend Basketmaker Papers No 3, Witte Museum, San Antonio, Texas.

Merriam, C. H.

1918 The Acorn: A Possibly Neglected Source of Food. National Geographic 34:129-137.

Morse, D. F.

1975 Paleoindian in the Land of Opportunity: Preliminary Report on the Excavations at Sloan Site (3 GE 94). In Cache River Archeological Project: An Experiment in Contract Archeology, assemmbled by M. B. Schiffer and J. H. House:135-143. Arkansas Archeological Survey, Research Series 8.

Newcomb, W. W., Jr.

1961 The Indians of Texas. University of Texas Press, Austin.

Nie, N. H., C. H. Hull, J. G. Jenkins, K. Steinbrenner, and D. H. Bent

1975 Statistical Package for the Social Sciences. McGraw-Hill, New York. Odell, G. H.

1979 A New and Improved System for the Retrival of Functional Information from Microscopic Observations of Chipped Stone Tools. In Lithic Use-Wear Analysis, edited by B. Hayden:329- 344. Academic Press, New York. 
1980 Towards a More Behavioral Approach to Archaeological Lithic Parker, A. C. Concentrations. American Antiquity 45(3):404-431.

1910 Iroquois Uses of Maize and Other Food Plants. New York State Museum Bulletin 144.

Patterson, L. W.

1979 Quantitative Characteristics of Debitage from Heat Treated Chert. Plains Anthropologist 24(85):255-260.

Patton P. C. and D. S. Dibble

1982 Archeologic and Geomorphic Evidence for the Paleohydrologic Record of the Pecos River in West Texas. American Journal of Science 282:97-121.

Pettigrew, R. M.

1979 Archaeological Investigations at Stinkingwater Pass, Harvey County, Oregon. University of Oregon Anthropological Papers 15.

Pilsbry, H. A.

1940 Land Mollusca of North America (North of Mexico). The Academy of Natural Sciences of Philadelphia, Monogragh, Vol. 1, Part 2:575-594.

Prewitt, E. R.

1981 Cultural Chronology in Central Texas. Bulletin of the Texas Archeological Society 52:65-90.

Renfro, H. B., D. E. Feray, and P. B. King

1973 Geological Highway Map of Texas. United States Geological Highway Map Series 7.

Saucier, R. T.

1981 Current Thinking on Riverine Processes and Geologic History as Related to Human Settlement in the Southeast. Geoscience and Man 22:7-18.

Schneider, S. H. and C. Mass

1975 Volcanic Dust, Sunspots, and Temperature Trends. Science 190(4216):741-746.

Schuetz, M. K.

1960 An Analysis of Val Verde County Cave Material: Part II. Bulletin of the Texas Archeological Society 31:167-205.

1963 An Analysis of Val Verde County Cave Materials: Part III. Bulletin of the Texas Archeological Society 33.

Schumm, S. A.

1965 Quaternary Paleohydrology. In The Quaternary of the United States, edited by H. Wright, Jr. and D. Frey, pp. 783-794. Princeton University Press, Princeton.

Semenov, S. A.

1973 Prehistoric Technology. Translated by M. W. Thompson. Adams and Hart, Bath.

Shackley, M. L.

1975 Archaeological Sediments: A Survey of Analytical Methods. Halsted, New York.

Shafer, H. D. and R. G. Holloway 
1977 Organic Residue Analysis and Stone Tool Function from Hinds Cave, Val Verde County, Texas: A Progress Statement. Texas A\&M, University Anthropology Laboratory, Special Series 1.

Sheets, P. D. and G. R. Muto

1972 Pressure Blades and Total Cutting Edge: An Experiment in Lithic Technology. Science 175:632-634.

Simkin, T., L. Siebert, L. McCelland, D. Bridge, C. Newhall, and J. H. Latter

1981 Volcanoes of the World. Smithsonian Institution, Washington, D.C.

Skinner, S. A.

1981 Aboriginal Demographic Changes in Central Texas. Plains Anthropologist 26(92):111-118.

Sollberger, J. B.

1969 The Basic Tool Kit Required to Make and Notch Arrow Shafts for Stone Points. Bulletin of the Texas Archeological Society 40:231-240.

Steward, J.

1938 Basin-Plateau Aboriginal Sociopolitical Groups. Bureau of

Streuver, S.

American Ethnology Bulletin 120.

1962 Implications of Vegetal Remains from an Illinois Hopewell Site. American Antiquity 27(4):584-587.

Suhm, D. A.

1958 A Review of Central Texas Archaeology. Bulletin of the Texas Archeological Society 29:63-107.

Suhm, D. A. and E. B. Jelks

1962 Handbook of Texas Archeology: Type Descriptions. Texas Archeological Society, Special Publication 1 and Texas Memorial Museum Bulletin 4 . Austin.

Thomas, D. H.

1973 An Empirical Test for Steward's Model of Great Basin Settlement Patterns. American Antiquity 38(2):155-176.

Thoms, A. B., J. L. Montgomery, and A. W. Portney

1981 An Archaeological Survey of a Portion of the Choke Canyon Reservoir Area in McMullen and Live Oak Counties, Texas. Center for Archaeological Tickell, F. G. Research, The University of Texas at San Antonio, Choke Canyon Series 3.

1965 The Techniques of Sedimentary Mineralogy. Elsevier Publishing Co., New York.

Turner, E. S.

1977a Exploring the Possibilities of Acorn Utilization in Texas. Manuscript on file at Center for Archaeological Research, The University of Texas at San Antonio.

1977b Ethnohistory. In Hop Hill: Culture and Climatic Change in Central Texas, by J. Gunn and R. Mahula, pp. 107-119. Center for Archaeological Research, The University of Texas at San Antonio, Special Report 5.

Weir, F. 
1976 The Central Texas Archaic. Ph.D. dissertation, Washington State University, University Microfilms, Ann Arbor.

Wendorf, F.

1975 Summary and Conclusions. In Late Pleistocene Environments of the Southern High Plains, edited by F. Wendorf and J. J. Hester, pp. 257-277. Fort Burgwin Research Center, Ranchos de Taos, New Mexico.

Wilmsen, E. N.

1968 Functional Analysis of Flaked Stone Artifacts. American Antiquity 33:151-161.

Wilson, M. and L. B. Davis

1978 Epilogue: Retrospect and Prospect in the Man-Bison Paradigm. Plains Anthropologist 23(82):312-335.

Yellen, J. E.

1977 Archaeological Approaches to the Present. Academic Press, New York. Young, W.

1983 Recent Finds at the Wilson-Leonard Site. Paper presented at the Paleoindian Lifeways Symposium II, Lubbock, Texas. 


\section{APPENDIX A-ANALYSIS OF FAUNAL MATERIAL (Hafernik, Gunn, Kerr)}

In general, one does not expect open sites to be conducive to the preservation of bone, and therefore not expect to recover great quantities of bone from an open site such as Moccasin Confluence. However, the test excavations did recover a modest amount of bone. Although not substantial, the bones do permit a preliminary assessment of subsistence practices of the prehistoric inhabitants of the site. This assessment will be a valuable guide to future excavations and analysis. While few conclusions can be drawn because of the minimal size of the sample, a few observations can be made with respect to the existing literature on man-fauna relationships in the area.

One-hundred sixty pieces of bone were recovered. The fragments were identified, counted, and weighed. Identification was made as to type of animal, and those fragments were counted and recorded by cultural period (Table A-1). Few fragments were identifiable to order, genera and species, although we favor the attitude of the late John Guilday, that all bone is identifiable though to different degrees. Knowing that a bone is of a large or small mammal can be a useful bit of evidence if properly treated.

TABLE A-1. FREQUENCIES OF BONE FRAGMENTS PER PERIOD

\begin{tabular}{|c|c|c|c|c|c|c|}
\hline & $\begin{array}{c}\text { White-tail } \\
\text { Deer }\end{array}$ & Bison & $\begin{array}{l}\text { Smal1 } \\
\text { Mammal }\end{array}$ & Reptile & 2 Unid. & Total \\
\hline Late Archaic & 3 & 1 & 0 & 1 & 32 & 37 \\
\hline Middle Archaic & 4 & 1 & 0 & 0 & 14 & 19 \\
\hline Early Archaic & 10 & 1 & 5 & 1 & 44 & 60 \\
\hline Paleoindian & 2 & 0 & 1 & 0 & 41 & 44 \\
\hline Total & 19 & 3 & 6 & 2 & 131 & 161 \\
\hline
\end{tabular}

The total amount of bone from each test unit was weighed to provide an estimate of yield per level. The condition of the bones, types of fracture, and evidence of burning, was noted since such data can shed light on subsistence activities, such as butchering and food preparation practices.

\section{OBSERVATIONS}

\section{Test Pit 1-3}

Test Pits 1, 2, and 3 form a $1 \times 3 \mathrm{~m}$ block. Test Pit 1 is the closest to Williams Creek, and Test Pit 3 the farthest. Percentage of bone weights per level for TP 1-3 are 
illustrated in Figure A-1. The level numbers are for TP 2. The percentage was developed from the level with the highest total weight, level 10 with $69 \mathrm{~g}$. The weight of each level was divided by 69 to arrive at a representative vertical distribution of total weights from all three test pits. The Late Archaic occupies approximately the first $35 \mathrm{~cm}$ from the surface. Of the faunal material recovered from these levels very little was identifiable with certainty. A distal end of a right deer tibia was found in Test Pit 3. The tibia had a break $64 \mathrm{~mm}$ from the medial malleobis, which resembled a spiral fracture. The weight was $26.4 \mathrm{~g}$. Other fragments, in Test Pit 2, appeared to be from white-tailed deer and small mammals. These showed signs of being subjected to heat. Test Pit 1 produced mostly crushed fragments which prevented positive identification. The bone fragments appeared to be from a medium-sized animal, possibly white- tailed deer.

The Middle Archaic levels $(9,10,11,12)$ contained numerous bone fragments in all three test pits. The fragments could not be positively identified but they were from a long bone and had features resembling those of monopole spiral fractures (Bonnichsen 1973). A portion of the fragments exhibited the fire stages: charred, blued, and calcined. The condition of the bone material suggests burning of refuse rather than preparation of food.

The Early Archaic levels (13 throught 24) produced several identifiable specimens. Test Pit 1 contained two fragments of partial astragalus from white-tailed deer. Also there was a Labyrinthic tooth probably from a white- tailed deer. Test Pit 2 yielded a large fragment of a white-tailed deer vertebra that included a partial spinous process. From this test unit came a possible bison tooth, weighing $3.4 \mathrm{~g}$ and measuring $30 \mathrm{~mm}$ in length. At this time depth the tooth may be Bison antiquus (E. Johnson, personal communication). It showed no signs of having been subjected to heat. Test Pit 3 contained a virtually complete right astragalus and a complete right terminal phalange identified as coming from white-tailed deer. Along with the identifiable bone there were numerous fragments, from all three test units that were crushed and showed signs of having been subjected to heat.

The majority of identifiable fragments from the Paleoindian levels ( 25 through 36 ) appear to be from rodents and small mammals. Test Pit 1 produced the distal end of a humerous of a woodrat with an entepicondylar foramen. A large flat bone, possibly a scapula or pelvis, was recovered from Test Pit 2. Test Pit 3 produced only framents that could not be identified. Most of the fragments from all three units showed signs of being subjected to heat.

Test Pit 4

Test Pit 4 was located on a rock midden approximately $42 \mathrm{~m}$ northwest of Test Pits 1 , 2, and 3. It contained artifacts from the Late Archaic to the Paleoindian period. Bone weights per level are shown in Figure A-1. The bone fragments from the Late Archaic levels ( 1 through 4 ) were not identifiable. It is notable, however, that the exterior of the fragments exhibited a darkened color postulated to result from association with the organically stained midden. 


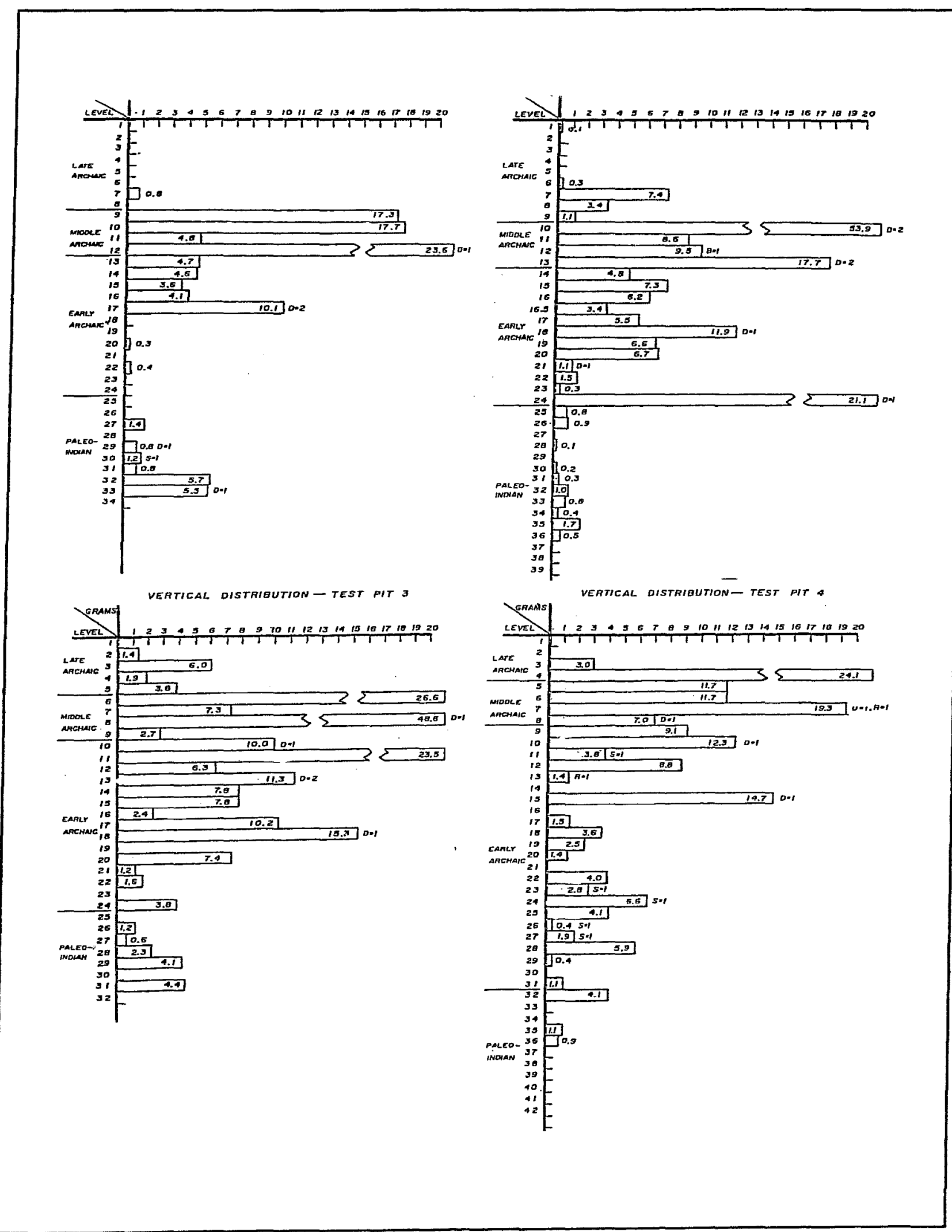

Figure A-1. Vertical Bone Weight Distributions: A. Test Pit 1, B. Test Pit 2, C. Test Pit 3, D. Test Pit 4. 
The fragments from the Middle Archaic levels (5 through 8) also appeared darkened due to the midden. Though few of the fragments were identifiable, there were two fragments of a herbivore's tooth, probably a white-tailed deer. Also, found was a femur resembling that of a cotton rat. Some of the bone fragments had been subjected to heat.

The Early Archaic levels (9 through 31) yielded several identifiable bone fragments. There was a proximal end of a right radius probably from a deer, exhibiting a spiral fracture approximately $32 \mathrm{~mm}$ from the head. Also recovered was a herbivore tooth, probably white-tailed deer. There were several rodent bones as well that showed minor signs of being subjected to heat. One bone fragment is distinguished by thicker walls which suggest a large animal the size of a bison.

The Paleoindian levels produced only fragments that were unidentifiable. A few of these showed signs of having been heated.

Test Pit 6

Test Pit 6 was located on a knoll across the road from the other test units (Figure 3.01). In this unit the greater weight is concentrated in the Late Archaic levels (1 through 9, Figure A-2). Several fragments were identified as deer bones. First is the proximal end of a right femur that includes the slightly crushed lesser trochanter. It had been broken at the neck and the greater trochanter was missing. The femur was split down the axis. The second fragment is the distal end of a left tibia with a break resembling a spiral fracture approximately $35 \mathrm{~mm}$ proximal to the medial malleolus. Third is the distal end of a phalange broken approximately 40 $\mathrm{mm}$ from the end. Also recovered was a partial vertebra, primarily the spinous process that included the anterior zygapophyses. In addition, a partial vertebra of a reptile, probably a snake, was recovered. And, perhaps of most interest, the proximal end of a phalange of a bison also came from this test unit.

The Middle Archaic levels (9 through 12) of Test Pit 6 produced only fragments, none of which could be identified. It is significant that none of the skeletal material showed signs of having been burned.

Table A-1 shows the counts of bones that were felt to be securely identified. Probably the most significant observation is that the three bison bones were recovered in the Middle and Late Archaic levels. Qualitatively this supports the hypothesis that the Late Archaic activities were more bison-related (Prewitt 1981). The presense of white-tail deer is continuous through the sequence. A rough correction for the number of levels in each period suggests an emphasis on deer in the Middle and Early Archaic: $\mathrm{P}=.20, \mathrm{EA}=.83, \mathrm{MA}=1.00, \mathrm{EA}=.38$. (The higher the index the greater the emphasis on deer per unit.) Future research should be focused on quantifying this potentially interesting relationship. The interplay of deer and bison is to be expected on the prairie-forest ecotone because of their complementary feeding habits, bison prefering the prairie grasses and deer woodland brouse. That this 
complementarity can be detected in archaeological sites has been demonstrated by Bryson and Baerreis (cited in Bryson and Murray 1977:31-44).

\section{CONCLUSIONS}

The skeletal material recovered, although not substantial of itself, suggests future avenues of research at Moccasin Confluence. Although the site was probably used as a camp by hunting parties, the limited range of skelletal elements indicate it was not used as a butchering site. The problem of preservation is relevant and needs to be dealt with in future research.

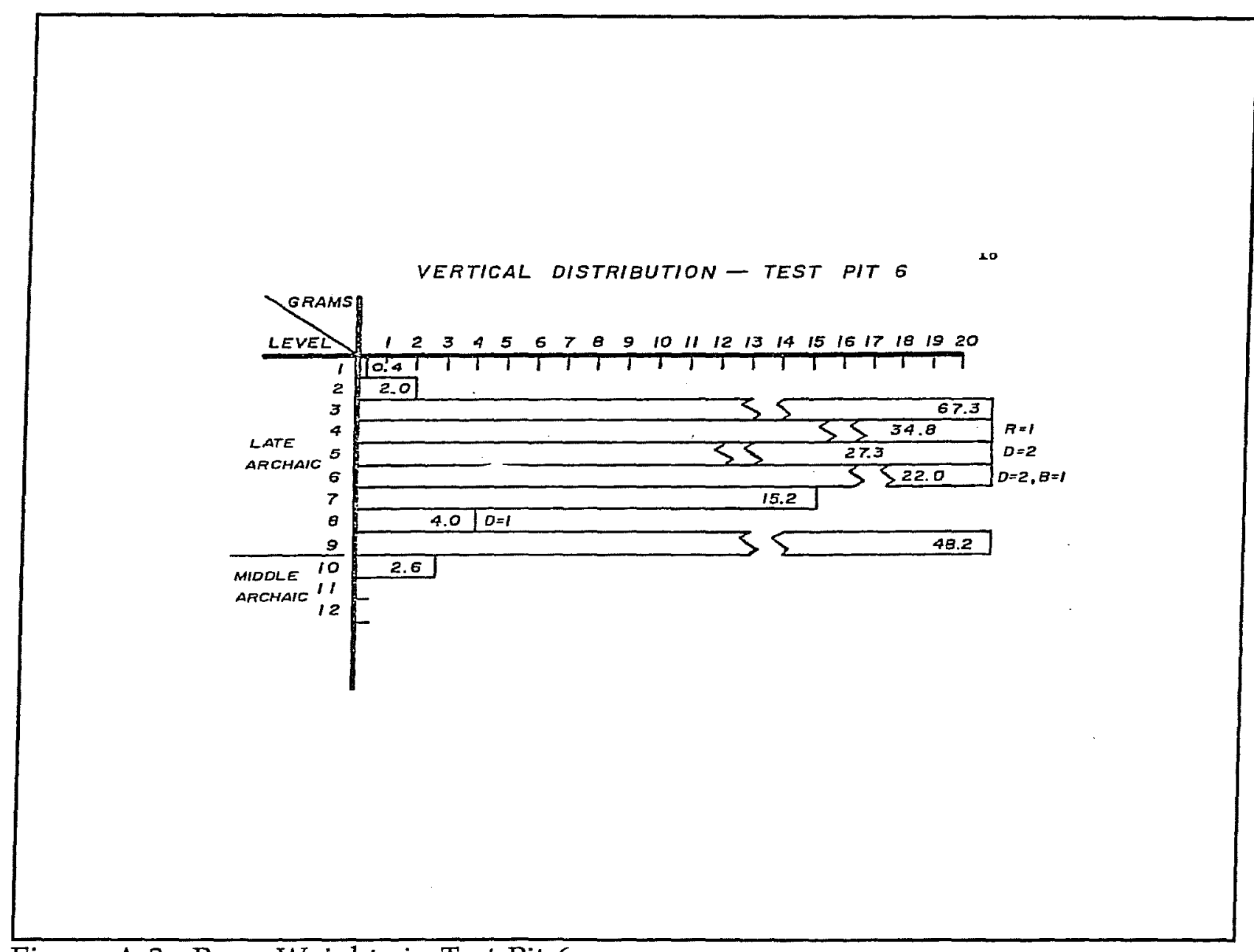

Figure A-2. Bone Weights in Test Pit 6.

The fact that the skeletal remains were in such small broken pieces suggests that the inhabitants were crushing the bones, probably to recover the marrow, and then burning the remaining fragments as refuse or fuel.

Indications from the literature are that there was a shift of emphasis from deer to bison from the Middle to Late Archaic. The potential to test this hypothesis appears 
to be present at Moccasin Confluence. It will be of interest to determine if deer-bison behave in a parallel manner to the relationships demonstrated on the central Plains by Bryson and Barreis (1968).

The five 1-m2 test pits analyzed from Moccasin Confluence Site produced a limited collection of faunal material but one clearly indicative of the potential of the site for additional research relevant to the prehistoric lifeways of the Edwards Plateau.

\section{REFERENCES CITED}

Bonnichsen, $\mathrm{R}$.

1973 Some Operational Aspects of Human and Animal Bone Alteration. In Mammalian Osteo-Archaeology: North America, edited by B. M. Gilbert:9-24. Missouri Archaeological Society, Columbia.

Bryson, R. A. and D. A. Barreis

1968 Climatic Change and the Mill Creek Culture of Iowa. Journal of the Iowa Archaeological Society 15-16:1-358.

Bryson, R. A. and T. J. Murray

1977 Climates of Hunger: Mahkind and the World's Changing Weather. University of Wisconsin Press, Madison.

Prewitt, E. R.

1981 Cultural Chronology in Central Texas. Bulletin of the Texas Archeological Society 52:65-90. 


\section{APPENDIX B-HOP HILL HUMAN SKELETAL REMAINS (Hafernik)}

During the 1978 season at Hop Hill a left mastoid process of a human was discovered at the bottom of a test pit in what eventually was found to be an old stream or spring channel under the site.

During the 1982 Hop Hill excavation more of this same individual was uncovered. The identified skeletal material included:

1. The distal end of a right humerus. The humerus included the nutrient foramen. The bone also showed some signs of animal gnawing. This portion of the humerus was $127 \mathrm{~mm}$ long and weighed $18.9 \mathrm{~g}$.

2. The mid-section of a tibia was recovered. Side determination of the fragment was impossible due to the small size. The tibia measured $46 \mathrm{~mm}$ and weighed $9.4 \mathrm{~g}$.

3. The proximal end of a right ulna was found. The fragment was crushed so as not to include the semilunar notch or the olecranon fosa. However, part of the radial notch was preserved. It was broken distally at the nutrient foramen. The ulna was $66 \mathrm{~mm}$ long and weighed $8.6 \mathrm{~g}$. The ulna and the humerus were recovered partially articulated. The articulation might have been more complete at the time of burial. However, observations in the field suggest that the individual was interred as a bundle burial.

4. The remaining fragments were primarily small and inconclusive. Many of them were small pieces of ribs. Only one of these was complete enough to include the head, coastal groove, and articular surface. Small crumbly fragments of the basiler portion of the occipital bone at the foramen magnum, and the transverse spinous process of a lumbar vertebra were also recovered. The pieces were so badly preserved as to make these identifications problematical.

The materials were all recovered at a depth of $110 \mathrm{~cm}$ in two of six square meters of excavation. A large flat rock over part of the bone suggests that it may have been buried in the upper end of the gully under some sort of cairn.

The skeletal remains are presently assumed to be of an adult female. The bones are the gracile, slim bones of a female. The individual was over the age of approximately 17-20 years old as indicated by the total fusion of the epiphesis of the proximal end of the ulna. This rules out the possibility that it was a subadult and therefore a gracile young male. The individual was probably of small, petite stature.

The observations on the human skeletal analysis were made under the guidance and supervision of Al B. Wesolowsky, UTSA-CAR, and Dr. Harry J. Shafer, Texas A\&M University. 

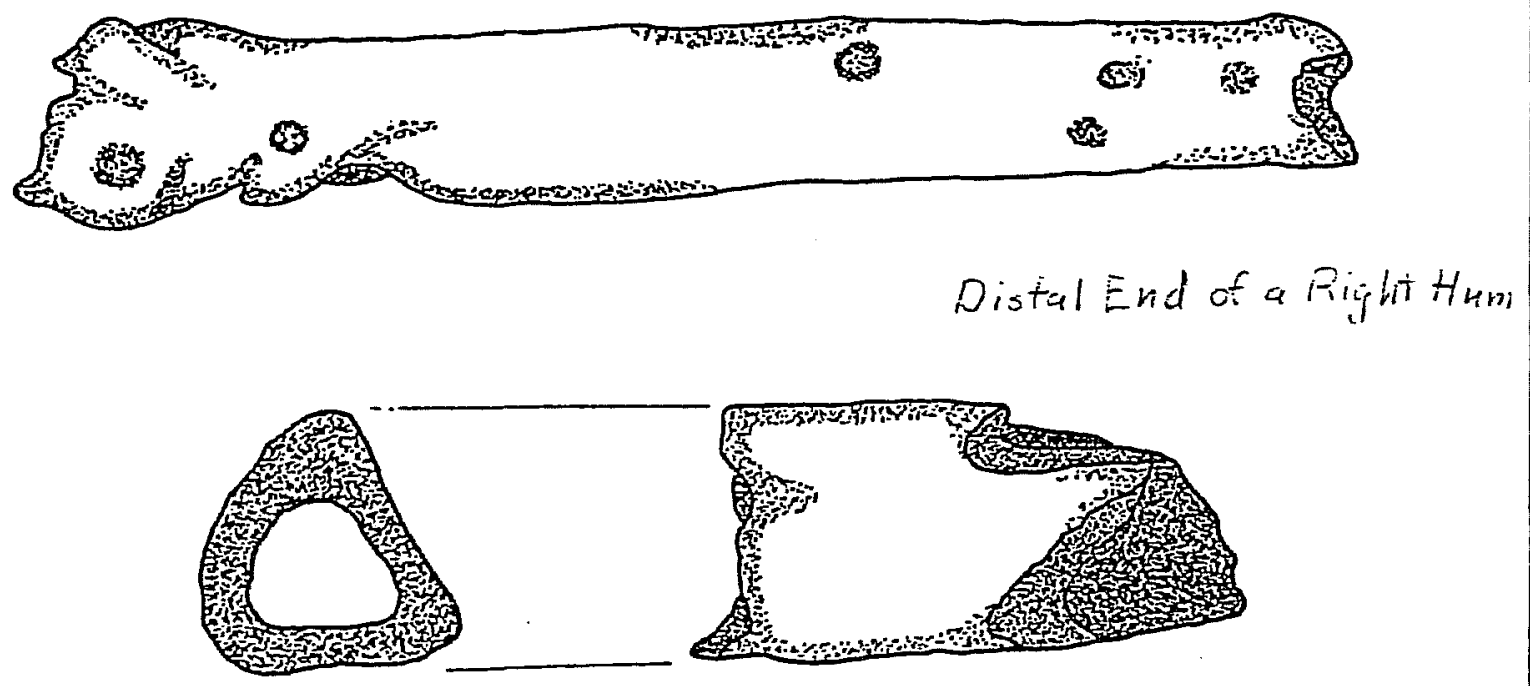

$$
\text { Mid-section of eivis }
$$

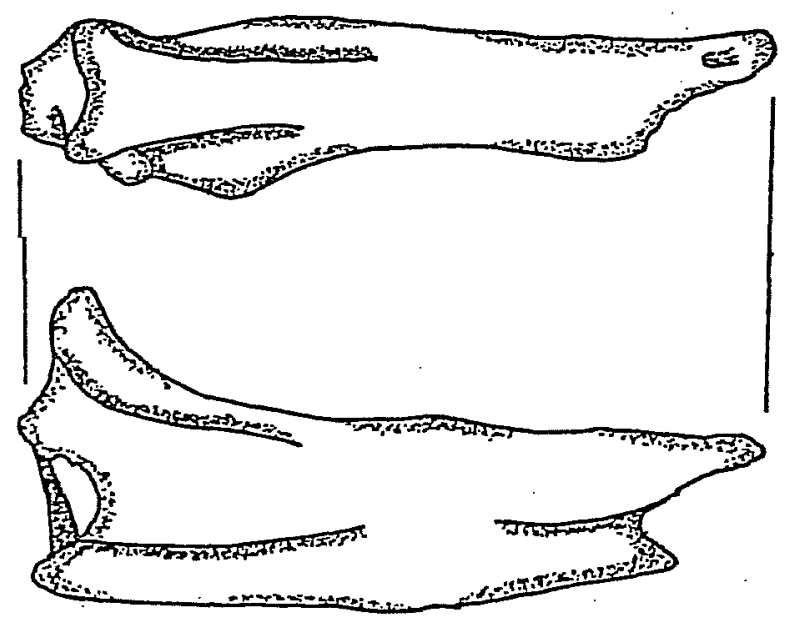

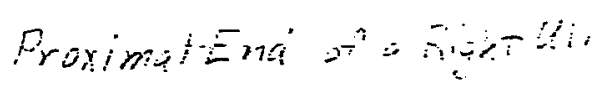

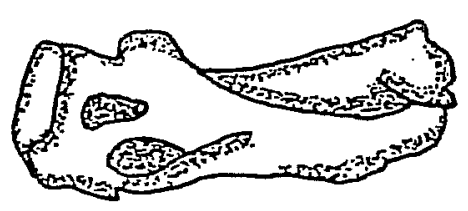

$$
\text { Ris Frajinent }
$$

Figure B-1. Human Bone from Hop Hill. 


\title{
APPENDIX C-MEASUREMENTS OF POINTS
}

\author{
RUN NAME \\ LBJ PROJECTILE POINTS, 1978 \& 1982 \\ VARIABLE LIST \\ FN SEQ VEC1 TO VEC20 \\ INPUT FORMAT \\ FIXED (F4.0,F1.0,20F3.0) \\ READ INPUT DATA
}

$\begin{array}{llllllllllllllllllllll}88 & 37 & 21 & 14 & 10 & 9 & 8 & 11 & 15 & 15 & 11 & 8 & 9 & 9 & 8 & 11 & 15 & 11 & 10 & 7 & 7\end{array}$

$\begin{array}{lllllllllllllllllllll}486 & 38 & 20 & 14 & 14 & 13 & 12 & 11 & 11 & 11 & 11 & 12 & 13 & 13 & 12 & 11 & 11 & 16 & 20 & 15 & 15\end{array}$

$\begin{array}{lllllllllllllllllllll}232 & 37 & 20 & 16 & 17 & 8 & 8 & 9 & 10 & 10 & 9 & 8 & 8 & 8 & 8 & 9 & 10 & 16 & 12 & 9 & 11\end{array}$

$\begin{array}{llllllllllllllllllllll}233 & 35 & 21 & 19 & 22 & 26 & 27 & 21 & 19 & 19 & 13 & 12 & 12 & 8 & 8 & 8 & 10 & 17 & 15 & 14 & 14\end{array}$

$\begin{array}{lllllllllllllllllllll}234 & 35 & 17 & 12 & 10 & 10 & 10 & 10 & 11 & 11 & 10 & 10 & 10 & 10 & 10 & 10 & 11 & 18 & 21 & 21 & 21\end{array}$

$\begin{array}{lllllllllllllllllllll}344 & 37 & 18 & 15 & 16 & 10 & 10 & 10 & 11 & 11 & 10 & 10 & 10 & 10 & 10 & 10 & 11 & 16 & 18 & 18 & 18\end{array}$

$\begin{array}{lllllllllllllllllllll}405 & 60 & 30 & 20 & 20 & 22 & 21 & 15 & 17 & 17 & 15 & 19 & 16 & 12 & 14 & 15 & 17 & 14 & 11 & 10 & 11\end{array}$

$\begin{array}{lllllllllllllllllllll}407 & 37 & 22 & 16 & 17 & 10 & 10 & 10 & 11 & 11 & 10 & 10 & 10 & 10 & 10 & 10 & 11 & 16 & 22 & 23 & 22\end{array}$

$\begin{array}{lllllllllllllllllllll}408 & 51 & 28 & 21 & 20 & 20 & 11 & 11 & 12 & 12 & 11 & 11 & 17 & 13 & 11 & 11 & 12 & 16 & 19 & 18 & 18\end{array}$

$\begin{array}{lllllllllllllllllllll}433 & 32 & 21 & 17 & 19 & 20 & 19 & 18 & 11 & 11 & 12 & 11 & 10 & 8 & 8 & 8 & 11 & 13 & 9 & 9 & 9\end{array}$

$\begin{array}{lllllllllllllllllllll}442 & 36 & 17 & 15 & 16 & 13 & 12 & 11 & 10 & 10 & 11 & 12 & 13 & 13 & 12 & 11 & 10 & 14 & 18 & 15 & 16\end{array}$

$\begin{array}{lllllllllllllllllllll}471 & 53 & 20 & 15 & 13 & 9 & 9 & 10 & 11 & 11 & 10 & 9 & 9 & 9 & 9 & 10 & 11 & 11 & 9 & 7 & 8\end{array}$

$\begin{array}{lllllllllllllllllllll}508 & 63 & 30 & 19 & 18 & 18 & 12 & 12 & 13 & 13 & 12 & 12 & 16 & 11 & 12 & 12 & 13 & 12 & 10 & 5 & 6\end{array}$

$\begin{array}{lllllllllllllllllllll}510 & 44 & 24 & 17 & 17 & 16 & 16 & 17 & 11 & 11 & 17 & 16 & 16 & 16 & 16 & 17 & 11 & 7 & 5 & 5 & 5\end{array}$

$\begin{array}{lllllllllllllllllllll}513 & 55 & 29 & 16 & 15 & 8 & 8 & 8 & 10 & 10 & 8 & 8 & 8 & 8 & 8 & 8 & 10 & 12 & 11 & 8 & 8\end{array}$

$\begin{array}{lllllllllllllllllllll}514 & 51 & 24 & 16 & 15 & 16 & 12 & 10 & 14 & 14 & 10 & 13 & 12 & 9 & 9 & 10 & 14 & 14 & 10 & 9 & 10\end{array}$

$\begin{array}{lllllllllllllllllllll}517 & 25 & 13 & 13 & 13 & 9 & 9 & 9 & 10 & 10 & 9 & 9 & 9 & 9 & 9 & 9 & 10 & 14 & 22 & 21 & 21\end{array}$

$\begin{array}{lllllllllllllllllllll}522 & 55 & 34 & 29 & 28 & 29 & 29 & 28 & 12 & 12 & 17 & 17 & 17 & 12 & 11 & 12 & 12 & 18 & 18 & 17 & 18\end{array}$

$\begin{array}{lllllllllllllllllllll}537 & 60 & 28 & 21 & 21 & 22 & 22 & 21 & 8 & 8 & 17 & 16 & 15 & 11 & 12 & 13 & 8 & 13 & 11 & 11 & 11\end{array}$

$\begin{array}{lllllllllllllllllllll}555 & 34 & 19 & 15 & 15 & 10 & 10 & 10 & 11 & 11 & 10 & 11 & 13 & 11 & 11 & 10 & 11 & 15 & 19 & 18 & 18\end{array}$

$\begin{array}{lllllllllllllllllllll}559 & 40 & 24 & 17 & 15 & 15 & 15 & 16 & 17 & 17 & 16 & 15 & 15 & 15 & 15 & 16 & 17 & 17 & 17 & 16 & 17\end{array}$

$\begin{array}{lllllllllllllllllllll}564 & 29 & 15 & 12 & 10 & 8 & 8 & 8 & 9 & 9 & 8 & 8 & 8 & 8 & 8 & 8 & 9 & 13 & 13 & 13 & 13\end{array}$

$\begin{array}{lllllllllllllllllllll}576 & 49 & 18 & 12 & 9 & 6 & 6 & 6 & 7 & 7 & 6 & 6 & 6 & 6 & 6 & 6 & 7 & 12 & 9 & 8 & 8\end{array}$

$\begin{array}{lllllllllllllllllllll}583 & 44 & 18 & 14 & 14 & 9 & 9 & 10 & 11 & 11 & 10 & 9 & 9 & 9 & 9 & 10 & 11 & 15 & 11 & 10 & 10\end{array}$

$\begin{array}{lllllllllllllllllllll}584 & 33 & 19 & 14 & 15 & 9 & 9 & 8 & 10 & 8 & 9 & 10 & 12 & 10 & 10 & 9 & 8 & 14 & 17 & 17 & 17\end{array}$

$\begin{array}{llllllllllllllllllllll}591 & 46 & 24 & 17 & 12 & 7 & 7 & 8 & 9 & 9 & 8 & 7 & 7 & 7 & 7 & 8 & 9 & 11 & 8 & 7 & 7\end{array}$

$\begin{array}{lllllllllllllllllllll}608 & 60 & 24 & 18 & 18 & 13 & 14 & 19 & 19 & 19 & 19 & 14 & 13 & 13 & 15 & 19 & 19 & 10 & 9 & 8 & 9\end{array}$

$\begin{array}{lllllllllllllllllllll}623 & 27 & 16 & 12 & 11 & 10 & 10 & 10 & 11 & 11 & 10 & 10 & 10 & 10 & 10 & 10 & 11 & 19 & 18 & 18 & 18\end{array}$

$\begin{array}{lllllllllllllllllllll}654 & 64 & 22 & 12 & 9 & 9 & 9 & 9 & 9 & 9 & 9 & 9 & 9 & 9 & 9 & 9 & 9 & 12 & 14 & 13 & 14\end{array}$

$\begin{array}{lllllllllllllllllllll}970 & 23 & 17 & 16 & 19 & 21 & 22 & 24 & 11 & 11 & 16 & 14 & 13 & 9 & 9 & 10 & 11 & 13 & 12 & 12 & 12\end{array}$

$\begin{array}{lllllllllllllllllllll}972 & 22 & 13 & 11 & 8 & 7 & 7 & 6 & 7 & 7 & 6 & 7 & 7 & 7 & 7 & 6 & 7 & 13 & 11 & 11 & 11\end{array}$

$\begin{array}{lllllllllllllllllllll}10072 & 26 & 14 & 9 & 9 & 11 & 11 & 11 & 11 & 11 & 11 & 11 & 11 & 11 & 11 & 11 & 11 & 12 & 10 & 10 & 10\end{array}$

$\begin{array}{lllllllllllllllllllll}10161 & 63 & 34 & 23 & 22 & 22 & 22 & 14 & 17 & 17 & 14 & 18 & 17 & 13 & 13 & 14 & 17 & 18 & 16 & 8 & 9\end{array}$

$\begin{array}{lllllllllllllllllllll}1030 & 30 & 19 & 15 & 19 & 12 & 13 & 14 & 18 & 18 & 14 & 13 & 12 & 12 & 13 & 14 & 18 & 12 & 10 & 10 & 10\end{array}$

$\begin{array}{lllllllllllllllllllll}1042 & 50 & 20 & 15 & 14 & 8 & 8 & 11 & 12 & 12 & 11 & 8 & 8 & 8 & 8 & 11 & 12 & 9 & 7 & 6 & 7\end{array}$

$\begin{array}{lllllllllllllllllllll}1048 & 41 & 21 & 15 & 17 & 12 & 12 & 13 & 18 & 13 & 11 & 11 & 11 & 11 & 11 & 11 & 13 & 17 & 13 & 11 & 12\end{array}$

$\begin{array}{lllllllllllllllllllll}1081 & 46 & 26 & 21 & 24 & 15 & 16 & 19 & 19 & 19 & 19 & 21 & 19 & 16 & 18 & 19 & 19 & 14 & 12 & 11 & 11\end{array}$

$\begin{array}{lllllllllllllllllllll}1127 & 49 & 18 & 13 & 11 & 9 & 5 & 11 & 13 & 13 & 11 & 8 & 9 & 9 & 8 & 11 & 13 & 9 & 7 & 7 & 7\end{array}$

$\begin{array}{lllllllllllllllllllll}1243 & 30 & 18 & 14 & 13 & 12 & 12 & 11 & 12 & 12 & 11 & 12 & 12 & 12 & 12 & 11 & 12 & 16 & 22 & 26 & 25\end{array}$

$\begin{array}{lllllllllllllllllllll}593 & 65 & 22 & 14 & 12 & 12 & 12 & 13 & 14 & 14 & 13 & 12 & 12 & 12 & 12 & 13 & 14 & 18 & 12 & 10 & 9\end{array}$

$\begin{array}{llllllllllllllllllllll}610 & 50 & 20 & 14 & 12 & 12 & 12 & 12 & 13 & 13 & 12 & 12 & 12 & 12 & 12 & 12 & 13 & 16 & 20 & 21 & 21\end{array}$ 
$\begin{array}{llllllllllllllllllllll}980 & 57 & 25 & 16 & 13 & 9 & 9 & 10 & 10 & 10 & 10 & 9 & 9 & 9 & 9 & 10 & 10 & 14 & 17 & 14 & 14\end{array}$ $\begin{array}{lllllllllllllllllllll}432 & 14 & 11 & 9 & 6 & 7 & 7 & 9 & 11 & 11 & 9 & 7 & 7 & 7 & 7 & 9 & 11 & 9 & 7 & 7 & 7\end{array}$ $\begin{array}{lllllllllllllllllllll}416 & 58 & 18 & 13 & 12 & 11 & 12 & 12 & 14 & 14 & 12 & 12 & 11 & 11 & 12 & 12 & 14 & 27 & 27 & 26 & 27\end{array}$ $\begin{array}{lllllllllllllllllllll}550 & 42 & 23 & 14 & 11 & 9 & 8 & 8 & 8 & 8 & 8 & 8 & 9 & 9 & 8 & 8 & 8 & 13 & 16 & 13 & 13\end{array}$ 


\section{APPENDIX D-RECOVERY FORMS}

Lower Fredericksburg Basin Page 206 


\title{
CENTER FOR ARCHAEOLOGICAL RESEARCH - U.T.S.A.
}

\author{
SHOVEL TEST RECORD
}

Data Recovery and Prompting Device

$11-2$

$23-8$

Before Excavation

$3 \quad 9-13$

$414-19$

$520-25$

$6 \quad 26-28$

$\begin{array}{lll}7 & 29\end{array}$

$8 \quad 30-32$

$9 \quad 33-35$

$10 \quad 36-38$

$11 \quad 39$

$1240-43$

$1344-45$

44

$14 \quad 46-47$

$1=\mathrm{clay}$

$4=$ sandy clay loan

$7=$ sandy loan

$10=10$ amy sandy

$\begin{array}{lc}15 & 48 \\ \text { After } & \text { Excavation } \\ 16 & 49 \\ 17 & 50 \\ 18 & 51 \\ 19 & 52 \\ 20 & 53 \\ 21 & 54-55 \\ 22 & 56 \\ 23 & 57 \\ 24 & 58\end{array}$

$25-59-60$

$26 \quad 61-62$

$2763-64$

$2865-66$
0 5 Record Number FN \#

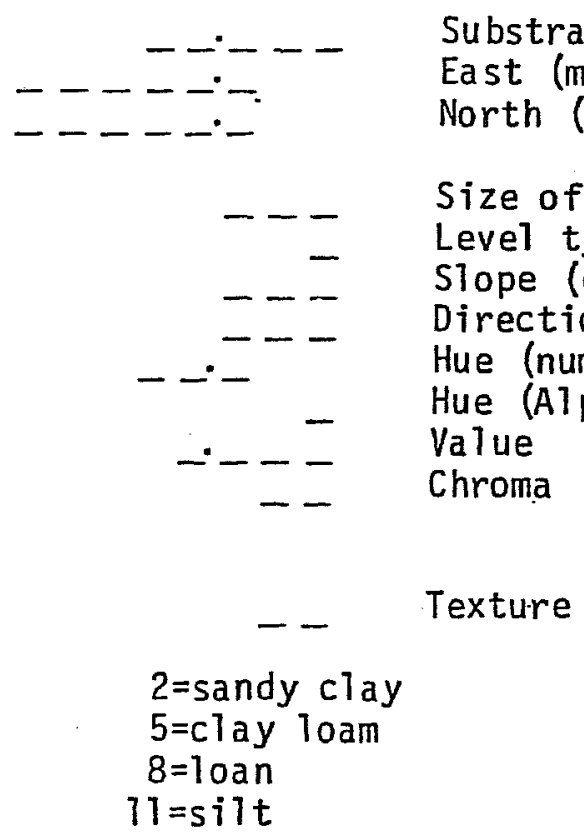

- Consolidation $(1=$ usual, $2=$ unusua $]$

Charcoal flecks (=absent, $2=$ present)

- Aquatic shell frags (=absent, $2=$ present)

- Land snail frags (=absent, 2=present)

- Chipped stone (=absent,2=present)

- Burned rock (=absent,2=present)

- - Recorder

- $\quad$ Mapped (1=no,2=yes)

- $\quad$ Flagged ( $T=$ no, 2=yes)

- Depth to Top on Transit Shot Format ( $1=$ no, 2=yes)

$\begin{array}{ll}- & \text { Inspector } \\ -- & \text { Day } \\ -- & \text { Month } \\ -- & \text { Year }\end{array}$

Excavator Photo \#s Pho to \#s 
248

Liv Fuldel rHASE IV JUN82

Center for Archaeological Research-U.T.S.A.

UNIT MAPPING RECORD

$\begin{array}{rc}1 & 1-2 \\ 2 & 3-8 \\ 3 & 9-10 \\ & \\ 4 & 11-15 \\ 5 & 16-18 \\ 6 & 19-20 \\ 7 & 21-23 \\ 8 & 24-25 \\ 9 & 26-27 \\ 10 & 28-29 \\ & =5 \mathrm{~mm}^{2}= \\ & \end{array}$

$$
\begin{aligned}
& \text { 2. } 5 \text { Record \# } \\
& \text { - }--- \text { Number of Depth measurements } \\
& \text { - }- \text { Substratum } \\
& \text { - Inspected (Inspector \#) } \\
& \text { - Scale }(5 \mathrm{~mm}=\mathrm{x}) \\
& - \text { Coder } \\
& \text { - Day } \\
& \text { - Year }
\end{aligned}
$$

$\begin{aligned} & \text { LEGEND } \\ \cdot= & \\ 0^{--} & =\text {flake } \\ x^{\prime} & =\text { chip } \\ *^{\prime} & =\text { burned chip } \\ \#= & \text { charcoal } \\ & =\end{aligned}$

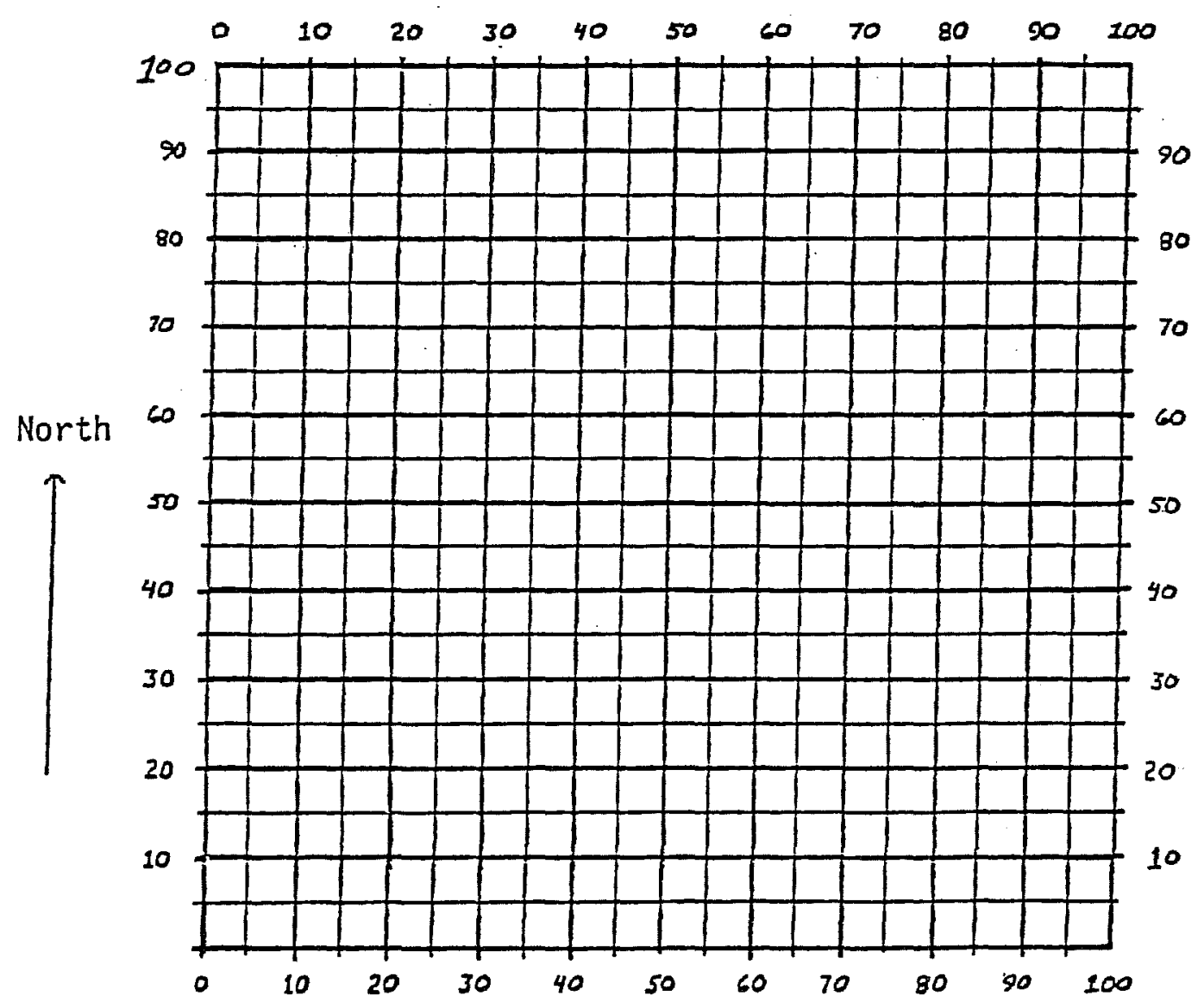


LBJ Project

SITE SURVEY PACKAGE

Site:

Reporter:

Comments: 
Point Types, List I

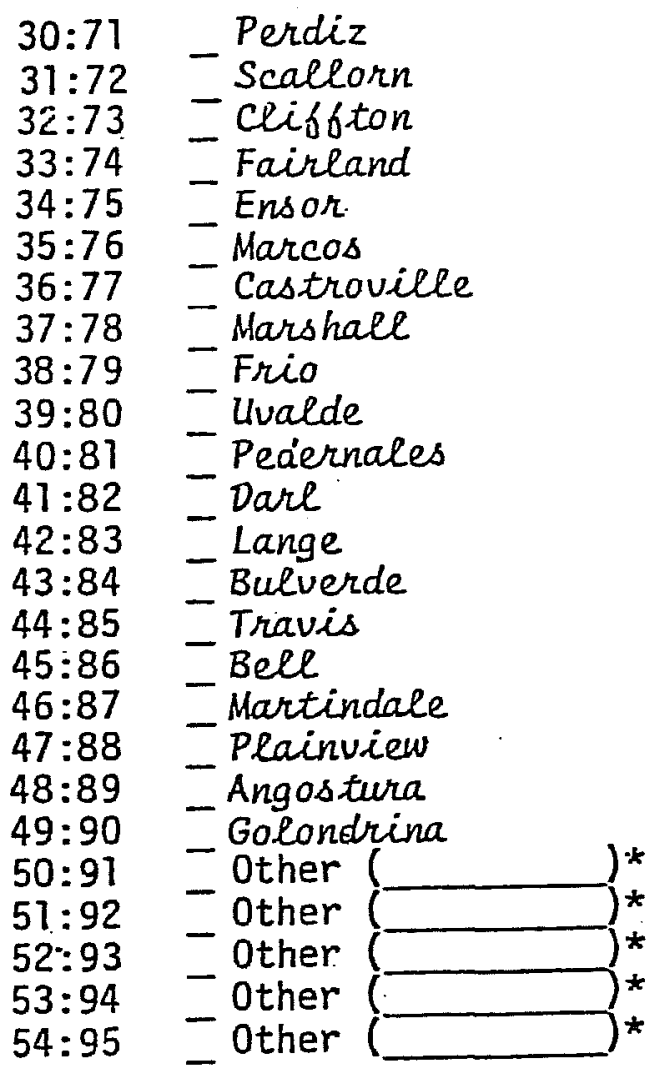

Cores, Tools, Flakes, etc.

55:96 - Hanmerstone
$56: 97$ - Chunk
$57: 98$ - Core
$58: 99$ - Core Fragment
$59: 100$ - Primary Flake
$60: 101$ - Secondary Flake
$61: 102$ - Interior Flake
$62: 103$ - Final Trimming Flake
$63: 104$ - Retouched Flake
$64: 105$ - Heat Spa11
$65: 106$ - Blade
$66: 107$ - Retouched Blade
$67: 108$ - Quarry Blank
$68: 109$ - Chopper
$69: 110$ - Biface
$70: 111$ - Side Scraper
$71: 112$ - End Scraper
$72: 113$ - Other Scraper
$73: 174$ - Uniface
$74: 115$ - Perforator
$75: 116$ - Graver
$76: 117$ - Burin
$77: 118$ - Burin Spall

78:119 - Denticulate

79:120 - Clear Fork tool

80:121 -Guadalupe tool

$81: 122$ - Metate

$82: 123$ - Mano

83:124 - Ceramics

84:125 - Glass, Worked

85:126 - Mussel Shell

86:127 - Snail She11

87:128 - Non-human Bone

88:129 - Charcoal

$89: 130$

$90: 131$

$91: 132$

$92: 133$

$93: 134$

$94: 135$

$95: 136$

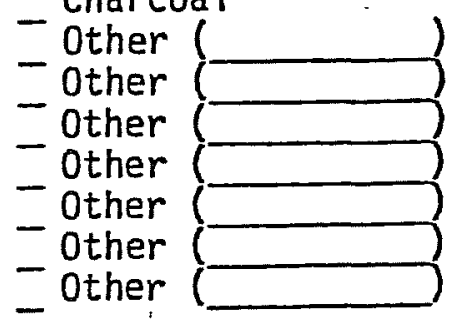

* Additional Point Types

$$
\begin{aligned}
& 91=\text { Langtry } \\
& 92=\text { Edwards } \\
& 93=\text { Side Notched } \\
& 94=\text { Gower } \\
& 95=\text { Early Side Notched }
\end{aligned}
$$


LOCATIONAL DETAILS: Distinctive nearby features, including nature of nearest water source.

SITE CHARACTERISTICS: Associations of artifacts with features, distribution of artifact types through site, no. and type of artifact concentrations and content (describe each).

CONDITION OF SITE: Type and extent of disturbance plus notes on how site content and artifact distribution may have been affected.

PRELIMINARY FIELD EVALUATION: Ideas regarding site function, occupation, character of deposits, etc.

RECOMMENDATIONS:

ACTIVITIES OF RECORDER: What was done and how.

PHOTOGRAPHIC RECORDS (rol1, exposure \#'s)

B\&W:

Color:

Col lection Bags

Recorder 


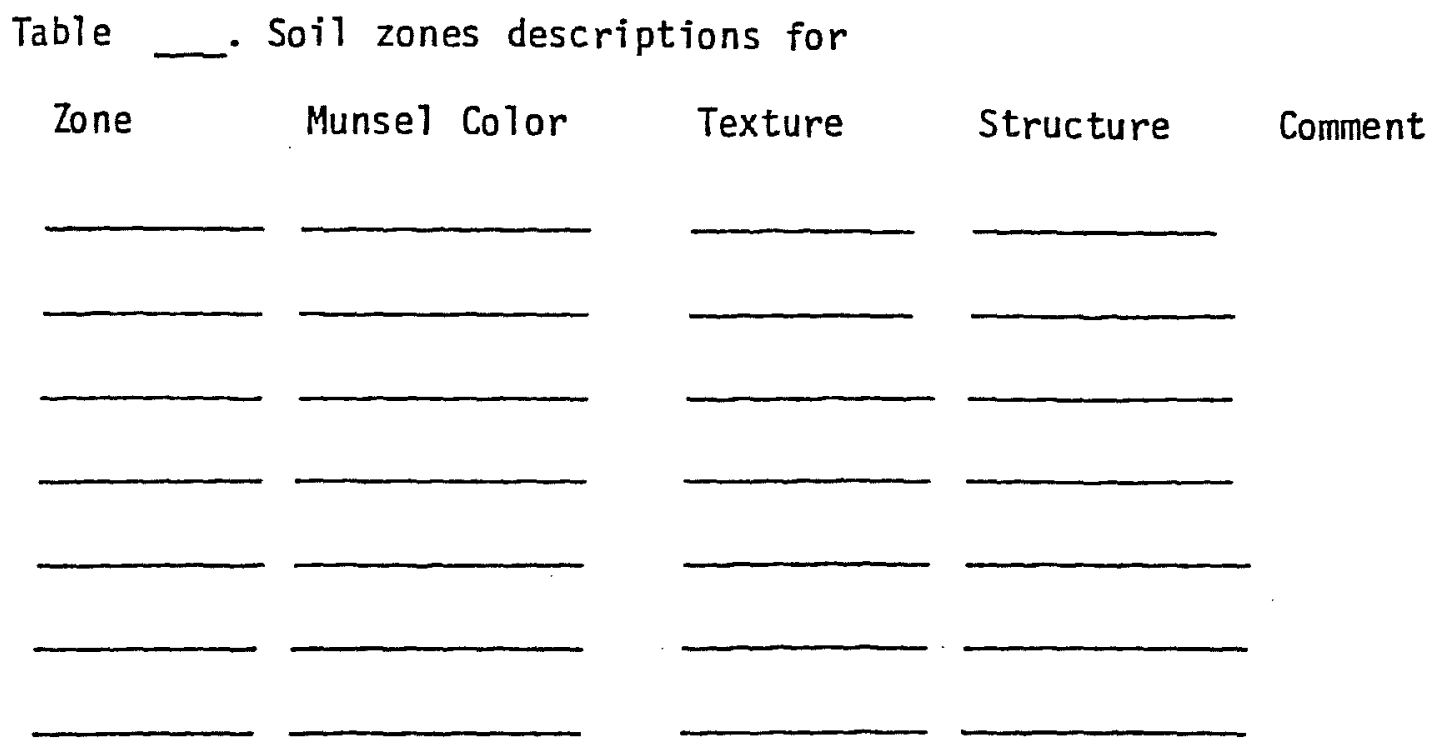

Culturally the site is evidenced on the surface

Subsurface cultural deposites

In the sottlment pattern 